\title{
Big Lost River Flood Hazard Study
}

\author{
Dean A. Ostenaa, Daniel R.H. OConnell
}

November 2005

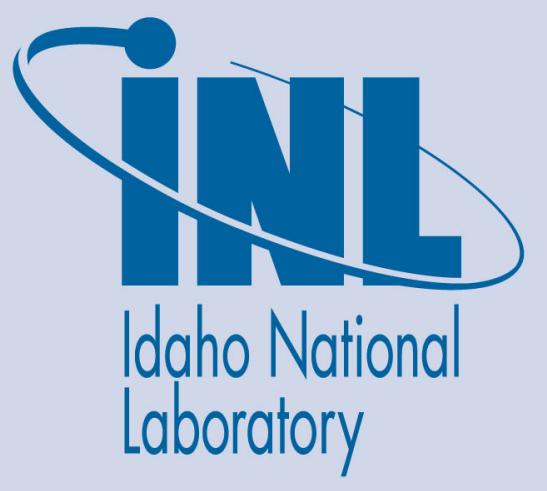

The INL is a U.S. Department of Energy National Laboratory operated by Battelle Energy Alliance 


\title{
Big Lost River Flood Hazard Study
}

\author{
Dean A. Ostenaa, Daniel R.H. OConnell
}

November 2005

\section{Idaho National Laboratory Idaho Falls, Idaho 83415}

http://www.inl.gov

Prepared for the U.S. Department of Energy Office of Nuclear Energy Under DOE Idaho Operations Office Contract DE-AC07-05ID14517 


\section{RECLAMATION Managing Water in the West}

\section{Big Lost River \\ Flood Hazard Study}

Idaho National Laboratory, Idaho

\section{Summary Document}
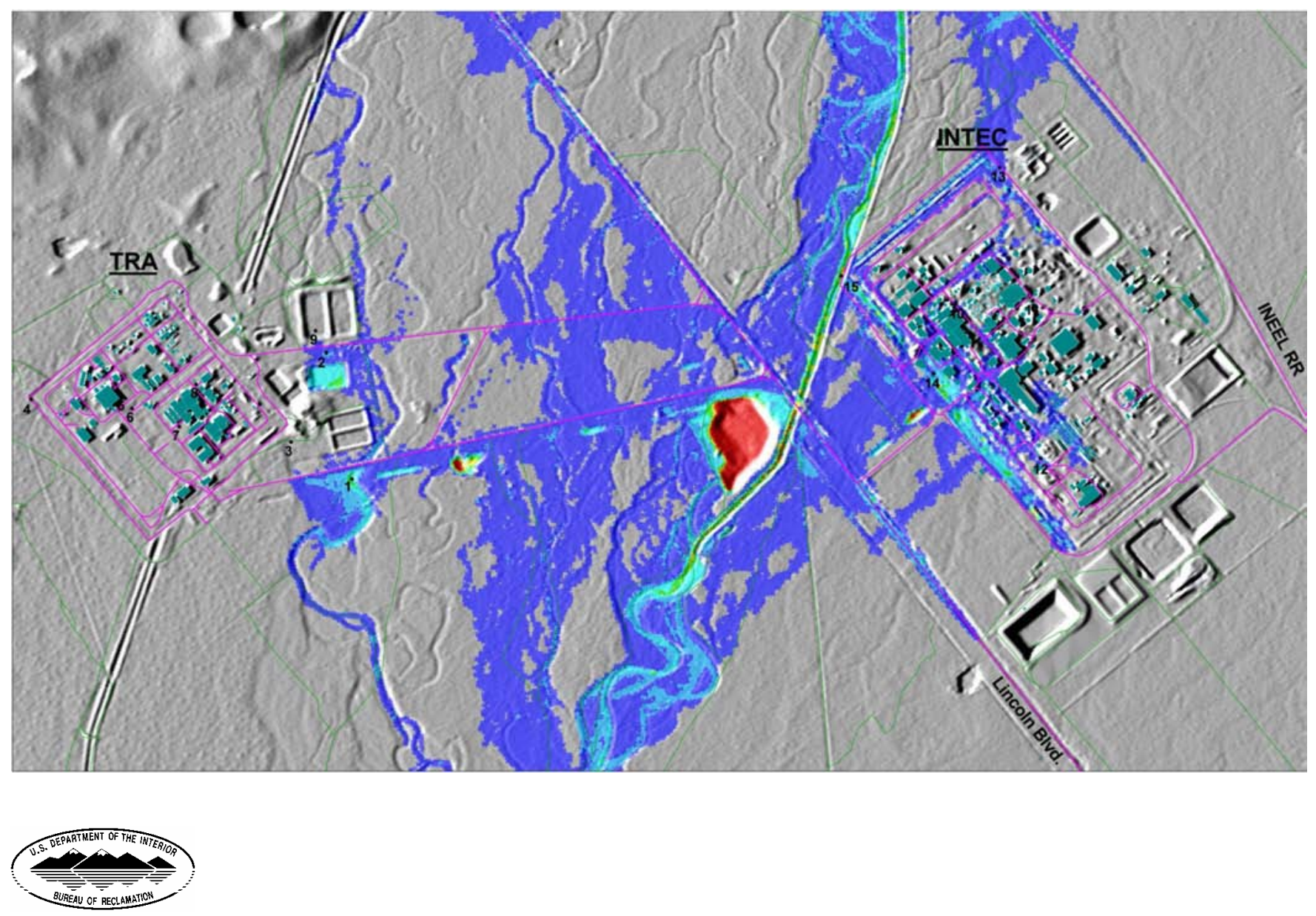

U.S. Department of the Interior

Bureau of Reclamation

Technical Service Center

Seismotectonics and Geophysics Group

Denver, Colorado 


\section{Mission Statements}

The mission of the Department of the Interior is to protect and provide access to our Nation's natural and cultural heritage and honor our trust responsibilities to Indian Tribes and our commitments to island communities.

The mission of the Bureau of Reclamation is to manage, develop, and protect water and related resources in an environmentally and economically sound manner in the interest of the American public. 


\section{Big Lost River \\ Flood Hazard Study Idaho National}

Idaho National Laboratory, Idaho

\section{Summary Document}

Report 2005-2

Prepared by

Dean A. Ostenaa

Daniel R.H. O'Connell

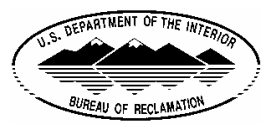

U.S. Department of the Interior

Bureau of Reclamation

Technical Service Center

Seismotectonics and Geophysic Group

Denver, Colorado 
Prepared by:

Dean A. Ostenaa

Daniel R.H. O’Connell
November 14, 2005

Date

November 14, 2005

Date

TSC Peer Review by:

Jon P. Ake

November 14, 2005

Date 


\section{OVERVIEW}

\section{Introduction and Objectives}

Paleoflood studies of the Big Lost River (Ostenaa et al., 1999; 2002) indicated that potential flood hazards for the Big Lost River at the Idaho National Laboratory (INL) (previously Idaho National Environmental and Engineering Laboratory (INEEL)) might be significantly different than portrayed by previous studies (e.g., Kjelstrom and Berenbrock, 1996). Because of the significant discrepancy between the previous studies (Table SO-1), additional studies aimed at reducing the uncertainty in flood hazard estimates at INL have been undertaken by both U.S. Geological Survey (USGS) (e.g., Hortness and Rousseau, 2003; Berenbrock and Doyle, 2004; Berenbrock et al., in prep.) and Bureau of Reclamation (BOR). The present document and the associated appendices describe the results from BOR studies of the Big Lost River flood hazard at INL. Differences in the estimate of the 100-year peak flow shown by previous studies (Table SO-1) are primarily due to the use of differing data in each of the analyses. Kjelstrom and Berenbrock (1996) and Hortness and Rousseau (2003) used stream-gage data from Big Lost River and surrounding region. Ostenaa et al. $(1999,2002)$ used stream-gage and paleoflood data from the Big Lost River at INL. Estimates of 100-year peak flow require extrapolation beyond the length of the available stream gage data record, whereas inclusion of geologic paleoflood data lengthens the record of peak flow to many times beyond a hundred-year time period.

The major objectives of the BOR studies are focused on two broad technical arenas; 1) geologic, geomorphic, and hydraulic modeling studies to reduce the uncertainty associated with paleohydrologic estimates used in flood frequency analyses, and 2) developing probabilistic flood stage estimates for specific facility locations at INTEC and TRA.

The paleohydrologic studies have focused on detailed studies of a 5-km (3-mi) reach of the Big Lost River that extends between the INEEL Diversion Dam and the historic Pioneer Diversion. In this reach, 1:4000-scale aerial photography flown in September 2000 was used to develop a 3-ft topographic grid that could be rendered as the base map for detailed geomorphic mapping of the study reach and as topographic input for updated two-dimensional hydraulic modeling. To improve the geologic data for paleoflood and paleohydrologic bound estimates, seven trenches at three detailed study sites were excavated within the study reach. From the geomorphic mapping, 
trenching data and updated hydraulic modeling, revised estimates of paleofloods and paleohydrologic bounds for the Big Lost River were developed. These data were used to revise and update the unregulated flood frequency analyses for the Big Lost River.

Table SO-1 Comparison of Revised Flood Frequency for the Big Lost River at the Diversion Dam with Previous Study Results.

\begin{tabular}{|c|c|c|c|c|c|c|c|}
\hline \multirow{3}{*}{$\begin{array}{l}\text { AEP } \\
(1 / y r)\end{array}$} & \multirow{3}{*}{$\begin{array}{l}\text { Return } \\
\text { period } \\
(\mathrm{yr})\end{array}$} & \multicolumn{3}{|c|}{ Present Study } & \multicolumn{3}{|c|}{ Previous Studies } \\
\hline & & $\begin{array}{c}5 \% \\
\left(\mathrm{~m}^{3} / \mathrm{s}\right)\end{array}$ & $\begin{array}{c}\text { mean } \\
\mathrm{m}^{3} / \mathrm{s}\left(\mathrm{ft}^{3} / \mathrm{s}\right)\end{array}$ & $\begin{array}{c}95 \% \\
\left(\mathrm{~m}^{3} / \mathrm{s}\right)\end{array}$ & $\begin{array}{l}\text { Ostenaa et } \\
\text { al. (1999) }\end{array}$ & $\begin{array}{l}\text { Kjelstrom } \\
\text { and } \\
\text { Berenbrock } \\
\text { (1996) }\end{array}$ & $\begin{array}{c}\text { Hortness } \\
\text { and } \\
\text { Rousseau } \\
\text { (2003) }\end{array}$ \\
\hline & & & & & $\begin{array}{c}\text { mean } \\
\mathrm{m}^{3} / \mathrm{s}\left(\mathrm{ft}^{3} / \mathrm{s}\right)\end{array}$ & $\begin{array}{c}\text { mean } \\
\mathrm{m}^{3} / \mathrm{s}\left(\mathrm{ft}^{3} / \mathrm{s}\right)\end{array}$ & $\begin{array}{c}\text { mean } \\
\mathrm{m}^{3} / \mathrm{s}\left(\mathrm{ft}^{3} / \mathrm{s}\right)\end{array}$ \\
\hline $5 \times 10^{-2}$ & 20 & 63 & 75 (2649) & 83 & 57 (2023) & & \\
\hline $2 \times 10^{-2}$ & 50 & 75 & 83 (2931) & 91 & 72 (2545) & & \\
\hline $1 \times 10^{-2}$ & 100 & 78 & 87 (3072) & 97 & 82 (2910) & 206 (7260) & 106 (3750) \\
\hline $5 \times 10^{-3}$ & 200 & 82 & 96 (3390) & 114 & 92 (3252) & & \\
\hline $2 \times 10^{-3}$ & 500 & 89 & 110 (3885) & 137 & 104 (3669) & & \\
\hline $1 \times 10^{-3}$ & 1000 & 101 & 131 (4626) & 163 & 112 (3960) & & \\
\hline $5 \times 10^{-4}$ & 2000 & 127 & 159 (5615) & 194 & 120 (4232) & & \\
\hline $2 \times 10^{-4}$ & 5000 & 148 & 188 (6639) & 236 & $129(4564)$ & & \\
\hline $1 \times 10^{-4}$ & 10,000 & 185 & 279 (9853) & 412 & 136 (4796) & & \\
\hline $5 \times 10^{-5}$ & $20,000 *$ & 245 & $416 *(14691)$ & $628 *$ & $142(5012)$ & & \\
\hline
\end{tabular}

Developing probabilistic stage estimates for INTEC and TRA facility sites included three major work activities: 1) reprocessing of the 1993 1:10,000-scale aerial photography along the Big Lost River to generate a 5-ft topographic grid for use in two-dimensional hydraulic modeling, 2) twodimensional hydraulic modeling of multiple flow scenarios between the INEEL Diversion Dam to downstream of INTEC and TRA, and 3) estimating stage probability curves for facility sites that could include alternate views and uncertainties in flood frequency, infiltration, and culvert flows on the INL site.

Initial hydraulic modeling for the paleohydrologic studies based on the 3-ft grid topographic data for the Diversion Dam reach showed results that differed significantly from the previous studies 
of Ostenaa et al. (1999, 2002) which used topographic data derived from the 1993 INEEL 2-ft contour map. Because the same two-dimensional hydraulic model was being used in both studies, the cause of this difference was clearly related to the input topography used in the models. To resolve these discrepancies, extensive GPS field surveys along the Big Lost River were conducted to assess the accuracy of the topographic mapping used in all phases of these studies. The GPS field surveys found that the 1993 INEEL 2-ft contour map did not appear to meet standards for 4$\mathrm{ft}$ contour interval mapping and that in the area of the paleoflood study reach the surface defined by this mapping was apparently warped (Appendix A). The lack of resolution and accuracy associated with the 19932 - $\mathrm{ft}$ contour map resulted in systematic overestimation of stages associated with discharge in the Big Lost River in the previous studies. Because similar issues to topographic accuracy would affect model estimates of flood stage probability at INTEC and TRA, data from the 1993 aerial photography was reprocessed to provide an updated topographic dataset for the hydraulic modeling. GPS field surveys of selected areas along the Big Lost River corridor demonstrate that the topographic data from the 2000 photography in the paleoflood study reach and reprocessed data from the 1993 photography both meet accuracy standards needed for the high-resolution flood modeling (Appendix A).

\section{Outline of the Final Report}

The overall scope of the present study is large and has included extensive data acquisition, field investigations, and computational efforts. Documentation of the study is contained in three elements: 1) this Overview, 2) Summary Document, and 3) Appendices. This Overview provides the major results of these efforts and key conclusions for flood hazard studies of the Big Lost River at INL. Within the Summary Document, Section 1 provides introduction and background. Section 2 and Section 3 describe the geologic, geomorphic and hydraulic modeling investigations to further evaluate the paleohydrologic data used for flood frequency estimates of the Big Lost River. Section 4 provides an updated flood frequency analyses based on these data. Section 5 describes the hydraulic modeling and conceptual framework for evaluating stage-probability estimates for selected sites at INTEC and TRA. Topographic and geomorphic maps for the Diversion Dam study reach are shown on Plate 1 and Plate 2. Additional supporting documentation is contained in several appendices that accompany this report as follows: 
Appendix A - Quality Assurance of Topographic Data

Appendix B - Geologic Data

Soil Profile Descriptions

Soil Particle Size Analysis Results from Colorado State University

Examination of Bulk Soil for Radiocarbon Datable Material from Along the Big

Lost River on the Idaho National Engineering and Environmental Laboratory

(INEEL) site by K. Puseman, Paleo Research Institute.

Radiocarbon Dating Results and Calibration Data from Beta Analytic

Summary Report on Detrital Zircon Ages of Samples from Big Lost River Trenches by P.K. Link, Idaho State Univ., and C.M. Fanning, Australian National University

Explanation, Plots, and Procedures for Point and Pebble Counts and Sieve Data by

V. Sheedy, Idaho State Univ.

Gamma Ray Spectrometry Results from J. Budahn, U.S. Geological Survey

Trench Sample Listings

Appendix B - Electronic Supplement - Trench Logs

Appendix C - Hydraulic Modeling Methodology and Quality Assurance

Part A - Methodology, mesh generation, and models

Part B - Quality Assurance

Appendix D - Hydraulic Modeling Results for Paleoflood Analyses

Evaluating Paleohydrologic Data with Stream Power and Shear Stress Results from Hydraulic Models

Appendix D - Electronic Supplement - Plots of Modeled Depth, Stream Power and Shear Stress for the Big Lost River, INEEL Diversion Dam Reach

Appendix E - Hydraulic Modeling to Estimate Big Lost River Flood Inundation at INEEL Facility Sites

Estimating Channel Infiltration Parameters from Historical Flow Data at INEEL

Infiltration Rates to Support High-Resolution Hydraulic Modeling at Idaho

National Engineering and Environmental Laboratory by F.R. Fiedler, University of Idaho

Culvert Survey Summary by C.O. Kingsford, Bechtel BWXT

Stage-Discharge Relations for Selected Culverts and Bridges in the Big Lost River Flood Plain at the Idaho National Engineering and Environmental Laboratory, Idaho by

C. Berenbrock and J.D. Doyle, U.S. Geological Survey

Appendix E - Electronic Supplement - Plots of Modeled Flood Inundation for the Big Lost River Downstream of the INEEL Diversion Dam

Appendix F - Stage Probability Plots for Selected Locations at INEEL Facility Sites 


\section{Geomorphic and Paleoflood Investigations}

The paleohydrologic studies of the Diversion Dam study reach are a continuation and expansion of the studies described in previous reports (Ostenaa et al., 1999, 2002). The objective of further studies is to further identify and reduce the uncertainty associated with previous estimates. Fieldscale investigations included four major tasks: 1) acquisition and processing of new detailed aerial photography to serve as a base map for geomorphic mapping and hydraulic modeling, 2) compilation of a detailed geomorphic map of the study reach, 3) trenching and detailed geologic descriptions and analyses in three areas of the study reach to confirm geologic/geomorphic relationships, and 4) additional two-dimensional hydraulic modeling using the new topographic data. The results of these investigations were expected to provide refined estimates, with improved understanding of the uncertainties, of the paleohydrologic parameters used in the prior flood frequency analyses. The present study results largely confirm and add additional details to the geologic components of the paleohydrologic parameters derived from the previous studies. However, because of the deficiencies associated with the topographic data (Appendix A) used in the earlier studies, hydraulic modeling for the present study results in substantially different estimates of discharge for the paleohydrologic parameters.

In evaluating discharge estimates for paleohydrologic bounds, the focus is on developing an estimate of the flood discharge required to modify or erode a geomorphic surface for which stability can be demonstrated for some prior length of time (e.g. Levish, 2002). Many geomorphologists have used stream power as a measure of the potential for channel and landscape modification with a focus on channel power or average cross section power (e.g., Baker and Costa, 1987; Magiligan, 1992). For engineering applications of erosion, channel stability, and sediment transport studies, many empirical and semi-theoretical relationships have been developed for hydraulic parameters such as depth, velocity, shear stress and stream power (e.g., see Carson and Griffiths, 1987 for a summary). However, in neither body of literature are there many examples of sites which might be considered long existing paleohydrologic bounds which have been overtopped by historical floods, and associated model estimates of the flow parameters associated with this overtopping developed. As noted by Jarrett and England (2002), documentation for the relationships between HWM (high water marks) and the estimated stage 
required to modify a geomorphic surface and thus define a paleohydrologic bound is lacking in the general literature.

In the present study, we develop a more formal framework for the application of shear stress and stream power to the problem of specification of discharge estimates for paleohydrologic bounds. The difficulties associated with developing conclusions within this framework are similar to those faced in seismic hazard assessment (e.g., SSHAC, 1995), in that uncertainty of the estimates is derived from several sources including limited data, imperfect knowledge and models of salient physical processes, and legitimate differences of scientific opinion.

Three major types of information are used to estimate the discharge range associated with a paleohydrologic bound: 1) geomorphic/geologic map and unit descriptions, 2) hydraulic modeling results of depth, unit stream power, and bed shear stress for differing input parameters, and 3) a criterion for erosion/modification of geomorphic surfaces based on empirical data compilations of unit stream power and shear stress.

Geomorphic map units define the spatial extent of areas with similar geologic/geomorphic processes and history. Individual map units are characterized by similarity in relative and absolute age, geomorphic processes and history over broad areas. Differences in age, process, and history between different areas define different geomorphic units. Thus, based on detailed mapping along the Diversion Dam study reach of the Big Lost River (Section 2, Plate 2, and Appendix B), four major geomorphic map groups, H1-2, H3-4, P2, and P3, are of primary importance to the issues of specifying paleohydrologic bounds. The similarities and differences within these broad map units are highlighted and defined through "point" investigations with trenches or soil description sites where stratigraphic details are described in detail. These detailed site descriptions provide the basis for areal extrapolation represented by the areal extent of the geomorphic map units. Individual geomorphic map unit areas naturally define the spatial limits of areas within which the variability of hydraulic parameters such as unit stream power and bed shear stress can be evaluated when that geomorphic unit is inundated by a modeled flow.

Two-dimensional hydraulic modeling (Section 2 and Appendix C) based on small grid cells relative to channel width is used to develop detailed information on the extent and spatial 
variability of flow for each modeled discharge. From the model results, shear stress and stream power are calculated for each grid cell providing a detailed depiction of the magnitude and spatial variability of these parameters over the inundated areas. This information can then be compared to the spatial extent and characteristics of differing geologic/geomorphic units. Results from the two-dimensional modeling of each discharge that are used to evaluate paleohydrologic information are 1) depth and spatial extent of inundation over a particular stratigraphic site or geomorphic surface, 2) magnitude and spatial extent of bed shear stress and/or unit stream power over a site or geomorphic surface, and 3) magnitude and spatial extent of bed shear stress and unit stream power in channel reaches. Evaluation based on depth and extent of inundation primarily considers whether or not a particular site or surface area is inundated by a given flow. For many sites, as a greater percentage of a given site or geomorphic surface is inundated, to progessively greater depths, the probability of surface modification and development of a preservable geologic record increases. Likewise, as the extent and depth of inundation increase, the magnitude and distribution of unit stream power and bed shear stress change across the geomorphic surface as well. The hydraulic conditions associated with flow across a geomorphic surface are varied and non-uniform due to topography, small- and large-scale roughness, turbulence, and mixing. Thus, actual and calculated values of stream power and shear stress vary spatially in magnitude across a given cross section and throughout the area of flow. The results or conclusions drawn from application of any criteria for surface modification is therefore dependent on the location chosen for evaluation. One advantage of the use of high-resolution, two-dimensional hydraulic models is that these models provide outputs that show the spatial variability of flow characteristics. Ideally, the spatial variability shown by hydraulic modeling can be evaluated separately for each geomorphic surface of interest.

The third major type of information used to estimate discharge associated with a paleohydrologic bound are empirical criteria and observational data on the magnitudes of stream power and shear stress that are likely associated with modification or erosion of differing geomorphic surfaces (Appendix D). From these data, limiting values for the estimated erosion or modification of differing surfaces can be subjectively estimated for the specific surface conditions and physical properties (e.g., vegetation, soil, and grain size) of each site or geomorphic surface. Because estimates of paleohydrologic bounds will ultimately have a probabilistic description for use in the 
flood frequency analyses, these criteria are formulated as probability density functions (PDF) that relate the relative probability of surface modification to particular values of shear stress or stream power. In general, the PDF's that describe the probability of surface modification are triangular distributions based on three estimated values. A lower value of shear stress or stream power represents a limit for which there is judged to be a reasonable possibility based on the existing empirical data that significant erosion or surface modification will occur. A central or preferred value represents a large body of data with high confidence. For some PDF's, the central values include a range of equal relative likelihood. An upper value limit defines a boundary beyond which there is virtual certainty of significant erosion or modification based on the available data. For application to the Diversion Dam reach of the Big Lost River, three separate criteria have been developed for unit stream power and bed shear stress, respectively (Appendix D). Two of the criteria are for application to the differing site, soil, and geologic conditions associated the geomorphic surfaces along the Big Lost River. The third criteria describes the more general conditions under which significant geomorphic modification of portions of the Big Lost River channel might result from various discharge levels.

Soils and geologic data from the Big Lost River lead to two general categories for erosion and surface modification, termed soil erosion and terrace erosion, based on the contrasting physical and vegetative characteristics of the soils and terrace deposits. Most of alluvial soils have an upper horizon(s), usually less than $30 \mathrm{~cm}$ thick, composed of silt and sand which is generally loose and unconsolidated. These horizons, usually designated as $\mathrm{A}, \mathrm{AB}$, and sometimes $\mathrm{Bw}$ in soil descriptions (Section 2 and Appendix B), lack carbonate cementation, are often bioturbated, and may include in their upper portions some component of recently active eolian sand. Some small grasses and plants have shallow roots in these horizons. In contrast, at most stream terrace sites, below a depth of more than $20-30 \mathrm{~cm}$ in most profiles, there is either carbonate cementation or gravel. In deposits that are mostly fine-grained, i.e., silty and sandy, soils with carbonate accumulation are stage I to II. In the gravel deposits maximum clast sizes are generally less than $200 \mathrm{~mm}$, and carbonate stages range from Stage I to III. Larger plants, such as sage, have widely scattered roots that extend into the gravel horizons. Based on the carbonate cementation and generally larger clast size associated with the terrace deposits, larger values of stream power and shear stress are required to initiate erosion. 
The criteria developed for channel stability is mainly derived from geomorphic study observations of major channel widening or change following floods (Appendix D). This criteria is only applicable to channels where banks are cut in alluvium. Most channel banks along the Big Lost River Diversion Dam study reach are composed of fine-grained alluvium with weakly to moderately developed carbonate soils similar to sections exposed in trenches $\mathrm{T} 4$, T5, T6, and description sites BLR2, BLR6, BLR7 and BLR8. Gravel, in Holocene fluvial deposits, is not present more than about $1 \mathrm{~m}$ above the present channel floor at these exposures. Based on geomorphic mapping (Plate 2), only very scattered sections of the channel banks are cut directly in the gravelly Pleistocene alluvium without an inset fine-grained fill terrace. More commonly, scattered basalt outcrops confine one or both channel banks. Within this varied channel setting, the hydraulic modeling results indicate large longitudinal variation in channel stream power and shear stress throughout the Diversion Dam study reach for a subset of modeled flows.

Table S0-2 summarizes the conclusions and evidence for paleofloods and paleohydrologic bounds that resulted from the current study of the Diversion Dam reach, primarily based on the geologic observations gleaned from several trenches (Section 2 and Appendix B - Electronic Supplement). As shown by previous studies (Ostenaa et al., 1999, 2002), there is clear evidence of late Holocene floods along the Big Lost River that are substantially larger than the largest historic floods. The present study confirms the approximate 400-yr age of one of these floods and suggests the possibility of infrequent, earlier floods of similar size as well as the existence of a more recent and slightly smaller paleoflood (Section 2 and Appendix B). The geologic and geomorphic basis for paleohydrologic bounds based on these data are consistent with previous studies but discharge estimates for both paleofloods and paleohydrologic bounds are substantially revised based on the updated hydraulic modeling (Section 2, Section 3 and Appendix D). Changes in these discharge estimates compared to previous studies are directly attributable to stage differences resulting from the use of new, more accurate topographic data in the current study (Appendix A). Results of the flow modeling are depicted on color-contoured plots of depth, unit stream power and bed shear stress overlain on shaded relief images of the high-resolution topography and the geomorphic map units from Plate 2 in Appendix D - Electronic Supplement. 


\section{Table S0-2 Big Lost River Paleofloods and Paleohydrologic Bounds}

\begin{tabular}{|c|c|c|c|}
\hline Event name & $\begin{array}{l}\text { Age or time span } \\
\text { (Cal yrs or Cal yr } \\
\text { B.P) }\end{array}$ & $\begin{array}{l}\text { Discharge } \\
\left(\mathrm{m}^{3} / \mathrm{s}\right) \text { and type } \\
\text { of distribution }\end{array}$ & Summary of Evidence \\
\hline \multicolumn{4}{|r|}{$\begin{array}{l}\text { Paleofloods } \\
\end{array}$} \\
\hline "white flood" & $\begin{array}{l}>100 y r \text { (pre- } \\
\text { gaging) but less } \\
\text { than } 400-600 y r\end{array}$ & $\begin{array}{l}90(80-100) \\
\text { uniform }\end{array}$ & $\begin{array}{l}\text { Based on thin deposit in T4. Not recognized in T5 or T6 (slightly higher sites). Possible correlative in T9(?). Age - } \\
\text { most likely } 100 \text { to } 150 \text { years based on absence of soil development. Discharge - Upper limit based on rapid } \\
\text { increase in power/shear stress at T4 and lack of deposit in T5/T6. }\end{array}$ \\
\hline "400-yr" flood & 400 to 600 years & $\begin{array}{l}150(130-175) \\
\text { triangular }\end{array}$ & $\begin{array}{l}\text { Apparently correlative deposits in T4, T5, T6 (also BLR2, BLR7 \& BLR8) with similar soils, stratigraphic setting, } \\
\text { and radiocarbon ages. Soil has stage I- Bk horizon. Stripping of A- and AB/Bw horizons at T8c, partial stripping at } \\
\text { T8b; lack of erosion at T8a. May represent more than one flood. }\end{array}$ \\
\hline "older flood" & $\begin{array}{l}1000 \text { to } 2000 \\
\text { years }\end{array}$ & $\begin{array}{l}150(130-175) \\
\text { triangular }\end{array}$ & $\begin{array}{l}\text { Deposits with Stage I to I+ Bk horizon that underlie "400-yr flood" deposits in T4, T5, T6 and T9. Appears to } \\
\text { indicate long period of stability with little or no deposition at these sites before deposition of deposits associated } \\
\text { with "400-yr" flood. Similar stratigraphy at BLR2 and BLR8. Likely represents multiple floods of similar or } \\
\text { smaller maximum discharge. Minimum discharge must inundate FP1-FP4, FP6-8, most of FP7, FP11-13, FP17- } \\
\text { 18, and FP19-21, which are areas with H1-2 geomorphic surfaces that appear to indicate Holocene flooding. }\end{array}$ \\
\hline \multicolumn{4}{|r|}{ Paleohydrologic Bounds } \\
\hline $400-y r \# 1$ & $400-600$ & $\begin{array}{l}130(110-150) \\
\text { triangular }\end{array}$ & $\begin{array}{l}\text { Preservation of recognizable stratigraphy at T4 and T6. No stripping of A-horizons from the youngest deposits at } \\
\text { T4 and T6. Apparently correlative H1-2 geomorphic surfaces at FP1, FP3-4, FP7, FP11-13, FP17, and FP19-20. }\end{array}$ \\
\hline $\begin{array}{l}\text { early Holocene } \\
\text { (H1 surfaces) }\end{array}$ & 6000 to 8000 & $\begin{array}{l}225(175-250) \\
\text { triangular }\end{array}$ & $\begin{array}{l}\text { Preservation of stratigraphy in T6, T4, and T8a,b,c. Banks at BLR6 and continuity of H1-2 geomorphic surfaces } \\
\text { along BLR. }\end{array}$ \\
\hline Pleistocene & $>10000$ & $\begin{array}{l}250(225-400) \\
\text { triangular }\end{array}$ & $\begin{array}{l}\text { Preservation of Pleistocene gravel surfaces throughout the study reach. Actual age of the underlying deposits is } \\
\text { older than } 12-15 \mathrm{ka} \text { (minimum age of deglaciation) and some may be older than } 20-25 \mathrm{ka} \text { (Last glacial maximum). } \\
\text { Length of time span for paleohydrologic bound is limited by post-glacial, warmer climate more similar to present }\end{array}$ \\
\hline
\end{tabular}




\section{Revised Big Lost River Flood Frequency Analyses}

The approach taken for this study is to incorporate paleoflood estimates and paleohydrologic bounds (Levish, 2002; Levish et al., 1994, 1996, 1997; Ostenaa and Levish, 1996) into nonparametric Bayesian flood frequency analysis that uses likelihood functions that incorporate both parameter and data (discharge and geologic age) measurement uncertainties (O’Connell et al., 1996, 1998; O’Connell, 2005).

A paleohydrologic bound is the time interval during which a given discharge has not been exceeded. Paleohydrologic bounds are not actual floods, but instead are limits on paleostage over a measured time interval. These bounds represent stages and discharges that have not been exceeded since a geomorphic surface stabilized. Through hydraulic modeling, discharge for a paleohydrologic bound can be derived from stage, just as a discharge is derived from the paleostage indicators of past floods. Used appropriately, paleohydrologic bounds are powerful constraints in flood frequency analyses, even if the number, timing, and magnitude of individual paleofloods are uncertain (Stedinger and Cohn, 1986).

It is necessary to revise flood frequency estimates from previous studies for two reasons. First, peak discharge values have been modified for several data points, including the paleohydrologic non-exceedence bounds. Second, the distribution of observed peak discharges and paleohydrologic information is sufficiently complex that parametric flood frequency functions are ill-suited to determine statistical quantities, such as credible or "confidence” limits for flood frequency estimates. Consequently, a newly-published nonparametric Bayesian flood frequency estimation approach (O’Connell, 2005) is used to obtain probabilistic minimum-bias estimates of flood frequency. This method accommodates complex flood behaviors such as event clustering (repeated instances of similar magnitude floods) and can use varied data, such as gage and historical peak discharges, and paleohydrologic upper and lower bounds on peak discharge, while rigorously accounting for a wide variety of measurement uncertainties. In contrast to nonparametric kernel estimation approaches, the stochastic assumption is used to generate flood frequency models that span the data and provide about twice the number of degrees of freedom of the data. Each generated flood frequency model is scored using likelihoods that account for data measurement uncertainties. A parametric estimation approach ensures high precision because 
posterior sampling is known. However, parametric approaches can produce substantial biases because the classes of allowed flood frequency models are restricted. These biases are completely undetectable within a parametric paradigm. To minimize these types of biases, the nonparametric approach used here surrenders some precision, but produces greater overall accuracy and assurance; it reveals the annual probabilities where discharge becomes unconstrained by the data, thereby eliminating unsubstantiated extrapolation. Parametric flood frequency estimation introduces strong extrapolation priors that make it difficult, if not impossible, to determine when flood frequency is not longer constrained by the data. These problems are apparent in the parametric method of O'Connell et al. (2002) used in the previous INL flood-frequency analyses (Ostenaa et al., 1999, 2002).

Present results show limits of extrapolation on AEP to be inversely proportional to about twice the length of record, corresponding to a minimum AEP of $\sim 1 / 20,000$ for which discharge estimation is credible. The data provide no constraints on how infrequent discharges larger than $300 \mathrm{~m}^{3} / \mathrm{s}$ may be, but place strong constraints on the maximum AEPs that can be associated with any discharge.

The present analysis only assumes that for extreme floods, upstream regulatory structures and diversions do not increase flood magnitudes downstream compared to the unregulated natural flows, except for cases where upstream regulating structures might fail. Flood probabilities for such scenarios should be evaluated separately, and account for the overall failure probability of the structure under all conditions. The impacts of regulation and variations in smaller flows, such as those of historical experience, on frequency estimates of extreme floods were addressed through sensitivity analyses in previous analyses (Ostenaa et al., 1999). 


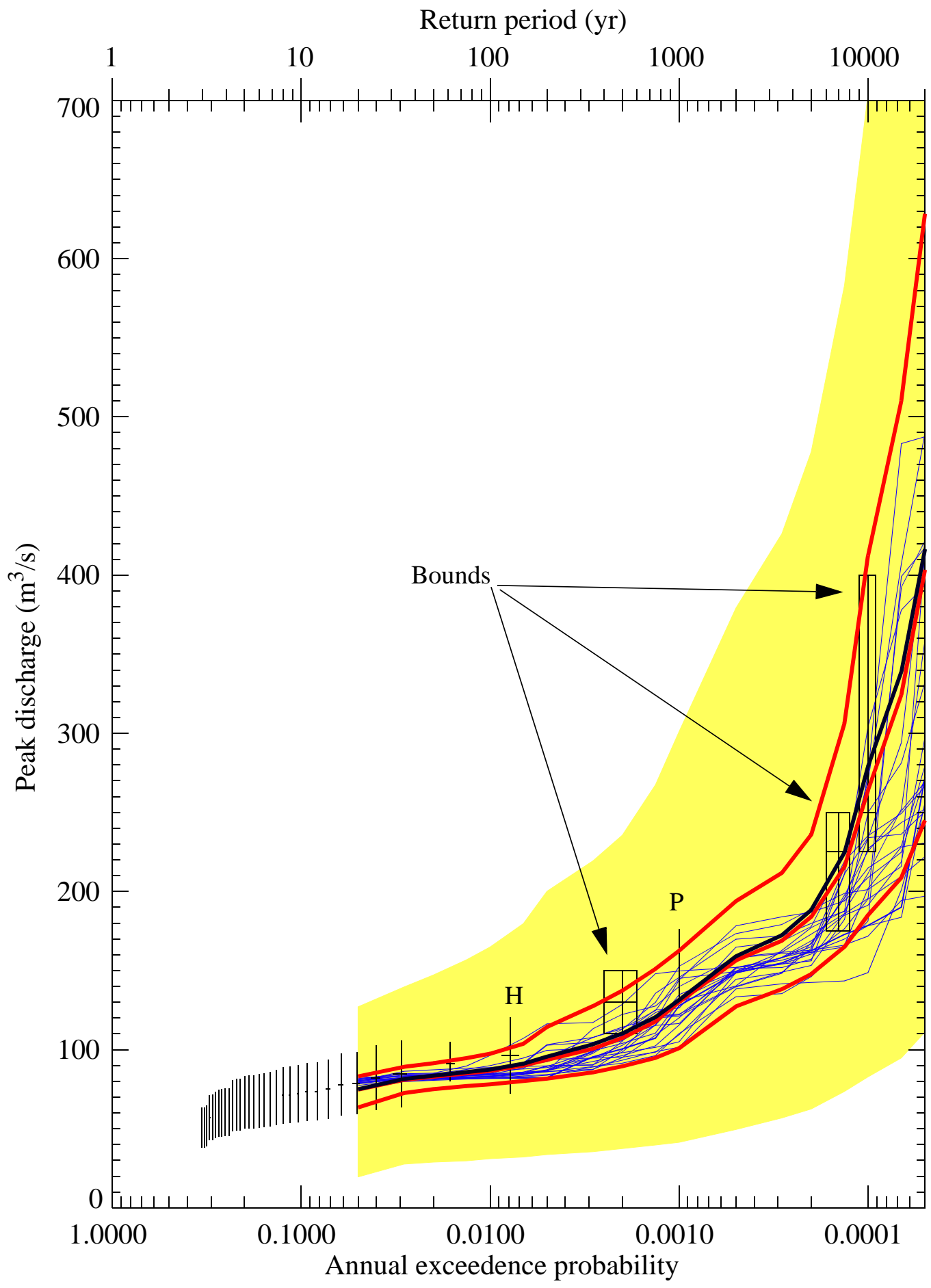

Figure SO-1 Revised flood frequency for Big Lost River at the INEEL Diversion Dam. Gaged flows (vertical black lines, with short horizontal lines indicating preferred discharge and plotting position uncertainty) are from Big Lost River at Howell Ranch (94 years) attenuated to the INEEL Diversion Dam based on methods of Hortness and Rousseau (2002). Geologic data includes two paleofloods (largest discharges labeled $\mathrm{H}$ and $\mathrm{P}$ ) and three paleohydrologic bounds (black boxes - vertical lines indicate discharge range, horizontal lines indicate duration range). Lower and upper red curves are 5\% and 95\% credible limits (middle red is median, and middle black is mean). Blue curves are models with relative likelihoods $>0.25$ of the maximum likelihood. Yellow region indicates the limits of sampling. 
Table SO-3 Nonparametric Flood Frequency for the Big Lost River at the Diversion Dam.

\begin{tabular}{|c|c|c|c|c|}
\hline $\begin{array}{c}\text { AEP } \\
(1 / \mathrm{yr})\end{array}$ & $\begin{array}{c}\text { Return } \\
\text { period }(\mathrm{yr})\end{array}$ & $\begin{array}{c}5 \% \\
\left(\mathrm{~m}^{3} / \mathrm{s}\right)\end{array}$ & $\begin{array}{c}\text { mean } \\
\left(\mathrm{m}^{3} / \mathrm{s}\right)\end{array}$ & $\begin{array}{c}95 \% \\
\left(\mathrm{~m}^{3} / \mathrm{s}\right)\end{array}$ \\
\hline \hline $5 \times 10^{-2}$ & 20 & 63 & 75 & 83 \\
\hline $2.86 \times 10^{-2}$ & 35 & 73 & 81 & 89 \\
\hline $2 \times 10^{-2}$ & 50 & 75 & 83 & 91 \\
\hline $1.33 \times 10^{-2}$ & 75 & 77 & 86 & 95 \\
\hline $10^{-2}$ & 100 & 78 & 87 & 97 \\
\hline $6.67 \times 10^{-3}$ & 150 & 80 & 91 & 104 \\
\hline $5 \times 10^{-3}$ & 200 & 82 & 96 & 114 \\
\hline $2.86 \times 10^{-3}$ & 350 & 86 & 103 & 127 \\
\hline $2 \times 10^{-3}$ & 500 & 89 & 110 & 137 \\
\hline $1.33 \times 10^{-3}$ & 750 & 95 & 121 & 151 \\
\hline $10^{-3}$ & 1000 & 101 & 131 & 163 \\
\hline $5 \times 10^{-4}$ & 2000 & 127 & 159 & 194 \\
\hline $2.86 \times 10^{-4}$ & 3500 & 138 & 172 & 212 \\
\hline $2 \times 10^{-4}$ & 5000 & 148 & 188 & 236 \\
\hline $1.33 \times 10^{-4}$ & 7500 & 165 & 224 & 306 \\
\hline $10^{-4}$ & 10,000 & 185 & 279 & 412 \\
\hline $6.67 \times 10^{-5}$ & 15,000 & 209 & $339 *$ & $510 *$ \\
\hline $5 \times 10^{-5}$ & 20,000 & 245 & $416^{*}$ & $628 *$ \\
\hline \hline
\end{tabular}

* Values with diminished or little statistical significance. 


\section{Probabilistic Flood Stage at INTEC and TRA}

The two-dimensional (depth-averaged) flow models TrimR2D and RiCOM (Appendix C) were used to calculate inundation and flow velocities for paleoflood and site inundation investigations at INL. TrimR2D uses a fixed-spacing staggered finite-difference approach that was used for hydraulic modeling of steady-state discharges in the paleoflood reach and with a larger grid spacing for the site inundation studies. RiCOM uses a staggered finite-element approach that provided an opportunity to employ high-resolution topography in a variable-sized element mesh constructed for the INL site inundation investigations. Both TrimR2D and RiCOM were used to investigate site inundation scenarios to assess the importance of parameters including topographic grid resolution, infiltration, and culvert performance, on estimated inundation corresponding to long-duration ( 20 hour-steady-state) discharges. Results from both models were post-processed for estimates of unit stream power and bed shear stress.

Monte Carlo nonparametric flood frequency estimation was used to incorporate measurement uncertainties in gaged, historical, and paleoflood discharges and nonexceedence bounds and to produce fully probabilistic flood frequency estimates for annual exceedence probabilities of specific discharges of interest. These annual exceedence probabilities were combined with stage estimates from TrimR2D and RiCOM discharge, infiltration, culvert, and topographic resolution scenarios to produce scenario probabilistic stage hazard curves for 15 sites located in the TRA/INTEC facilities (Appendix F). Annual exceedence probabilities and associated credible limits are provided for map-scale inundation plots to provide scenario probabilistic inundation maps (Appendix E). These products provide a basis to develop weights for logic tree branches associated with infiltration and culvert performance scenarios to produce probabilistic inundation maps.

Two-dimensional hydraulic modeling using a broad range of discharges conducted for the reach of the Big Lost River downstream of the INEEL Diversion Dam to approximately the INEEL railroad grade downstream of INTEC and TRA provide one element needed for probabilistic flood stage estimates at these facilities. A conceptual framework for evaluating the model results and flood frequency information was developed in the early stages of this study to guide the evaluations. Uncertainties in probabilistic flood stage estimates are discussed in the context of 
that framework. Based on this framework, results and uncertainties for stage - probability curves for fifteen specific sites within INTEC and TRA are discussed.

Appendix E - Electronic Supplement presents maps depicting the results of two-dimensional hydraulic modeling conducted to estimate probabilistic flood stage at INTEC and TRA. These maps show results for both the entire reach downstream of the INEEL Diversion Dam as well as enlarged views in the immediate vicinity of the facilities. For TrimR2D, the output flow quantities included water surface elevations and vector flow velocities interpolated to the water surface elevation positions at cell-centered positions in the staggered grid. Using the input topography, derived quantities such as depth, bed shear stress, and unit stream power were obtained. For RiCOM, the output flow quantities included water surface elevations and vector flow velocities interpolated to the element vertices using the finite-element basis functions. The inverse transformation operators were then applied to produce flow quantities in the INL state-plane coordinate system. For most modeled discharges, results are presented for modeled flow depth, unit stream power, and bed shear stress based on the TrimR2D results. RiCOM results are presented mostly as plots showing the difference in water-surface elevation from TrimR2D results for the same input discharge. A full set of RiCOM results (depth, unit stream power, bed shear stress) are presented only for four quantile results of the 100- and 500-yr discharges from the flood frequency analyses. Additional depth difference plots from TrimR2D models depict end member differences for infiltration and culvert scenarios.

Each of the inundation maps for a specific discharge could be associated with mean and credible limits on AEP associated with that discharge. However, such AEP's would not represent complete probabilistic inundation maps (PIM) for INL. There are additional probabilities (or weights) that must be assigned to aleatory (random-by-nature) parameters, such as infiltration and culvert conveyance. A conceptual framework for evaluating these uncertainties that was developed in the early stages of this study to guide the investigations. Epistemic uncertainties include factors such as flow model variability and appropriate scenario terrain models used in the simulations. Elicitation and assignments of weights to all aleatory and epistemic factors are required to produces comprehensive PIM’s. Each of the major elements will be briefly described below. 
Aleatory uncertainties include estimated flood frequency, hydrograph shape, infiltration, and culvert discharge characteristics. Several different infiltration and culvert performance scenarios were used to incorporate aleatory uncertainties associated with these parameters. A wide range of discharges were used to quantify the impacts of flood frequency aleatory uncertainty on probabilistic stage estimates. A long-duration steady-state flow assumption was used. Consequently, the impacts of varying hydrograph shape were not investigated. Generally, infiltration and culvert uncertainties had only small impacts relative to epistemic topography uncertainties, as discussed below.

Epistemic uncertainties include topography and computational flow models. Potential epistemic uncertainties associated with the two flow models are discussed in Appendix C, Part B, Section 1. These tests and output comparisons (difference plots in Appendix E - Electronic Supplement) show that negligible differences in water-surface elevation at most sites can be attributed to the choice of flow model. Much larger epistemic uncertainty is associated with the ability to accurately resolve subtle topographic features in the model inputs. Epistemic uncertainty associated with the input topography for the hydraulic models is not quantified in a statistical sense, but is shown by the differences in stage hazard plots for TrimR2D compared to RiCOM. These effects are often largest for flows less than about $200 \mathrm{~m}^{3} / \mathrm{s}$ where the differences in the ability of the input grids to resolve subtle features of the input topography leads to areas inundated to higher or lower levels between the flow models (See TrimR2D minus RiCOM difference plots in Appendix E - Electronic Supplement). A full appreciation of the impact of these factors on inundation characteristics is best provided by the large-scale inundation maps. The stage - AEP curves for the fifteen TRA/INTEC sites suggest these effects are mostly less than $\sim 0.5 \mathrm{ft}$ (Appendix F), but it is the maps (Appendix E - Electronic Supplement) that provide the best illustrations of the strong sensitivity of portions of the inundation to topographic resolution and relatively subtle topographic features such as roads and old diversion structures.

\section{Inundation Discussion}

Stage hazard curves are provided in Appendix F for fifteen specific sites near TRA or INTEC as listed in Table SO-4 and Table SO-5. For each site there are four plots of flow simulation results: 1) TrimR2D, 2) RiCOM, 3) TrimR2D - RiCOM comparisons, and 4) RiCOM Lincoln Ave 
blockage scenarios. Comparisons within and between these four sets of plots isolate or compare specific factors that could influence estimated stages. The TrimR2D simulations are the primary suite of results for final estimate of stage hazard curves and isolate the effects of variations in infiltration and secondary culvert blockage. Generally, the secondary culverts have virtually no impact on inundation at most sites, with only minor impacts on inundation at sites outside TRA along Monroe Avenue. Infiltration has only a modest impact on inundation and generally does not change the hazard curves much. The RiCOM simulations and TrimR2D -RiCOM simulations illustrate the impacts of topographic resolution and persistent topographic features such as roads, old diversions, etc. These factors have the strongest impacts on inundation over the entire site. The RiCOM simulations with blockage of the Big Lost River channel at Lincoln Avenue has the strongest impact on inundation for portions of INTEC, particularly for the simulations of discharges less than about $250 \mathrm{~m}^{3} / \mathrm{s}$.

The inundation maps in Appendix E - Electronic Supplement provide an essential tool to understand the stage hazard curves in Appendix F. It is clear that small-scale (possibly transient) changes to topography can significantly impact inundation at TRA and INTEC. This is a consequence of the relatively flat terrain in the vicinity of the Big Lost River and these INL facilities. However, the maps also provide a tool to determine small-scale changes to topography that could substantially reduce inundation hazards at TRA and INTEC. For instance, flow along the northern side of the old diversion channel west of TRA could be blocked by rather small-scale topographic modifications about $3.2 \mathrm{~km}$ west of TRA near the western end of the old diversion channel. The inundation impacts of topographic modification scenarios could be easily investigated by running new flows with modifications to the detailed topographic RiCOM mesh. Clearly, the performance of the Big Lost River culverts at Lincoln Avenue have a profound influence on stage hazards for several sites at INTEC, especially for the lower end of the discharges simulated. Similarly, although an explicit culvert blocking scenario was not constructed for the railroad embankment bridge downstream of INTEC, blockage of conveyance through the railroad embankment may also significantly influence stage hazards for portions of INTEC. 
The stage hazard curves contained in Appendix $\mathrm{F}$ have the same limitations for extrapolation to small AEP (AEP < 0.0001) as do the flood frequency results presented in Section 4. Because the flood frequency results are largely unconstrained for small AEP, no meaningful estimate of 95\% limits is contained in the revised flood frequency analyses to promulgate into the stage probability estimate. Given the nearly unlimited upper bounds of extrapolation that might be possible for small AEP from the present flood frequency analyses, development of stage hazard curves for smaller AEP would also require additional hydraulic modeling for discharges much larger than $700 \mathrm{~m}^{3} / \mathrm{s}$, which is the largest discharge considered in the present study. 
Table SO-4 Probabilistic Stage Estimates for INTEC and TRA Sites (100- and 500-year floods).

\begin{tabular}{|c|c|c|c|c|c|c|c|}
\hline \multicolumn{2}{|r|}{ Site } & \multirow{2}{*}{\multicolumn{3}{|c|}{$\begin{array}{c}\text { AEP }=10^{-2} \\
\text { Return period }=100 \mathrm{yr} \\
\text { Modeled Water Surface Elevation }(\mathrm{ft})\end{array}$}} & \multirow{2}{*}{\multicolumn{3}{|c|}{$\begin{array}{c}\text { AEP }=2 \times 10^{-3} \\
\text { Return period }=500 \mathrm{yr} \\
\text { Modeled Water Surface Elevation }(\mathrm{ft})\end{array}$}} \\
\hline Map & \multirow{2}{*}{ Description } & & & & & & \\
\hline Ref \# & & $5 \%$ & mean & $95 \%$ & $5 \%$ & mean & $95 \%$ \\
\hline \multicolumn{8}{|c|}{ TRA Sites } \\
\hline 1 & TRA - Monroe Ave & 4924.49-4924.56 & $4924.55-4924.60$ & 4924.61-4924.65 & $4924.58-4924.63$ & 4924.67-4924.70 & 4924.72-4924.75 \\
\hline 2 & $\begin{array}{l}\text { TRA-715 (evap. } \\
\text { pond) }\end{array}$ & 4918.36-4918.56 & 4918.50-4918.64 & 4918.63-4918.71 & 4918.57-4918.67 & 4918.73-4918.81 & 4918.81-4918.91 \\
\hline 3 & TRA southeast corner & dry & dry & dry & dry & dry & dry \\
\hline 4 & TRA northwest corner & dry & dry & dry & dry & dry & dry \\
\hline 5 & TRA-670 (ATR) & dry & dry & dry & dry & dry & dry \\
\hline 6 & TRA-670 (ATR) & dry & dry & dry & dry & dry & dry \\
\hline 7 & TRA-632 & dry & dry & dry & dry & dry & dry \\
\hline 8 & TRA-621 & dry & dry & dry & dry & dry & dry \\
\hline 9 & $\begin{array}{l}\text { TRA-715 (evap. } \\
\text { pond) }\end{array}$ & dry & dry & dry & dry & dry & dry \\
\hline \multicolumn{8}{|c|}{ INTEC Sites } \\
\hline 10 & INTEC Tank Farm & 4912.57-4913.12 & 4912.92-4913.29 & 4913.26-4913.45 & 4913.09-4913.37 & 4913.50-4913.65 & 4913.72-4913.85 \\
\hline 11 & NWCF (Bldg 659) & dry & dry & dry & dry & dry & dry \\
\hline 12 & СРP-749 & 4916.30-4916.40 & 4916.42-4916.51 & 4916.54-4916.60 & 4916.48-4916.55 & 4916.63-4916.69 & 4916.71-4916.78 \\
\hline 13 & INTEC - NE corner & 4907.04-4907.17 & 4907.18-4907.27 & 4907.31-4907.35 & 4907.25-4907.31 & $4907.42-4907.47$ & 4907.53-4907.59 \\
\hline 14 & INTEC -nr west gate & 4916.30-4916.40 & 4916.42-4916.51 & 4916.54-4916.60 & 4916.48-4916.55 & 4916.63-4916.69 & 4916.71-4916.78 \\
\hline 15 & $\begin{array}{c}\text { BLR - NW corner of } \\
\text { INTEC }\end{array}$ & $4913.03-4913.10$ & $4913.13-4913.18$ & $4913.22-4913.26$ & 4913.18-4913.22 & 4913.34-4913.38 & $4913.46-4913.50$ \\
\hline
\end{tabular}

xxii 
Table SO-5 Probabilistic Stage Estimates for INTEC and TRA Sites (2000- and 10,000-year floods).

\begin{tabular}{|c|c|c|c|c|c|c|c|}
\hline \multicolumn{2}{|r|}{ Site } & \multirow{2}{*}{\multicolumn{3}{|c|}{$\begin{array}{c}\text { AEP }=5 \times 10^{-4} \\
\text { Return period }=2000 \mathrm{yr} \\
\text { Modeled Water Surface Elevation }(\mathrm{ft})\end{array}$}} & \multirow{2}{*}{\multicolumn{3}{|c|}{$\begin{array}{c}\text { AEP }=1 \times 10^{-4} \\
\text { Return period }=10000 \mathrm{yr} \\
\text { Modeled Water Surface Elevation }(\mathrm{ft})\end{array}$}} \\
\hline Мар & \multirow{2}{*}{ Description } & & & & & & \\
\hline Ref \# & & $5 \%$ & mean & $95 \%$ & $5 \%$ & mean & $95 \%$ \\
\hline \multicolumn{8}{|c|}{ TRA Sites } \\
\hline 1 & TRA - Monroe Ave & 4924.68-4924.71 & 4924.77-4924.80 & $4924.86-4924.90$ & 4924.83-4924.86 & 4925.04-4925.09 & 4925.36-4925.43 \\
\hline 2 & $\begin{array}{l}\text { TRA-715 (evap. } \\
\text { pond) }\end{array}$ & 4918.74-4918.82 & 4918.91-4918.99 & 4919.06-4919.13 & 4919.01-4919.07 & 4919.36-4919.45 & 4919.89-4919.99 \\
\hline 3 & TRA southeast corner & dry & dry-4922.21 & 4922.36-4922.45 & 4922.20-4922.37 & 4922.81-4922.96 & 4923.76-4924.02 \\
\hline 4 & $\begin{array}{l}\text { TRA northwest } \\
\text { corner }\end{array}$ & dry & dry & dry & dry & 4923.38-4923.52 & 4924.14-4924.20 \\
\hline 5 & TRA-670 (ATR) & dry & dry & dry & dry & dry & dry \\
\hline 6 & TRA-670 (ATR) & dry & dry & dry & dry & dry & 4923.29-4923.32 \\
\hline 7 & TRA-632 & dry & dry & dry & dry & dry & dry \\
\hline 8 & TRA-621 & dry & dry & dry & dry & dry & dry \\
\hline 9 & $\begin{array}{l}\text { TRA-715 (evap. } \\
\text { pond) }\end{array}$ & dry & dry & dry & dry & dry & dry \\
\hline \multicolumn{8}{|c|}{ INTEC Sites } \\
\hline 10 & INTEC Tank Farm & 4913.54-4913.68 & 4913.87-4913.98 & $4914.08-4914.18$ & 4914.01-4914.11 & $4914.49-4914.57$ & 4914.86-4914.89 \\
\hline 11 & NWCF (Bldg 659) & dry & dry-4911.35 & 4911.77-4911.81 & 4911.22-4911.77 & 4911.93-4911.96 & 4912.03-4912.06 \\
\hline 12 & СРP-749 & 4916.64-4916.71 & 4916.79-4916.85 & 4916.93-4916.96 & 4916.88-4916.92 & 4917.15-4917.24 & 4917.45-4917.48 \\
\hline 13 & INTEC - NE corner & 4907.44-4907.49 & 4907.58-4907.64 & 4907.71-4907.77 & 4907.66-4907.72 & 4907.91-4907.95 & 4908.09-4908.13 \\
\hline 14 & INTEC -nr west gate & 4916.64-4916.71 & 4916.79-4916.85 & 4916.93-4916.96 & 4916.88-4916.92 & 4917.15-4917.22 & 4917.41-4917.45 \\
\hline 15 & $\begin{array}{c}\text { BLR - NW corner of } \\
\text { INTEC }\end{array}$ & $4913.36-4913.40$ & $4913.52-4913.62$ & $4913.71-4913.75$ & 4913.64-4913.71 & 4913.90-4913.93 & 4914.07-4914.13 \\
\hline
\end{tabular}

Xxiii 


\section{TABLE OF CONTENTS}

Section

Title

Page

OVERVIEW. III

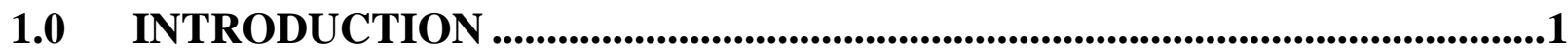

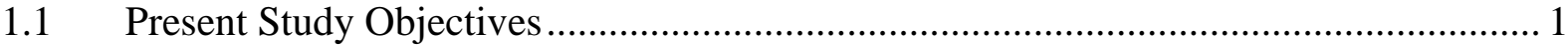

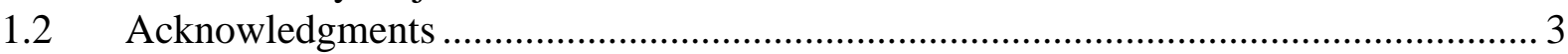

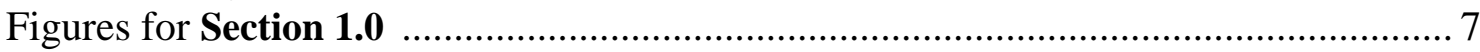

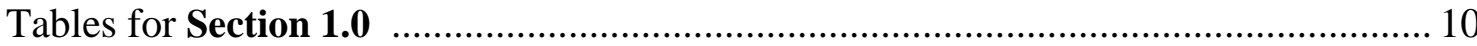

2.0 GEOLOGIC AND GEOMORPHIC STUDIES OF THE DIVERSION DAM

STUDY REACH ..............................................................................................12

2.1 Geologic and Geomorphic Setting of the Diversion Dam Study Reach ..................... 12

2.1.1 Big Lost River historical stream flow.................................................................. 13

2.1.2 Big Lost River - Diversion Dam study reach................................................. 14

2.2 Geomorphic Mapping of the Diversion Dam Study Reach....................................... 17

2.2.1 Quaternary Basalts - Rb, Rbe, Rd and Rde .................................................... 17

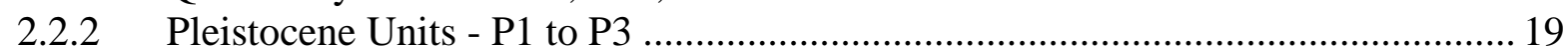

2.2.2.1 Age Constraints from Regional Glaciation.................................................. 20

2.2.2.2 Earth Mounds .......................................................................................... 21

2.2.2.3 Geomorphic Evidence for Holocene Modification of the Pleistocene Units...... 23

2.2.3 Holocene Units - H1 to H4 .............................................................................. 24

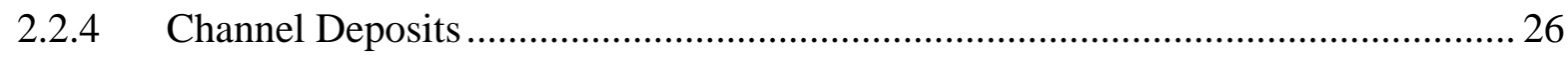

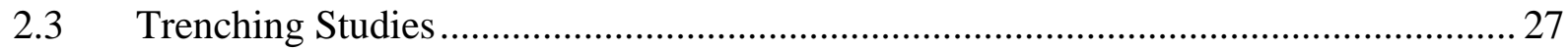

2.3.1 Trenches T1, T2, and T3 - Big Loop Study Area............................................. 28

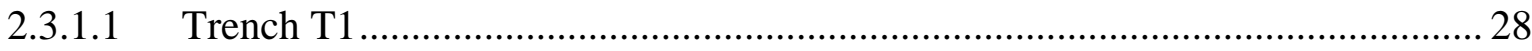

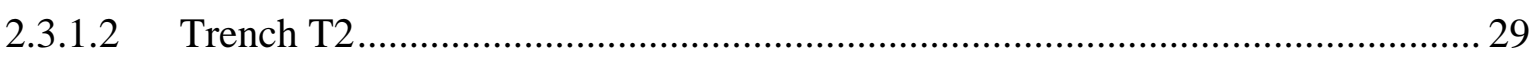

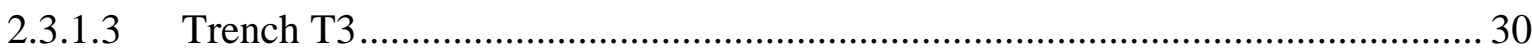

2.3.2 Trenches T4, T5, T6, and T7 - Saddle Constriction Study Area ........................... 31

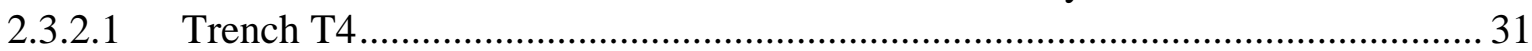

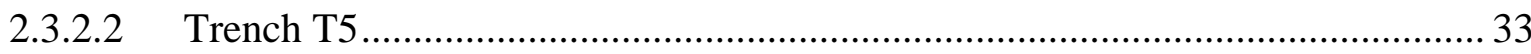

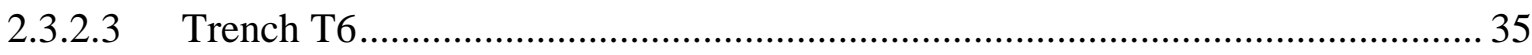

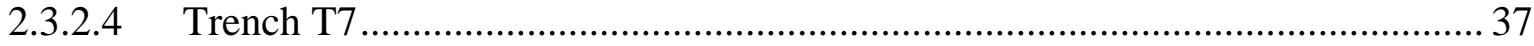

2.3.3 Trenches T8 and T9 - BLR8 Study Area...................................................... 38

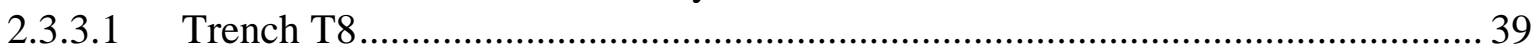

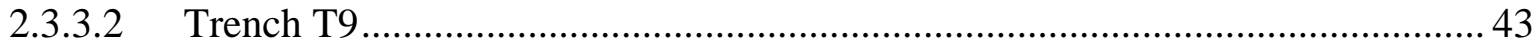

2.4 Summary of Geomorphic and Geologic Data for Paleofloods and Paleohydrologic

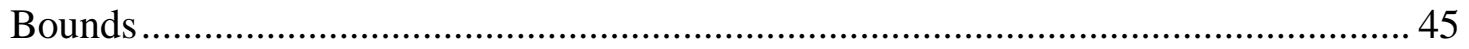

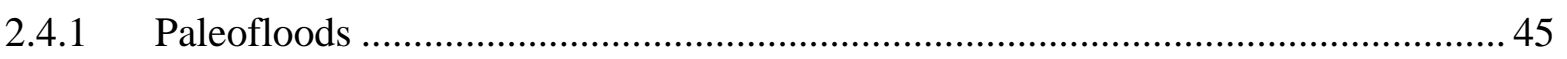

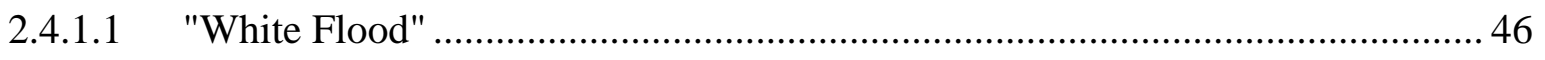

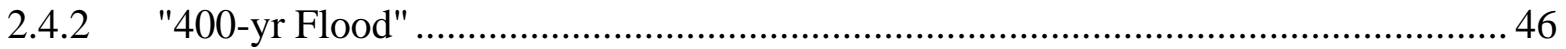

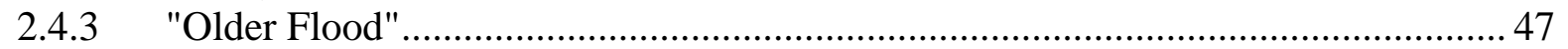

2.4.4 Paleohydrologic Bounds ............................................................................... 48

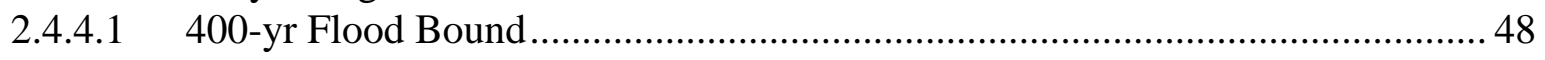

2.4.4.2 Early Holocene (H1 surfaces) Bound ........................................................ 49

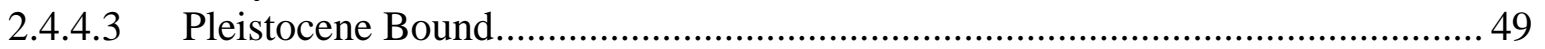

$2.5 \quad$ Hydraulic Modeling of the Diversion Dam Study Reach ....................................... 50 


\section{TABLE OF CONTENTS}

Section

$\underline{\text { Title }}$

Page

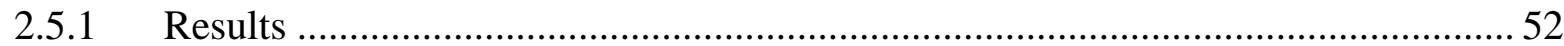

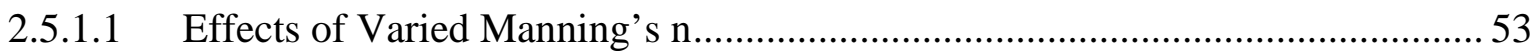

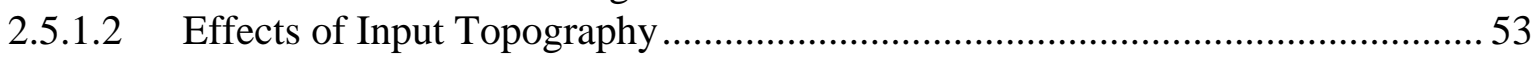

2.5.1.3 Comparisons to Previous Studies ..................................................................... 54

2.5.1.4 Results from Specific Study Areas ................................................................. 55

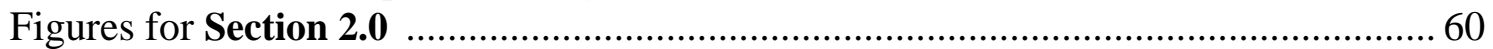

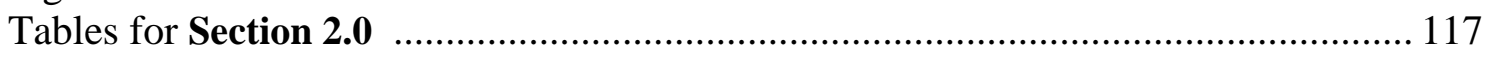

3.0 PALEOFLOODS AND PALEOHYDROLOGIC BOUNDS FOR THE BIG

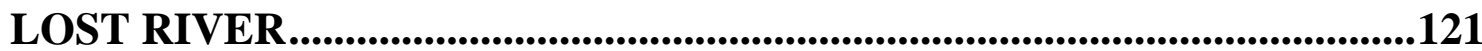

3.1 Background to the Use of Paleohydrologic Bounds................................................. 121

3.1.1 Geologic and geomorphic evidence of flooding................................................... 121

3.2 Criteria and Approach for Evaluating Paleohydrologic Information ......................... 122

3.2.1 Evaluating Spatial Extent and Variability .......................................................... 127

3.2.1.1 Uncertainty in Discharge Estimates of Modification for each Subarea............. 129

3.2.1.2 Combining Estimates from Multiple Subareas ................................................... 130

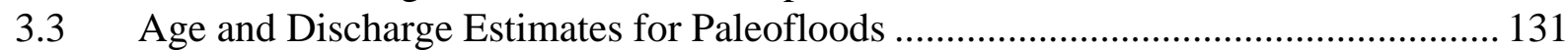

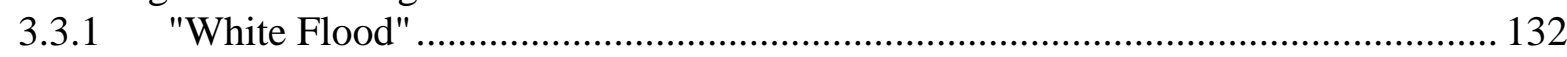

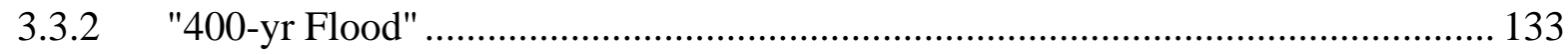

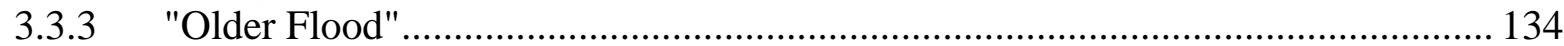

3.4 Age and Discharge Estimates for Paleohydrologic Bounds.................................... 135

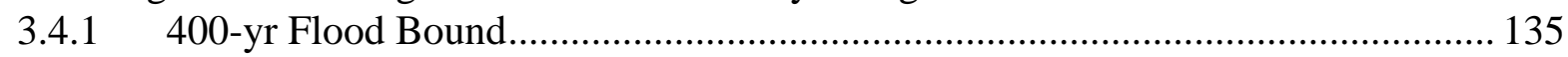

3.4.2 Early Holocene (H1 surfaces) Bound ................................................................. 137

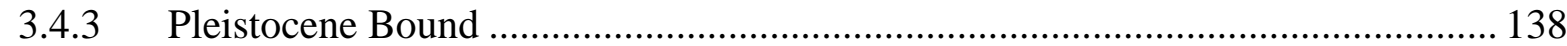

3.4.3.1 Catastrophic Channel Change.................................................................... 139

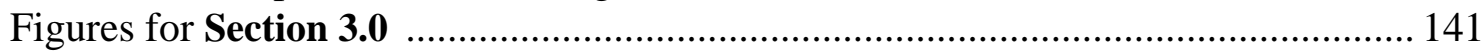

Tables for Section 3.0

4.0 REVISED FLOOD FREQUENCY FOR THE BIG LOST RIVER AT THE IN-

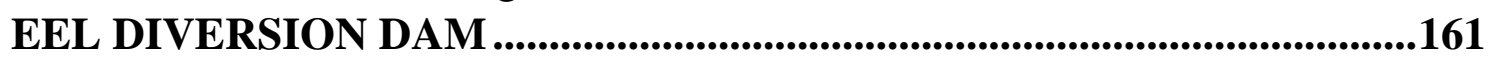

4.1 Nonparametric Flood Frequency for the Big Lost River at INL ................................ 161

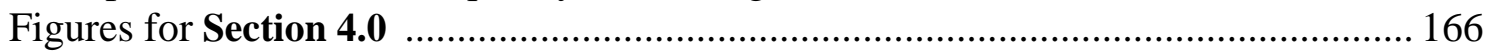

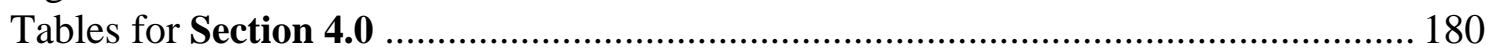

5.0 PROBABILISTIC FLOOD STAGE AT INTEC AND TRA .......................183

5.1 Topographic Input to Two-Dimensional Models ...................................................... 183

5.2 Two Dimensional Hydraulic Modeling .................................................................... 183

5.2.1 Infiltration Implementation and Scenarios ............................................................ 184

5.2.2 Culvert Implementation and Scenarios............................................................. 184

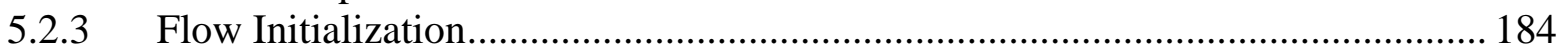

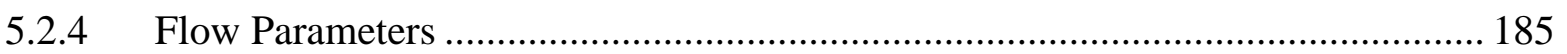

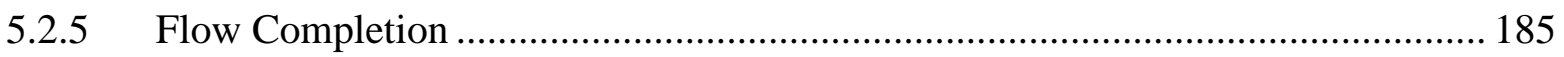

5.2.6 Flow Output ................................................................................................... 186

5.3 Conceptual Framework for Development of Probabilistic Inundation Maps and Flood

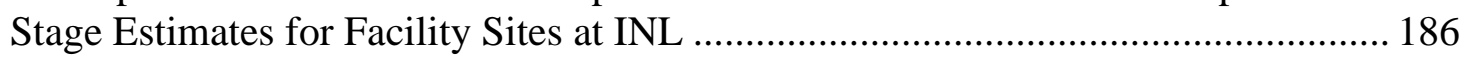

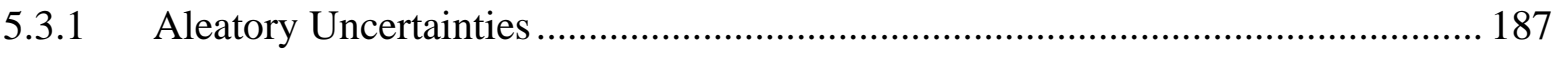


TABLE OF CONTENTS

Section

Title

Page

5.3.1.1

Flood Frequency Analyses.

187

5.3.1.2

Hydrograph Shape

188

5.3.1.3

Infiltration

188

5.3.1.4 Culverts

188

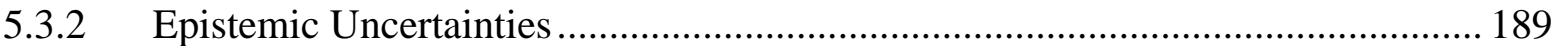

5.3.2.1 Topography and Flow Model Uncertainty........................................................ 189

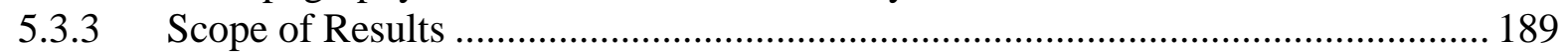

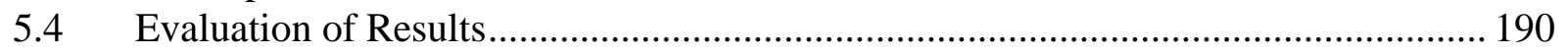

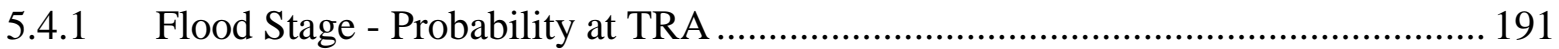

5.4.2 Flood Stage - Probability at INTEC …………...................................................... 191

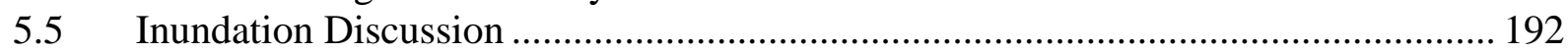

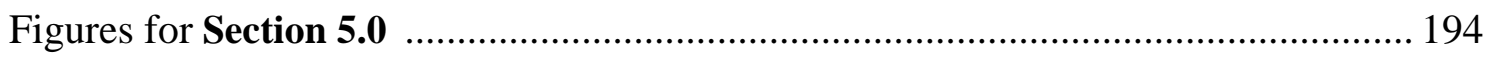

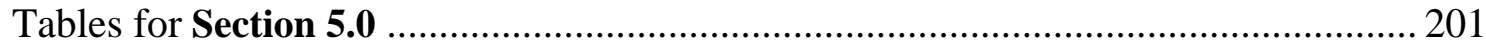

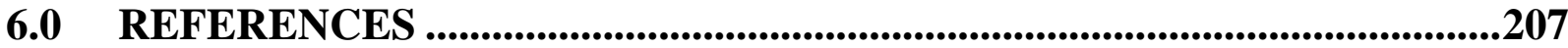




\section{LIST OF FIGURES}

Figure No.

Figure SO-1

Figure 1-1

Figure 1-2

Figure 2-1

Figure 2-2

Figure 2-3

Figure 2-4

Figure 2-5

Figure 2-6

Figure 2-7

Figure 2-8

Figure 2-9

Figure 2-10

Figure 2-11

Figure 2-12

Figure 2-13

Figure 2-14

Figure 2-15

Figure 2-16

Figure 2-17

Figure 2-18

Figure 2-19

Figure 2-20

Figure 2-21

Figure 2-22

Figure 2-23

Figure 2-24

Figure 2-25

Figure 2-26

Figure 2-27

Figure 2-28

Figure 2-29

Figure 2-30

Figure 2-31

Figure 2-32

Figure 2-33

Figure 2-34

Figure 2-35
Title

Page

Revised flood frequency for Big Lost River at the INEEL Diversion Dam...... XV Location map of INL (INEEL) and study area............................................ 8 INL study area, Big Lost River and significant facility locations. ..................... 9 Annual peak discharge estimates for upstream (light shaded bars) and downstream gaging stations (dark shaded bars) on the Big Lost River. ................................ 61

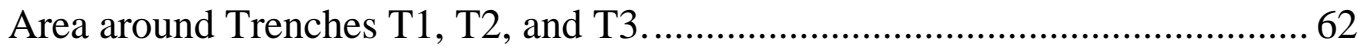
Area around "Saddle" and Trenches T4 and T5 downstream of saddle constriction 63

Detail of area around Trenches T4, T5 and T6 downstream of saddle constriction

Area around BLR8 and Trenches T8 and T9................................................. 65

Modeled water surface elevation near trenches T4 and T5..............................66 66

Modeled water surface elevation near trench T9..........................................67 67

Summary plot of age constraints for late Holocene paleofloods .......................68

Channel power for the Diversion Dam study reach subareas........................... 69

Model results for 100 and $150 \mathrm{~m} 3 / \mathrm{s}$ from Ostenaa et al. (1999, 2002) near the

Saddle 70

Figure 5 from Ostenaa et al. (2002) with revised stage estimates at BLR study sites

6-ft flow model results for $130 \mathrm{~m}^{3} / \mathrm{s}$ in the Big Loop study area. ....................... 72

6-ft flow model results for $150 \mathrm{~m}^{3} / \mathrm{s}$ in the Big Loop study area. ...................... 73

6-ft flow model results for $175 \mathrm{~m}^{3} / \mathrm{s}$ in the Big Loop study area. ...................... 74

6-ft flow model results for $200 \mathrm{~m}^{3} / \mathrm{s}$ in the Big Loop study area. ..................... 75

6-ft flow model results for $225 \mathrm{~m}^{3} / \mathrm{s}$ in the Big Loop study area. ...................... 76

6-ft flow model results for $250 \mathrm{~m}^{3} / \mathrm{s}$ in the Big Loop study area. ........................... 77

5 -ft flow model results for $200 \mathrm{~m}^{3} / \mathrm{s}$ in the Big Loop study area. ........................... 78

5-ft flow model results for $250 \mathrm{~m}^{3} / \mathrm{s}$ in the Big Loop study area. ...................... 79

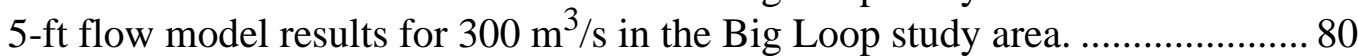

5-ft flow model results for $350 \mathrm{~m}^{3} / \mathrm{s}$ in the Big Loop study area. ...................... 81

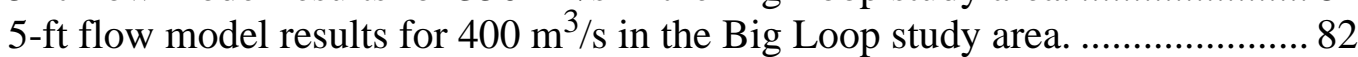

6 -ft flow model results for $150 \mathrm{~m}^{3} / \mathrm{s}$ in the Saddle constriction study area........ 83

6 -ft flow model results for $200 \mathrm{~m}^{3} / \mathrm{s}$ in the Saddle constriction study area........ 84

6 -ft flow model results for $250 \mathrm{~m}^{3} / \mathrm{s}$ in the Saddle constriction study area........ 85

5 -ft flow model results for $200 \mathrm{~m}^{3} / \mathrm{s}$ in the Saddle constriction study area......... 86

5 -ft flow model results for $250 \mathrm{~m}^{3} / \mathrm{s}$ in the Saddle constriction study area........ 87

5-ft flow model results for $300 \mathrm{~m}^{3} / \mathrm{s}$ in the Saddle constriction study area........ 88

5 -ft flow model results for $350 \mathrm{~m}^{3} / \mathrm{s}$ in the Saddle constriction study area........ 89

5 -ft flow model results for $400 \mathrm{~m}^{3} / \mathrm{s}$ in the Saddle constriction study area......... 90

6-ft flow model results for $70 \mathrm{~m}^{3} / \mathrm{s}$ in the T4/T5/T6 study area........................ 91

6-ft flow model results for $100 \mathrm{~m}^{3} / \mathrm{s}$ in the T4/T5/T6 study area...................... 92

6-ft flow model results for $130 \mathrm{~m}^{3} / \mathrm{s}$ in the T4/T5/T6 study area...................... 93

6-ft flow model results for $150 \mathrm{~m}^{3} / \mathrm{s}$ in the T4/T5/T6 study area............................ 94

6-ft flow model results for $175 \mathrm{~m}^{3} / \mathrm{s}$ in the T4/T5/T6 study area...................... 95 


\section{LIST OF FIGURES}

Figure No.

Figure 2-36

Figure 2-37

Figure 2-38

Figure 2-39

Figure 2-40

Figure 2-41

Figure 2-42

Figure 2-43

Figure 2-44

Figure 2-45

Figure 2-46

Figure 2-47

Figure 2-48

Figure 2-49

Figure 2-50

Figure 2-51

Figure 2-52

Figure 2-53

Figure 2-54

Figure 2-55

Figure 2-56

Figure 3-1

Figure 3-2

Figure 3-3

Figure 3-4

Figure 3-5

Figure 3-6

Figure 3-7

Figure 3-8

Figure 3-9

Figure 4-1

Figure 4-2

Figure 4-3

Figure 4-4

Figure 4-5
Title

Page

6-ft flow model results for $200 \mathrm{~m}$ 3/s in the T4/T5/T6 study area...................... 96

6-ft flow model results for $225 \mathrm{~m}^{3} / \mathrm{s}$ in the T4/T5/T6 study area...................... 97

6-ft flow model results for $250 \mathrm{~m}^{3} / \mathrm{s}$ in the T4/T5/T6 study area....................... 98

5 -ft flow model results for $200 \mathrm{~m}^{3} / \mathrm{s}$ in the T4/T5/T6 constriction study area... 99

5 -ft flow model results for $250 \mathrm{~m}^{3} / \mathrm{s}$ in the T4/T5/T6 constriction study area. 100 5-ft flow model results for $300 \mathrm{~m}^{3} / \mathrm{s}$ in the T4/T5/T6 constriction study area. 101

5 -ft flow model results for $350 \mathrm{~m}^{3} / \mathrm{s}$ in the T4/T5/T6 constriction study area. 102

5-ft flow model results for $400 \mathrm{~m}^{3} / \mathrm{s}$ in the T4/T5/T6 constriction study area. 103

6-ft flow model results for $70 \mathrm{~m}$ 3/s in the BLR8 study area............................ 104

6-ft flow model results for $100 \mathrm{~m}^{3} / \mathrm{s}$ in the BLR8 study area........................... 105

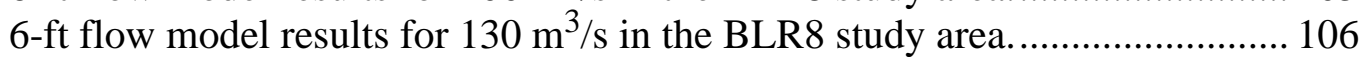

6-ft flow model results for $150 \mathrm{~m}^{3} / \mathrm{s}$ in the BLR8 study area.......................... 107

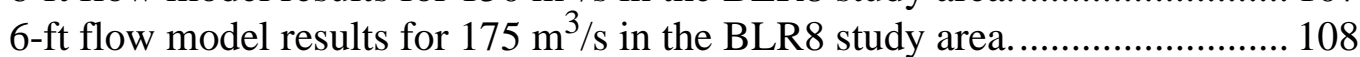

6-ft flow model results for $200 \mathrm{~m}^{3} / \mathrm{s}$ in the BLR8 study area............................. 109

6-ft flow model results for $225 \mathrm{~m}^{3} / \mathrm{s}$ in the BLR8 study area............................. 110

6-ft flow model results for $250 \mathrm{~m}^{3} / \mathrm{s}$ in the BLR8 study area........................... 111

5-ft flow model results for $200 \mathrm{~m}^{3} / \mathrm{s}$ in the BLR8 constriction study area....... 112

5-ft flow model results for $250 \mathrm{~m}^{3} / \mathrm{s}$ in the BLR8 constriction study area....... 113

5-ft flow model results for $300 \mathrm{~m}^{3} / \mathrm{s}$ in the BLR8 constriction study area....... 114

5-ft flow model results for $350 \mathrm{~m}^{3} / \mathrm{s}$ in the BLR8 constriction study area....... 115

5-ft flow model results for $400 \mathrm{~m}^{3} / \mathrm{s}$ in the BLR8 constriction study area....... 116

Schematic representation of different types of geomorphic and stratigraphic

evidence for paleofloods and paleohydrologic bounds.....

142

Probability density functions for erosion based on shear stress and stream power for

Big Lost River applications.

143

Probability distributions for major channel modifications based on channel

averaged stream power and shear stress values. 144

Stream power and shear stress sample areas along Big Lost River Diversion Dam study reach.

145

Example of stream power and shear stress results for subarea FP11.............. 146

Combined discharge limits for late Holocene paleofloods and paleohydrologic

bounds

147

Combined discharge limits for early Holocene paleohydrologic bound .......... 148

Combined discharge limits for Pleistocene paleohydrologic bound ................ 149

Combined discharge limits for catastrophic channel change.......................... 150

Measurement uncertainties for gage, bound, and paleoflood discharges on the Big

Lost River at the INEEL Diversion Dam.................................................... 167

Revised flood frequency for Big Lost River at the INEEL Diversion Dam..... 168

Peak discharges distributions for AEP's 0.01 and 0.00667 on the Big Lost River at the INEEL Diversion Dam. 169

Peak discharges distributions for AEP's 0.005 and 0.00286 on the Big Lost River at the INEEL Diversion Dam. 170

Peak discharges distributions for AEP's 0.002 and 0.00133 on the Big Lost River 


\section{LIST OF FIGURES}

Figure No.

Title

Page

at the INEEL Diversion Dam

171

Figure 4-6 Peak discharges distributions for AEP's 0.001 and 0.0005 on the Big Lost River at the INEEL Diversion Dam. 172

Figure 4-7 Peak discharges distributions for AEP's 0.000286 and 0.00002 on the Big Lost

River at the INEEL Diversion Dam. 173

Figure 4-8 Peak discharges distributions for AEP's 0.000133 and 0.00001 on the Big Lost

River at the INEEL Diversion Dam 174

Figure 4-9 Peak discharges distributions for AEP's 0.0000667 and 0.000005 on the Big Lost River at the INEEL Diversion Dam 175

Figure 4-10 AEP distributions for $250 \mathrm{~m}^{3} / \mathrm{s}$ and $300 \mathrm{~m}^{3} / \mathrm{s}$ on the Big Lost River at the INEEL Diversion Dam. 176

Figure 4-11 AEP distributions for $400 \mathrm{~m}^{3} / \mathrm{s}$ and $700 \mathrm{~m}^{3} / \mathrm{s}$ on the Big Lost River at the INEEL Diversion Dam. 177

Figure 4-12 AEP distributions for $106 \mathrm{~m}^{3} / \mathrm{s}$ and $150 \mathrm{~m}^{3} / \mathrm{s}$ on the Big Lost River at the INEEL Diversion Dam. 178

Figure 4-13 AEP distributions for $176 \mathrm{~m}^{3} / \mathrm{s}$ and $200 \mathrm{~m}^{3} / \mathrm{s}$ on the Big Lost River at the INEEL Diversion Dam. 179

Figure 5-1 Map of monitoring site locations (numbered black squares within blue boxes) for inundation at TRA and INTEC 195

Figure 5-2 Conceptional logic tree for probabilistic INL inundation modeling................ 196

Figure 5-3 Stage hazard curves for site TRA map ref \#1_.......................................... 197

Figure 5-4 Stage hazard curves for TRA-632 map ref \#7............................................ 198

Figure 5-5 Stage hazard curves for INTEC map ref \#13.............................................. 199

Figure 5-6 Stage hazard curves for the INTEC tank farm map ref \#10.......................... 200 


\section{LIST OF TABLES}

Table No.

$\underline{\text { Title }}$

Page

Table SO-1 Comparison of Revised Flood Frequency for the Big Lost River at the Diversion Dam with Previous Study Results. ................................................................ iv

Table S0-2 Big Lost River Paleofloods and Paleohydrologic Bounds................................. xii

Table SO-3 Nonparametric Flood Frequency for the Big Lost River at the Diversion Dam.xvi

Table SO-4 Probabilistic Stage Estimates for INTEC and TRA Sites (100- and 500-year floods)

Table SO-5 Probabilistic Stage Estimates for INTEC and TRA Sites (2000- and 10,000-year

floods)............................................................................................... Xxiii

Table 1-1 Summary of some results from previous flood hazard studies at INL .............. 11

Table 1-2 Comparison of Measured and Required Accuracy Values for Areas Downstream of INEEL Diversion Dam (Appendix A) ........................................................ 11

Table 2-3 Geologic and Geomorphic Summary for Big Lost River Paleofloods and

Paleohydrologic Bounds .......................................................................... 117

Table 2-1 Discharge and modeling scenarios for the INEEL Diversion Dam study reach118

Table 2-2 Soils and Radiocarbon Summary ............................................................... 119

Table 2-3 Geologic and Geomorphic Summary for Big Lost River Paleofloods and

Paleohydrologic Bounds ......................................................................... 120

Table 3-1 Hydraulic modeling sample area characteristics - floodplain subareas ............ 152

Table 3-2 Hydraulic modeling sample area characteristics - channel subareas ............... 155

Table 3-3 Summary of limiting discharge values from hydraulic modeling sample areas157

Table 3-4 Applicability of hydraulic modeling sample areas to paleofloods and paleohydrologic bounds estimates ............................................................. 158

Table 3-5 Big Lost River Paleofloods and Paleohydrologic Bounds.............................. 159

Table 4-1 Least frequent peak discharge generation nodes. ......................................... 181

Table 4-2 Nonparametric Flood Frequency for the Big Lost River at the Diversion Dam.182

Table 5-1 Discharge and modeling scenarios used to construct the stage - probability

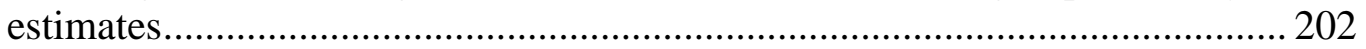

Table 5-2 Discharge-AEP Results from the FFA...................................................... 203

Table 5-3 Stage - Probability Sites........................................................................ 204

Table 5-4 Probabilistic Stage Estimates for INTEC and TRA Sites (100 and 500 floods).205

Table 5-5 Probabilistic Stage Estimates for INTEC and TRA Sites (2000 and 10000 year

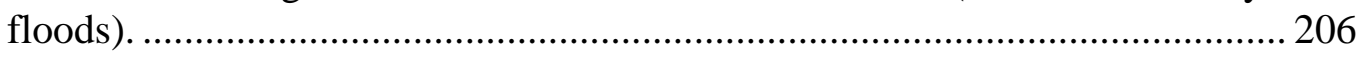




\section{List of Plates}

(Folded sheets in pocket and PDF files on CD)

Plate

Title

1 Shaded Relief, Contour, and Orthophoto Maps of the INEEL Diversion Dam Study Reach Big Lost River, Idaho

2 Geomorphic Maps of the INEEL Diversion Dam Study Reach - Big Lost River, Idaho

\section{Appendices}

(Separate documents or on CD's)

Appendix

$\underline{\text { Title }}$

A Topographic Data for Flood Hazard Modeling at INEEL

Quality Assurance of Topographic Data for the Big Lost River Flood Hazard Study, Idaho National Engineering and Environmental Laboratory, Idaho

Shaded Relief, Contour, and Orthophoto Maps of the INEEL Diversion Dam Study

Reach - Big Lost River, Idaho

Shaded Relief, Contour, and Orthophoto Maps of the INEEL Reach - Big Lost River, Idaho

Coordinate and Photogrammetric Data Appendices

\section{B Geologic Data}

Soil Profile Descriptions

Soil Particle Size Results from Colorado State University

Examination of Bulk Soil for Radiocarbon Datable Material from Along the Big Lost River on the Idaho National Engineering and Environmental (INEEL) Site, Southern Idaho, by Kathryn Puseman, Paleo Research Institute.

Radiocarbon Dating Results and Calibration Data from Beta Analytic

Summary Report on Detrital Zircon Ages of Samples from Big Lost River Trenches, P.K

Link, Idaho State University and C.M Fanning, Australian National University

Explanation, Plots, and Procedures for Point Count and Pebble Counts and Sieve Data, by V. Sheedy, Idaho State University

Gamma-Ray Spectrometry Results from J. Budahn, U.S. Geological Survey

Trench Sample Listings

Appendix B - Electronic Supplement - Trench Logs

C Hydraulic Modeling Methodology and Quality Assurance

Part A - Methodology, Mesh Generation, and Models

Part B - Numerical Model Validation and Verification/Peer Review Comments 
D Hydraulic Modeling Results for Paleoflood Analyses

Evaluating Paleohydrologic Data with Stream Power and Shear Stress Results from Hydraulic Models

Appendix D - Electronic Supplement - Plots of modeled depth, stream power and shear stress for the Big Lost River, INEEL Diversion Dam Study Reach

E Hydraulic Modeling to Estimate Big Lost River Flood Inundation at INEEL Facility Sites

Estimating Channel Infiltration Parameters from Historical Flow Data at INEEL

Infiltration Rates to Support High-Resolution Hydraulic Modeling at Idaho National

Engineering and Environmental Laboratory by F.R. Fiedler, University of Idaho

Culvert Survey Summary by C.O. Kingsford, Bechtel BWXT

Stage-Discharge Relations for Selected Culverts and Bridges in the Big Lost River Flood Plain at the Idaho National Engineering and Environmental Laboratory, Idaho by C. Berenbrock and J.D. Doyle, 2003, DOE/ID-22184, WRIR 03-4066, U.S. Geological Survey

Appendix E - Electronic Supplement - Plots of modeled flood inundation for the Big Lost River downstream of the INEEL Diversion Dam

F Stage Probability Plots for Selected Locations at INEEL Facility Sites 


\subsection{INTRODUCTION}

Paleoflood studies of the Big Lost River (Ostenaa and others, 1999; 2002) indicated that potential flood hazards for the Big Lost River at the Idaho National Laboratory (INL) (Figure 1-1) might be significantly different than portrayed by previous studies (e.g., Kjelstrom and Berenbrock, 1996). Because of the significant discrepancy between the previous studies (Table 1-1), several further studies aimed at reducing the uncertainty in flood hazard estimates at INL have been undertaken by both USGS and BOR. The present document and the associated appendices describe the results from BOR studies of the Big Lost River flood hazard at INL.

In previous studies of flood hazard for the Big Lost River, Kjelstrom and Berenbrock (1996) and Hortness and Rousseau (2003) used stream-gage data from Big Lost River and surrounding region. Ostenaa et al. (1999, 2002) used stream-gage and geologic paleoflood data from the Big Lost River at INL. The differences in the resulting estimate of the 100-year peak flow shown by previous studies (Table 1-1) are primarily due to the use of differing data in each of the analyses. The lower peak flow estimate by Hortness and Rousseau (2003) can be attributed to their evaluation of flow attenuation within the Big Lost River system downstream of stream gages used to estimate flood frequency. The paleoflood study sites of Ostenaa et al. $(1999,2002)$ are downstream of the gages and should therefore include this attenuation. All estimates of 100-year peak flow require extrapolation beyond the length of the available stream gage data record. The geologic paleoflood data lengthens the available record of peak flow and constrain estimates of the 100-year peak flow to be within the data record of geologic observation.

\subsection{Present Study Objectives}

The major objectives of the BOR studies are focused on two broad technical arenas; 1) geologic, geomorphic, and hydraulic modeling studies to reduce the uncertainty associated with paleohydrologic estimates used in flood frequency analyses, and 2) developing probabilistic flood stage estimates for specified facility locations at INTEC and TRA.

The paleohydrologic studies have focused on detailed studies of a 5-km (3-mi) reach of the Big Lost River that extends between the INEEL Diversion Dam and the historic Pioneer Diversion (Figure 1-2) In this reach, 1:4000-scale aerial photography flown in September 2000 was used to 
develop a 3-ft topographic grid that could be rendered as the base map for detailed geomorphic mapping of the study reach and as topographic input for updated two-dimensional hydraulic modeling (Plate 1). To improve the geologic data for paleoflood and paleohydrologic bound estimates, seven trenches at three detailed study sites were excavated within the study reach. From the geomorphic mapping, trenching data and updated hydraulic modeling, revised estimates of paleofloods and paleohydrologic bounds for the Big Lost River were developed. These data were used to revise and update the flood frequency analyses.

Developing probabilistic stage estimates for INTEC and TRA facility sites included three major work activities: 1) reprocessing of the 1993 1:10,000-scale aerial photography along the Big Lost River to generate a 5-ft topographic grid, 2) two-dimensional hydraulic modeling of multiple flow scenarios between the INEEL Diversion Dam to downstream of INTEC and TRA, and 3) estimating stage probability curves for facility sites that could include alternate views and uncertainties in flood frequency, infiltration, and culvert flows on the INL site.

Initial hydraulic modeling based on the 3-ft grid topographic data for the Diversion Dam reach showed results that differed significantly from the previous studies of Ostenaa and others (1999) which used topographic data derived from the 1993 INEEL 2-ft contour map. Because the same two-dimensional hydraulic model was being used in both studies, the cause of this difference was clearly related to the input topography used in the models. To resolve these discrepancies, extensive GPS field surveys along the Big Lost River were conducted to assess the accuracy of the topographic mapping used in all phases of these studies. The GPS field surveys found that the 1993 INEEL 2-ft contour map did not appear to meet standards for 4-ft contour interval mapping (Table 1-2) and that in the area of the paleoflood study reach the surface defined by this mapping was apparently warped (Appendix A). The lack of resolution and accuracy associated with the 19932 -ft contour map resulted in systematic overestimation of stages associated with discharge in the Big Lost River in the previous studies. GPS field surveys of selected areas along the Big Lost River corridor demonstrate that the topographic data from the 2000 photography in the paleoflood study reach and reprocessed data from the 1993 photography both meet accuracy standards needed for the high-resolution flood modeling (Table 1-2) (Appendix A). 
The two-dimensional (depth-averaged) flow models TrimR2D and RiCOM (Appendix C) were used to calculate inundation and flow velocities for paleoflood and site inundation investigations at INL. TrimR2D uses a fixed-spacing staggered finite-difference approach that was used for hydraulic modeling of steady-state discharges in the paleoflood reach and with a larger grid spacing for the site inundation studies. RiCOM uses a staggered finite-element approach that provided an opportunity to employ high-resolution topography in a variable-sized element mesh constructed for the INL site inundation investigations. Both TrimR2D and RiCOM were used to investigate site inundation scenarios to assess the importance of parameters including topographic grid resolution, infiltration, and culvert performance, on estimated inundation corresponding to long-duration ( 20 hour-steady-state) discharges. Results from both models were post-processed for estimates of stream power and shear stress.

Monte Carlo nonparametric flood frequency estimation was used to incorporate measurement uncertainties in gaged, historical, and paleoflood discharges and nonexceedence bounds and to produce fully probabilistic flood frequency estimates for annual exceedence probabilities of specific discharges of interest. These annual exceedence probabilities were combined with stage estimates from TrimR2D and RiCOM discharge, infiltration, culvert, and topographic resolution scenarios to produce scenario probabilistic stage hazard curves for 15 sites located in the TRA/INTEC facilities (Appendix F). Annual exceedence probabilities and associated credible limits are provided for map-scale inundation plots to provide scenario probabilistic inundation maps (Appendix E). These products provide a basis to develop weights for logic tree branches associated with infiltration and culvert performance scenarios to produce probabilistic inundation maps.

\subsection{Acknowledgments}

This project has been funded through an Interagency Agreement (DE-AI07-00ID13972) between the Department of Energy (DOE) Idaho Operations Office and the Bureau of Reclamation (BOR) Technical Service Center in Denver. Robert Creed is the DOE Program Manager, who has enabled the extensive assistance and coordination required for the assembly of data and field activities on the INL site. Chris Martin (S.M. Stoller Corp.) developed initial QA documents and provided assistance with review activities. 
The overall framework of this study as developed by R. Creed was intended to be a collaborative and inclusive effort that included contributions, inputs, and viewpoints from other individuals and institutions. While BOR was the primary lead on the paleohydrologic and hydraulic modeling components, assistance from a participatory review group following development of the initial scope of work consisting of N. Katapodes (University of Michigan), P.K. House (Nevada Bureau Mines and Geology), and K. Coppersmith (Coppersmith Consulting, Inc.) was highly beneficial. Other collaborators in the study including many INL staff, and study collaborators from USGS, University of Idaho, Idaho State University (ISU) also provided significant input.

J. Ake (BOR) worked with us and the participatory review group to develop the original and revised scope of work for this project. He also provided final review comments on the summary document.

Matt Jones (BOR) is a co-principal investigator responsible for production of many products that are integral to this project. Matt conducted the GPS surveys for the photogrammetry and topographic analyses, generated all of the photogrammetric products and topographic grid data used as input for the hydraulic modeling, and generated all of the visualizations used to display the results of the geomorphic mapping and hydraulic modeling.

Roger Denlinger of the USGS provided the 2D explicit finite-volume flow code and performed flow calculations on the Verde and Stanislaus rivers that provide a unique opportunity to provide an independent check of the TrimR2D and RiCOM flow codes (Appendix C). Roy Walters developed the TrimR2D and RiCOM flow codes and performed many tests of these codes to replicate and supplement testing performed by the authors of the report (Appendix C).

Collection and analyses of topographic data from the INL site could not have been completed without the extensive help of K. Beard (INL). Ken assisted with GPS surveys upstream of the INEEL Diversion Dam and graciously provided extensive assistance and consultations regarding the topographic and survey issues at the INL site. We also thank R. Smith (INL) for extensive help locating data needed for reanalyses of the 1993 aerial photography data. The INL GIS Laboratory provided several pieces of GIS data used to construct base maps for the inundation modeling. 
Matt Norake (VECTORS, Inc.) assisted with reduction of much of GPS data used for control on the 2000 photography and with field surveys to evaluate the 1993 topographic results.

The insight and assistance of R. Smith (INL) with basalt stratigraphy and overall geologic processes at the INL was indispensable to this project. The initial phase of geomorphic mapping, conducted prior to the trenching, also benefited greatly from the insights and review comments of R. Klinger (BOR).

Logging and description of the trenches required extended field efforts and assistance from several individuals. Val Sheedy (ISU) provided extended assistance with logging and descriptions of the trenches and with sedimentological analyses. David Simpson (URS Consultants) assisted with soil descriptions for trenches T1 to T7. Lucy Piety (BOR) provided additional expertise in interpretations of the soils, and with extending the soil descriptions and mapping throughout the trenches. Piety and L. Anderson (BOR) also assisted in logging of trenches T8/T9. K. Duran and W. Gonzales (BOR) provided field assistance in the initial phases of trench gridding and surveying and extensive support in assembling the photomosaics used as base maps for trench logging (Appendix B-electronic supplement).

Many helpful and insightful comments were received along the way from G. Thackery and P. Link of ISU through several field visits and discussions during the mapping and trench logging. In addition, they provided oversight to V. Sheedy and the sedimentological analyses. P. Link conducted detrital zircon analyses of several samples.

Kathy Puseman at PaleoResearch Laboratories provided macrofloral identifications of samples from the trenches. Radiocarbon dating was conducted through Beta Analytic. Mel Kuntz (USGS) provided assistance with attempts to identify potential tephras in samples from the trenches. Jim Budahn (USGS) conducted gamma-ray spectrometry on an set of test samples to evaluate isotopic activity.

In February 2005, after most maps and supporting documentation for this report had been finalized, the Idaho National Laboratory (INL) became the new official name of the former Idaho National Environmental and Engineering Laboratory (INEEL). The new name has been adopted 
in the text of this summary report for most references to the site and staff. Exceptions include figures where the boundaries and features are labeled with the INEEL name on underlying images and references to stream-gaging stations and data, all references to the INEEL Diversion Dam. The previous name was retained for consistency in this report because all of the supporting maps and images were completed with the old name. Most site references within appendices to this report were completed prior to the name change and thus retain the old name. 
Figures for Section 1.0 


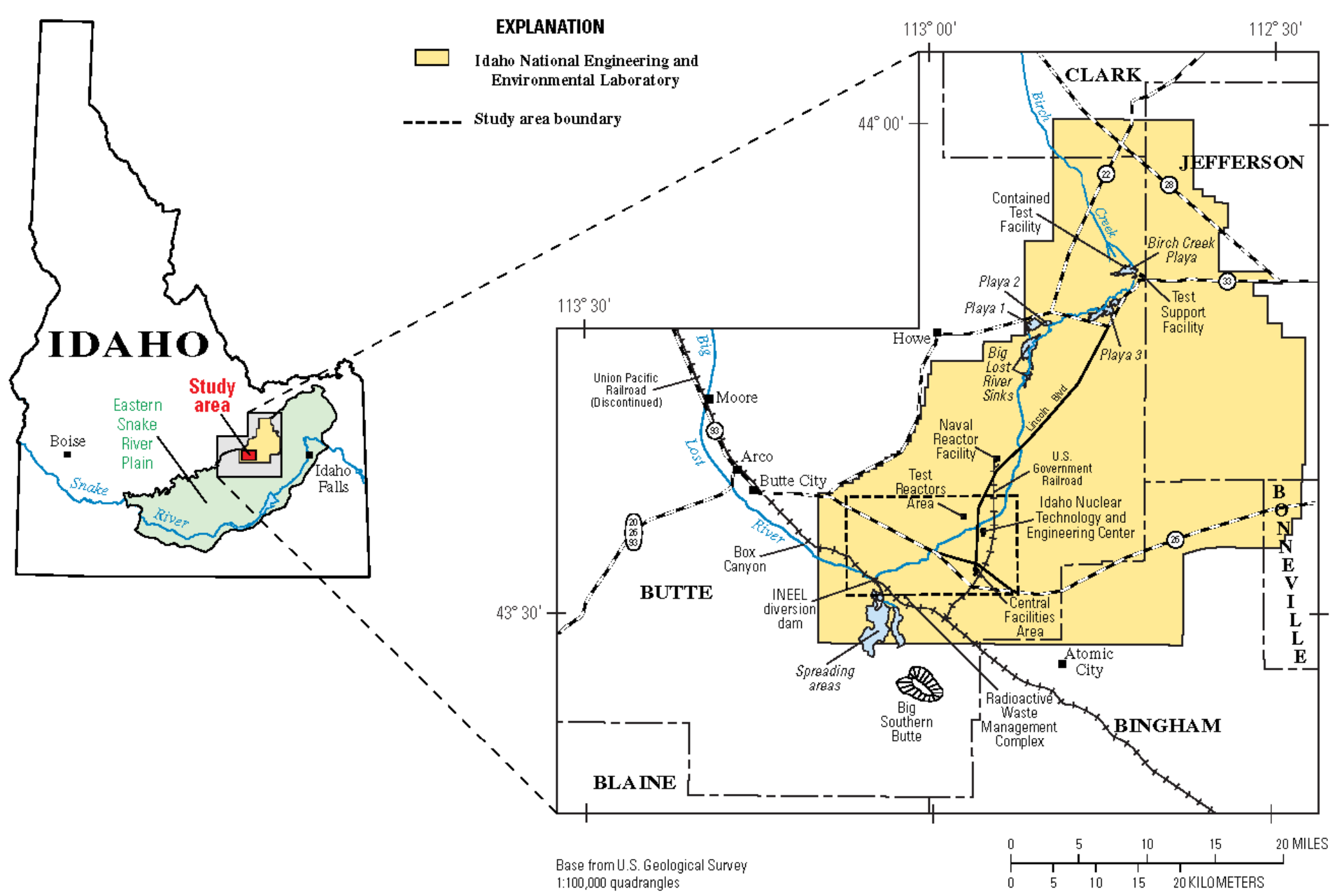

Figure 1-1 Location map of INL (INEEL) and study area. Diversion Dam study reach is located along the Big Lost River between the Union Pacific Railroad and Highway 26. Figure from Berenbrock and Doyle (2002). 


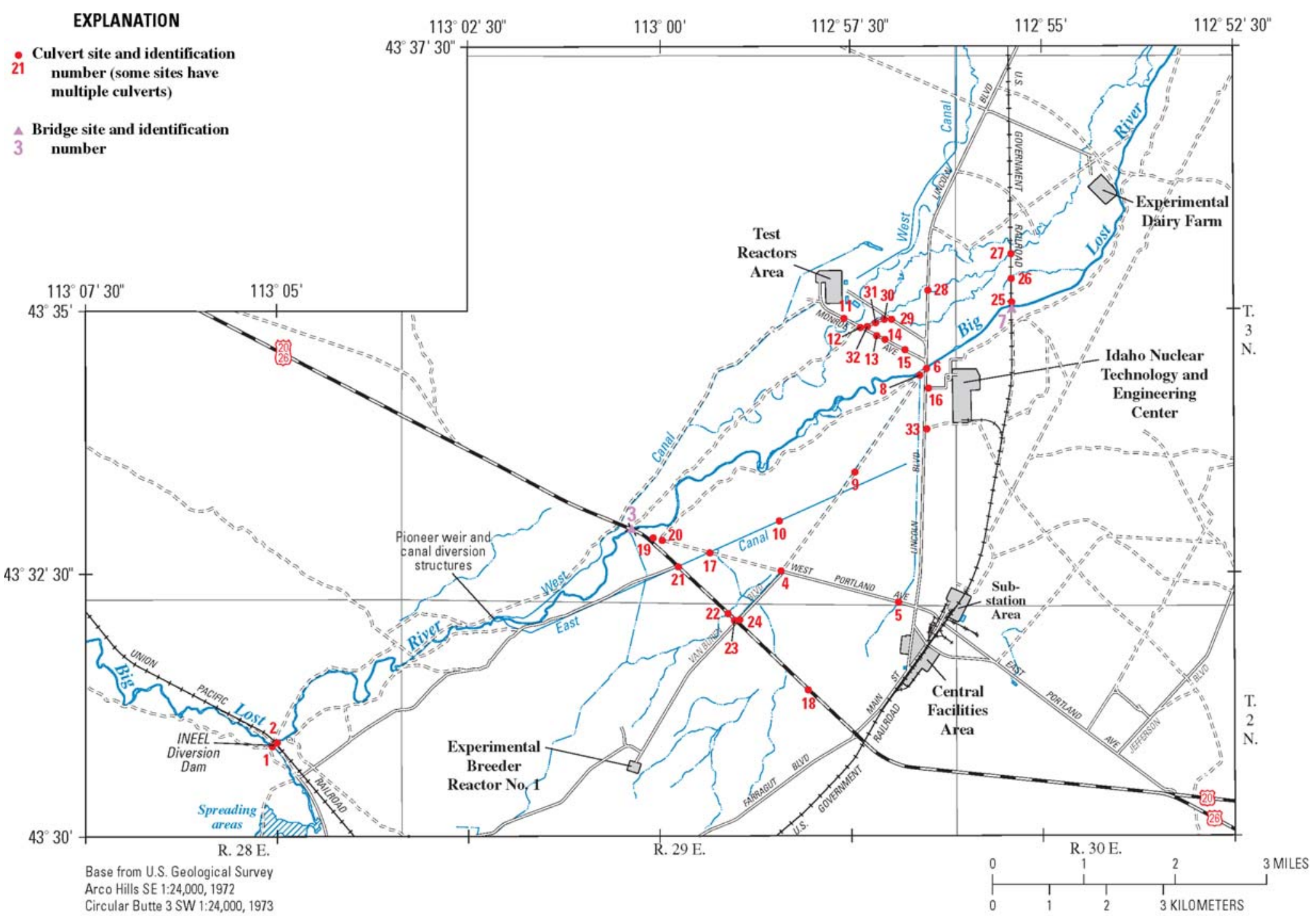

Figure 1-2 INL study area, Big Lost River and significant facility locations. Paleohydrologic studies were conducted for the reach between the INEEL Diversion Dam and the Pioneer diversion structures. Stage probability estimates are required for sites at the Test Reactor Area (TRA) and Idaho Nuclear Technology and Engineering Center (INTEC). Figure from Berenbrock and Doyle (Appendix E). 
Tables for Section 1.0 
Table 1-1 Summary of some results from previous flood hazard studies at INL

\begin{tabular}{|c|c|c|}
\hline \multicolumn{3}{|c|}{ Estimates of 100-year peak flow for the Big Lost River near INEEL Diversion Dam } \\
$\mathrm{m}^{3} / \mathrm{s}\left(\mathrm{ft}^{3} / \mathrm{s}\right)$
\end{tabular}

Table 1-2 Comparison of Measured and Required Accuracy Values for Areas Downstream of INEEL Diversion Dam (Appendix A)

\begin{tabular}{|c|c|c|c|c|c|c|c|}
\hline \multirow[t]{3}{*}{ Map/Data Source } & \multicolumn{3}{|c|}{ Measured Values } & \multicolumn{4}{|c|}{ Required Values } \\
\hline & \multicolumn{3}{|c|}{ NSSDA } & \multicolumn{2}{|c|}{$\begin{array}{l}\text { NMAS } \\
\text { (Accuracy) }\end{array}$} & \multicolumn{2}{|c|}{$\begin{array}{l}\text { ASPRS class } 1 \\
\left(\mathrm{RMSE}_{\mathrm{z}}\right)\end{array}$} \\
\hline & $n=$ & Accuracy & $\mathrm{RMSE}_{\mathrm{z}}$ & 2-ft CI & 4-ft CI & 2-ft CI & 4-ft CI \\
\hline \multicolumn{4}{|l|}{$\begin{array}{l}1993 \text { AG 2-ft Contours } \\
\text { (Paleoflood Study Reach) }\end{array}$} & \multirow{10}{*}{1.192} & \multirow{10}{*}{2.383} & \multirow{10}{*}{0.677} & \multirow{10}{*}{1.333} \\
\hline Aug. 2000 panel points & 61 & 2.246 & 1.146 & & & & \\
\hline July 2002 check survey & 827 & 3.038 & 1.550 & & & & \\
\hline \multicolumn{4}{|l|}{ (Downstream Hwy 20/26) } & & & & \\
\hline Oct. 2002 check survey & 519 & 2.446 & 1.248 & & & & \\
\hline \multicolumn{4}{|l|}{$\begin{array}{l}2003 \text { BOR 5-ft Grid } \\
\text { (Paleoflood Study Reach) }\end{array}$} & & & & \\
\hline Aug. 2000 panel points & 61 & 1.752 & 0.894 & & & & \\
\hline July 2002 check survey & 827 & 1.746 & 0.891 & & & & \\
\hline \multicolumn{4}{|l|}{ (Downstream Hwy 20/26) } & & & & \\
\hline Oct. 2002 check survey & 519 & 1.586 & 0.809 & & & & \\
\hline
\end{tabular}




\subsection{GEOLOGIC AND GEOMORPHIC STUDIES OF THE DIVERSION DAM STUDY REACH}

The paleohydrologic studies of the Diversion Dam study reach are a continuation and expansion of the studies described in previous reports (Ostenaa et al., 1999, 2002). The objective of further studies is to identify and reduce the uncertainty of the previous estimates. Field-scale investigations included four major tasks: 1) acquisition and processing of new detailed aerial photography to serve as a base map for geomorphic mapping and hydraulic modeling, 2) compilation of a detailed geomorphic map of the study reach, 3) trenching and detailed geologic descriptions and analyses in three areas of the study reach to confirm geologic/geomorphic relationships, and 4) additional two-dimensional hydraulic modeling using the new topographic data. In the following sections, the setting of study reach is reviewed (Section 2.1), followed by discussions of the geomorphic mapping (Section 2.2), and trenching investigations (Section 2.3). Section 2.4 summarizes the combined results of the geomorphic and trenching investigations. The scope and updated results from new two-dimensional modeling of the Diversion Dam study reach are in Section 2.5. Section 3.0 describes the framework for evaluating the geomorphic and hydraulic modeling data to support conclusions regarding paleofloods and paleohydrologic bounds for the Big Lost River. These conclusions are outlined in Section 3.3 and Section 3.4 and used in the updated flood frequency analyses presented in Section 4.0.

\subsection{Geologic and Geomorphic Setting of the Diversion Dam Study Reach}

Ostenaa et al. (1999, 2002) summarize the setting and extent of the Diversion Dam study reach, and the application of paleohydrologic bounds to the issues of estimating flood frequency for the Big Lost River.

The INL site is located on the eastern Snake River Plain of Idaho (Figure 1-1), a large area of Quaternary basaltic lava flows that are mantled with extensive, thin, wind-blown deposits and lesser areas of alluvium and lacustrine deposits (Kuntz et al., 1994). Mid- to late Cenozoic extension in the Basin and Range Province mountains that lie to the north and south is overprinted by the volcanic activity on the eastern Snake River Plain, presumably in response to passage of the Yellowstone Hot Spot (e.g., Pierce and Morgan, 1992). 
The headwaters of the Big Lost River are in the glaciated mountains of the Idaho Basin and Range Province north of the Snake River Plain. The upper basin includes peaks that exceed elevation $3500 \mathrm{~m}$ in the northeast-facing basins of the Pioneer Mountains and the southeastern portion of the steep southwest-facing front of the Lost River Range. The river flows southeast for a distance of about 80-km through the Big Lost River Valley, a late Cenozoic structural basin filled with alluvium. Mackay Reservoir, about 30-km upstream of Arco, stores irrigation water for users in the downstream Big Lost River Valley. At the northern edge of the Snake River Plain near Arco, the drainage basin includes an area of about $3650 \mathrm{~km}^{2}$ that lies above an elevation of $1550 \mathrm{~m}$. About 10-km downstream of Arco, the river flows onto the INL site where it turns northeast and flows another $35 \mathrm{~km}$ to its natural terminus in the Big Lost River Sinks and several playas at the northern edge of the INL site. The last portion of the river course parallels the axis of the Big Lost Trough, a late Cenozoic depositional center on the north side of the eastern Snake River Plain (Geslin et al., 2002). Subsidence along the Big Lost Trough has been more or less matched by the rate of volcanic and sedimentary infill (Geslin et al., 2002). Thus, on the Snake River Plain and the INL site, a sequence of late Pleistocene terraces along the Big Lost River records only a few meters of net incision in the last 95 ka (Ostenaa et al., 1999; Simpson et al., 1999).

2.1.1 Big Lost River historical stream flow. Average annual precipitation in the Big Lost River basin ranges from about $1250 \mathrm{~mm} / \mathrm{yr}$ in the mountainous upper basin areas to about $200 \mathrm{~mm} / \mathrm{yr}$ across much of the INL site on the Snake River Plain. This precipitation occurs mostly in the winter months and is largely derived from moisture from the northern Pacific Ocean (Kjelstrom, 1991). During the late spring and summer snowmelt period, the air flow from the Pacific generally consists of relatively dry, subtropical air that produces only sporadic thunderstorms across Idaho. Southeastern Idaho can be affected as well by summer monsoon flow from the south and southwest, which can cause increased precipitation (Kjelstrom, 1991). Meteorological conditions favorable for long-duration winter rainfall are uncommon (Kjelstrom, 1991), especially for large drainage basins.

Annual stream flow, and the largest annual peak discharge, in the Big Lost River are dominated by the spring and early summer snowmelt and runoff from the mountains in the upper drainage basin. Stream flow records are available from the upper basin since 1904 and from the Arco area 
since 1947 (Ostenaa et al., 1999, 2002) (Figure 2-1). The timing of the snowmelt is regular, usually beginning in late May or early June of each year, with significant flows extending into July. The magnitude of the annual peak discharge typically decreases in a downstream direction with increasing drainage area. Significant downstream decreases in peak discharge, even in the wettest years, indicate that the decrease is at least in part due to large amounts of natural channel infiltration and storage in the Big Lost River Valley (Stearns et al., 1938). Additional decreases in peak discharge result from storage in Mackay Reservoir, about 65 km upstream of the INL site, and irrigation diversions upstream of Arco and the INL site. Hortness and Rousseau (2003) evaluated the changes in peak discharge at gaging stations along the Big Lost River and documented a systematic attenuation in peak discharge from the upstream gaging stations to the INL area. This attenuation appears to exist even for the largest historical streamflows and is not solely due to regulation effects.

2.1.2 Big Lost River - Diversion Dam study reach. South of Arco, the Big Lost River leaves the alluvium-filled Big Lost River valley (Figure 1-1) and flows across middle to late Quaternary basalt on the Snake River Plain that is locally mantled with alluvium of varied thickness (Kuntz et al., 1994). Near Box Canyon (Figure 1-1), the river is incised from 5- to 30-m into the basalt, and only small areas of alluvium are preserved in the canyon. Downstream of Box Canyon, on the southwestern portion of the INL site, Kuntz et al. (1994) mapped extensive areas of alluvium along the Big Lost River. However, even in this reach, basalt exposures are common in the bed and banks of the river and as isolated outcrops on the alluvial surfaces near the channel, indicating that the alluvium overlying the basalt is relatively thin in this area (Plate 2).

The geologic and geomorphic descriptions, and hydraulic modeling analyses, focus on a 6-kmlong study reach just downstream of the INEEL Diversion Dam (Plates 1 and 2). Throughout the Diversion Dam reach, the Big Lost River is incised about 2- to 4-m into the relatively flat alluvial surfaces on either side. Areas of relief are associated with Pleistocene basalt outcrops that stick out above the alluvium. Previous mapping depicts most of this alluvium as Pleistocene in age based on the degree of soil development and alluvial surface morphology (e.g., Rathburn, 1991; Kuntz et al., 1994). The Pleistocene alluvium is gravelly with a 0.5- to 1-m-thick cover of loess, mostly deposited before about 10 ka (Forman et al., 1993). Exposures in nearby gravel pits, 
stream banks, and trenches excavated for this study show a moderate- to well-developed soil with stage II or greater calcium carbonate accumulation in the gravel and loess.

Soils at sites BLR3 and BOR25 contain stage II or greater calcium carbonate accumulation (Ostenaa et al., 1999, 2002) as do soils exposed in the trench intervals excavated into the Pleistocene alluvium (e.g., T1, T2, T3, T6, T7, T8 and T9; see Plate 2 for locations). Soils in the gravelly alluvium and overlying loess have well developed calcic horizons, (stage II to III), generally considered indicative of a late Pleistocene age (e.g., Scott, 1982; Birkeland, 1999).

Topographic maps and images of the Pleistocene surfaces show a distinct pattern of relic channels with a subdued morphology (Plate 2). The pattern of these channels is consistent with the development of these surfaces as Pleistocene glacial outwash plains, as is the sedimentology of the gravels exposed in the trenches. The youngest fluvial-related features on these gravel surfaces are 1- to 1.5-m deep braid channels infilled with fine sand and silt in which a Stage II carbonate soil is developed, consistent with a Pleistocene age. The surfaces also have a well-developed pattern of earth mounds, which often follow and overprint the channels (Tullis, 1995).

The overall channel configuration of the Big Lost River in this study reach (Plate 2) is controlled by several locations where the river crosses outcrops of basalt. The sharp bend at the INEEL Diversion Dam results from the impingement of the Big Lost River on a flow tongue of Quaking Aspen Basalt. Downstream of this bend, through the study reach extent shown on Plates 1 and 2, the overall sinuosity is about 1.5. However, upstream of BLR2 (see Plate 1 for locations), sinuosity is about 1.2. The central section from BLR2 to the Saddle Constriction area has sinuosity of 2.4, while downstream sections have an overall sinuosity of about 1.2. The most sinuous sections of the channel are formed in reaches with mostly alluvial banks upstream of where the Big Lost River impinges on partially buried basalt outcrops, such as at the Saddle Constriction study area (Plate 2 and Figure 2-3). Reaches with relatively lower sinuosity tend to have more areas of outcropping basalt in the channel bed and banks, suggesting that the stream course and form is primarily controlled by interactions with rock outcrops. The basalt outcrops in the study reach form constrictions that locally create hydraulic controls on flow and indicate that the overall configuration of the channel has been stable since the river incised below the level of the Pleistocene surfaces. Well-developed soils on some of the inset fine-grained terraces, such as 
at BLR6 and in Trench T6 and T8, and radiocarbon ages from these deposits (Table 2-2), indicate that this incision has an age of at least $10 \mathrm{ka}$ and more likely $13 \mathrm{ka}$.

In the central portion of the Diversion Dam study reach, the Big Lost River flows through a narrow basalt constriction (Saddle Constriction study area - Plate 2). This constriction is formed by a ridge of basalt that extends across the Big Lost River and protrudes above the level of the Pleistocene alluvial surface south of the river. Upstream of this constriction lies a meandering reach of the river that is flanked by an extensive area of Holocene alluvium inset below the level of the Pleistocene alluvial surfaces on either side (Plate 2). On the north side of the river, a low ridge apparently underlain by basalt forms the contact between the Holocene and Pleistocene alluvium (Figure 2-3). The surface of the ridge is capped with gravel and eolian deposits. The low point along this ridge, informally known as the Saddle, is a location where high flows could spill over onto the Pleistocene surface downstream of the ridge due to elevated stage caused by hydraulic ponding at the basalt constriction.

Throughout the Diversion Dam study reach are Holocene surfaces with distinctly different morphology that are inset within, and below the level of the Pleistocene surfaces. An extensive area of Holocene alluvium lies just upstream of the Saddle (Plate 2), but elsewhere in the reach these deposits are of limited extent. Downstream of the Saddle, Holocene surfaces are limited to narrow terraces that mostly parallel the main channel, but which are somewhat wider at locations where high flows have cut across bends, such as near site BLR8 (Figure 2-5). On the higher Holocene surfaces, approximately 2- to 3-m above the low-flow channel, the surface morphology is generally smooth, with only small, subdued channels evident. In contrast to the Pleistocene surfaces, earth mounds are absent. A 0.5- to 1-m-high terrace riser is often present at the back edge of these surfaces defining the contact with the Pleistocene surfaces On the geomorphic maps these surfaces are mapped as the H1-2 units (Appendix B and Plate 2). Surfaces that are less than 2-m above the low-flow channel are distinctly channeled (H3-4 units on Plate 2). Floated historical debris indicates that these lower surfaces and deposits have been flooded by recent flows.

Descriptions in trenches T4, T5, T6, T8 and T9, (Section 2.3) and at sites BLR2, BLR7, and BLR8, (Ostenaa et al., 1999, 2002) in the Diversion Dam reach show that the Holocene terrace 
deposits of the Big Lost River are generally fine-grained, consisting of sand and silt. Gravel is generally present only as small bars in the channel, or underlying the fine-grained deposits in these terraces. Rathburn (1991) also noted that the Holocene deposits of the Big Lost River on the INL site are more fine-grained than the Pleistocene alluvium.

\subsection{Geomorphic Mapping of the Diversion Dam Study Reach}

Mapping of the Diversion Dam study reach was done using stereo photography and digital terrain models using Intergraph ZI Imagestation Software. Imagery and terrain models were obtained from the 2000 aerial photography flown for this study (Appendix A). Most final contacts were not field checked in detail, but the mapping was heavily supplemented with field notes compiled on 1993 and 2000 aerial photography and their associated topographic map products, as well as data from previous mapping. One major mapping objective was to characterize the spatial extent of the significant geomorphic units within the study reach for comparison and analyses with the results of the two-dimensional flow modeling. A second objective was identify and characterize sites for subsurface investigations of stratigraphy and soils. Characteristics of the major units depicted on Plate 2 are discussed in the following subsections, followed by summaries of the setting of the sites identified for further investigations.

2.2.1 Quaternary Basalts - Rb, Rbe, Rd and Rde. Previous geologic mapping of the INL site area (Kuntz et al., 1994) depicts two Quaternary basalt units in the area of the Diversion Dam study reach. An older unit, previously mapped as Qbd, includes basalt flows with estimated ages of 400 to $730 \mathrm{ka}$, mostly derived from sources north of the present Big Lost River. For the present study (Plate 2), flows of this group are mapped as Rd, and Rde for outcrop areas discontinuously and thinly covered by eolian sand and loess. A younger unit, previously mapped as Qbb, includes flows dated between 15 to $200 \mathrm{ka}$. Qbb flows in the Diversion Dam study reach have sources near Quaking Aspen Butte, several km to the southwest. Dating studies near the RWMC, just south of the Diversion Dam study reach, indicate that the flow at that site is about 95 ka (Forman et al., 1993; Kuntz et al., 1994). For the present study, the Quaking Aspen flows are mapped as Rb, and Rbe for outcrop areas discontinuously and thinly covered by eolian sand and loess. 
Both of the basalt map units are locally covered by a variable thickness of loess and eolian cover. Locally, many areas have a well-developed stone pavement consisting of angular basalt pebbles and carbonate detritus. Earth mounds are present in some areas where loess accumulation is apparently thicker. The flow tops are highly irregular, with local surface relief that exceeds $5 \mathrm{~m}$.

At least two flows from the Quaking Aspen Butte lava field (Rb) intercepted the course of the Big Lost River in the map area (Plate 2). One flow tongue extends northeast from the INEEL Diversion Dam for about $2 \mathrm{~km}$ and appears to have deflected the late Pleistocene course of the Big Lost River to the northeast. A second flow extends across the course of the Big Lost River from the Saddle area to the Old Pioneer Diversion Dam area. This flow tongue extends southeast to the RWMC area where it has an estimated age of 95 ka (Forman et al., 1993; Kuntz et al., 1994). Pleistocene gravel sheets, mapped here as P1-2, bury the margins of the flow tongues, and have breached the low areas of both flow tongues as shown by radial, fan-shaped surfaces downstream of the $\mathrm{Rb}$ flows. In addition, the Pleistocene gravel surface extends around the northwest side of the Rb flow about $2 \mathrm{~km}$ north of the Old Pioneer Diversion Dam. Rb outcrops are present in bed and banks of the Big Lost River channel at the INEEL Diversion Dam, and from the Saddle area to the Old Pioneer Diversion Dam area. Outcrops that protrude above the Pleistocene surfaces by more than about $1 \mathrm{~m}$ generally retain primary cooling features including vesicular plates on flow tops. Limited areas of loess accumulation are present on larger outcrops, which often have well-developed pavements of basalt fragments. Fissures along the crests of pressure ridges are only partially infilled with eolian deposits. In hand specimens, the Rb flows are distinguished by very fine-grained groundmass with common olivine phenocrysts.

The Rd units are part of a large area of basalt, mapped as Qbd by Kuntz et al. (1994) that lies north and northwest of Big Lost River downstream of the INEEL Diversion Dam. The margins of these flows are buried by Pleistocene alluvium. Extensive outcrops are present in the river channel bed and banks downstream of the INEEL Diversion Dam near BOR20, and scattered outcrops are present along the river downstream from BLR7 to BLR2 and the meander bend upstream of BLR3. The Rd units generally have a thicker cover of eolian deposits and more subdued morphology than Quaking Aspen ( $\mathrm{Rb})$ flows. In hand specimen, these basalts are 
distinguished by fine-grained groundmass, common plagioclase phenocrysts, and rare olivine phenocrysts.

2.2.2 Pleistocene Units - P1 to P3. Initial mapping of the study reach defined three relative-age subdivisions, termed P1-2, P2, and P3, of the Pleistocene surfaces within the Diversion Dam study reach. The oldest surfaces, P1-2, are composed of broad, low-relief, fanshaped surfaces that radiate from low saddles in the basalt ridges. Relic channels are subdued or not apparent, and large earth mounds up to 0.5-m-high are common and appear evenly spaced or random across the surface (Plate 2). The P1-2 surfaces are generally most distant from the present Big Lost River channel and are about 4.0 to $4.5 \mathrm{~m}$ above the channel.

The P2 surfaces are the most extensive Pleistocene surface within the Diversion Dam study reach and are generally 3.5 to $4.0 \mathrm{~m}$ above the channel. These surfaces have prominent relic cutoff and braid channels that are clear on aerial photography, and typically have $0.5-\mathrm{m}$ relief as shown by contour maps. Because these surfaces are slightly inset relative to the P1-2 surface, the radial pattern from saddles in the basalt ridges is slightly subdued, but is still present. Large earth mounds up to 0.5-m-high are also common on the P2 surfaces. In some areas, the mounds often appear to follow relic channels, but are also present on interfluves. Over some large areas of P2 surfaces the mound pattern is subdued, but other morphology is unchanged. The mapped extent of P2 includes some slightly higher areas that are gradational to P1-2 and not mapped separately.

The gravel deposits that underlie the P1-2 and P2 surfaces are distal, glacial outwash from late Pleistocene glaciation in the upper Big Lost River drainage (Kuntz et al., 1994). The surface morphology on these units indicates deposition as an extensive gravel braid-plain, that predates the incision and establishment of the present Big Lost River channel. Thus, surface slopes and patterns on the P1-2 and P2 surfaces are generally unrelated to the present Big Lost River channel system. Rathburn (1991) also noted this, but viewed the gravels as having been deposited by the waning stages of a late Pleistocene glacial outburst flood, about 20 ka (Cerling et al., 1994). Subsequent work has suggested that any exceptionally large glacial outburst flood on the Big Lost River is likely older than about 50 ka (Ostenaa et al., 1999: Knudsen et al., 2002). 
The gravel deposits that underlie the P1-2 and P2 surfaces are typically overlain by $25-150 \mathrm{~cm}$ of loess, with stage II-III carbonate developed in the loess and underlying gravel (Ostenaa et al., 1999, 2002; and Section 2.3 following).

The P3 surfaces, 3.0 to $3.5 \mathrm{~m}$ above the Big Lost River channel are of limited extent compared to older P1-2 and P2 surfaces (Plate 2). In contrast to the older Pleistocene surfaces, the average surface gradient of the P3 surfaces is generally consistent with the Holocene channel and the inset H1-2 surfaces, although some P3 surfaces have a gentle slope towards the channel. A pattern of earth mounds are apparent on aerial photography and digital imagery (Plates 1 and 2), but larger mounds with topographic relief are present only on the rear, higher portions of these surfaces. Mounds with topographic relief are absent along lower portions. A distinct plant mound pattern is apparent on all surfaces; more developed than on $\mathrm{H} 1$ surfaces. The P3 surfaces are underlain by gravels, capped by a layer of loess which is generally thinner than on the P1-2 or P2 surfaces. Soils generally have Stage II carbonate in the gravels (Section 2.3 following).

\subsubsection{Age Constraints from Regional Glaciation.}

Regional approaches have linked loess deposition to glaciation because the landscapes associated with regional glaciation such as aggraded river valleys, active alluvial fans, and fluctuating pluvial lake margins, provide the most viable sources for the loess (Forman et al., 1993). Based on luminescence ages from loess samples at INL, Forman et al. (1993) concluded that the latest period of loess deposition commenced about 35,000 to 40,000 years ago and ceased approximately 10,000 years ago. The youngest luminescence ages for loess on the eastern Snake River Plain near INL are 20-30 ka, and the age for cessation of loess deposition was based on age estimates for deglaciation in the Eastern Snake River Plain region.

Limiting ages for glaciation in the region surrounding the Snake River Plain are available from three areas, 1)Yellowstone, Wyoming to the east, 2) Wallowa Mountains Oregon to the northwest, and 3) Sawtooth Mountains, Idaho, to the north.

Radiocarbon ages on materials recovered from drill holes at Jackson Lake, Wyoming indicate that the southern outlet glaciers of the Yellowstone Plateau ice cap had retreated from maximum 
positions in the Jackson Lake area by about $15,000{ }^{14} \mathrm{C}$ yr B.P., an age roughly equivalent to 17,000 to 18,000 calendar years (Pierce and Good, 1992; Good and Pierce, 1997; Connor, 1998). Northern outlet glaciers may have reached maximum positions somewhat later, about $16,200 \pm 300{ }^{10} \mathrm{Be}$ yr B.P. (16,500 $\pm 400{ }^{3} \mathrm{He}$ yr B.P.) possibly reflecting differences in ice accumulation source area characteristics (Licciardi et al., 2001). Earlier work in the area had suggested somewhat older ages for glacial maximums in northern Yellowstone (e.g., Sturchio et al., 1994), but all agree that deglaciation of the area was well underway, or even nearly complete, no later than about 14,000 cal. yr B.P. (e.g., Licciardi et al., 2001; Whitlock, 1993; Richmond, 1986; Pierce, 1979). In the Wallowa Mountains, Oregon, Licciardi et al., 2004 infer significant glacial advances at about $17,000 \pm 300{ }^{10} \mathrm{Be}$ yr B.P. based on ages from moraines located only a short distance upvalley of the LGM moraines dated to $21,100 \pm 400{ }^{10} \mathrm{Be}$ yr B.P. In the Sawtooth Mountains of Idaho, just to the west of the headwaters of the Big Lost River, Thackery et al. (2004) showed that the maximum glacial advances occurred shortly before about $\sim 14,000{ }^{14} \mathrm{C}$ yr B.P (16,900 cal. yr B.P.), roughly 4000 years later than the regional LGM. These ice positions were either maintained until or reoccupied as late as about $11,900{ }^{14} \mathrm{C}$ yr B.P (13,950 cal. yr B.P.), followed shortly by major deglaciation.

2.2.2.2 Earth Mounds. A ubiquitous feature of the Pleistocene surfaces, particularly the P1 and P2 surfaces, are large circular features termed earth mounds by Tullis (1995) in a previous study of these features on the INL. Tullis reviewed the extensive literature on the similar features which exist throughout the world, with several potential origins, including biological (primarily burrowing animals) and cryogenic (related to past glacial climates). Although unable to fully characterize all aspects of the origin of the earth mounds, Tullis (1995) concluded that a cryogenic origin was most likely for the INL mounds, although biological activity was a clear factor in the present mound characteristics. Soil development within and between the mounds indicated that the mounds developed during the late Pleistocene (Tullis, 1995) and many areas between the mounds have a weak to moderate gravel pavement (e.g., McFadden et al., 1998). Recent literature provides additional mechanisms for the initial origin of the mounds that would be consistent with a cryogenic origin (e.g., Kessler and Werner, 2003), as well as concepts for the biological exploitation of such sites (Johnson and Johnson, 2003). 
Trench exposures (Appendix B - Electronic Supplement and Section 2.3 following) through eleven mounds for this study confirm the relative antiquity and longevity of the mounds. The mounds formed in a variety of stratigraphic settings, clearly post-date gravel deposition, but also include strongly developed soils that indicate long-term spatial persistence. The trench exposures did not reveal evidence for eroded or abandoned mound sites. Only limited evidence of moundrelated cryogenic features were observed in the trenches for this study. As noted by Tullis (1995), the mounds are preferred locations for Holocene biological activity based on abundant active and inactive burrows and disrupted soils of various development and ages.

Soil development within the mounds that indicates long-term spatial persistence, probably since the late Pleistocene, together with the occasional observations of associated cryogenic features noted in the trenches and by Tullis (1995), seems to support the hypothesis that the initiating condition for the mounds at INL was likely cryogenic. Mechanisms such as those discussed by Kessler and Werner (2003) would have led to formation of shallow depressions that would initially provide thicker sites of finer sediments on the gravel braid plain. Most likely these would then become colonizing sites for biological activity (e.g., Johnson and Johnson, 2003) and the process of building the topographic relief that distinguishes the present mounds. This framework of origin and mound growth implies a cryogenic process for initial subsurface relief and expression of the mounds, which are then strongly modified by the biological activity that is primarily responsible for building the surface relief and expression of the mounds. It further implies a strong likelihood that the topographic expression of the mounds on the Pleistocene surfaces has been gradually increasing, primarily due to biological processes, since they were initiated.

The surficial expression of the mounds consist largely of loess (Tullis, 1995) and would be highly erodible, as would the loess cover on the Pleistocene alluvium, if there was significant surface flow around or over the mounds. As shown on Plate 2, there are significant variations in the expressions of the earth mounds throughout the study reach. On the older Pleistocene surfaces, P1-2 and P2, these variations are not clearly related to obvious any patterns of flow that develop based on modeling of extreme flood discharges through the study reach. A likely cause of some of the observed variations is mound deflation due to wind following the August 2000 wildfire which 
burned over most of Diversion Dam study reach a few weeks prior to the flight for aerial photography used for the base map images of Plates 1 and 2. In other areas, mounds have been modified by cultural activities at INL, especially early agriculture and grazing.

In contrast to the older Pleistocene surfaces, the geomorphic expression of the mounds on the P3 surfaces does appear to be modified by flow related to the present Big Lost River system. Earth mounds are only prominent on the higher, more distal portions of the P3 surfaces. The absence of mounds on the inset Holocene surfaces is more complex. Similar mounds may not have formed due to differences in the materials underlying the Holocene surfaces, or if the initial origin of the mounds required a much colder climate, the Holocene surfaces may post-date periods of climate favorable for mound initiation. Alternately, the expression of mounds on the Holocene surfaces may have been modified by younger floods.

\subsubsection{Geomorphic Evidence for Holocene Modification of the Pleistocene}

Units. The pattern of relic braid channels on the P1-2 and P2 surfaces shows no evident relation to potential patterns of large flows associated with the present Big Lost River channel. Rather, these channels are directly related to the overall radial fan shape of the P1-2 and P2 surfaces that is controlled by breaches through low saddles in the basalt ridges that flank and cross the Big Lost River (Plate 2). The braid channels have overall similar morphology, and do not display geomorphic evidence of having conveyed any significant, recent flow. One site that could appear as a possible exception to this is located about $250 \mathrm{~m}$ northeast of trench T1 (Figure 2-2 and Plate 1) where a sharp cut is present in the terrace riser onto the P2 surface. Field inspection of this feature suggests that it was excavated for vehicle access and was not an erosional feature and there are numerous other old wheel tracks and ruts in this area. About $150 \mathrm{~m}$ north of that site, the upstream continuation of the same terrace riser intersects a channel at the back edge of the highest P3 surface in this area, and at this location there appears to be a small fan built from the mouth of this channel onto the H1-2 surface. Trench T3 crosses this channel about $80 \mathrm{~m}$ to the west (upchannel) from this site. Exposures in trench T3 are permissive of small flows and limited amounts of sediment transport (Section 2.3.1.3 following).

The morphology of several areas of the P3 surface contrasts sharply with the P1-2 and P2 surfaces. The large area mapped as P3 on the northwest edge of the Big Loop study area (Plate 2) 
lacks earth mound morphology and there is subtle evidence of small fans built off the downstream edge of this surface. Just downstream, on the north side of the Big Lost River between the large meanders, another large area of P3 has smoother morphology, and small erosional features on its downstream edge. On the higher portions of the surface, more distant from flow, earth mounds are present. This area also appears to have been plowed or farmed, as evidenced by the surface morphology and by diversion canals built across it and on the upstream edge. It is not clear how much of the morphology results from anthropomorphic activities versus geomorphic modifications due to floods. On the next meander bend, on the south side of the river, the P3 surface also shows two distinct morphologies. To the northwest, on the lower portions of the surface closest to the river bend, the surface is smooth, and downstream edges of terrace risers appear to be channelled and eroded. To the southeast, the surface is slightly higher, and the surface is rougher, with obvious earth mounds. These morphology differences on the P3 surfaces appear to bracket the limits of significant flow modification by floods that are much younger than the surfaces. Two other areas of P3 surfaces, one upstream across from BLR7, and a section downstream of the Saddle Constriction study area near trenches T6 and T7, are both slightly higher and do not display geomorphic evidence of recent flooding.

2.2.3 Holocene Units - H1 to H4. Previous mapping has recognized the presence of a generally fine-grained fill inset within the Pleistocene gravels along the Big Lost River (Rathburn, 1991; Kuntz et al., 1994). The oldest portions of this fill likely relate to the latest Pleistocene deglaciation and changes in flow regime at the end of the Pleistocene (Rathburn, 1991). Subsequently, the fill has been partially reworked and a series of surfaces, cut onto the original fill and younger deposits.

In the present mapping, four groups of surfaces, $\mathrm{H} 1$ to $\mathrm{H} 4$ were defined according to their geomorphic characteristics. The oldest surface, H1, is preserved only as small, often narrow, remnants along the outer, higher, margins of the Holocene fill deposits. These surfaces appear to be underlain by an intact early Holocene soil characterized by $>0.5$-m-thick Bk-horizons with Stage II carbonate accumulation. The slope of these surfaces generally follows the present channel slope and these surfaces are typically 2.5 to $3.0 \mathrm{~m}$ above the channel. 
Inset $\mathrm{H} 2$ surfaces record erosion and deposition by at least one late Holocene flood (s), most recently about 400-600 years ago (Ostenaa et al., 1999, 2002). Locally, the boundary of H1-2 surfaces is expressed by a subtle break in slope with $<0.5-\mathrm{m}$ relief, but in other areas, there is only a gradual slope or rise towards the back edge of the Holocene surfaces. The $\mathrm{H} 2$ surfaces are typically 1.8 to $2.2 \mathrm{~m}$ above the present channel. Areas of the $\mathrm{H} 2$ surfaces that are more than a few meters from the bank of the Big Lost River appear to be mostly underlain by early Holocene fine-grained fill deposits with variably stripped remnants of a soil similar to that developed on the H1 surfaces as shown by exposures in trenches T6 and T8 (Section 2.3.2.3 and Section 2.3.3.1 following). The outer margins of the $\mathrm{H} 2$ surfaces, and streambank exposures along the edge of the $\mathrm{H} 2$ surfaces typically expose a 1 -m-thick section of fine-grained fill in which the upper-most deposits have weakly developed soils and a Bk horizon with Stage I- carbonate accumulation. Radiocarbon ages from the upper-most deposits indicate an age of 400-600 years, for the units with Stage I- carbonate in the Bk horizon (Ostenaa et al., 1999, 2002). Some of these soils may be partly cumulic, and the subsequent addition of thin deposits $(1-5 \mathrm{~cm})$ of fine sand and silt to the uppermost soil horizons probably cannot be ruled out.

In some of the lowest exposures along the edges of the $\mathrm{H} 2$ surfaces, for example trench $\mathrm{T} 4$ (Section 2.3.2.1 following), these younger additions to the soil profile are readily recognizable and appear to indicate a subsequent, and smaller discharge paleoflood. In most other exposures, it appears that the deposits of the 400-600 year flood extend to the present ground surface with only a few cm of eolian sand mixed into the upper most A-horizon. Deposits of the 400-600 year flood are typically 20-50 cm thick in the streambank exposures, e.g., BLR2, 7, and 8 (Ostenaa et al., 1999, 2002). In trench exposures T4, T5, and T6, deposits of 400-600 year old late Holocene flood thicken toward the streambanks, to a maximum of $0.5 \mathrm{~m}$, but all of the trench exposures begin about 1-2 m from present bank margin. In most bank exposures, and in channel-ward ends of the trench exposures, 1 m of stratified silt and sand underlie the deposits of the 400-600 flood. Locally, these deposits retain a variably developed, and sometimes eroded carbonate horizon, indicating that a wide range in ages for the underlying deposits. Where there is sufficient depth of exposure, gravels often underlie the fine-grained section, but generally only to elevations about 1 $\mathrm{m}$ above the current streambed. Exposures at T8b and T8c (Section 2.3.3.1 following) are an 
exception to this, where channel-facies, fine gravels are higher in the section of the early Holocene deposits just upstream of a bedrock constriction.

Deposits that underlie the H3 and H4 surfaces are not exposed in any of the trenches, and were not described as soil description sites in this or previous studies (e.g., Ostenaa et al, 1999, 2002). Field reconnaissance of many bank exposures along the margins of the H3 and H4 surfaces shows that deposits that underlie these surfaces are well stratified, with very weakly developed soils. Recognizable soil horizons are limited to thin A- and AB- horizons, consistent with the inferred historical ages of these surfaces. With the exception of the meandering reach of the Big Lost River that lies upstream of the Saddle constriction and downstream of BLR7, H3 surfaces are generally limited to very narrow, $<1 \mathrm{~m}$ wide, terrace treads that are inset below the edges of the more extensive H2 surfaces. Within the meandering reach upstream of the Saddle constriction, H3 surfaces are more extensive and the underlying deposits are more heterogeneous. In that subreach, deposits underlying H3 surfaces likely include stripped and eroded remnants of the early Holocene fine-grained fill deposits that underlie H1 surfaces, abandoned channel and associated overbank deposits of early- to late-Holocene ages, and late Holocene to historic fine-grained deposits capping older units. The upper limit of the H3 surfaces is typically about $1.8 \mathrm{~m}$ above the present channel and is often expressed as a subtle scallop on gently sloping surfaces. At a few locations, near BLR2 and the Saddle Constriction area, this limit appeared to coincide the floated, milled timber, suggesting that this may have been associated with an earlier, historic flood. However, much this evidence was burned in the August 2000 wildfire.

Throughout the Diversion Dam study reach, the H4 surfaces are characterized by narrow, paired, terrace treads, typically $<1$ - to 5 - $\mathrm{m}$ wide, that are about $1 \mathrm{~m}$ above the low-flow channel. These surfaces are often capped by thin sand deposits from the 1997 flows, which resulted in shallow overtopping of the H3 surfaces, and these surfaces support a thicker cover of grass and vegetation than any other surfaces. The underlying deposits consist of well stratified silt, sand, and gravel. Soil profiles consist of very thin A-horizons, although silty and fine sand units are significantly bioturbated and there are extensive roots which penetrate throughout exposures in these deposits.

2.2.4 Channel Deposits. Sand and gravel within the low-flow channel are the most recent deposits of the Big Lost River. These deposits occur in small bedforms, generally less than 
0.5 to $1 \mathrm{~m}$ in height. Over much of the study reach the bed is armored with small cobbles. Near constrictions, the armor is absent and bedforms composed of finer gravel are present. Many of these bedforms appear fresh and likely were reactivated during flows in 1995-1999, when there was peak flow in the range of $10-13 \mathrm{~m}^{3} / \mathrm{s}$ on multiple occasions downstream of the INEEL Diversion Dam (Appendix E). Downstream of bedrock constrictions, there are often small pendant and lateral bars composed of larger, more angular blocks of basalt that appear to be locally derived from the outcrop constriction immediately upstream. Maximum clasts in these bars are typically less than about $0.5 \mathrm{~m}$, and bar heights are similar.

Berenbrock et al. (2003) characterized the bed armor and channel deposits in the central part of the study area from near BLR8 to upstream of the Saddle Constriction study area (Plate 1). They found that $\mathrm{d}_{50}$ of the armor layer ranged from 6-49 $\mathrm{mm}$ and was typically $15-35 \mathrm{~mm}$ at sites away from constrictions. The underlying channel deposits were slightly finer, with $d_{50}$ ranging from 0.17-35 mm. Trench exposures showed that these deposits ranged from massive to stratified. Maximum clast sizes in the underlying gravels were typically less than about $50 \mathrm{~mm}$.

\subsection{Trenching Studies}

Within the Diversion Dam study reach, three areas were selected based on the initial geomorphic mapping as sites for subsurface investigations and more detailed study: 1) Big Loop, 2) Saddle Constriction, and 3) BLR8 (Plate 2). The overall objectives of additional detailed investigations were to improve the characterization of the Big Lost River paleofloods and paleohydrologic bounds portrayed in Ostenaa et al. $(1999,2002)$. Each of the areas identified had the potential to provide differing types of data towards those goals based on their individual geomorphic and hydraulic setting. Improved characterization of the paleoflood record required excavation at sites where deposits of paleofloods might be preserved and at sites where erosion from these floods might be evident. It was also hoped that these sites would yield additional datable samples that could improve the knowledge of the age(s) of Big Lost River paleoflood(s). Improved characterization of the paleohydrologic bounds required extension of the trenching to additional sites where no geomorphic evidence of recent floods was apparent. At these sites, exposures of soils and stratigraphy would permit better assessment of the time spans over which the geomorphic conclusions could be extended. 
In 2002, nine shallow trenches with a total length of $635 \mathrm{~m}$ were excavated at the three study sites. Trench configurations and procedures were generally similar at all three study areas and are described in Appendix B - Electronic Supplement. The trench logs were mapped in the field on a photographic base and are presented in that format here. The final logs (Appendix BElectronic Supplement) are compiled at a scale of $~ 1: 45$ when printed on 11x17-inch paper. This permits assembly of pairs of 15-m long sections of the trenches on a single sheet and facilitates visualization of the lateral continuity of the deposits. In the digital version, high resolution is maintained and the logs can printed on larger sheets or in sections at a larger scale. Two sets of logs are presented in Appendix B - Electronic Supplement, one set with interpretations, and a second set of unmarked photographs. On the interpretive logs, stratigraphic contacts and units are labeled with lithofacies codes adapted from Miall (1996); soil horizons use nomenclature adapted from Birkeland (1999). Soil profile descriptions are contained in Appendix B. Sample locations are labeled and numbered on the logs. Data from sample analyses and disposition of samples are compiled in Appendix B.

2.3.1 Trenches T1, T2, and T3 - Big Loop Study Area. The Big Loop study area encompasses three trenches, T1, T2, and T3, sited on the large expanse of Pleistocene surfaces south of the Big Lost River about 0.5- to 1.5-km downstream of the INEEL Diversion Dam (Plate 1). Much of this area is mapped as $P 2$, but the study area includes the transition area between $P 2$ and P3 (Section 2.2.2). Braid channels and large earth mounds are prominent throughout the area and the three trenches were sited to intersect both types of features (Figure 2-2). The objectives of trenching in this area include: 1) to evaluate whether differences in the morphology of the P3 units compared to P2 might have resulted from Holocene paleoflood inundation of those surfaces; 2) to evaluate further the characteristics of the earth mounds, particularly in areas where they appeared somewhat subdued or muted; and 3) to confirm, with soils and stratigraphic observations, the geomorphic conclusion that the braid channels on the P2 surfaces were relic features, and were not features produced by post-Pleistocene modification of the P2 surface.

2.3.1.1 Trench T1. Trench T1, about 73-m long, was sited across an area that is transitional between P2 surfaces and P3 surfaces (Figure 2-2). The southern end of the trench begins with a short section on the P2 surface, then drops down a small terrace riser into a channel 
bounding an slightly lower area mapped as P3. The trench alignment exposed two earth mounds, centered at stations 25 and 53.

Trench logs for trench T1 are contained on three sheets (Appendix B- Electronic Supplement). No age dates were obtained from samples in this trench. No sedimentological analyses were conducted on samples from this trench. Soil profiles were described at Stations 3, 15, 20, and 61; particle size data is available for all four profiles. (Appendix B).

The basal units in trench T1 are a sequence of lateral accretion gravels composed of beds 20 $100-\mathrm{cm}$ thick. The uppermost bed in this sequence is coincident with the surface channel at approximately stations 15 to 35. The channel fill, massive-to-poorly-stratified, pebbly-to-silty sand, is best expressed near stations 8 - 14. Loess, 30-50 cm thick, extends the entire length of the trench although it is difficult to distinguish from the channel fill in many areas. The sequence of loess over gravel and soil development in these deposits illustrated in soil descriptions at stations 3, 15, 20, and 61 appears typical of that repeated on the Pleistocene deposits throughout the study reach.

Soil horizons mapped in the gravels, vary laterally, but continue through the channel sequence suggesting the channel is similar in age to the gravels. Within the channel, there is no deposit or erosional feature that disrupts stratigraphy or soil horizons implying significant Holocene flow through this channel. Conversely, carbonate morphology through the channel section of trench T1 is somewhat weaker compared to channels in trenches T2, T3, T6, and T7. Thus, if Holocene flow has been present in the channel at $\mathrm{T} 1$, it was limited to amounts that did not result in any significant soil erosion at the site.

2.3.1.2 Trench T2. Trench T2, about 44-m long, crosses a prominent braid channel on the interior of the P2 surface (Figure 2-2). The braid channel follows a terrace riser that separates slightly lower areas of the P2 surface to the north from slightly higher areas to the south. In addition to crossing the channel and flanking surfaces, the trench alignment crossed and exposed two earth mounds, centered on stations 19 and 36. 
Trench logs for trench T2 are contained on three sheets (Appendix B- Electronic Supplement). No age dates were obtained from samples in this trench. No sedimentological analyses were conducted on samples from this trench. Soil profiles were described at Stations 1, 20, and 28. Particle size data is available for profiles at stations 1 and 28. (Appendix B).

The basal units in trench T2 are a sequence of lateral accretion gravels composed of beds 20 $100 \mathrm{~cm}$ thick. These gravels are overlain throughout the trench by $30-50 \mathrm{~cm}$ of sandy to pebbly silt, of which loess is a major component. Frequency of pebbles decreases upward from the gravel contact and where the finer deposits thicken; Bk horizons are formed in the finer units.

Earth mounds in trench T2 are large and well-developed. Carbonate accumulation beneath the mounds is enhanced, suggesting long-term spatial stability. Deposits and soils within the mounds are highly variable and disrupted, indicating continued bioturbation within the mounds.

2.3.1.3 Trench T3. Trench T3, about 57-m long, crosses a prominent braid channel on the back side of the P2 surface (Figure 2-2). The braid channel follows a terrace riser that separates the slightly higher P1-2 areas to the south from the main extent of P2 surfaces to the north. At the T3 site, the riser is very subdued, and the trench did not extend far enough south to expose a soil that might be fully representative of soils associated with the P1-2 surfaces. The south end of trench T3 begins on this subdued riser, drops into the channel and extends onto the main P2 surface to the north. Two earth mounds are crossed by the alignment, centered at stations 15 and 53.

The log of trench T3 is contained on three sheets (Appendix B- Electronic Supplement). No age dates were obtained from samples in this trench. Pebble and point counts were done on a sample from station 5 and sieve analyses of a sample from station 20 (Appendix B). Soil profiles were described at stations 2, 15, and 28. Particle size data is available for profiles at stations 2 and 28 (Appendix B).

The basal units in trench T3 are a sequence of lateral accretion gravels composed of beds 30 - 50 $\mathrm{cm}$ thick. The uppermost bed in this sequence is gently undulatory along the length of the trench and appears to have a low point that would be approximately coincident with the surface channel 
at stations 13 to 17, where a large earth mound is located and no channel fill deposits are recognized. Stage III carbonate is extensive beneath this mound, as well as the mound at station 54, and there is high variability of soils within both mounds. Between the two mound crossed by trench T1, loess that overlies the gravel is $\sim 25-\mathrm{cm}$ thick. The base of the loess in this area is highly irregular, suggesting disruption by frost wedges and bioturbation.

2.3.2 Trenches T4, T5, T6, and T7 - Saddle Constriction Study Area. The Saddle Constriction study area encompasses four trenches, T4, T5, T6, and T7, that include two very distinct settings (Plate 1 and Figure 2-3). Trenches T4, T5, and the southern portion of T6 are sited on narrow areas of H1-2 surfaces that flank the river downstream of a bedrock constriction (Figure 2-4). These sites were chosen because they appeared likely to preserve a record of vertical accretion deposits from Holocene floods and/or a record of erosion resulting from floods that may have overtopped them. The lower portions of trenches T4, T5, and T6, were located on portions of the H1-2 surface that appeared to include deposits of the "400-yr" paleoflood identified in the previous study (Ostenaa et al., 1999, 2002). The northward extension of trenches T6 and T7 extend across higher P3 and P2 units, and lie downstream of the feature know as the Saddle, from previous studies (Ostenaa et al., 1999, 2002) (Section 2.1.2). The objectives of these trenches are to evaluate, through soils and geomorphic observations, whether or not there was evidence on these surfaces of flow having overtopped the saddle during the Holocene. Geomorphic evidence, shown by faint channels on the P3 surface at trench T6 and the southern end of T7 suggests that the youngest flow on these surfaces was associated with the inset of the P3 surface into the P2 surface and that flow was through the bedrock constriction at the present channel location (Figure 2-3). Flow through the saddle would be in a direction orthogonal to these channels. Similar to the objective for trenching in the Big Loop area, the northern continuation of trench T7 would allow evaluation of whether differences in the morphologies of P3 and P2 surfaces might be related to younger flooding, and to confirm geomorphic conclusions related to the origins and ages of the braid channels on the P2 surfaces and issues related to the earth mounds.

2.3.2.1 Trench T4. Trench T4, about 21-m-long, is located on a small H1-2 terrace about 100 m downstream of the Saddle bedrock constriction (Figure 2-3). The terrace is inset on the downstream side of a basalt outcrop that deflects the channel slightly to the north. The south 
end of the trench was limited by a small road and lies on the edge of the slope off the P2 surface south of the river. That portion of the trench encountered a small area of gravels overlain by a pebbly silt that is probably related to a poorly expressed earth mound whose expression was muted by activity along the road and position coincident with the terrace riser on the north. Excavation depth of the trench was limited by outcrops of basalt through much of the central and sloping section of the trench which crosses the terrace riser. Loess, colluvium, and deposits related to the earth mound are intermixed in the central portion of the trench, then grade laterally and downslope to stratified sequence of fine-grained flood deposits that underlie the flattest portion of the H1-2 surface.

Trench logs for T4 are contained on a single sheet (Appendix B- Electronic Supplement). Five radiocarbon ages were obtained from samples in this trench (Table 2-2). Gamma-ray spectrograph data is available for three samples from station 20 and one sample from the $\mathrm{H} 4$ terrace deposit immediately below the trench (Appendix B). No sedimentological analyses were conducted on samples from this trench. One soil profile was described at station 20 (Appendix B).

The sequence of flood units exposed in the lower portion of trench T4, stations 17-21, provides evidence of at least three late Holocene paleofloods. The basal unit in this section of trench T4 is a 1-m-thick silty fine sand with a stage II carbonate morphology in the upper portion. A radiocarbon age of 7320-7200 cal yr B.P. from this soil horizon provides a minimum age for this deposit (Table 2-2 and Appendix B). Similar ages, sedimentology, and soil development are observed in other sections that underlie the higher portions of H1-2 surfaces along the Big Lost River (Section 2.2.3). The top of this unit is eroded, and three separate overlying silty-fine sand units are recognized primarily through soil properties. The lower and thickest unit is wedgeshaped and increases in thickness from about $40 \mathrm{~cm}$ at station 18 to nearly $1 \mathrm{~m}$ at station 21 . In the upper portion of the unit, an $\sim 20$-cm thick Ab1 horizon with no visible carbonate morphology overlies a thicker Bk1b horizon with stage I- carbonate morphology. Radiocarbon ages from this unit at stations 19 and 20 range between 1000 to 2000 cal yr B.P. (Table 2-2 and Appendix B). This age range may represent a minimum time range for deposition and subsequent soil formation. Alternatively, it could indicate that the deposit includes multiple stratigraphic units 
whose boundaries have been overprinted by soil development. This deposit is considered part of the evidence for the "older paleoflood" discussed in later sections.

The second sand unit is less than $20-30 \mathrm{~cm}$ thick, and extends from about stations $18.5-21$. The soil in the underlying unit does not suggest significant erosion associated with this deposit, but the basal contact is inset into the underlying soil upslope. This unit is mostly at the surface and includes the A1/A2 horizons of the soil on the present H1-2 surface at this site. A single radiocarbon age in the lower part of this unit from station 20 indicates an age of 630-510 cal yr B.P. (Table 2-2 and Appendix B). This is the age range associated with other similar flood deposits on the lower portions of the H1-2 surfaces. These sites collectively are evidence for the "400-yr" paleoflood.

The third, and youngest flood deposit in trench T4 consists of a thin, 5-10 cm layer of highly calcareous silty fine sand, slightly lighter in color than is present only about station 20-21 and is referred to as the "white flood". This unit is at the surface and has minimal soil development. It must be considerably younger than the underlying soil because the underlying A-horizon is relatively depleted in carbonate and much less effervescent. No datable material was recovered from samples of this unit. Cesium and lead activity from a sample at station 20 was similar to that in the underlying deposits, but substantially lower than a sample from an $\mathrm{H} 4$ terrace in the bank just below the trench (Appendix B). The H4 terrace is overtopped by post-INEEL Diversion Dam flows and is therefore likely younger than the mid-1950's. The lower activity in the samples from this unit appears to indicate that it pre-dates that time period.

2.3.2.2 Trench T5. Trench T5, about 10-m long, is located on a H1-2 surface about 100-m downstream of the Saddle bedrock constriction and directly across from trench T4 (Figure 2-3). The T5 site is at the very upstream end of a long, narrow H1-2 terrace that extends several hundred meters downstream on the north side of the river. The H1-2 surface at T5 is slightly higher than at trench T4 (Figure 2-6).

The south or lower end of T5, beneath the flattest portion of the H1-2 surface, exposed a sequence of fine-grained flood deposits that are generally similar to those in trench T4. These flood deposits are cut into well-bedded gravels that dip moderately to the north and which underlie the back 
portion of the H1-2 surface and lower portion of the terrace riser at the back edge of the surface. Trench excavation was rapidly limited by basalt outcrops which were overlain by loess and colluvium.

The log for Trench T5 is contained on a single sheet (Appendix B- Electronic Supplement). Two radiocarbon ages were obtained from samples in this trench (Table 2-2). No sedimentological analyses were conducted on samples from this trench. One soil profile was described at station 2 (Appendix B).

The gravels that underlie the terrace slope between stations 4-10 dip moderately to the north and other than orientation they appear similar to P2/P3 gravels in all other trenches. Stratification and bedding in the gravels is disrupted in a steeply dipping zone between stations 6-7 and suggests that these gravels are possibly involved in a small bank failure that rotated and displaced them slightly. The fill of colluvium and loess near the upper end of the trench straddles the contact between basalt outcrops and the gravels. Significant carbonate accumulation in this fill suggests that the block has been stable for at least a few thousand years.

A sequence of flood deposits are cut into the gravels between stations 0-5. A basal colluvium is overlain by a stratified sequence of sand to sandy silt that probably represents one or more paleofloods. This sequence is capped by a Bk1b soil horizon at a depth of about 20-25 between stations 0-2. Overlying this contact and soil horizon boundary between stations is a thin deposit of silty fine sand that appears to be inset into an A1/A2 horizon in silty eolian deposits south of station 2. A radiocarbon age of 760-660 cal yr B.P. at station 0, from the top of the Bk1b indicates the minimum age of burial of this unit by the upper silty fine sand. The underlying deposit has an interval of stronger carbonate development at a depth of $56-74 \mathrm{~cm}$, is also more silty than units above and below. This interval may represent an older, eroded soil buried by two flood deposits, or has more carbonate because of the finer texture. The contact and horizon boundary is not obviously erosional, based on sharpness and irregularity. Deposits below this interval are distinctly more pebbly and incorporate clasts derived from the underlying colluvium. A radiocarbon age near the base of the lower unit gave an age of 1900-1720 cal yr B.P. (Table 2-2 and Appendix B). 
Based on the radiocarbon ages and soils from this site, the upper silty fine sand south of station 2 is correlated to the "400-yr flood" and the underlying deposits are considered correlative with the "older flood".

2.3.2.3 Trench T6. Trench T6, about $121 \mathrm{~m}$ long, is located about $100 \mathrm{~m}$ downstream of trench T5 (Figure 2-3). The south end of T6 begins on the same H1-2 surface as trench T5, extends north across that surface, then up the terrace riser onto the adjacent P3 surface. The southernmost section of the trench, stations 1-5, exposes late Holocene flood deposits similar to those in trenches T4 and T5. Stations 5 to 25 expose mid- to early-Holocene soils and fine-grained channel fill. The sequence of deposits beneath the terrace riser, stations 25-45, includes a sequence of gravels that records the lateral migration and incision of the Big Lost River below the level of the P3 surface. Overlying slope colluvium and soils on the riser grade into equivalent units that underlie the H1-2 surface to the south. The remainder of the trench, stations 45-121, exposes mostly plane-stratified gravels, similar to those in trenches T1, T2, and T3. The gravels are overlain in most areas by $\sim 20 \mathrm{~cm}$ of finer gravels which grade laterally into a pair of channels between stations 66 to 96. The finer gravels and channels appear to represent the last phase of fluvial erosion and deposition on the P3 surface. Loess, typically $20 \mathrm{~cm}$ thick, overlies the entire sequence from stations 45-121 and forms the upper horizons of the carbonate soil developed through all the deposits. The low point in the same ridge to the west, termed the Saddle, lies about 50-70 west of the section of trench T6 near stations 75-100. Near station 95, an earth mound deposit overprints the edge of the channel sequence.

Trench logs for Trench T6 are compiled on four sheets (Appendix B- Electronic Supplement). Six radiocarbon ages were obtained from samples in this trench (Table 2-2). Detrital zircons were analyzed from samples at stations 12 and 66 (Appendix B). Pebble and point counts were done on samples from stations 23 and 99 (Appendix B). Gamma-ray spectrograph data is available for two samples each from stations 0 and 4 (Appendix B). Seven soil profiles were described at stations $1,7,17,43,57,72$, and 118. Particle size data are available for profiles at stations 43 and 57 (Appendix B).

The physical stratigraphy and soils at the southern end of T6, stations 1-5, appear very similar to the sequences in trenches T4 and T5. A stratified wedge of silty-fine sand, with relatively weakly 
developed soils, truncates sand silt and sand units with much stronger carbonate soils. At station $1-2$, this wedge appears to consist of a single unit of silty fine sand which contains an increasing percentage to the north of carbonate-cemented cicada clasts that appear to be derived from Bk soil units similar to those between stations 4-20. The basal part of the wedge is contains about 10 per cent pieces of older soil. At station 4, two radiocarbon ages from a bulk sample of this unit barely overlap in the range of 790-540 cal yr B.P. Based on these ages and the associated soil development, it appears most likely that this deposit is correlative to the "400-yr" flood. Deposits correlative to an "older flood" may be represented by the lower-most units at the very end of the trench.

Trench T6 extends across the entire H1-2 terrace at this location and the trench exposure demonstrates the lateral continuity of stratigraphy and soils beneath the surface. From the south end of the trench to near station 23, a thick basal sand unit, locally stratified, is overlain by a similarly thick silty fine sand in which a strong Bk horizon is developed with abundant cicada burrows. From the south to north in this interval, the surface horizons that overlie this Bk horizon become thicker and more complex. Beyond about station 14, to station 25, the horizons are consistent and thick. This change, near station 14, appears to mark the northern limit of erosion associated with the younger flood deposit that contains clasts of Bk material near stations 1-4.

Three radiocarbon ages potentially limit the age of Bk soil and associated deposits in the southern end of trench T6. At station 4, a radiocarbon age on a mixture of very small charcoal fragments recovered from a large bulk soil sample has an age of 3480-3360 cal yr B.P. (Table 2-2 and Appendix B). The sample site is surrounded by prominent burrows, and has an anomalously young age compared to samples from other sites with similar soil development. A similarly anomalous age was obtained at station 20, again on a mixture of very small charcoal fragments recovered from a bulk sample of the basal sand unit. This sample had an age of 2870-2760 cal yr B.P. (Table 2-2 and Appendix B). An apparently more reliable age is from a snail shell recovered from a bulk sample of the basal sand at station 6. This sample had an age of 12,800 - 11,940 cal yr B.P. (Table 2-2 and Appendix B). This age implies a very late Pleistocene age for incision of the Big Lost River that is consistent with the regional glacial chronology (Section 2.2.2.1) and with 
ages from similar soils at trench T4 (Section 2.3.2.1) and BLR6 (Ostenaa et al., 1999, 2002) located just downstream of trench T6 (Plate 1).

The ages, soil development, and continuity of the stratigraphy and soils beneath the H1-2 terrace indicate that this surface has been largely unmodified by floods through much of the Holocene. Stabilization of the surface, and formation of the Bk soil horizon in the silty fine sand unit, likely post-dates deposition of the basal sand at $12 \mathrm{ka}$, but is still most likely early Holocene, based on comparisons to ages at other sites. Since that time, there has been only limited modification of the surface, as recorded by the sequence of deposits at stations 1-4 which are cut into the Bk horizon, and which stripped the upper horizons to approximately station 14.

The objectives of extending trench T6 north across the P3 surface downstream of the Saddle were to determine if there was evidence of erosion due to flows through the Saddle during the Holocene. From station 45-121, the trench exposes stratified gravels, which in many areas are capped with a finer, sandy gravel that appears to laterally grade into fine-grained channel fills. A thin loess, in turn capped by a very thin layer of eolian sand, overlies both the gravels and the channel fills. Basal units in the channels are typically sandy to pebbly and fine upwards to silty fine sands that are texturally similar to loess. A carbonate soil with highly variable, but common stage II morphology, appears to be continuous across the entire sequence. Variability in the soil is apparently related to small variations in texture of the uppermost gravels. A single radiocarbon age was obtained from near the top of the $\mathrm{Bk}$ in the channel fill at station 68. The age of 660-540 cal yr B.P. (Table 2-2 and Appendix B) is a very minimum age that reflects the continuing input of young material into the soil profile.

There is no apparent stratigraphic evidence of erosion removing significant thicknesses of loess, or of erosion affecting the top of the gravels. The channel fills coincide with faint geomorphic suggestions of flow parallel to the ridge that forms the Saddle, suggesting that they are related to flow from south to north on the P3 surface, not west to east indicated by flow through the Saddle (Figure 2-3).

2.3.2.4 Trench T7. Trench T7, about $256 \mathrm{~m}$ long, overlaps and continues north from the north end of trench T6 (Figure 2-3). The southern portion of T7, stations 1-25, exposes gravels 
with channel fill, loess thickness, and soils that are similar to those in the central and northern portions of trench T6. This section of trench T7 coincide with the mapped extent of the P3 surface (Plate 1) and a 0.4-m-step in the ground surface between stations 25-30. From about station 25 to 50, excavation depth was limited by basalt beneath the gravels. Thin exposures of gravels are overlain by another group of channel deposits and loess that underlie a slightly higher surface than the area near stations 1-25. Beyond station 50, the surface steps up another 0.3-0.4 $\mathrm{m}$ to the level of the main P2 surface downstream of the northern continuation of the ridge near the saddle. North from station 50, channel fill deposits that overlie the main gravel units thin, and laterally grade to thin sandy gravel and gravelly sand units. These are in turn typically overlain by 20-30 $\mathrm{cm}$ of loess, and a variable thickness of eolian sand, including locally mappable accumulations of post-2000 sand. These are identified where they overlie the 2000 burn horizon. Beyond station 130, to the north end of the trench at station 256, the upper sandy units are not present, and variably stratified gravels are overlain by $20-40 \mathrm{~cm}$ of loess. Earth mound deposits interrupt the stratigraphic continuity along the trench near stations 60, 116, 166, and 258.

Trench logs for T7 are compiled on nine sheets (Appendix B- Electronic Supplement). No radiocarbon ages were obtained from samples in this trench. Detrital zircons were analyzed from samples at stations 107 and 109 (Appendix B). Pebble and point counts were done on a sample from station 231 and sieve analyses of a sample from station 136 (Appendix B). Seven soil profiles were described at stations 36, 44, 95, 108, 158, 167, and 237 (Appendix B).

Similar to trench T6, there is no apparent stratigraphic evidence of erosion removing significant thicknesses of loess or of erosion affecting the top of the gravels throughout the length of trench T7. The channel fills coincide with faint geomorphic suggestions of flow parallel to the ridge that forms the Saddle, suggesting that they are related to flow from south to north on the P3 surface, not west to east, as indicated by flow through the Saddle (Figure 2-3).

2.3.3 Trenches T8 and T9 - BLR8 Study Area. The BLR8 study area includes two trenches, T8 and T9, on the south side of a sharp bend located upstream of a bedrock constriction (Figure 2-5). The BLR8 site of Ostenaa (1999, 2002) is on the opposite bank. Trench T8 is located mostly on an H1-2 surface, the lower part of which appears correlative to the position of BLR8. The site is downwind and adjacent to extensive areas of basalt outcrops and associated eolian 
sand deposits (Plate 1). Thus, all units in this area have relatively thicker eolian surface units than most other sites. Trench T8 was originally proposed as a continuous excavation that extended from the H3-4 units through the H1-2 and into units mapped as P3. However, pre-trenching archaeological investigations showed this to be a potentially significant cultural site. A scaledback trench layout was adopted consisting of three short trenches, each about 6 to $7 \mathrm{~m} \mathrm{long}$, designated T8a, T8b, and T8c. Prior to excavation of these smaller trenches, an extensive archaeological mitigation investigation was carried out which included excavating several test units along the trench alignments (Peterson and Harding, 2002). The final trenches partly incorporated and retained the archeaology units so that stratigraphy in those units could be related to the trenches. Trench T9 was excavated on the upstream side of the bedrock constriction where the channel impinged on the edge of the P3 surface. Because the sites were located upstream of a bedrock constriction, and based on the exposures at BLR8, there appeared to be potential for both trenches to expose a datable record of paleofloods. This would be most likely in the northern end of the trenches. The southern end of both trenches extended onto higher and older surfaces, thus providing the potential to define the limits of erosion associated with past floods.

2.3.3.1 Trench T8. The final excavation for Trench T8 consisted of three trench segments (Figure 2-5), labeled from south to north, T8a, T8b, and T8c. The locations of two archaeology units not incorporated in the final trenches, designated Locality A, 101N/100E and 105N/100E (Peterson and Harding, 2002) lie between T8b and T8c. Correlation of units described by Peterson and Harding with those mapped in the trenches follows discussion of the three trenches.

Trench logs for T8 are compiled on one sheet (Appendix B - Electronic Supplement). No radiocarbon ages were obtained from samples in this trench. Artifacts recovered by the archaeology investigations provide some evidence for the age of these sites. Pebble and point counts were done on a sample from T8a, station 3 (Appendix B). No soil profiles were described separately; horizons are mapped on the logs.

Trench T8a. Trench T8a, the southernmost of the three trenches was about $7 \mathrm{~m}$ long and sited on the edge of a small P3 surface surrounded by basalt (Plate 1). Gravels, with overlying loess and eolian sand at the southern end of this trench are similar to and have similar soils to the 
Pleistocene gravels in trenches at the Big Loop (Section 2.3.1) and Saddle Constriction study areas (Section 2.3.2). These gravels interfinger with a channel fill, also with stage II carbonate morphology, and again are very similar to the channel fills and soils exposed in T6 and T7 at the Saddle Constriction study area. The stratigraphic relationships of the gravels and channel fill in T8a, and the soil developed across these boundaries demonstrate the late Pleistocene age of these channel fills on the P3 and P2 surfaces. Pebble stringers, found near the middle of the channel fill at stations 4-5, show that much of the fill is fluvial. The upper portion of the fill grades upwards and laterally with loess that overlies the gravels. The complete soil profile, and upper eolian units are truncated or removed from the northern portion of the trench and reflected in the surface topography by a 20-30 cm high, gentle scarp. Removal of these upper units is old enough that the top of the Bk in the channel fill section and parallels the ground surface and maintains a constant depth.

Trench T8b. Trench 8b is the middle trench at site and is about $6 \mathrm{~m}$ long. Locality A, 96N/100E and 95N/100E units of Peterson and Harding (2002) are partially retained in the north end of the trench. The basal units exposed in T8b are fluvial as shown by beds of sand and fine sandy silt. The section fines upward, becoming more silty and similar in texture to loess. Extensive cicada burrows and soil carbonate have overprinted any bedding or stratification. The section in T8b is slightly coarser than the channel fill in T8a and is likely the lateral extension of the same channel fill unit. Stratification of the upper part of the fill in T8b is based primarily on the relatively abrupt increase in soil carbonate (2Bk1/2Bk2 horizon boundary). The same horizon boundary in T8a is gradational. This difference may be due to subtle texture differences in the original stratified fill, or to erosion and redeposition of the upper unit in T8b. Carbonate morphology of the Bk1 horizons in both trenches is similar. Surficial soils in T8b and the north end of T8a are similar, suggestive of removal or stripping of surface horizons in the past few hundreds of years.

Trench T8c. Trench T8c is the northernmost trench at the site, about $6 \mathrm{~m}$ long, and closest to the Big Lost River channel (Figure 2-5). The basal units exposed in T8c are fine pebbly sands and sandy gravels which may or may not be a lateral facies of the channel fill sands exposed in T8b and T8a. The lower units in T8c are capped by the eroded remnants of a well-developed 
carbonate soil, similar to that present in the other trenches. The uppermost unit in T8c is mostly a massive sand that contains abundant carbonate-cemented cicada burrow clasts. These appear to be derived from a Bk horizon of channel fill or a fine-grained fluvial deposit similar to those exposed in the southern portion of T6 (Section 2.3.2.3). Soil development in this upper unit is very weak, limited to scattered occurrences of stage I carbonate morphology on occasional pebbles and filaments on the edges of the cicada clasts.

Correlation to Archaeological Stratum. Peterson and Harding (2002) designated the area around trench T8 as Locality A, and defined twelve stratigraphic units (stratum) based on bedding, grain size, and soil development. The oldest, basal stratum is designated I, and the youngest stratum at the surface is XII. They divided the recovered cultural remains into two components based on the diagnostic projectile points and natural stratigraphy. Diagnostic materials for the younger component were recovered on the surface, but were associated with stratums X, XI, and XII based on soil development. Diagnostic points from the older component were identified in stratum IX and at the top of stratum VIII at depths of $30-40 \mathrm{~cm}$ in Locality A, 95N/100E and 105N/101E.

The location of 95N/100E at Locality A corresponds to stations 4-6 in trench T8b. In trench T8b, stratum XII and XI of Peterson and Harding (2002) appear to correspond to eolian sand and the AB soil horizon, about 10-15 cm thick across the trench. A 2Bk1 soil horizon formed in the upper fluvial sand corresponds to stratum IX and X of Peterson and Harding. A 2Bk2 soil horizon formed in a lower fluvial sand corresponds to stratum VIII. The depth range of 30-40 is coincident with the contact between two the fluvial units.

105N/101E at Locality A is located $10 \mathrm{~m}$ north of T8b, and 5 south of T8c (Figure 2-5). We did not remap this exposure, but from field inspection, it appears that the eolian sand is thinner and that more likely, stratum XI corresponds to an A-horizon formed in fluvial silty sand. Stratum IX includes a Bk horizon forming in silty sand that appears to include re-worked cicada burrow clasts similar to the uppermost fluvial unit and Bk horizon in trench T8c. Correlation of this unit to the upper fluvial unit in T8b is less clear, because reworked and broken cicada clasts are not so obvious in T8b, and the upper fluvial unit in T8b is slightly finer. The irregular contact at the base of stratum IX in 105N/101E suggests it is erosional, as does the significant increase in carbonate 
morphology observed in stratum VIII beneath this contact. Because of the irregularity of the basal contact, the recovered artifacts may have been originally part of either unit. Stratum VIII to I in 105N/101E resemble lateral equivalents of the lower fluvial units in trench T8c. The lower fluvial units in T8c are finer, and the lower units in 105N/101E and T8c may either be equivalent lateral facies to T8b or a younger inset.

Peterson and Harding (2002) Locality A site 111N/1000E and 112N/100E correspond to stations 0-2 of trench T8c. In T8c, units mapped as eolian sand correspond to stratum XI and XII. The upper most fluvial unit in T8c includes all of Peterson and Harding stratum IX and X, as well as portions of stratum VIII. This fluvial unit contains extensive broken and reoriented cicada burrow clasts and has an irregular, erosional basal contact. Below this contact are eroded remnants of a Bk horizon with stage II+ carbonate formed in a bedded sequence of silt, sand, and gravel beds and lenses. Peterson and Harding designated individual beds within this fluvial sequence as stratum II through VIII. From the larger exposure of trench T8c, it appears that most of their stratum VIII corresponded to the eroded remnant of a well-developed Bk horizon formed in a silty sand capping a well-bedded fluvial sequence. Variability in carbonate accumulation within the sequence is the result of variations of carbonate accumulation in the lower portions of soil profile in beds of differing initial texture.

Peterson and Harding (2002) and Harding (2002) identified two Northern Side-notched projectile points from their Component I, which are considered to range in age from 7500 to 4400 years ago. Recovery of these points at depths of 30-40 cm suggests that they were most likely entrained in the upper fluvial unit exposed in T8c, and possibly T8b as well. These units appear to contain reworked clasts of cicada burrows derived from the underlying soils. It seems less likely that these points had been worked into the underlying Bk horizon of the lower fluvial unit in the trenches, because artifact recovery decreased dramatically below 30-40 cm depths. Artifacts recovered at the surface have a potential age range of 100 to 1700 years. This age range brackets the possible age range of late Holocene paleofloods along the Big Lost River and is thus not diagnostic here.

T8 Combined Interpretations. The lack of continuous exposure across the T8 site somewhat limits interpretations, but the physical stratigraphy and soils have enough similarities that some conclusions can be reached. Soils and stratigraphy in the southern portion of T8a, 
stations 1-3, are very similar to those found on the Pleistocene surface elsewhere in trenches T1, T2, T3, T6, and T7. This appears to be typical of the soil profile and stratigraphy developed on unmodified Pleistocene surfaces throughout the site, with the addition of eolian sand on top of the loess. Long-term stability of the site is shown by the development of stage II Bk-horizons across the boundary of gravel, fine-grained channel fill, and loess units. Soil horizons and stratigraphy are truncated at the northern end of T8a, indicating a lateral limit to erosion in this trench at about stations 3-4. Erosion of the profile in the underlying loess/channel fill sequence is minimal in the northern section of the trench. Depth-to-top of Bk horizon is $\sim 20 \mathrm{~cm}$, suggesting this erosion is at least a few hundred years in age. The upper portion of trench T8b is somewhat more stratified than T8a, but is generally similar to the channel fill/loess sequence in T8a. The presence of two $\mathrm{Bk}$ horizons may result from burial of an older soil by the upper-most fluvial unit or increased carbonate accumulation due to subtle difference in texture of the original deposits. Horizons at the surface are similar in both trenches.

The stratigraphy of the upper unit in trench T8c is distinctly different. The uppermost fluvial unit in T8c is a fine sand that contains clasts of broken and reoriented carbonate-cemented cicada burrows. Coarser sand and pebbly lenses along the base are cut into a Bk horizon with stage II morphology developed in an underlying fluvial sequence. The $\mathrm{Bk}$ in the upper fluvial unit has stage I- morphology, suggesting an age of no more than a few hundred years. The cicada burrow clasts consist of carbonate-cemented silty, fine sand that could be derived older channel fill units or H1 age units. Incorporation of Middle Prehistoric artifacts (7500 - 4500 years old) would be consist with the apparent age of soils incorporated as clasts in this much younger deposit. These ages may indirectly indicate a minimum age for the underlying deposits in T8c as well.

2.3.3.2 Trench T9. Trench T9 is approximately 35-m long and extends on the south from the relatively flat, sand covered P3 surface down a 2-m-high terrace riser onto a small H34 terrace (Figure 2-5). The site is located just upstream of a bedrock constriction, which results in backwater effects even for moderate flows (see plots in Appendix D - Electronic Supplement). In this setting the H3-4 terrace was inferred as likely site of fine-grained deposition during floods, and the presence of several subtle steps and inflections in the terrace riser (see log profile at stations 30 and 32) suggested a possibility of an extended record of paleofloods at this site. The 
trench was extended back onto the P3 surface to expose the continuity of stratigraphy through the riser and because preliminary hand-auger borings suggested a thick, fine-grained sequence was present. Pre-trenching archaeological investigations (Peterson and Harding, 2002) along this trench alignment found only a few artifacts. The final trench incorporates a portion of archaeological excavations between stations 11-14. No diagnostic artifacts were recovered at this site.

Trench logs for T9 are compiled on one sheet (Appendix B - Electronic Supplement). Three radiocarbon ages were obtained from samples in this trench (Table 2-2). Pebble and point counts were done on a sample from station 18 and on a sample from a mid-channel bar just below the end of the trench (Appendix B). No soil profiles were described separately; horizons are mapped on the logs.

At the south end of trench T9, the basal gravels exposed from stations 1-30, resemble the Pleistocene gravels that underlie P2 and P3 surfaces in other trenches. These gravels are interrupted between stations $23-28$ by a channel fill with steeply inclined stratification along one side. In the southern portion of the trench, the gravels are overlain by about $1 \mathrm{~m}$ of fine sand. A well-developed Bk horizon in this sand has stage II and locally stage III carbonate morphology and to the north, as the sand thins, the strong Bk horizon extends from the sand into the gravel. A radiocarbon age of about 2750 cal yr B.P on a small piece of charcoal (Table 2-2 and Appendix B) found in the lower part of the sand at station 2 is anomalously young based on soil development in the sand. Extensive burrowing in the sand is likely responsible for downward transport of young charcoal to this depth. The burrowing has also disrupted the soil to a significant extent. The upper horizons of the soil in the southern part of the trench show that there is significant input of younger sand across this surface at this site. Soil profile development in the sands, channel fill, into the gravels are similar to profiles developed in Trench 8a, as well as other trenches on the Pleistocene P2 and P3 surfaces at the Big Loop (Section 2.3.1) and Saddle Constriction study areas (Section 2.3.2). A similar age is inferred at trench T9 for the gravels, channel fill and overlying sand with strong Bk development. The uppermost sands above the Bk are possibly younger, reflecting new eolian input from sand dunes on the basalt to southwest (upwind) of this site. North of station 14, the slope steepens, and near the edge of the terrace riser 
these upper loose, sandy horizons thin and terminate northward. Similar to soil evidence at T8a and T8b, some stripping of the uppermost portion of the Pleistocene profile between stations 14 to 28.

Colluvium on the terrace riser slope grades downslope to a sequence of fine-to-medium sand beds. Between stations 32-33, these are separated by $\mathrm{A} / \mathrm{Bw}$ horizons, with abundant organic material. Radiocarbon ages from this section calibrate to ages less than 300 cal yr B.P. and include historic ages (Table 2-2 and Appendix B). The high limit of these deposits on the terrace riser slope corresponds to a discharge of about $70 \mathrm{~m} 3 / \mathrm{s}$ (Figure 2-7 and Section 2.5.1.4 following), roughly the upper limit of historic flood discharge in the Big Lost River (Section 2.1.1). Some of these deposits could potentially correlate to the youngest flood deposit in trench T4 (Section 2.3.2.1), but this correlation is only speculative. The radiocarbon ages, and discharge range that inundates this site, suggest that these deposits are most likely associated with floods that pre-date the INEEL Diversion Dam and had discharges near or only slightly larger than the largest historical floods.

The lowest deposits in trench T9 are a sequence of sand beds that underlie the flat portion of the H3-4 terrace at station 34-35. This inset sequence is inundated by discharges of less than $50 \mathrm{~m}^{3} / \mathrm{s}$ (Figure 2-7) and likely accumulated from historic floods. Minimally developed soils in these deposits are consistent with a young age.

\subsection{Summary of Geomorphic and Geologic Data for Paleofloods and Paleohydrologic Bounds}

The geologic studies described in the preceding sections found evidence of at least three late Holocene paleofloods, and are the basis for describing three paleohydrologic bounds that can be used with these data in the flood frequency analyses (Section 4.0).

2.4.1 Paleofloods. From the geomorphic mapping and trenching investigations, evidence of three paleofloods have been identified within the Diversion Dam study reach of the Big Lost River (Table 2-3). This evidence is briefly reviewed below. Studies to date have not located any site along the study reach that dependably preserves a long or detailed full record of large floods. Rather, over time, there is a progressive self-censoring (House et al., 2002) such that 
only successively smaller floods can be recognized for shorter periods of time. For the sites observed, any large flood essentially obliterates the record of smaller floods that preceded it. Likewise, only limited remnants of larger, but older floods might remain. The primary focus for selecting sites for this study has been of evaluating evidence for floods that potentially much larger than the largest historical floods. All but a small portion of 1 of the trenches used for this study are located outside the inundation limits of historic floods.

2.4.1.1 "White Flood". Stratigraphic evidence for this flood is recognized at a single site, Trench T4 (Section 2.3.2.1). A thin, $\sim 7 \mathrm{~cm}$, deposit of silty sand caps the sequence of flood deposits exposed beneath the lowest surface at the end of trench T4, stations 19-21, and appears to bury the soil formed on deposits of the "400-yr" flood. Soil descriptions (Appendix B) designate this unit as the A1-horizon of the present soil and soil development is weak in comparison to other sites. The deposit is not associated with historic floods because no historic floods would have been large enough to inundate the site (Section 2.1.1 and Figure 2-6). No similar deposit is present or recognized in trenches T5 or T6, both of which are only slightly higher relative to the discharge at which they are inundated (e.g. Figure 2-6) and it does not appear that soils in deposits of the "400-yr" flood were eroded more recently at these sites (Section 2.3.2.2 and Section 2.3.2.3). A radiocarbon age from the underlying A2 horizon at T4 has a calibrated age range between 630510 cal yr B.P. (Table 2-2 and Appendix B). Deposits in lowest portions of trench T9 have young radiocarbon ages (Section 2.3.3.2 and Table 2-2), but are also inundated by discharges that might have occurred prior to construction of the INEEL Diversion Dam (Figure 2-7). Thus, the age of a paleoflood associated with this deposit is constrained to be prior to the beginning of streamgaging records (A.D.1903) by the minimum discharge required to reach the site. The deposit is younger than the 630-510 cal yr B.P. age from the underlying soil, and is most likely about 100150 years based on the relative soil development.

2.4.2 "400-yr Flood". Stratigraphic evidence for this paleoflood was recognized in the earlier paleoflood study by Ostenaa et al. $(1999,2002)$ at four sites in the Diversion Dam study reach (Figure 2-11). Deposits with similar soils and stratigraphy that are apparently correlative are present in trenches T4, T5 and T6 (Table 2-3 and Section 2.3.2). These deposits appear to be associated with the prominent geomorphic expression of the $\mathrm{H} 2$ surface that can be mapped 
throughout the study reach (Plate 2 and Section 2.2.3). Soil development in these deposits, and radiocarbon ages from these deposits and from underlying deposits constrain the age to about 600 - 400 cal yr B.P. (Figure 2-8).

Because the flood deposits recognized by Ostenaa $(1999,2002)$ and in the trenches for this study appear to be associated with $\mathrm{H} 2$ geomorphic surface (Plate 2), one constraint for evaluating the discharge of this paleoflood is that the discharge be large enough to inundate the full extent of this surface throughout the study reach.

2.4.3 "Older Flood". Trench and bank exposures along the H1-2 surface all demonstrate that the deposits of the "400-yr" paleoflood overlie eroded soils developed in slightly older, similar flood deposits (Ostenaa et al., 1999, 2002; and Section 2.3). The soils in these deposits are generally similar, or slightly more developed than soils developed in the past 400-600 years. This implies a similar length of time over which no flood either eroded or resulted in significant deposition over these deposits. Likewise, the limited extent of the deposits of the "400yr" flood relative to the H1-2 surface indicate that overall the surface must be a composite of deposits with similar origins, but differing ages. The significant scatter in radiocarbon ages from site to site, and the variability in soils that underlie the "400-yr" flood deposits appear to support this concept. As shown on Figure 2-8, there is much less correlation of the potential time brackets for a single older flood than for the "400-yr" paleoflood and some possibility that multiple floods may have occurred in the time interval since about 3000 cal yr B.P. However, both the stratigraphic and the chronologic resolution to define multiple floods in this time period are lacking in the present exposures. The existing age constraints appear to indicate that a conservative age range for this flood would lie in the range of 2000 to 1000 Cal yr B.P.

The stratigraphy in trenches T4 and T5, where evidence of this flood is best expressed, could also be interpreted as evidence for more than one flood. Interpretations of multiple floods in these sections is most supported by breaking out beds in the lower portions of these stratigraphic sections. If that is done, the upper stage limit to associate with these floods is no longer associated with the H1-2 surface, but is down in the section at an elevation below the stage level that would be associated with the largest historic floods, $\sim 70 \mathrm{~m}^{3} / \mathrm{s}$ (Figure 2-6). The addition of temporally sparse data in that discharge range does not improve the assessment of the flood frequency. This 
type of information would be more useful if it could be independently reasoned that these floods must have been much larger than historical floods, either near or exceeding the discharge of the "400-yr" flood.

Because deposits that are associated with the "older flood" underlie the H1-2 surfaces, inundation of the full spatial extent of those surfaces provides a constraint for evaluating the discharge associated with this paleoflood.

2.4.4 Paleohydrologic Bounds. For use in the flood frequency analyses, geomorphic and stratigraphic data are used to define three paleohydrologic bounds that span differing time intervals over the past 10,000 years (Table 2-3). The geologic basis for each of these bounds is summarized below.

The geologic data show that over different time intervals and areas along the Big Lost River, there is evidence of relative geomorphic stability. Thus, the preservation of paleoflood deposits as the surface units on portions of the H1-2 geomorphic surfaces shows that no floods large enough to modify or remove these deposits have occurred since the time of those paleofloods. As summarized in, there is stratigraphic and geologic data along the Big Lost River that allows for defining three paleohydrologic bounds Geomorphic mapping delineates the characteristics and extent of surfaces of similar age that are potentially useful as paleohydrologic bounds (Section 2.1.2). Stratigraphic data from trenches and exposures defines the characteristics of the surfaces and the evidence for relative surface stability over time.

2.4.4.1 400-yr Flood Bound. In trenches at the Saddle Constriction study area, deposits of a paleoflood with an age of 400- to 600- years are the parent materials of the surface soils (Section 2.3.2). Weakly developed soils developed in the flood deposits at these sites indicate that no significant erosion or deposition by other floods or other geomorphic processes have disrupted these surfaces in that time span. Similar relationships, preserved at multiple sites, demonstrate stability of these surfaces since the time of the "400-yr" flood, approximately 400- to 600-years ago (Section 2.4.2). Even at trench T4, where the "400-yr" deposits are buried by thin deposit of a younger paleoflood, the soil profile in the underlying deposits is intact, indicating that this site was not significantly eroded by that flood (Section 2.4.1.1), and hence has been stable 
since deposition 400-600 years ago. Throughout the reach, the H1-2 surfaces which include these deposits are unmodified by younger erosion (Section 2.2.3 and Plate 2).

The H1-2 surfaces and deposits of the "400-yr" flood are preserved in many differing hydraulic settings throughout the Diversion Dam study reach. Thus, for use as a paleohydrologic bound, some of these sites are much more strongly limiting than others (Section 3.2.1.2 following). In particular, at Trench T4, unit stream power and bed shear stress increase very rapidly with increasing discharge and thus that site is very important to discharge limits for "400-yr" bound.

2.4.4.2 Early Holocene (H1 surfaces) Bound. The stratigraphic evidence to support this paleohydrologic bound is the preservation of extensive areas of generally fine-grained fluvial sediments with well-developed carbonate soils that underlie the H1-2 surfaces. The most extensive exposures of these sediments and soils are in trench T6, stations 1 to $~ 30$, and in the disconnected sequence of trenches at BLR8 study area, T8a,b,c (Section 2.3.2.3, and Section 2.3.3.1). Smaller remnants are present at T4, stations 16 to 20 (Section 2.3.2.1), and at BLR6 (Ostenaa et al., 1999, 2002). These deposits and soils apparently are part of an aggradational fill of latest Pleistocene to early Holocene age (Section 2.2.3). Stage II carbonate soil horizons in these deposits are generally 50- to $100 \mathrm{~cm}$ thick, indicative of an early Holocene age for stabilization of the surface, and radiocarbon ages from these deposits ranging from about 12,8007200 cal yr B.P support this age (Section 2.2.3 and Section Table 2-2). Based on these data, a conservative time interval of 6000 to 8000 years has been chosen for use as a paleohydrologic bound. Most of radiocarbon ages from these sites are older than this range, but the shorter time interval reflects the possibility interpretation that aggradation of the sequence continued and the surfaces did not stabilize and begin forming soils until somewhat later.

2.4.4.3 Pleistocene Bound. The extensive areas of unmodified Pleistocene surfaces that flank the Big Lost River are the stratigraphic and geomorphic basis for this paleohydrologic bound (Table 2-3). The Pleistocene P2 surfaces have a braid-channel morphology that is inherited from Pleistocene gravel deposition and unrelated to present flows in the Big Lost River (Section 2.2.2). The more limited areas of Pleistocene P3 surfaces generally follow the present river channel and are also underlain by gravels, and likely represent the last episode of Pleistocene deglaciation (Section 2.2.2). Trench exposures in T6, T7, T8 and T9 indicate that the last phase of 
deposition on these surfaces was aggradation of fines in small channels on the P3 surfaces (Section 2.2.2, Section 2.3.2, and Section 2.3.3). Subsequent deposition, shown by the inset deposits that underlie the Holocene surfaces has been dominated by fines. Soils on the Pleistocene surfaces are characterized by an upper loess cap, generally less than 0.5-m-thick in the Diversion Dam study reach and well-developed carbonate morphology (Section 2.2.2). The Pleistocene age of both the P2 and P3 surfaces is established regionally by depositional links to regional glaciation, and in a local context by radiocarbons ages of $\sim 10,000$ to 12,800 cal yr B.P. obtained from the inset fine-grained deposits (Section 2.2.2 and Table 2-2).

\subsection{Hydraulic Modeling of the Diversion Dam Study Reach}

TrimR2D (Appendix C, Part A; Ostenaa et al., 1999) was used with the topographic data for the Diversion Dam reach (Appendix A) to calculate steady-state 2D inundation and flow velocities using a 6-ft cell flow grid for the discharges listed in Table 2-1. A $3 \mathrm{ft}$-spacing uniform grid was produced after a clockwise rotation of $31.4^{\circ}$ of a subset of the high-resolution topographic grid (2000 photography, Appendix A) for the Diversion Dam study reach, which was subsampled by TrimR2D to produce a 6-ft staggered finite-difference grid. To accommodate the larger inundated areas associated with discharges larger than $200 \mathrm{cms}$, a larger region of topography containing the Diversion Dam study reach was extracted from the 5-ft spacing topographic mesh from the reprocessed 1993 aerial photography at INL (Appendix A) after a 36.9 clockwise rotation of the topographic mesh and interpolated to produce a 2.5-ft-spacing topographic input grid for TrimR2D. TrimR2D then subsampled the 2.5-ft-spacing topographic grid to produce a 5-ftspacing staggered finite-difference grid. To ensure that flow was entrained within the grid to the downstream edges of the grids, high elevation walls were added to the western, northern, and southern edges of the grids. The impact of these walls in the 6-ft grid is most clearly apparent for the larger discharges (generally discharges of $200 \mathrm{cms}$ or larger, see Table 2-1 and plots in Appendix D) and motivated the development of the 5-ft grid that encompassed a larger area south of the channel to allow more realistic routing of discharges of $200 \mathrm{cms}$ or larger.

In both grids the minimum elevation in the grid was removed from all points in the grid to maximize numerical precision in quantities involving elevations. Coordinate transformation 
equations were constructed for both the 5-ft and 6-ft TrimR2D flow grids to convert the TrimR2D local grid coordinates to their original INL state-plane coordinates and elevations.

The grids were initially wetted using springs distributed along the channel and that were activated for several minutes of flow to partially fill the channels. To produce steady-state flows for specific discharges, springs were activated immediately downstream of the diversion dam in the active channel with a total flux equal to the specific discharge. For the smaller flows on the 6-ft grid, 22 springs were used to minimize stages in the vicinity of the springs and 28 springs were used with the larger discharges on the 5 -ft grid. Flows for all discharges were calculated using a sequential approach, where the first flow calculation started with the smallest discharges. The results of the preceding smaller discharge were used as the initial wetting condition to start flow calculations for the next larger discharge. This minimized the impact of transient flow features like bores on the wetted area. Outlet flow water surface elevations were set to ensure subcritical outflow conditions.

Time steps were established at $5 \mathrm{~s}$ for the 6 - $\mathrm{ft}$ grid and the smaller discharges to ensure Courant numbers of larger than 4 given main channel flow velocities of $1-2 \mathrm{~m} / \mathrm{s}$ for discharges of $10 \mathrm{cms}$ to $\sim 200 \mathrm{cms}$. Main channel flow velocities for discharges of $200 \mathrm{cms}$ and larger were generally $>2 \mathrm{~m} / \mathrm{s}$. Consequently, a time step of $3 \mathrm{~s}$ for the 5 -ft grid to ensure Courant number larger than 4 . As indicated in Table 2-1, two bed roughness scenarios using Manning's $n$ of 0.030 and 0.038 were implemented in the 6-ft-grid flow calculations.

A total of 15 hydrograph monitoring positions were established throughout the channel sections of the study reaches. These hydrographs were monitored to determine when the flows had reached steady state. Typically, flow times of about four hours where required to achieve steady-state conditions throughout both study reaches. Steady-state conditions were defined as attaining an essentially static water surface elevation at all the hydrograph monitoring positions (natural highfrequency water surface elevation oscillations, typically of several centimeters, were ignored).

The flow quantities output included water surface elevations and vector flow velocities interpolated to the water surface elevation positions at cell-centered positions in the staggered grid. Using the known topography, derived quantities such as depth, shear stress, and power were 
obtained. The inverse transformation operators were then applied to produce flow quantities in the INL state-plane coordinate system.

2.5.1 Results. Complete results of the flow modeling are depicted on maps contained in Appendix D - Electronic Supplement. Color-contoured plots of depth, stream power and shear stress are overlain on shaded relief images of the high-resolution topography and the geomorphic map units shown on Plate 2. Plots showing differences in flow depth for simulations with varied inputs of Manning's $n$ or the input topographic grid are also included in Appendix D - Electronic Supplement. Plots in Appendix F (Figures D3-6 through D3-37) depict the effects of these same variations on unit stream power and bed shear stress in each of the sampling subareas. The plots in Appendix F can be used to directly assess the affects of the varied inputs on the estimated discharges associated with paleofloods and paleohydrologic bounds (see Section 3.2).

The model results show that depth, stream power, and shear stress vary significant throughout the study reach based on the local conditions of flow. For example, along the length of the channel, unit stream power increases and decreases significantly for areas with more or less constricted flow (Figure 2-9). Unit stream power increases with discharge in reaches which are less constricted; but locally decreases significantly upstream of some constrictions as flow stagnates with increasing discharge. The smallest flows simulated, 10, 12, and $15 \mathrm{~m}^{3} / \mathrm{s}$, correspond to the range of the largest gaged flows downstream of the INEEL Diversion Dam, including a series of flows from 1995-1999 (Appendix E). In channel values of unit stream power and bed shear stress from this range of discharge that generally remain within the ranges of values associated with soil erosion (Appendix D and Figure 3-2) appear to be qualitatively consistent with field observations of a mostly intact, armored gravel bed through many areas of the central part of the study reach (Section 2.2.4). Areas at channel constrictions have somewhat higher values unit stream power and bed shear stress, and appear to be areas where sediment was mobilized by these flows.

For simulations up to about $70 \mathrm{~m}^{3} / \mathrm{s}$, most flow remains confined to the main channel system with progressively greater inundation of flanking H3-4 and locally, limited areas of some H1-2 surfaces. Flows up to this level generally do not reach the geomorphic surfaces of interest for this study. The complex network of abandoned and cutoff channels in the Big Loop area and upstream 
of the Saddle constriction gradual inundates with relatively low velocity and stagnated flow that is independent of the pattern of channel cutoffs, but instead controlled by changing patterns of flow constrictions through and downstream of the Big Loop area. Simulations for discharges of 100 and $130 \mathrm{~m}^{3} / \mathrm{s}$ show that essentially all areas of H1-2 surfaces along the Big Lost River become inundated by shallow flow, and simulations for $150 \mathrm{~m}^{3} / \mathrm{s}$ and larger discharges show progressive encroachment of this flow into the lowest areas of Pleistocene deposits and surfaces along the river. Discharges greater than $200 \mathrm{~m}^{3} / \mathrm{s}$ show progressive expansion of flows through the networks of braid channels on the Pleistocene surfaces.

2.5.1.1 Effects of Varied Manning's $\boldsymbol{n}$. Difference plots of TrimR2D flow depth with varied Manning's $n$ of 0.038 and 0.030 , for discharges of 100, 200, and $250 \mathrm{~m}^{3} / \mathrm{s}$, show that effects on the flow depth from variations in this parameter vary spatially throughout the study reach (Appendix D - Electronic Supplement). The largest differences are present in subreaches where flow accelerates, and flow depths for the lower $n$-value are reduced by 0.5 - 1-ft $(0.1$ $0.3 \mathrm{~m})$. In subreaches where flow stagnates, which includes large areas of the study reach, this parameter has little effect on flow depth. Thus, simulations based on a Manning's $n$ of 0.030 indicate slightly reduced depths as flow is initiated through braid channels leading to trench T3, and in the straight reach between trenches T4/T5 and T6. However, initiation of flow over the Saddle and across the large area of Pleistocene (P2) surfaces north of the Big Lost River between the Saddle and the BLR8 site is unaffected by variations of Manning's $n$ because flow depth in those areas is controlled by backwater effects at bedrock constrictions in the channel.

Effects on estimates of unit stream power and bed shear stress also vary spatially throughout the reach. On the plots in Appendix F (Figures D3-6 through D3-37), dotted lines depicting the results for simulations using a Manning's $n$ of 0.030 are close to, or shifted slightly to the right of lines for simulations using a Manning's $n$ of 0.038. This implies a potential increase in the discharge associated with a threshold criteria of about 0 - 25 per cent, depending on the characteristics of flow through any specific subarea.

2.5.1.2 Effects of Input Topography. Most flow simulations for the study reach were used a 6-ft computational grid derived from the 2000 topographic data. However, as modeling commenced, it became clear that the extent model reach needed to expanded to simulate 
the larger discharges. Thus, a 5-ft topographic grid of larger extent was derived from the reprocessed 1993 topographic data. As shown in Appendix A, the 1993 data has somewhat reduced accuracy compared to the 2000 data resulting in a lower resolution topographic input model, particularly in channelled or confined areas. These effects were shown on difference plots of flow depth for two discharges, 200 and $250 \mathrm{~m}^{3} / \mathrm{s}$, common to both sets of simulations (Appendix D - Electronic Supplement). In general, simulations based on the 1993 topographic data resulted in flow depths that were $0.5-1 \mathrm{ft}(0.1-0.3 \mathrm{~m})$ larger throughout most of the study reach. Effects on estimates of unit stream power and bed shear stress are complex and controlled by local flow conditions (See plots in Appendix D, Figures D3-6 through D3-37). In some areas, unit stream power and bed shear stress increase due to the higher stage and flow velocity represented in the 5-ft grid model. In other areas, higher stage results in increased backwater and flow stagnation, leading to a reduction in unit stream power and bed shear stress.

2.5.1.3 Comparisons to Previous Studies. Initial inspections of model results derived from the 6-ft grid showed significant differences compared to the flow results developed for previous studies (Ostenaa et al., 1999, 2002) using the same flow model. These differences are illustrated by results from the Saddle area depicted in Ostenaa et al. (1999, 2002) (Figure 2-10). Increasing discharge from $100 \mathrm{~m}^{3} / \mathrm{s}$ to $150 \mathrm{~m}^{3} / \mathrm{s}$ resulted in a new path for flow named the Saddle, and development of high values of unit stream power on the geomorphic surfaces just downstream of the Saddle. In contrast, results from the 6-ft grid for this study showed that for a discharge of $150 \mathrm{~m}^{3} / \mathrm{s}$ (Figure 2-23), flow through the Saddle did not commence until modeled discharge reached of $250 \mathrm{~m}^{3} / \mathrm{s}$ (Figure 2-24 and Figure 2-25). The smallest discharge modeled with the 5 -ft grid was $200 \mathrm{~m}^{3} / \mathrm{s}$ (Figure 2-26) and these results showed significant flow through the Saddle as well as at a similar location slightly upstream. Because the initiation of through the Saddle is controlled by the backwater effects at the bedrock constriction (Ostenaa et al., 1999, 2002, and Figure 2-10) it appears that much of this difference is attributable to the lack of resolution in the original 2-ft contour data used in the earlier modeling. This resulted in higher stages upstream of the constriction for relatively lower discharges compared to the topographic models used as inputs for the present study. 
Initial comparisons of modeling results for other areas of the study reach did not show a consistent difference (Section Figure 2-11). At BLR7, the most upstream site in the Diversion Dam study reach, modeled stage increased by about $0.5 \mathrm{~m}$ compared to the previous results. At BLR2, BLR6, and BLR8, modeled stage decreased by about 0.1-0.2 m compared to the previous results. When evaluation of the topographic data (Appendix A) revealed discrepancies in the accuracy of the 2-ft contour data used as input for the modeling by Ostenaa et al. $(1999,2002)$, the previous modeling results were eliminated from further consideration.

2.5.1.4 Results from Specific Study Areas. As a supplement to the reach-scale plots of the flow simulation results contained in Appendix D - Electronic Supplement, large-scale plots near the detailed geologic study areas were prepared that show unit stream power and bed shear stress. The plots in this section illustrate results for TrimR2D simulations using a Manning's $\mathrm{n}$ of 0.038 , and results are shown for both 6-ft and 5-ft topographic grids. Only the larger flow simulations, those which are pertinent to the evaluations of paleofloods and paleohydrologic bounds for each of the study reaches are included. The full set of flow simulations in included in Appendix D - Electronic Supplement and used to define specific discharge limits as discussed in Appendix D, Figures D3-6 through D3-37, and following this section in Section 3.2.

Big Loop Study Area, Trenches T1, T2 and T3. Trenches T1, T2, and T3 were all located across braid channels on the extensive Pleistocene (P2) surface (Plates 1, 2, and Section 2.3.1). Trench $\mathrm{T} 1$ is lowest of these sites, and flow through the channel at $\mathrm{T} 1$ and on the $\mathrm{P} 3$ surface surrounding the trench is seen in simulations for discharges of $130 \mathrm{~m}^{3} / \mathrm{s}$ and larger (Figure 2-12). For modeled flows of 150 and $175 \mathrm{~m}^{3} / \mathrm{s}$ (Figure 2-13 and Figure 2-14), inundation extent extends across most of the P3 surface and low values of unit stream power $\left(<2 \mathrm{~W} / \mathrm{m}^{2}\right)$ and bed shear stress (1-5 N/m ${ }^{2}$ ) are present in limited areas of channels where flow is concentrated. For larger discharges, 200, 225, and $250 \mathrm{~m}^{3} / \mathrm{s}$ (Figure 2-15 through Figure 2-17), the magnitude and extend of unit stream power exceeding $2 \mathrm{~W} / \mathrm{m}^{2}$ and bed shear stress exceeding $1-5 \mathrm{~N} / \mathrm{m}^{2}$ increases with discharge, particularly as flow concentrates in the braid channels and is diverted around small area of higher topography. For this discharge range, some flow is beginning in upstream braid channels on the P2 surface, but no flow has reached trenches T2 or T3. 
Flow simulations using the 5 - $\mathrm{ft}$ topographic grid for discharges of 200 and $250 \mathrm{~m}^{3} / \mathrm{s}$ (Figure 2-18 and Figure 2-19) show increased flow depth and extent compared to the simulations using the 6-ft topographic gird (discussed above in Section 2.5.1.2). Thus, flow extent, and the magnitude and extent of values of unit stream power and bed shear stress for $200 \mathrm{~m}^{3} / \mathrm{s}$ on the 5 -ft grid is only slightly less than values shown for $250 \mathrm{~m}^{3} / \mathrm{s}$ on the 6-ft grid (compare Figure 2-18 and Figure 217). Flow simulations for 300, 350, and $400 \mathrm{~m}^{3} / \mathrm{s}$ (Figure 2-20 through Figure 2-22) show increased flow across the P2 surface in the Big Loop study area, first concentrated in former braid channels, but gradually expanding across much of the surface. For this range of discharges, unit stream power and bed shear stress commonly reach values of $10-30 \mathrm{~W} / \mathrm{m}^{2}$ and $10-25 \mathrm{~N} / \mathrm{m}^{2}$, respectively, in the braid channels on the P2 surface where flow first concentrates. In the braid channels crossed by trenches T2 and T3, unit stream power and bed shear stress reach values of 5$10 \mathrm{~W} / \mathrm{m}^{2}$ and $5-10 \mathrm{~N} / \mathrm{m}^{2}$, respectively.

Saddle Constriction and T4/T5/T6 Study Areas. The initiation of flow through the Saddle area and onto the extensive Pleistocene (mostly P2) surfaces downstream of the Saddle was an important piece of evidence used by Ostenaa et al. $(1999,2002)$ to define the basis for a paleohydrologic bound over the past 10,000 years (Section 2.3.2). As noted above, (Section 2.5.1.3), flow simulations for this study, using the 6-ft grid derived from the 2000 topography, showed that flow was not initiated across the Saddle except for discharges of $250 \mathrm{~m}^{3} / \mathrm{s}$ and larger (Figure 2-23 through Figure 2-25). Trenches T6 and T7 were sited to determine if there was geologic evidence downstream of the Saddle area of such flows. Flow simulations using the 5 -ft topographic grid from the 1993 topography again show higher stages compared to simulations based on the 6-ft topographic grid (Section 2.5.1.2). For the smallest discharge simulated using the 5 -ft grid, $200 \mathrm{~m}^{3} / \mathrm{s}$, significant flow is present through the saddle, as well as at a second location about $200 \mathrm{~m}$ to the northwest (Figure 2-26). For the northernmost portion of trench T6 and a small area at the south end of trench T7, unit stream power and bed shear stress exceed 5-10 W/m $\mathrm{m}^{2}$ and 5-10 N/m², respectively, due to flow through the Saddle. Simulations based on either the 6-ft or 5ft topographic grid (Figure 2-25 and Figure 2-26) indicate that the initial flow onto the P3 surface from the Saddle would cross the geomorphic patterns on the P3 surface downstream of the Saddle. Flows that would follow channel patterns on the P3 surface at trench T6 and the southern end of trench T7 must reach that surface due to high stages in the Big Lost River downstream of 
the Saddle constriction. Flow simulations based on the 5-ft grid indicate that this does not happen except for discharges of $250 \mathrm{~m}^{3} / \mathrm{s}$ and larger (Figure 2-27 through Figure 2-30). These simulations show that as flow across the topographic barrier associated with the Saddle increases, unit stream power and bed shear stress commonly reach values of $10-30 \mathrm{~W} / \mathrm{m}^{2}$ and $10-25 \mathrm{~N} / \mathrm{m}^{2}$, respectively, in the braid channels on the P2 surface downstream as flow re-concentrates in these channels.

The T4/T5/T6 study area is located along the main Big Lost River channel downstream of the Saddle constriction (Plate 1). For flow simulations as large as about $70 \mathrm{~m}^{3} / \mathrm{s}$ (Figure 2-31), flow remains confined to the relatively straight channel flanked by H1-2 and P2 surfaces. Flow simulations of $100 \mathrm{~m}^{3} / \mathrm{s}$ (Figure 2-32) show inundation of the lowest portions of H1-2 surfaces, such as near T4, and for a discharge of $130 \mathrm{~m}^{3} / \mathrm{s}$ (Figure 2-33), the entire H1-2 surface near T4/T5/T6 is inundated. In some areas, such as the north end of trench T4, unit stream power and bed shear stress increase rapidly with increased discharge and begin to exceed $30 \mathrm{~W} / \mathrm{m}^{2}$ and 25 $\mathrm{N} / \mathrm{m}^{2}$, at a discharge of $100 \mathrm{~m}^{3} / \mathrm{s}$. In other areas, such as along the main H1-2 surface on the north side of the river between $\mathrm{T} 5$ and $\mathrm{T} 6$, the increase is slower and patchy, with unit stream power and bed shear stress generally $<5 \mathrm{~W} / \mathrm{m}^{2}$ and $5 \mathrm{~N} / \mathrm{m}^{2}$ for a discharge of $130 \mathrm{~m}^{3} / \mathrm{s}$. Increasing discharge results in progressive increases in the extent of larger values of unit stream power and bed shear stress on the H1-2 surfaces. For a discharge of $150 \mathrm{~m}^{3} / \mathrm{s}$ (Figure 2-34), large areas of unit stream power and bed shear stress in the range of $10-30 \mathrm{~W} / \mathrm{m}^{2}$ and $10-25 \mathrm{~N} / \mathrm{m}^{2}$, respectively, are shown on the H1-2 surface, and these expand over most of that surface in simulations for $175 \mathrm{~m}^{3} / \mathrm{s}$ (Figure 2-35). These values continue to increase in simulations for 200, 225, and $250 \mathrm{~m}^{3} / \mathrm{s}$ (Figure 2-36 through Figure 2-38). Simulations for $225 \mathrm{~m}^{3} / \mathrm{s}$ show unit stream power and bed shear stress in the range of $30-50 \mathrm{~W} / \mathrm{m}^{2}$ and $25-50 \mathrm{~N} / \mathrm{m}^{2}$, respectively, over most of $\mathrm{H} 1-2$ surface between $\mathrm{T} 5$ and T6, and unit stream power exceeding $50 \mathrm{~W} / \mathrm{m}^{2}$ in many areas for a discharge of $250 \mathrm{~W} / \mathrm{m}^{2}$.

Simulation results for the T4/T5/T6 study area based on the 5-ft topographic grid again show greater flow depth than do equivalent discharge simulations based on the 6-ft topographic grid (Section 2.5.1.2). However, for discharges of $200 \mathrm{~m}^{3} / \mathrm{s}$, unit stream power and bed shear stress magnitude and extent on the H1-2 surfaces are generally similar, near $30 \mathrm{~W} / \mathrm{m}^{2}$ and $25 \mathrm{~N} / \mathrm{m}^{2}$, respectively, for simulations using either the 5-ft or 6-ft topographic grid (compare Figure 2-36 
and Figure 2-39). Because of the higher stage present in the 5-ft grid model, flow overtops edge of the P3 surface north of the river, resulting in slightly reduced unit stream power and bed shear on the flanking H1-2 surface. For larger discharges simulated using the 5-ft topographic grid (Figure 2-40 through Figure 2-43), the high values unit stream power and unit stream power are present across the entire extent of the H1-2 surface near trenches T5 and T6.

In both sets of flow simulations, for discharges larger than $150 \mathrm{~m}^{3} / \mathrm{s}$, unit stream power exceeds $100 \mathrm{~W} / \mathrm{m}^{2}$ bed shear stress approaches $100 \mathrm{~N} / \mathrm{m}^{2}$ over most of the channel area through this subreach.

BLR8 Study Area, Trenches T8 and T9. For discharges up to $70 \mathrm{~m}^{3} / \mathrm{s}$ (Figure 2-44), flow simulations indicate that the main path of flow follows the Big Lost River channel around the sharp bends that define this subreach. For the larger discharges in this range, there is a decrease in channel power and shear stress in the downstream portion of the reach, and an increase in area near the Rb outcrops flanking the downstream bedrock constriction. Near trench T8a,b,c, the inundation extent for a discharge of $70 \mathrm{~m}^{3} / \mathrm{s}$ is roughly coincident with the transition between H1-2 and H3-4 surfaces (Figure 2-44). Deposits at the north end of trench T9 are inundated by discharges of less than $50 \mathrm{~m}^{3} / \mathrm{s}$, and unit stream power and bed shear stress remains low at this site through the full range of simulated discharges flow depth increases. Discharges of 100 and $130 \mathrm{~m}^{3} / \mathrm{s}$ (Figure 2-45 and Figure 2-46) both inundate the full extent of H1-2 surfaces to the vicinity of trench T8b. Unit stream power and bed shear values increase significantly near trench T8c with each increase in the modeled discharge, but remain low at the edge of the flow near trench T8b. Discharge of $150 \mathrm{~m}^{3} / \mathrm{s}$ (Figure 2-47) results in inundation to the southern end of trench T8a and is roughly coincident with the lower edge of the P3 surface near trench T9. At this discharge and larger, unit stream power and bed shear stress near trench T8c, the northernmost trench, remain generally above values of $50 \mathrm{~W} / \mathrm{m}^{2}$ and $25 \mathrm{~N} / \mathrm{m}^{2}$. For discharges of $175,200,225$, and $250 \mathrm{~m}^{3} / \mathrm{s}$ (Figure 2-48 through Figure 2-51) flow depth progressively increases in the areas of T8a and T8b, increasing the range unit stream power and bed shear stress to $5-25 \mathrm{~W} / \mathrm{m}^{2}$ and 5-30 $\mathrm{N} / \mathrm{m}^{2}$, respectively. Near T8c, values of unit stream power and bed shear stress increase somewhat but remain above $50 \mathrm{~W} / \mathrm{m}^{2}$ and $25 \mathrm{~N} / \mathrm{m}^{2}$. Near trench T9, increasing discharge above $150 \mathrm{~m} / \mathrm{s}$, 
results in gradual southward extension of the inundation extent with low unit stream power and bed shear stress values.

Simulations of the larger discharges using the 5-ft grid topography have higher stages and greater flow depths (Section 2.5.1.2), but the most significant difference from the 6-ft grid results is a small shift to the south in the band of highest intensity unit stream power and bed shear stress across the H1-2 surface near T8b and T8c. The results based on the 5-ft topographic grid for 200 and $250 \mathrm{~m}^{3} / \mathrm{s}$ (Figure 2-52 and Figure 2-53) show a distinctly different pattern of high values of unit stream power and bed shear stress compared to results based on the 6-ft topographic grid (Figure 2-49 and Figure 2-51). For the larger discharges modeled, 300, 350 and $400 \mathrm{~m}^{3} / \mathrm{s}$ (Figure 2-54 through Figure 2-56) the full extent of the P3 surface near the trenches becomes inundated. In the largest flows, unit stream power and bed shear stress begin to decrease across the site due to backwater effects from the bedrock outcrops at the downstream edge of the study area. 
Figures for Section 2.0 


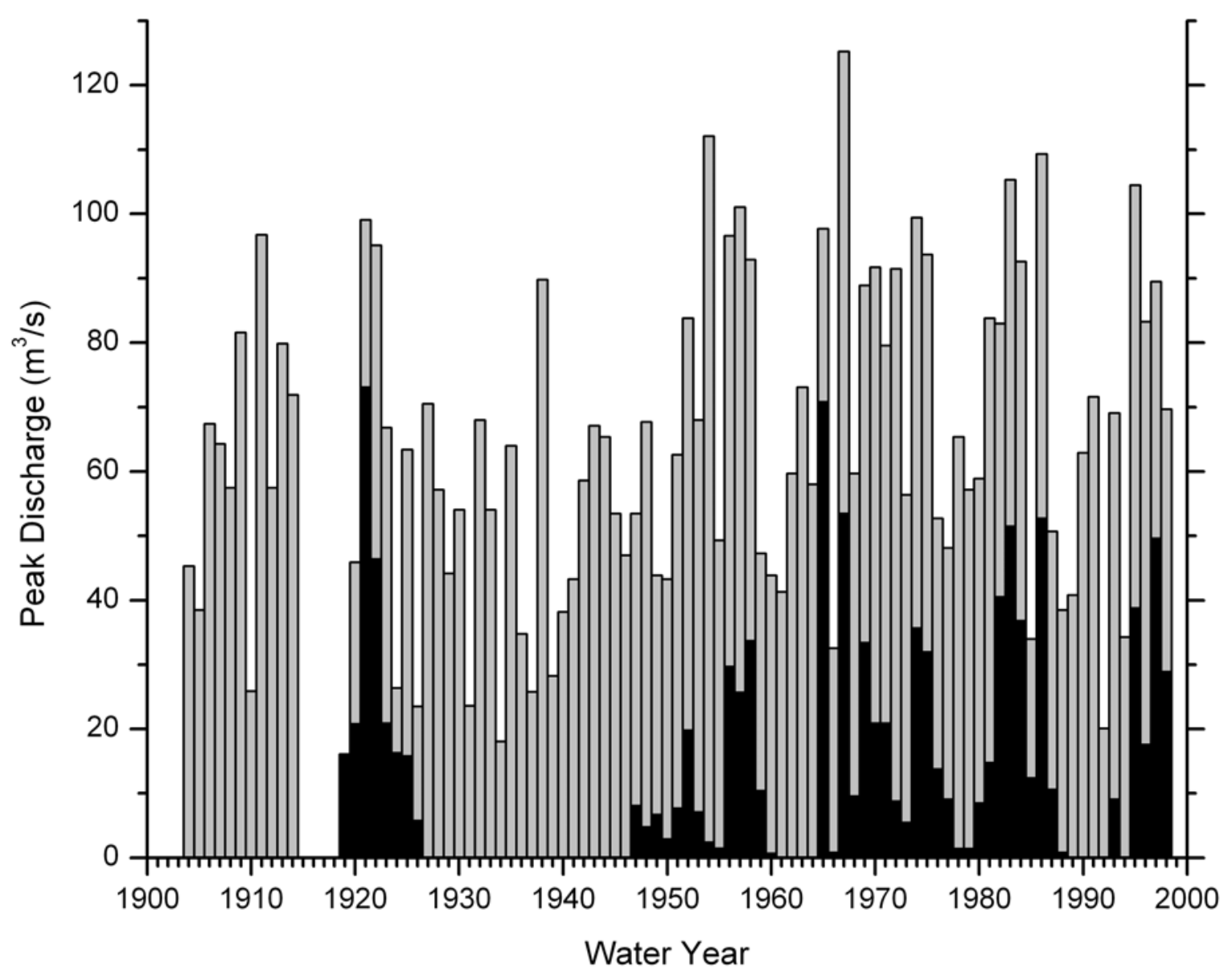

Figure 2-1 Annual peak discharge estimates for upstream (light shaded bars) and downstream gaging stations (dark shaded bars) on the Big Lost River. Upstream estimates are from Big Lost River at Howell Ranch from 1904 to 1998. Downstream estimates are from Big Lost River near Arco from 1947 to 1998 except for period 1919 to 1926 which are peak discharge estimates from stations at Leslie and near Moore, early gages located a short distance upstream of Arco. No peak discharge estimates are available from sites near Arco for the periods 1905 to 1918, 1927 to 1945, and 1962 to 1964. Figure from Ostenaa et al., 2002. 


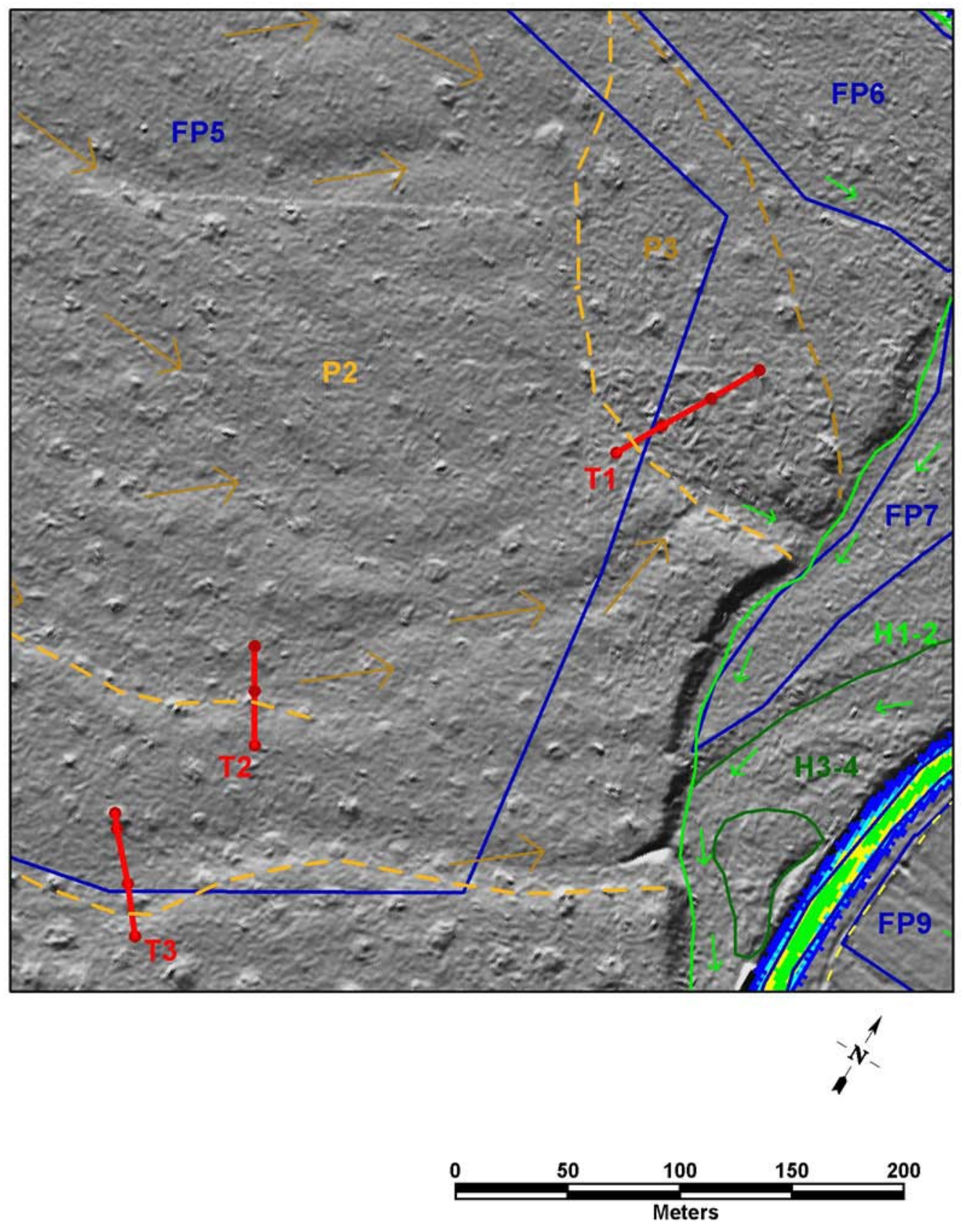

Figure 2-2 Area around Trenches T1, T2, and T3. Shaded relief image and geology from Plate 2. Blue boxes are stream power and shear stress sample areas (Section 3.2). Red lines are trench locations; red dots along the lines show end stations and 25-m stationing intervals beginning at south end. See Plate 2 for explanation of geologic symbols and labels. Flow direction in Big Lost River is from upper left to lower right. 

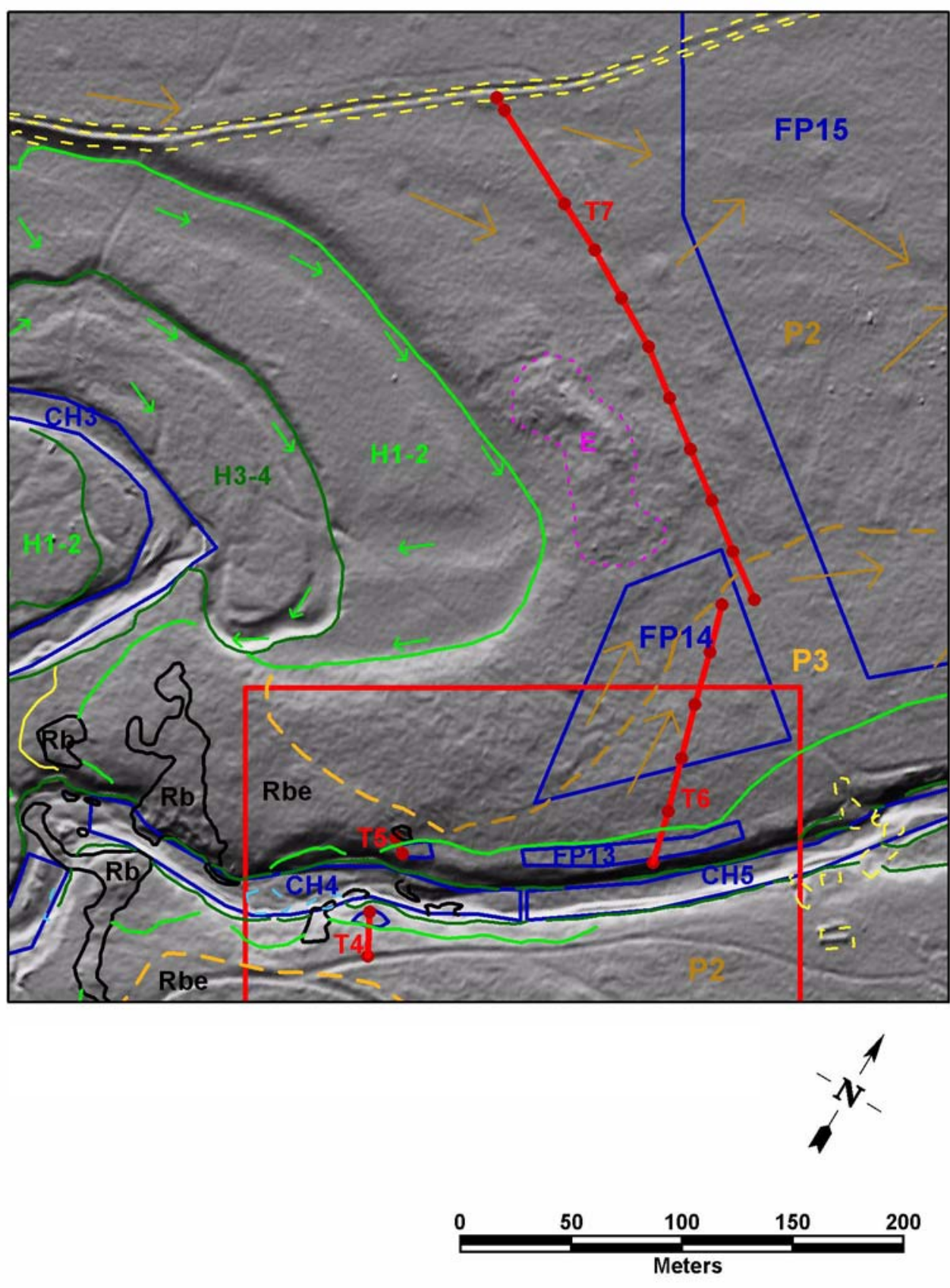

Figure 2-3 Area around "Saddle" and Trenches T4 and T5 downstream of saddle constriction. Shaded relief image and geology from Plate 2. Blue boxes are stream power and shear stress sample areas (Section 3.2). Red lines with dots and labels show trench locations; red dots along the lines show end stations and 25-m stationing intervals beginning at south end. Red box in lower part of figure shows partial extent of inset area shown in Figure 2-4. See Plate 2 for explanation of geologic symbols and labels. River flow direction is from left to right. 

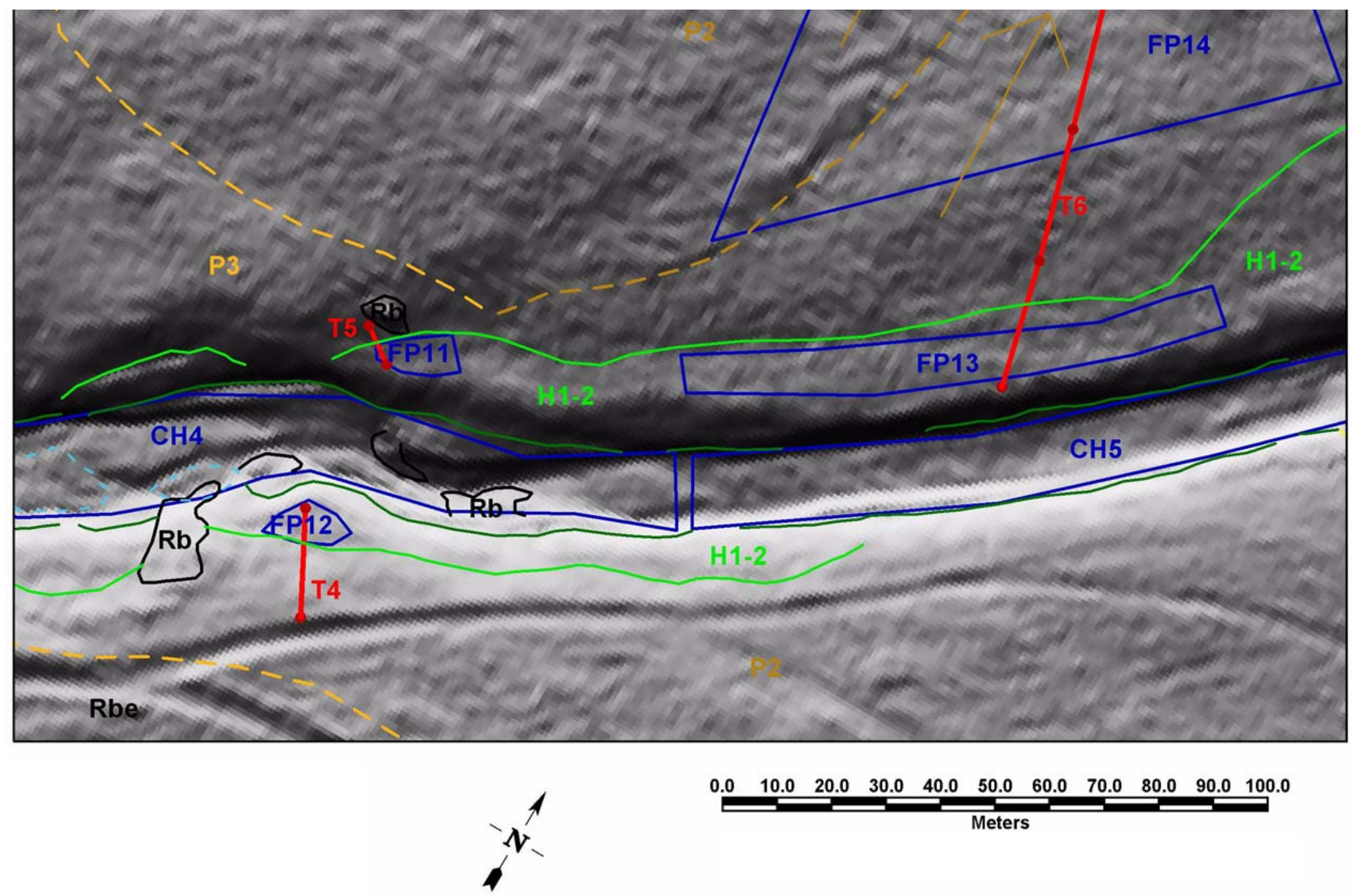

Figure 2-4 Detail of area around Trenches T4, T5 and T6 downstream of saddle constriction. Shaded relief image and geology from Plate 2. Blue boxes are stream power and shear stress sample areas (Section 3.2). Red lines with dots and labels show trench locations; red dots along the lines show end stations and 25-m stationing intervals beginning at south end. See Plate 2 for explanation of geologic symbols and labels. 

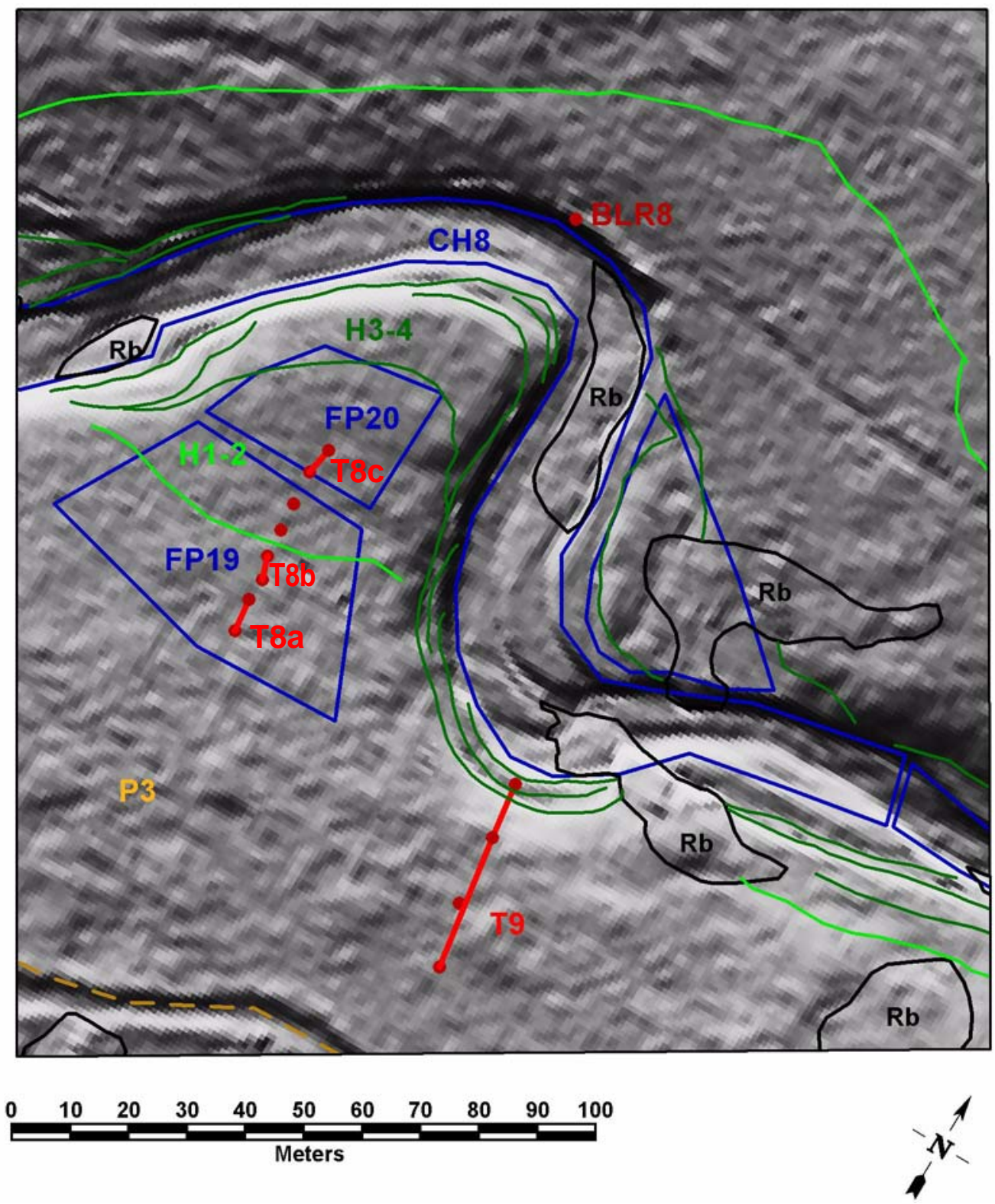

Figure 2-5 Area around BLR8 and Trenches T8 and T9. Shaded relief image and geology from Plate 2. Blue boxes are stream power and shear stress sample areas (Section 3.2). Red lines with dots and labels show trench locations; red dots along the lines show end stations and 25-m stationing intervals beginning at south end. See Plate 2 for explanation of geologic symbols and labels. River flow is from left to right. 


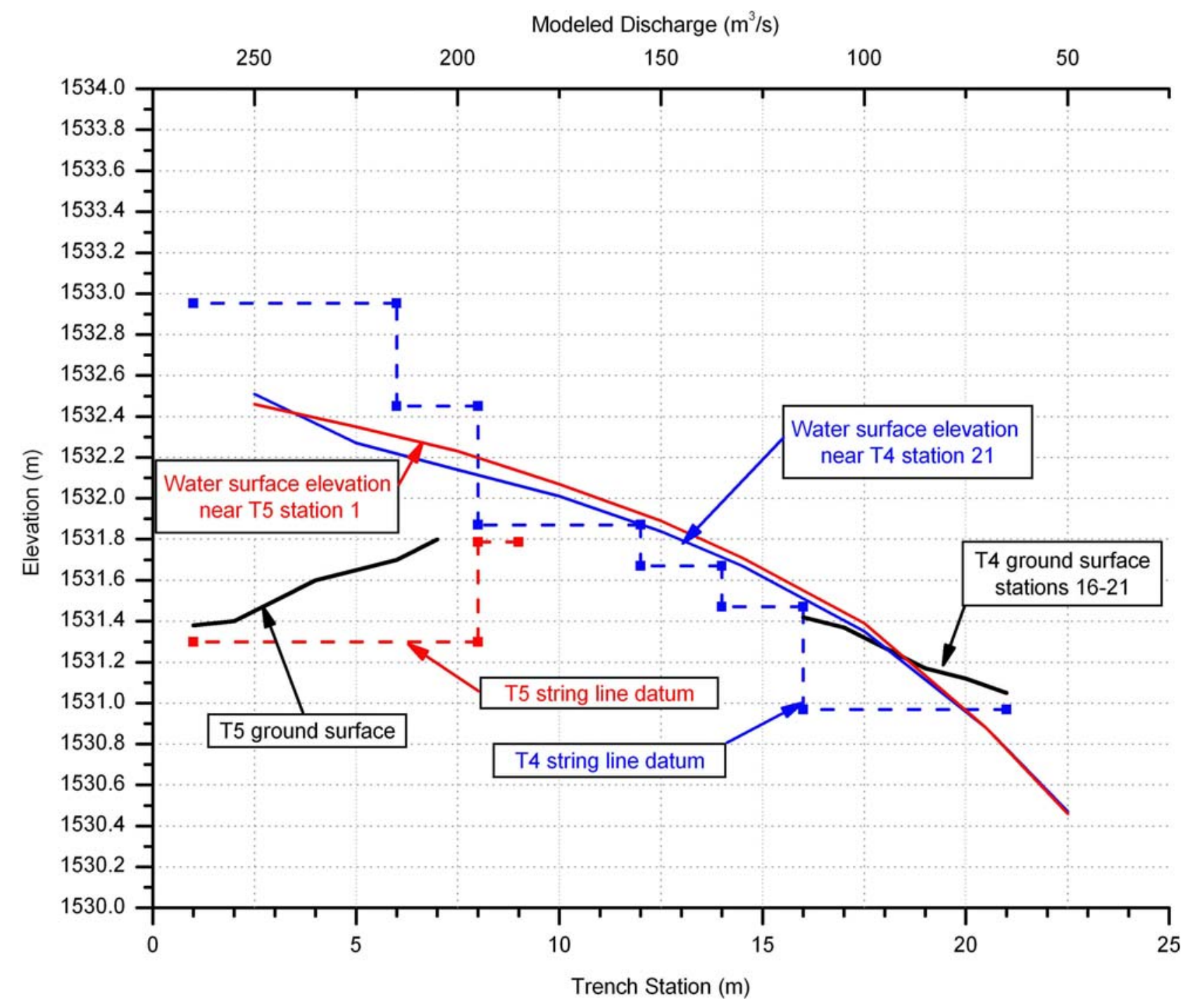

Figure 2-6 Modeled water surface elevation near trenches T4 and T5. Results for $\mathrm{n}=0.038$ from TrimR2D models on 6-ft topographic grid. $\mathrm{S}$ 


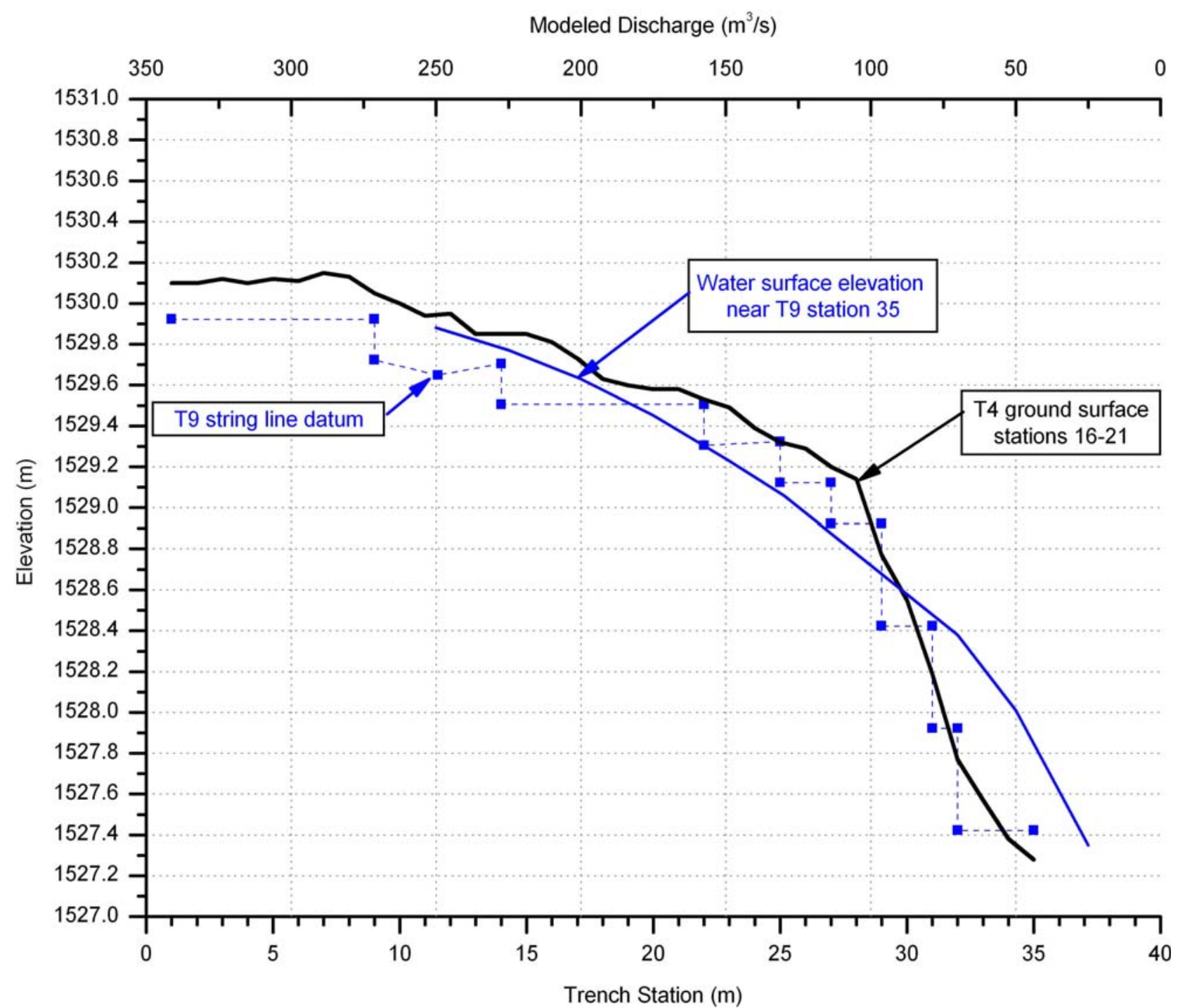

Figure 2-7 Modeled water surface elevation near trench T9. Results for $\mathrm{n}=0.038$ from TrimR2D models on 6-ft topographic grid. $\mathrm{S}$ 


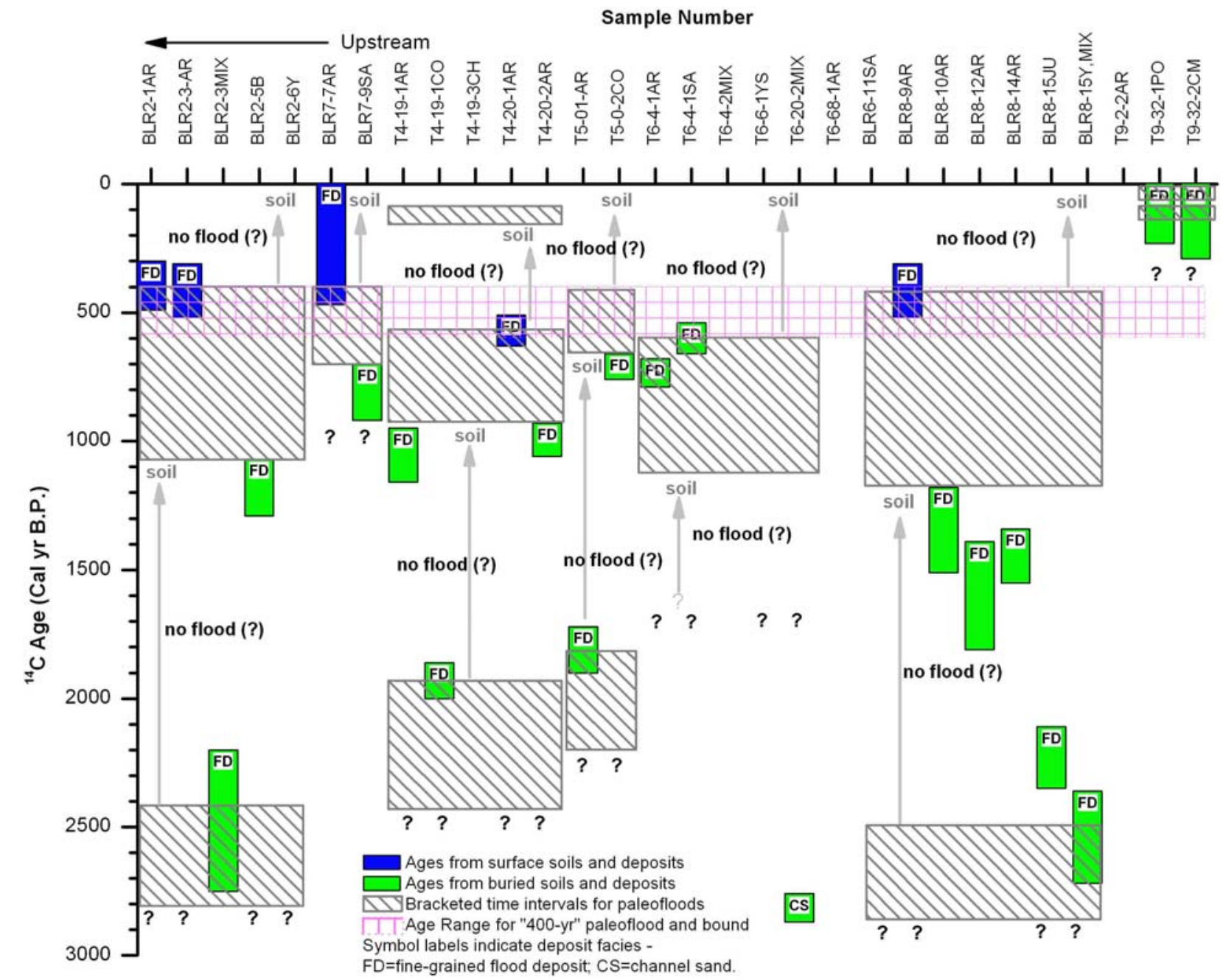

Figure 2-8 Summary plot of age constraints for late Holocene paleofloods. Cross-hatched boxes correspond to bracketed time intervals for paleoflood deposits at each site and are wider for sites with more age control. Green and blue boxes are calibrated radiocarbon age ranges (Table 2-2). BLR* samples are from Ostenaa et al. (1999, 2002); T* samples are from this study. Samples from within a paleoflood deposit either date the flood directly or are minimum soil ages that overlap the bracketed range. Samples that are buried by the paleoflood deposit are shown abutting the bracketed time intervals and are presumed to be maximum ages for the paleoflood. Vertical arrows show relative intervals of soil development on bracketing deposits at each site. ? ? show maximum age which for which paleofloods at each site can be constrained. 


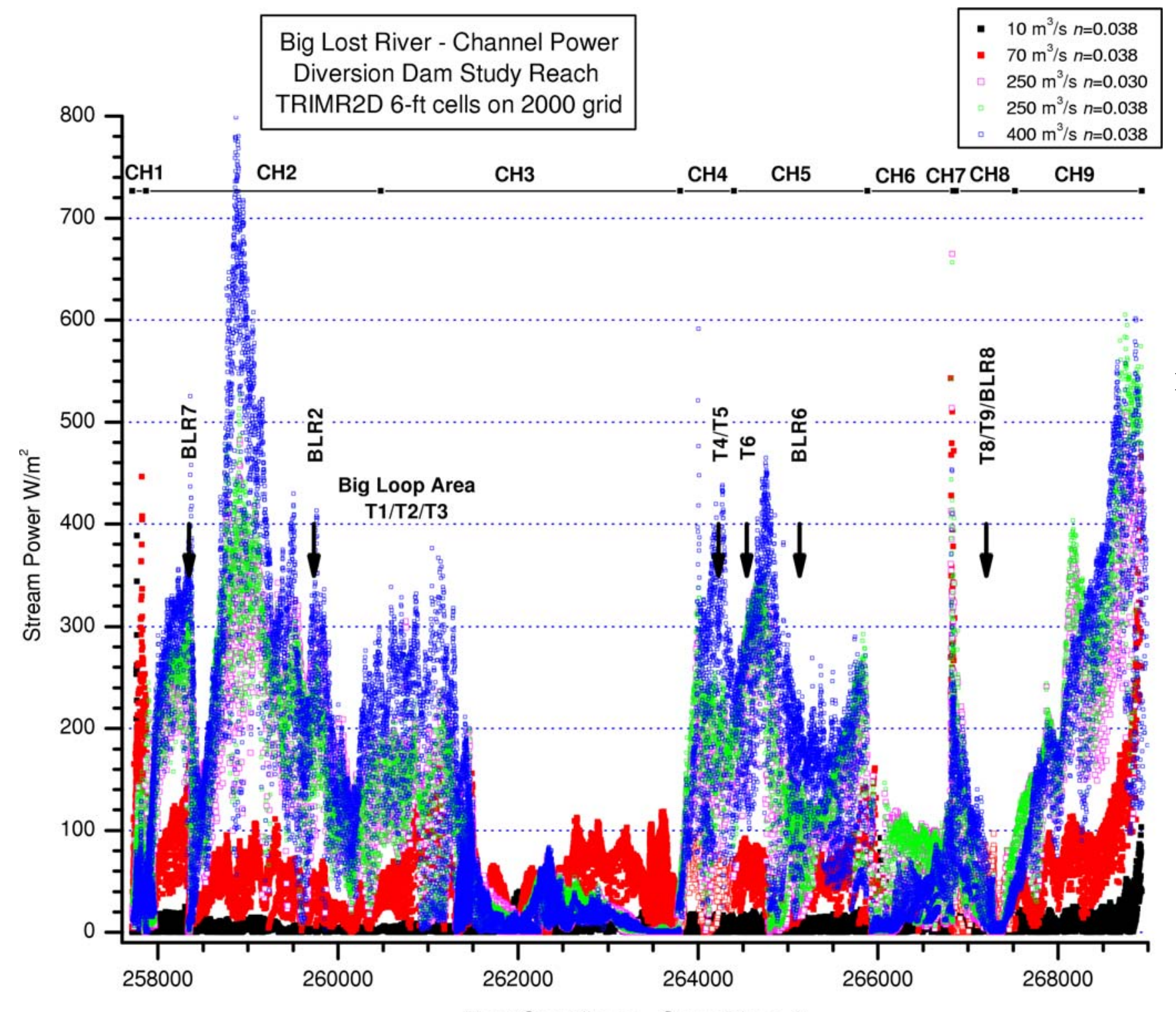

East Coordinate - State Plane ft

Upstream

Downstream

69 

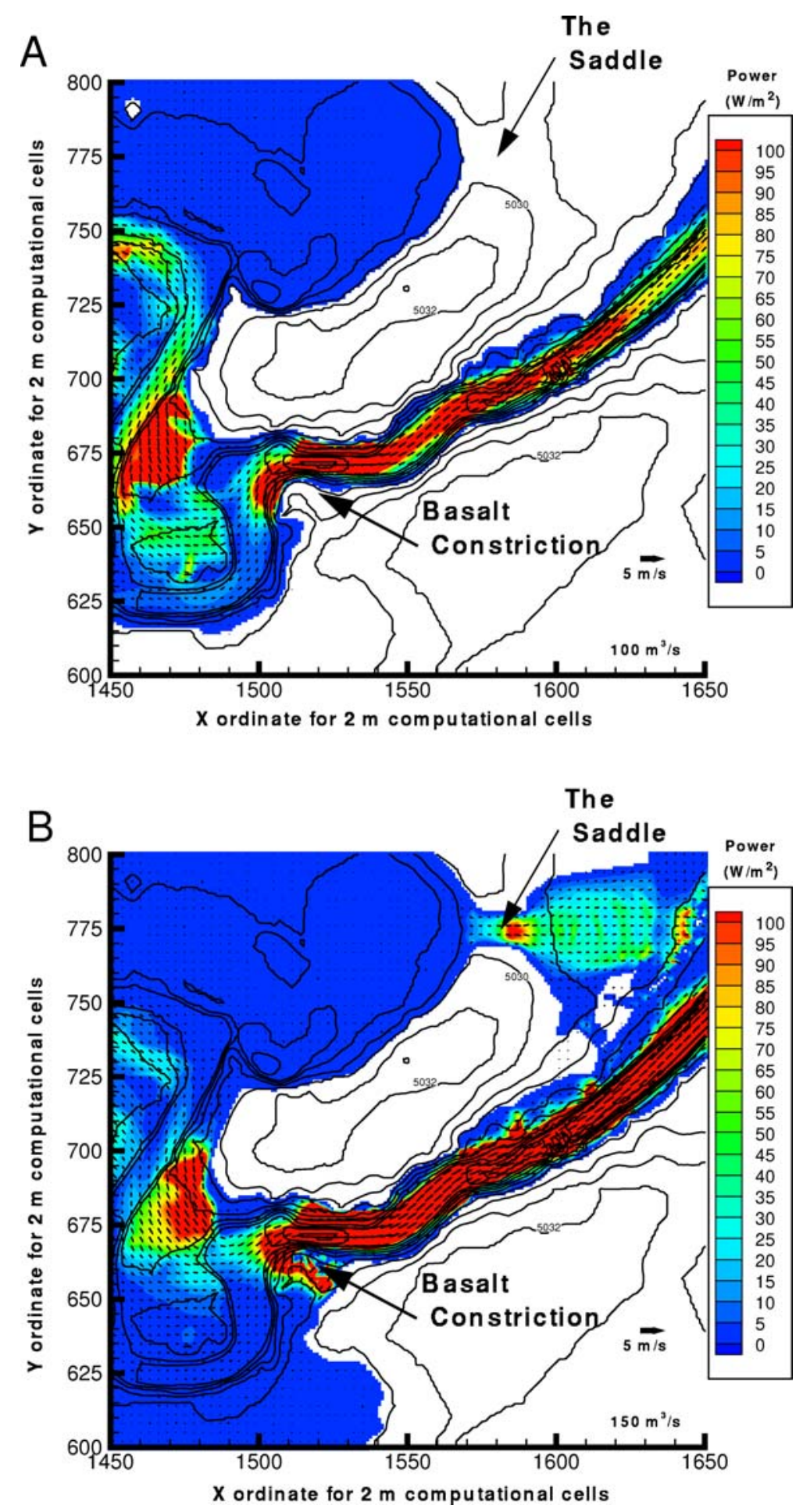

Figure 2-10 Model results for 100 and $150 \mathrm{~m}^{3} / \mathrm{s}$ from Ostenaa et al. $(1999,2002)$ near the Saddle. A) Inundation and unit stream power for $100 \mathrm{~m}^{3} / \mathrm{s}$; B) Inundation and unit stream power for 150 $\mathrm{m}^{3} / \mathrm{s}$. Flow is from left to right in both plots. 


\section{BLR7}

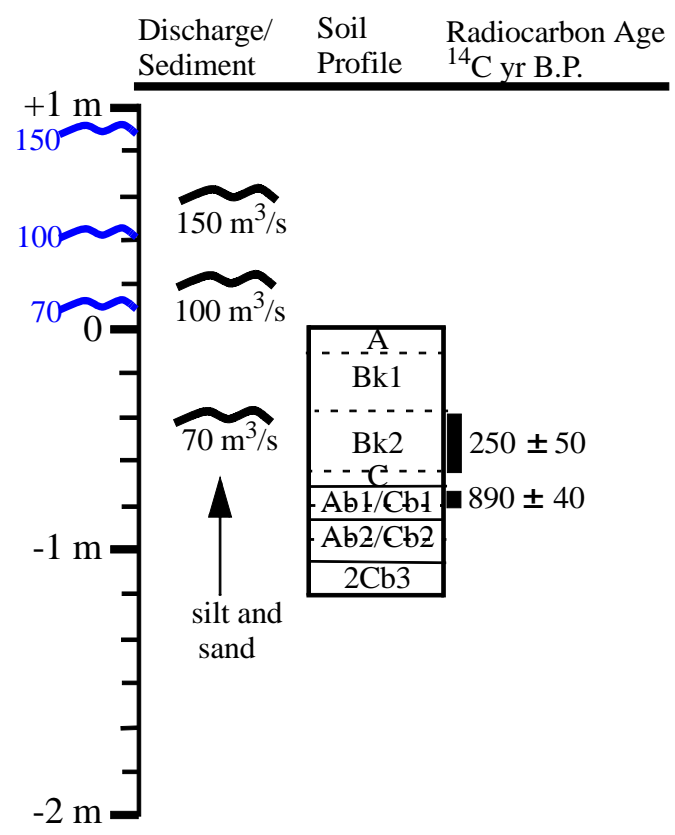

BLR6

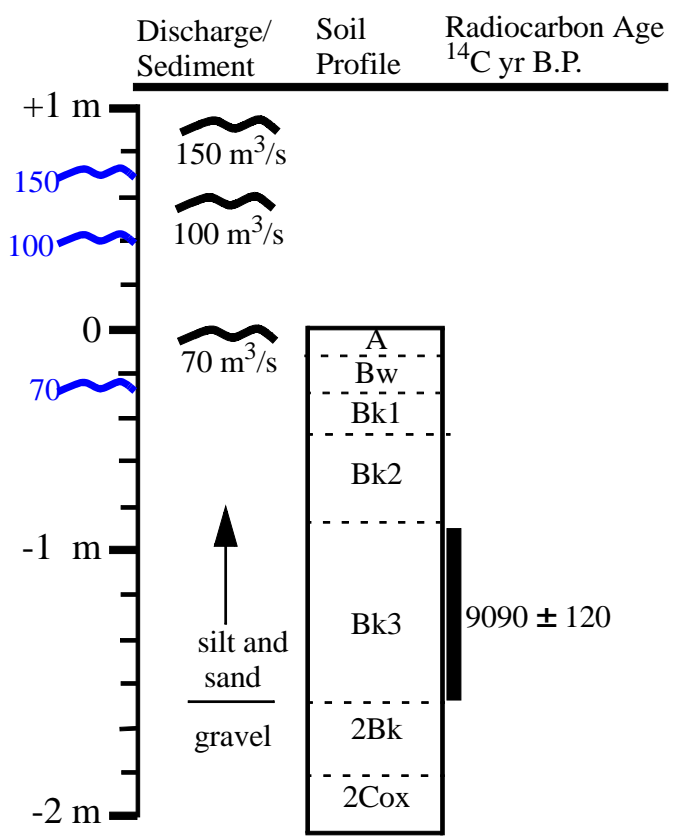

BLR2

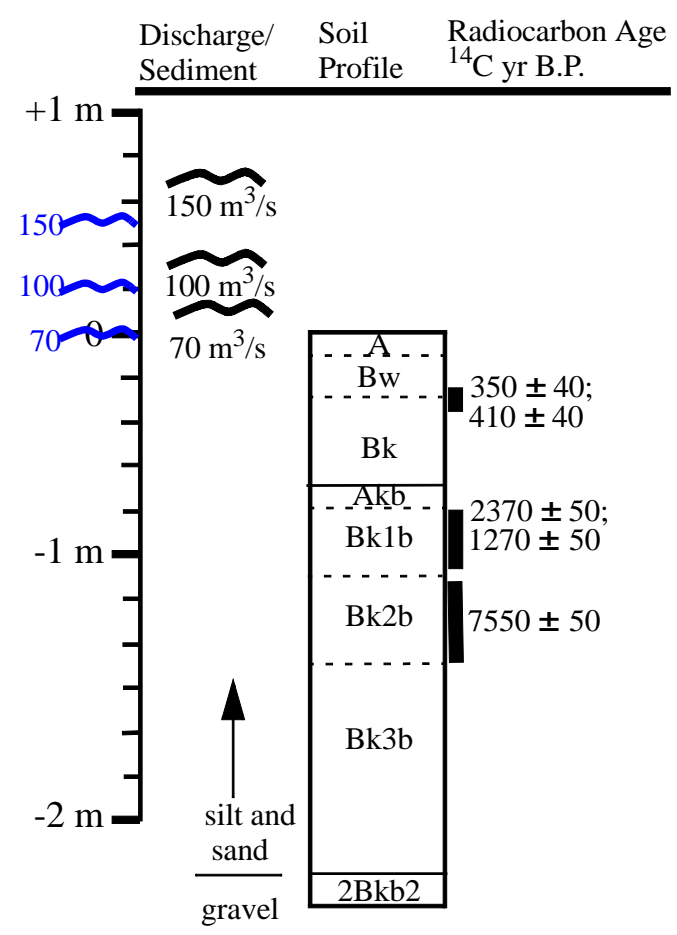

BLR8

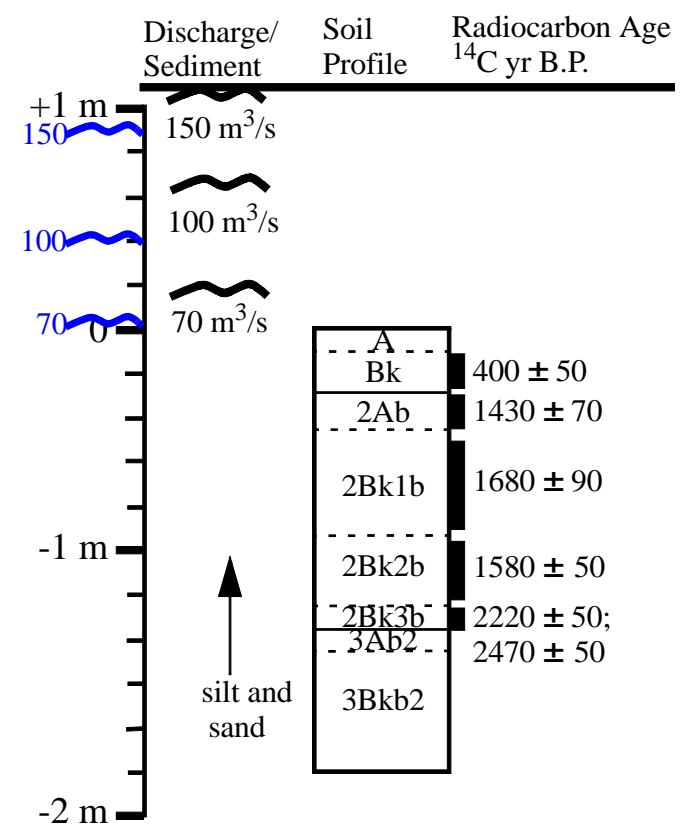

Figure 2-11 Figure 5 from Ostenaa et al. (2002) with revised stage estimates at BLR study sites. Wavy blue lines along axis show current study model results from 6 -ft grid for $n=0.038$. All other data from Ostenaa et al. (2002). Study site locations are shown on Plates 1 and 2. 



TRIMR2D FLOW MODEL $130 \mathrm{cms}$ ( $4590 \mathrm{cfs})$

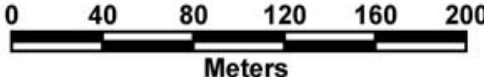

File: 6ftc_bigpal_130cms_n_p038_dt_5s.txt

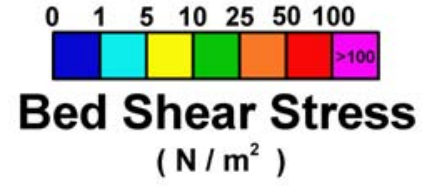

$\left(\mathrm{N} / \mathrm{m}^{2}\right)$

Figure 2-12 6-ft flow model results for $130 \mathrm{~m}^{3} / \mathrm{s}$ in the Big Loop study area. Base map symbology is from Figure 2-3 and Plate 2. 

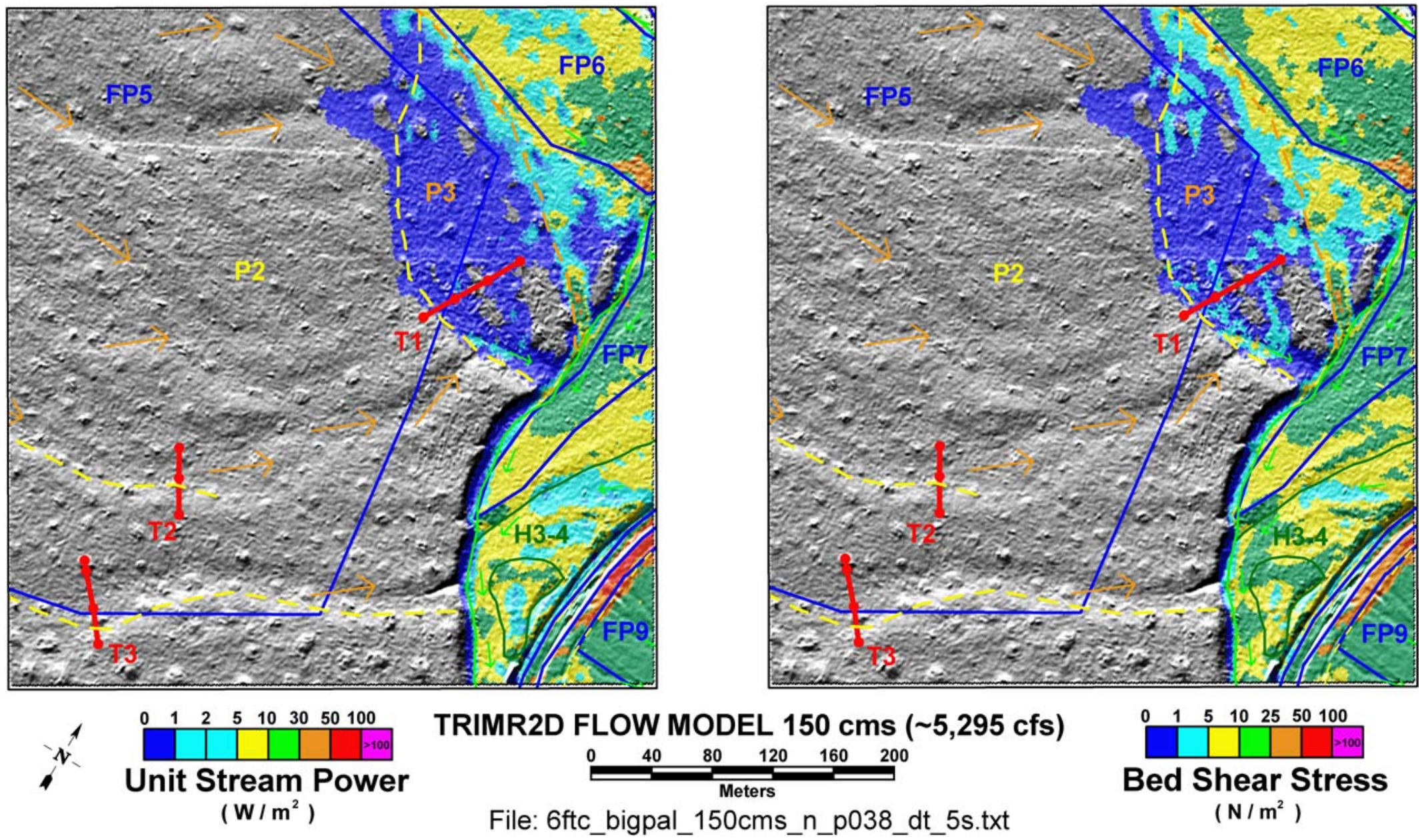

Figure 2-13 6-ft flow model results for $150 \mathrm{~m}^{3} / \mathrm{s}$ in the Big Loop study area. Base map symbology is from Figure 2-3 and Plate 2. 

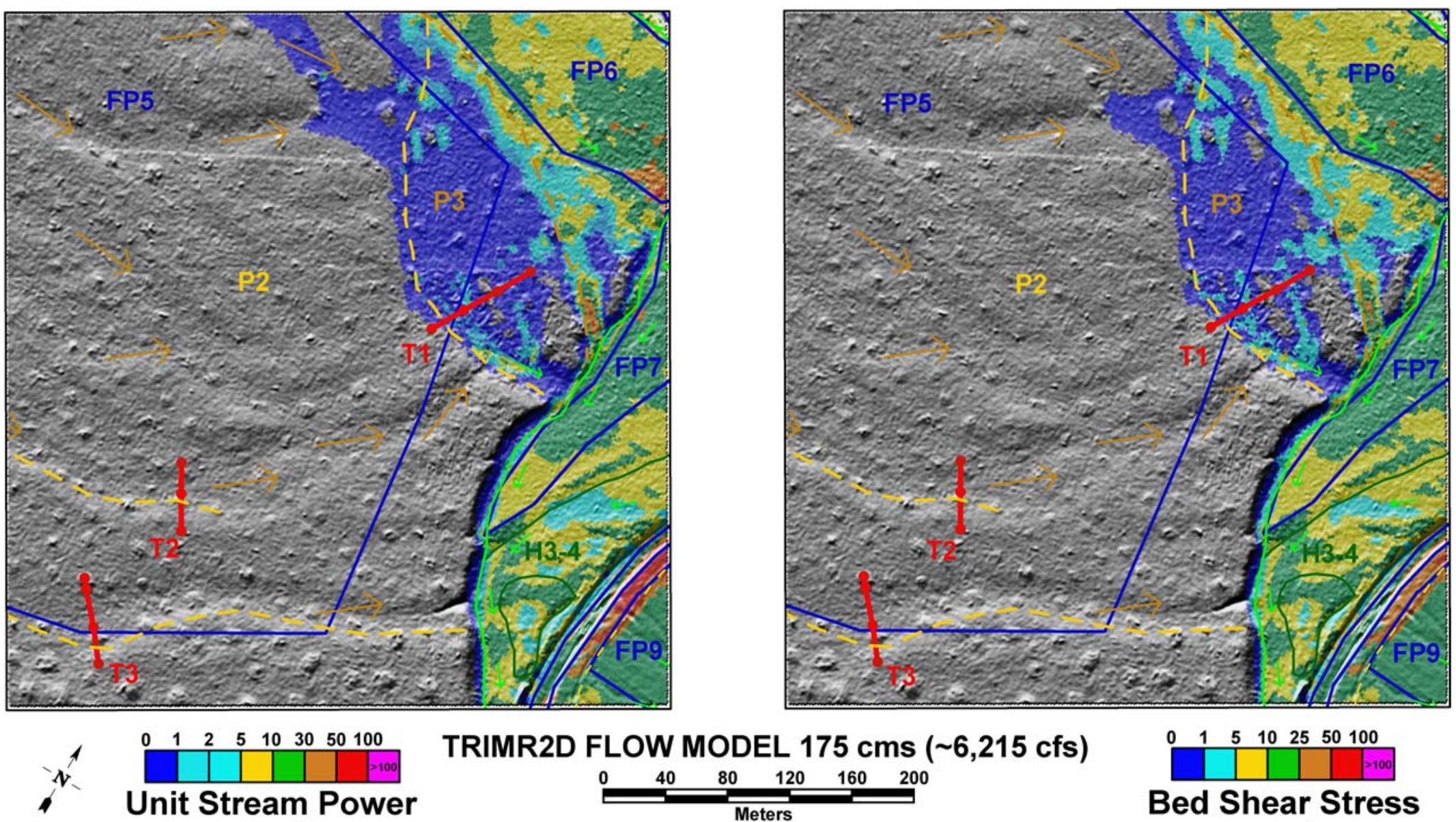
$\left(\mathrm{W} / \mathrm{m}^{2}\right)$

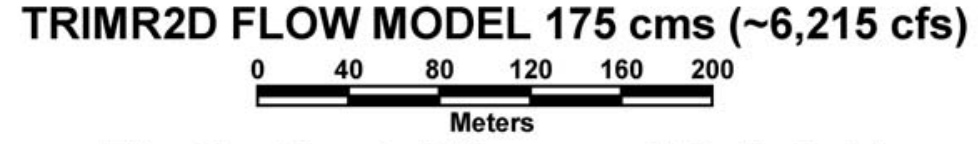

File: 6ftc_bigpal_175cms_n_p038_dt_5s.txt

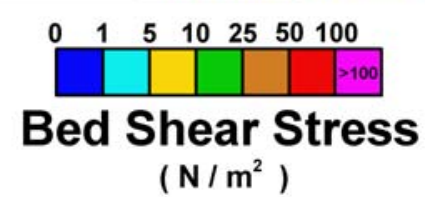

$\left(\mathrm{N} / \mathrm{m}^{2}\right)$

Figure 2-14 6-ft flow model results for $175 \mathrm{~m}^{3} / \mathrm{s}$ in the Big Loop study area. Base map symbology is from Figure 2-3 and Plate 2. 

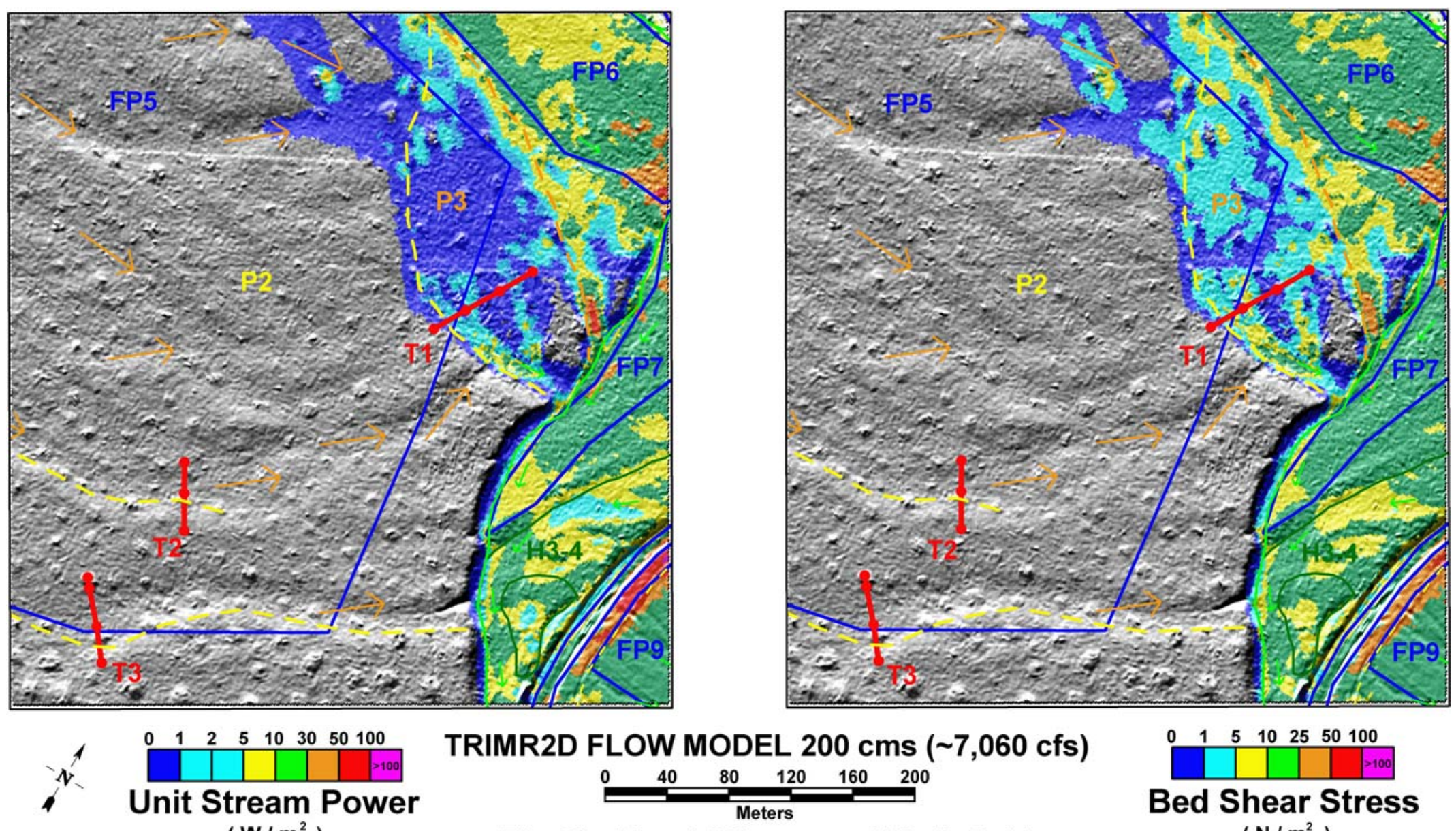

TRIMR2D FLOW MODEL $200 \mathrm{cms}(\sim 7,060 \mathrm{cfs})$

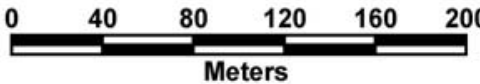

$\left(\mathrm{W} / \mathrm{m}^{2}\right)$

File: 6ftc_bigpal_200cms_n_p038_dt_5s.txt

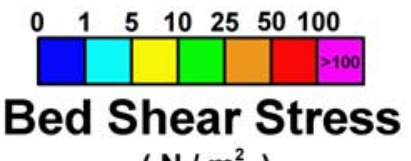

$\left(\mathrm{N} / \mathrm{m}^{2}\right)$

Figure 2-15 6-ft flow model results for $200 \mathrm{~m}^{3} / \mathrm{s}$ in the Big Loop study area. Base map symbology is from Figure 2-3 and Plate 2. 

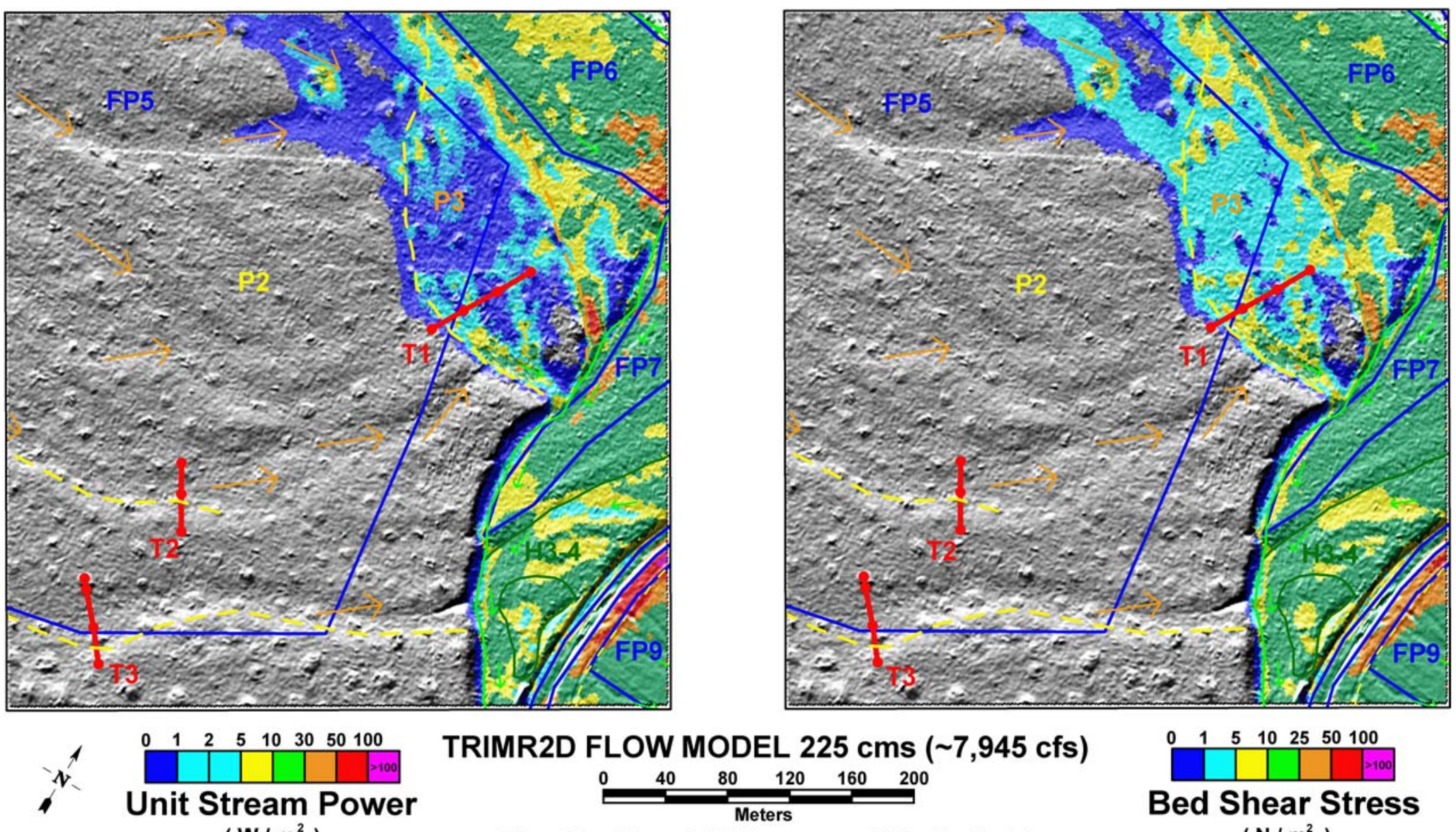

TRIMR2D FLOW MODEL $225 \mathrm{cms}(\sim 7,945 \mathrm{cfs})$

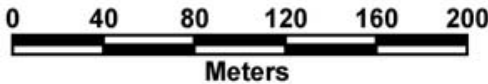

$\left(\mathrm{W} / \mathrm{m}^{2}\right)$

File: 6ftc_bigpal_225cms_n_p038_dt_5s.txt

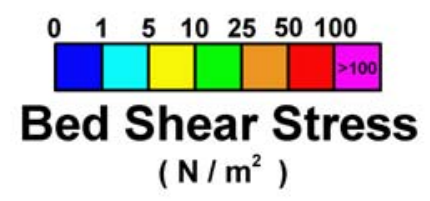

Figure 2-16 6-ft flow model results for $225 \mathrm{~m}^{3} / \mathrm{s}$ in the Big Loop study area. Base map symbology is from Figure 2-3 and Plate 2. 

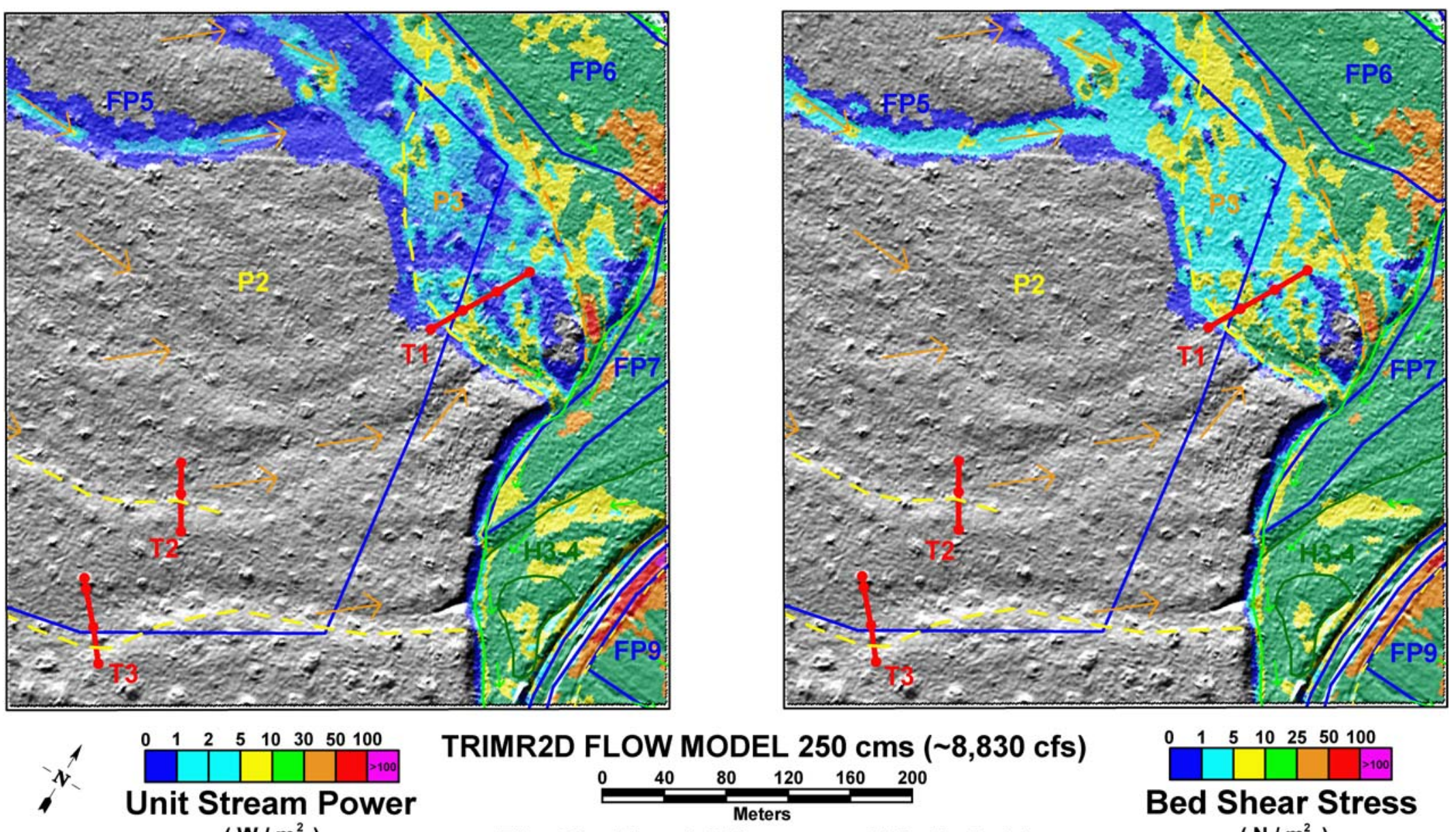

TRIMR2D FLOW MODEL $250 \mathrm{cms}(\sim 8,830 \mathrm{cfs})$

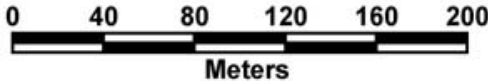

$\left(\mathrm{W} / \mathrm{m}^{2}\right)$

File: 6ftc_bigpal_250cms_n_p038_dt_5s.txt

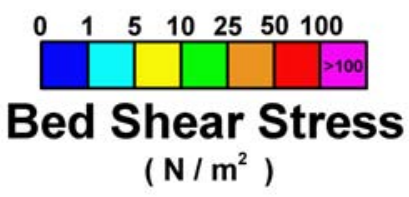

Figure 2-17 6-ft flow model results for $250 \mathbf{~ m}^{3} / \mathrm{s}$ in the Big Loop study area. Base map symbology is from Figure 2-3 and Plate 2. 

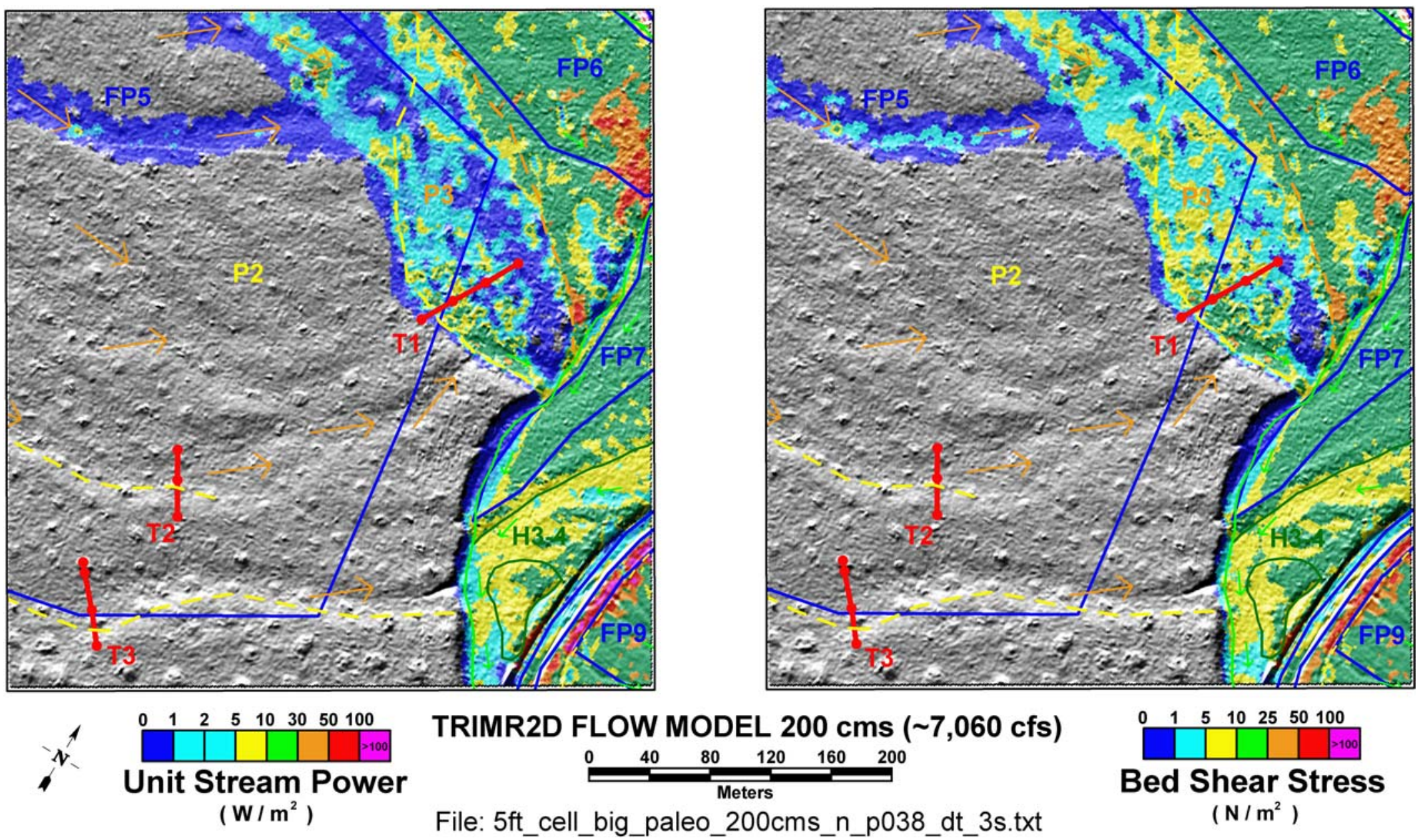

Figure 2-18 5-ft flow model results for $200 \mathrm{~m}^{3} / \mathrm{s}$ in the Big Loop study area. Base map symbology is from Figure 2-3 and Plate 2. 

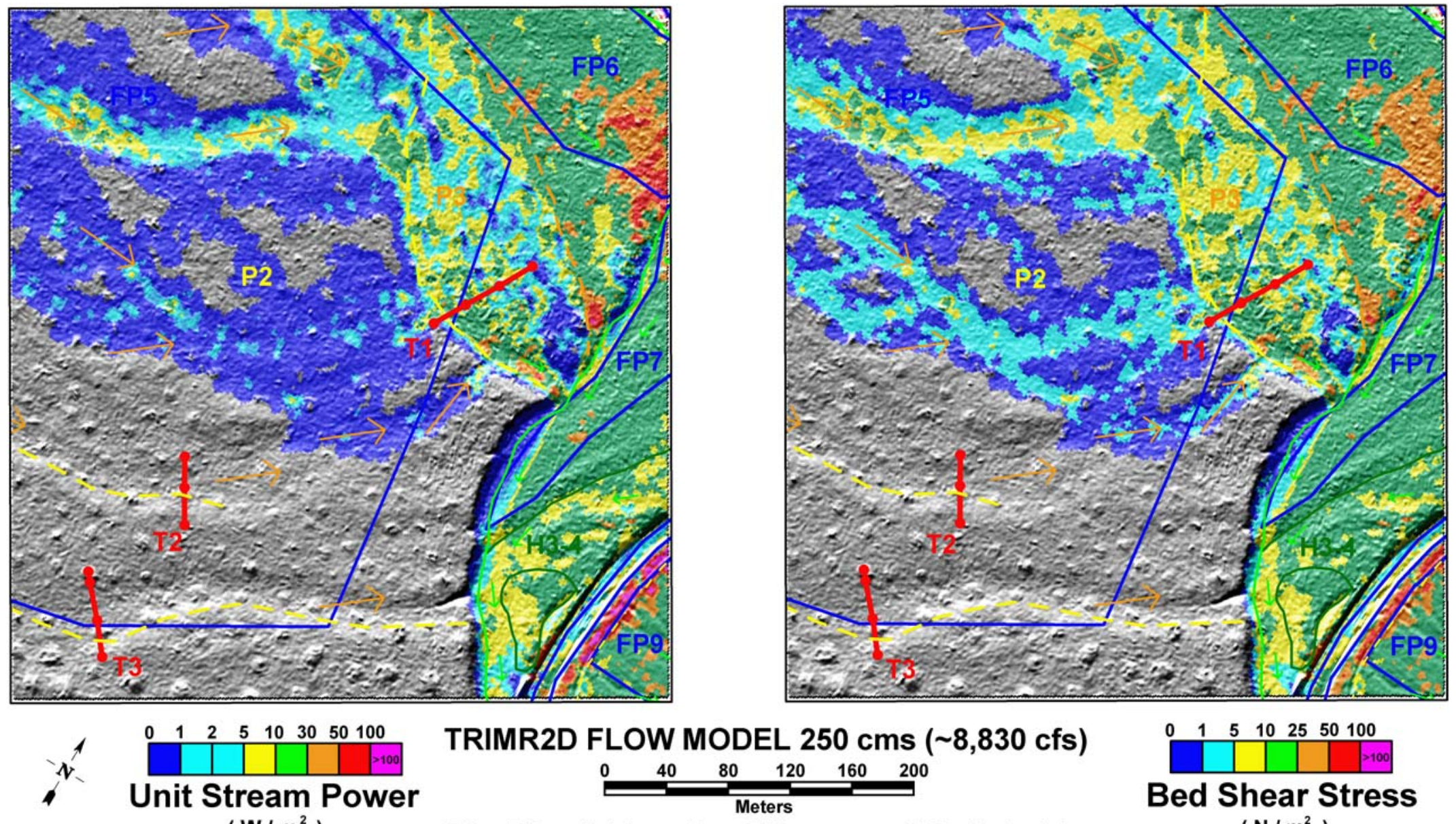

TRIMR2D FLOW MODEL $250 \mathrm{cms}(\sim 8,830 \mathrm{cfs})$

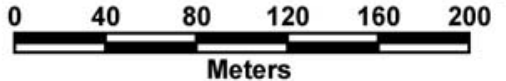

$\left(\mathrm{W} / \mathrm{m}^{2}\right)$

File: $5 \mathrm{ft}$ _cell_big_paleo_250cms_n_p038_dt_3s.txt

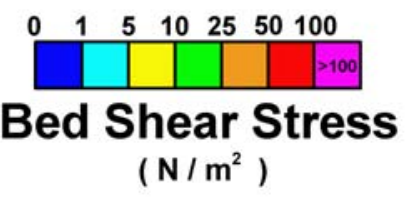

Figure 2-19 5-ft flow model results for $250 \mathrm{~m}^{3} / \mathrm{s}$ in the Big Loop study area. Base map symbology is from Figure 2-3 and Plate 2. 

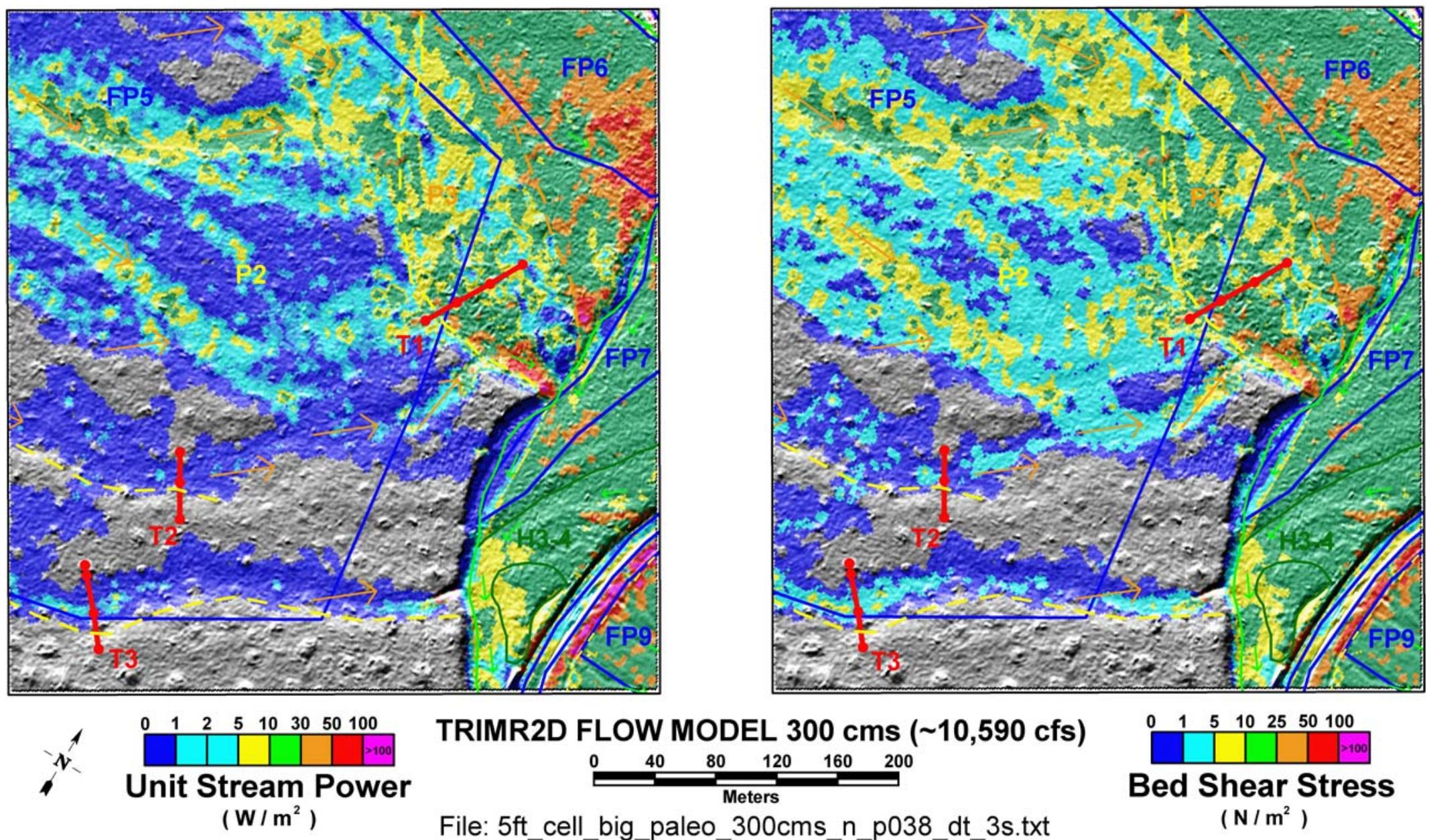

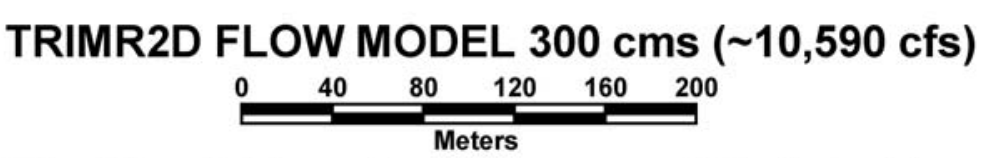

File: 5ft_cell_big_paleo_300cms_n_p038_dt_3s.txt

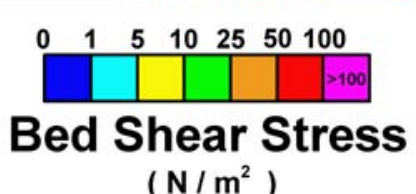

$\left(\mathrm{N} / \mathrm{m}^{2}\right)$

Figure 2-20 5-ft flow model results for $300 \mathrm{~m}^{3} / \mathrm{s}$ in the Big Loop study area. Base map symbology is from Figure 2-3 and Plate 2. 

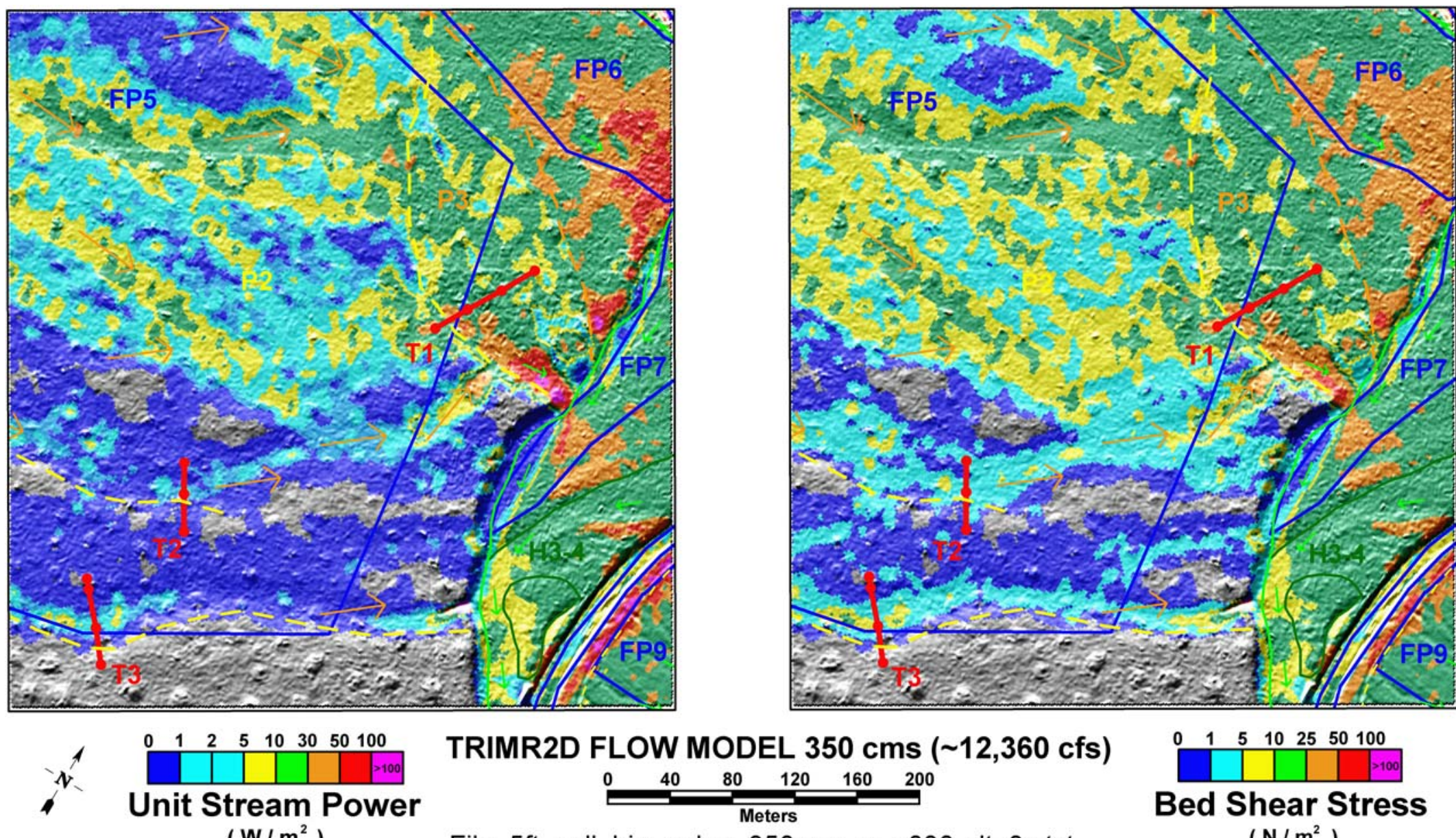

File: $5 \mathrm{ft}$ _cell_big_paleo_350cms_n_p038_dt_3s.txt

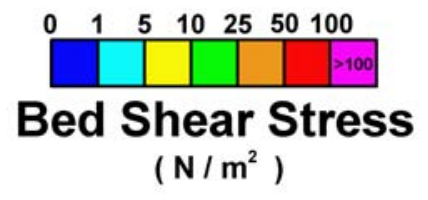

Figure 2-21 5-ft flow model results for $350 \mathrm{~m}^{3} / \mathrm{s}$ in the Big Loop study area. Base map symbology is from Figure 2-3 and Plate 2.

81 

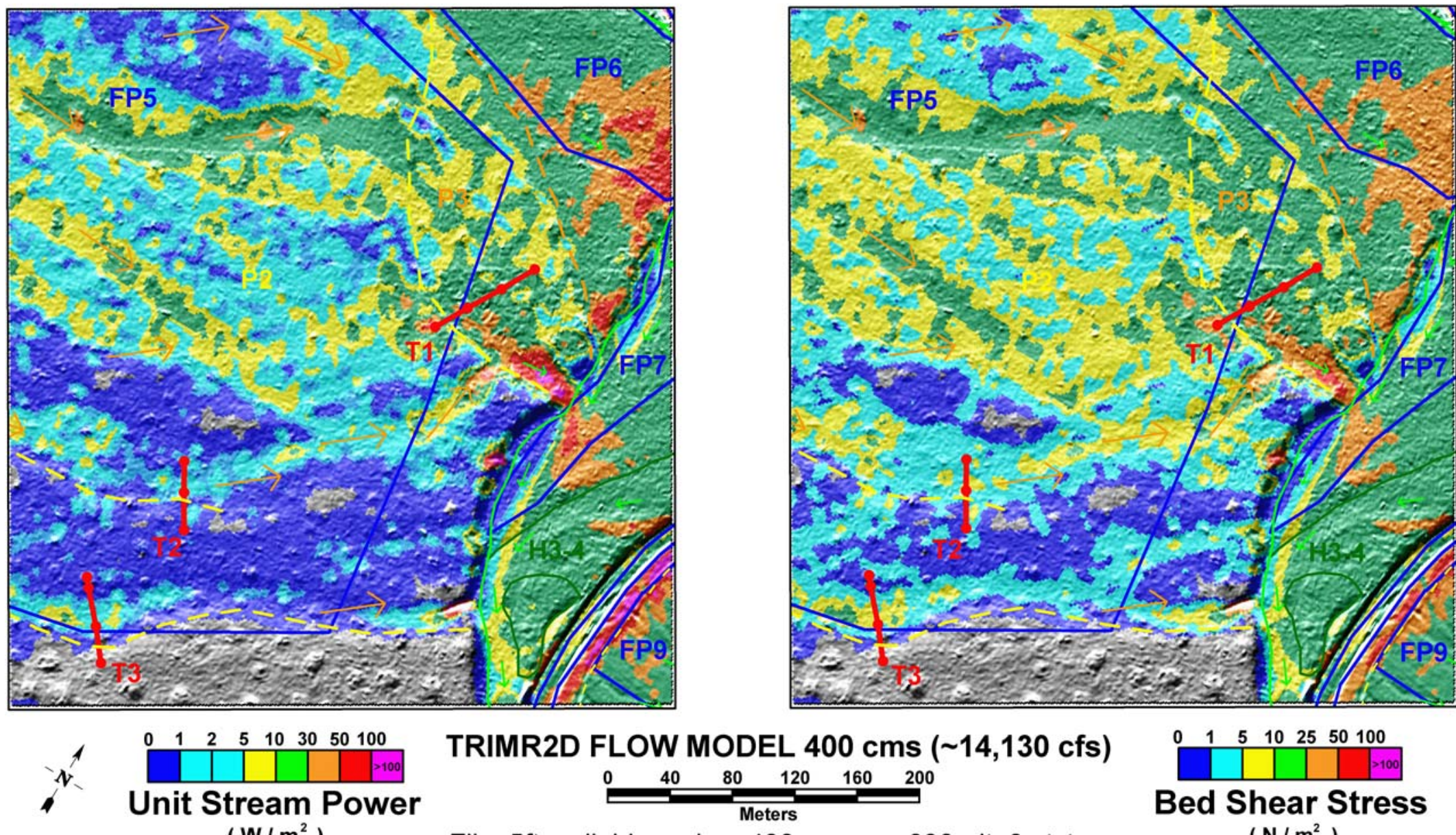

File: $5 \mathrm{ft}$ _cell_big_paleo_400cms_n_p038_dt_3s.txt

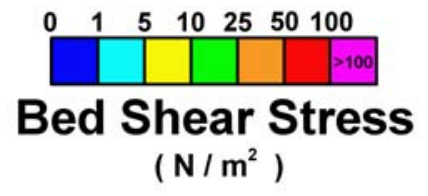

Figure 2-22 5-ft flow model results for $\mathbf{4 0 0} \mathrm{m}^{3} / \mathrm{s}$ in the Big Loop study area. Base map symbology is from Figure 2-3 and Plate 2. 

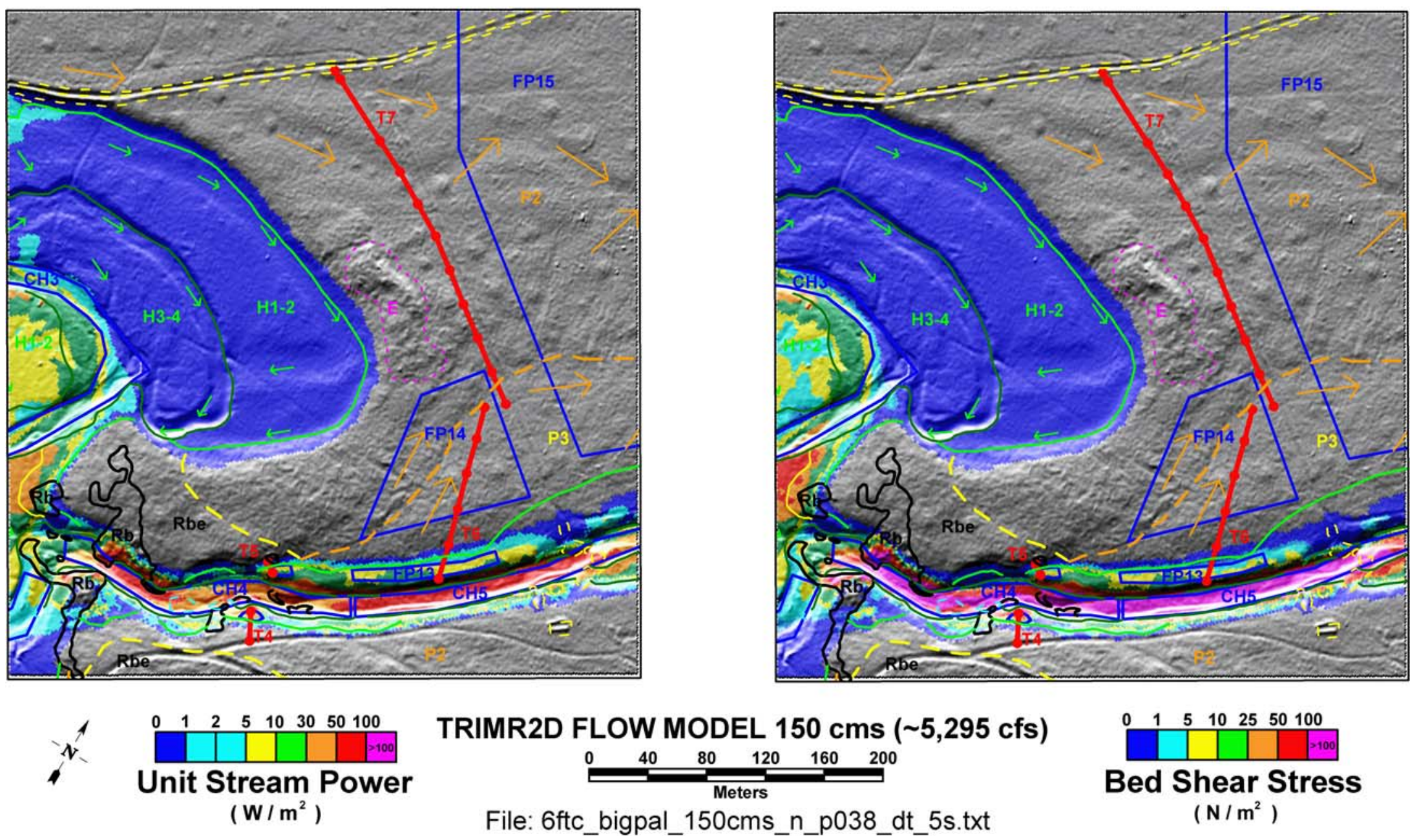

Figure 2-23 6-ft flow model results for $150 \mathrm{~m}^{3} / \mathrm{s}$ in the Saddle constriction study area. Base map symbology is from Figure 2-3 and Plate 2. 



TRIMR2D FLOW MODEL $200 \mathrm{cms}(\sim 7,060 \mathrm{cfs})$

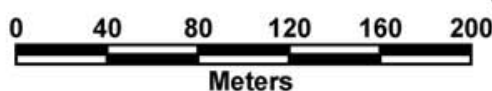

File: 6ftc_bigpal_200cms_n_p038_dt_5s.txt

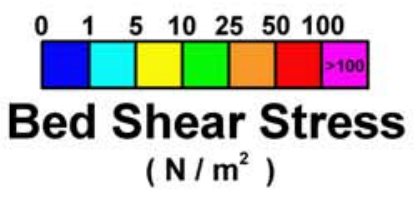

Figure 2-24 6-ft flow model results for $200 \mathrm{~m}^{3} / \mathrm{s}$ in the Saddle constriction study area. Base map symbology is from Figure 2-3 and Plate 2. 

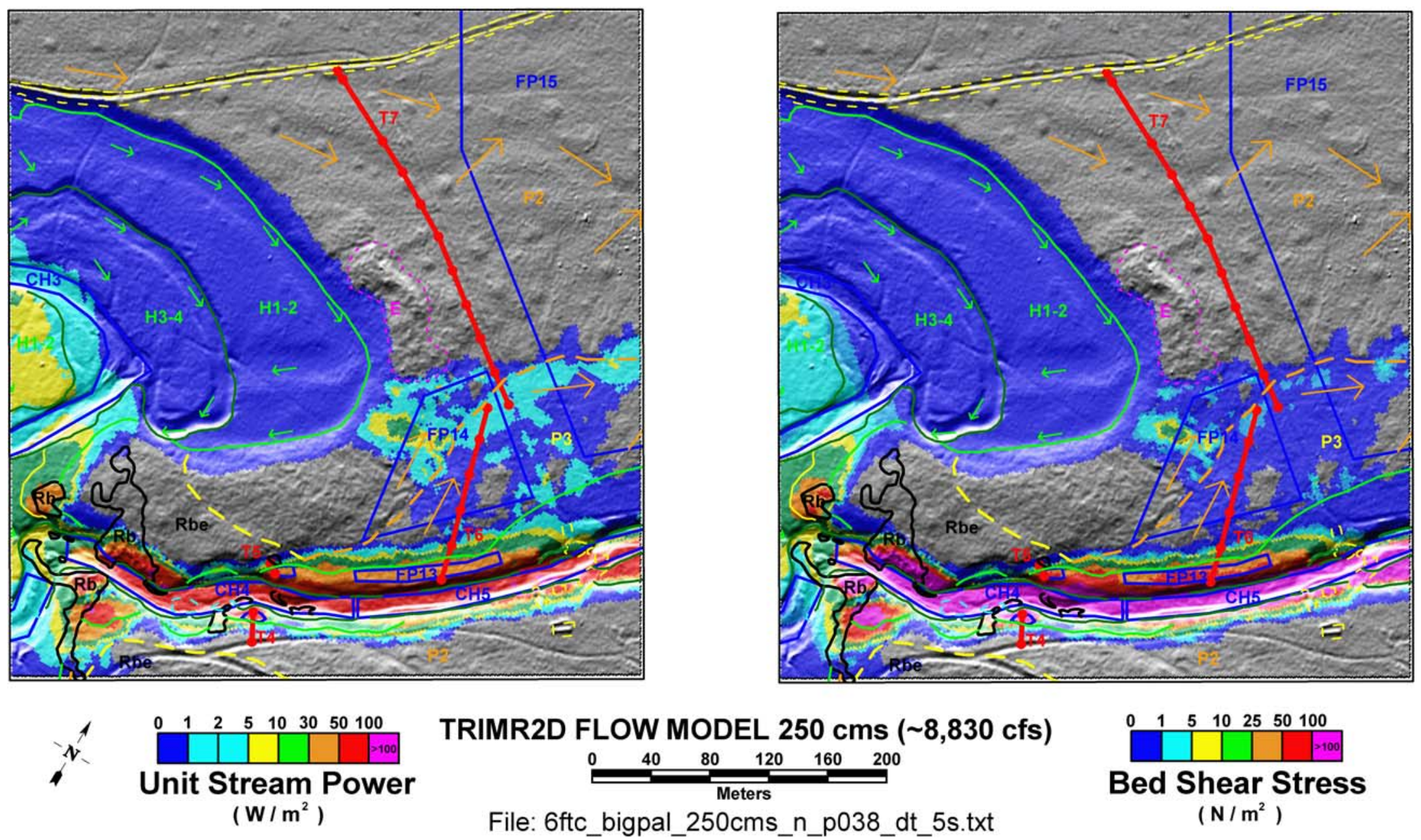

Figure 2-25 6-ft flow model results for $250 \mathrm{~m}^{3} / \mathrm{s}$ in the Saddle constriction study area. Base map symbology is from Figure 2-3 and Plate 2. 

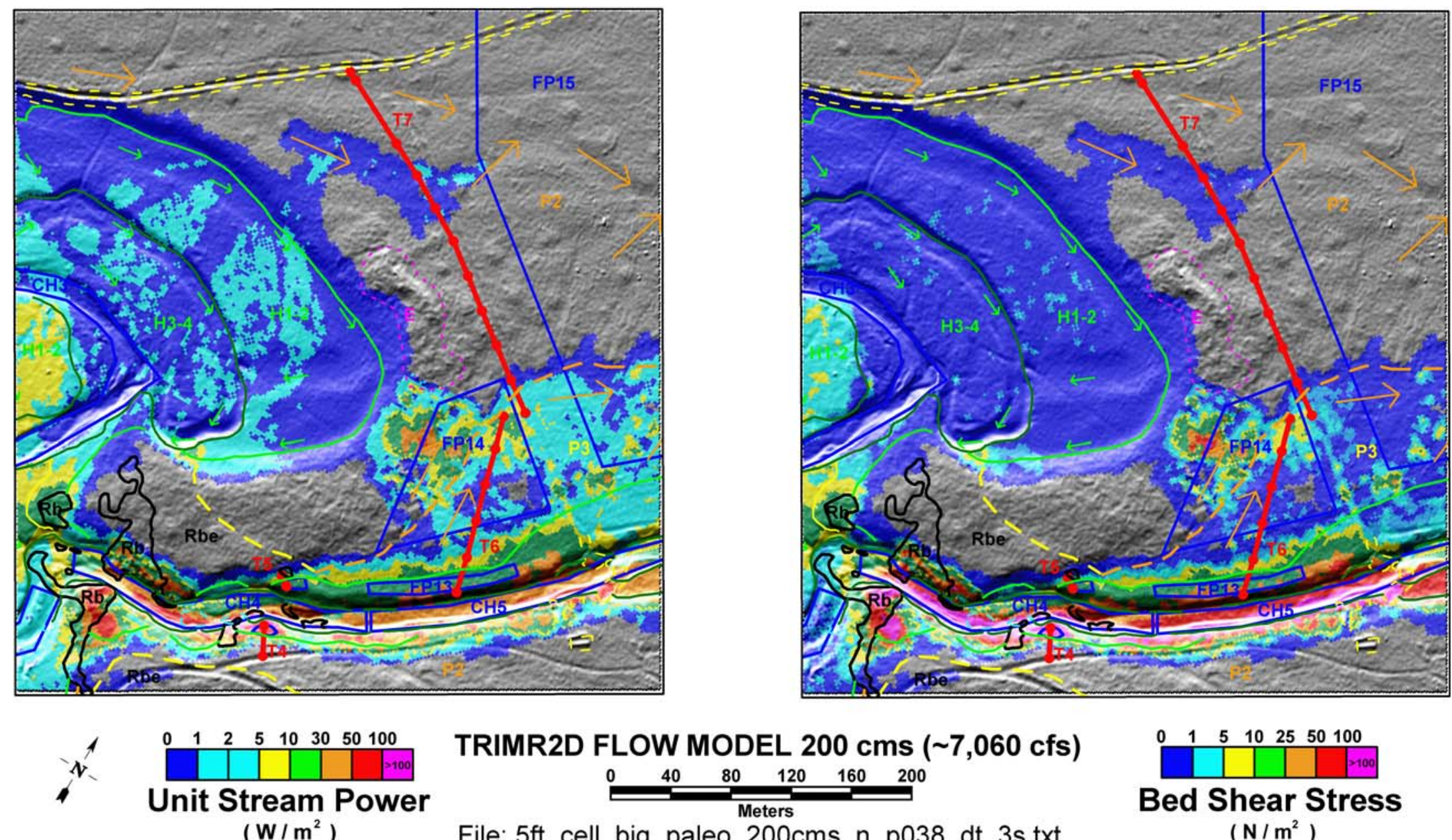

TRIMR2D FLOW MODEL $200 \mathrm{cms} \mathrm{(} \mathrm{7,060} \mathrm{cfs)}$

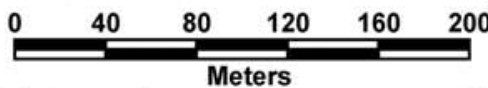

File: 5ft_cell_big_paleo_200cms_n_p038_dt_3s.txt

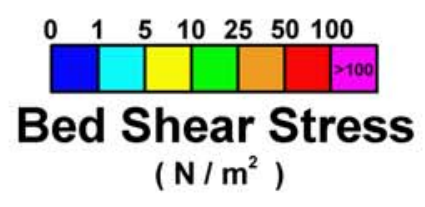

Figure 2-26 5-ft flow model results for $200 \mathrm{~m}^{3} / \mathrm{s}$ in the Saddle constriction study area. Base map symbology is from Figure 2-3 and Plate 2. 

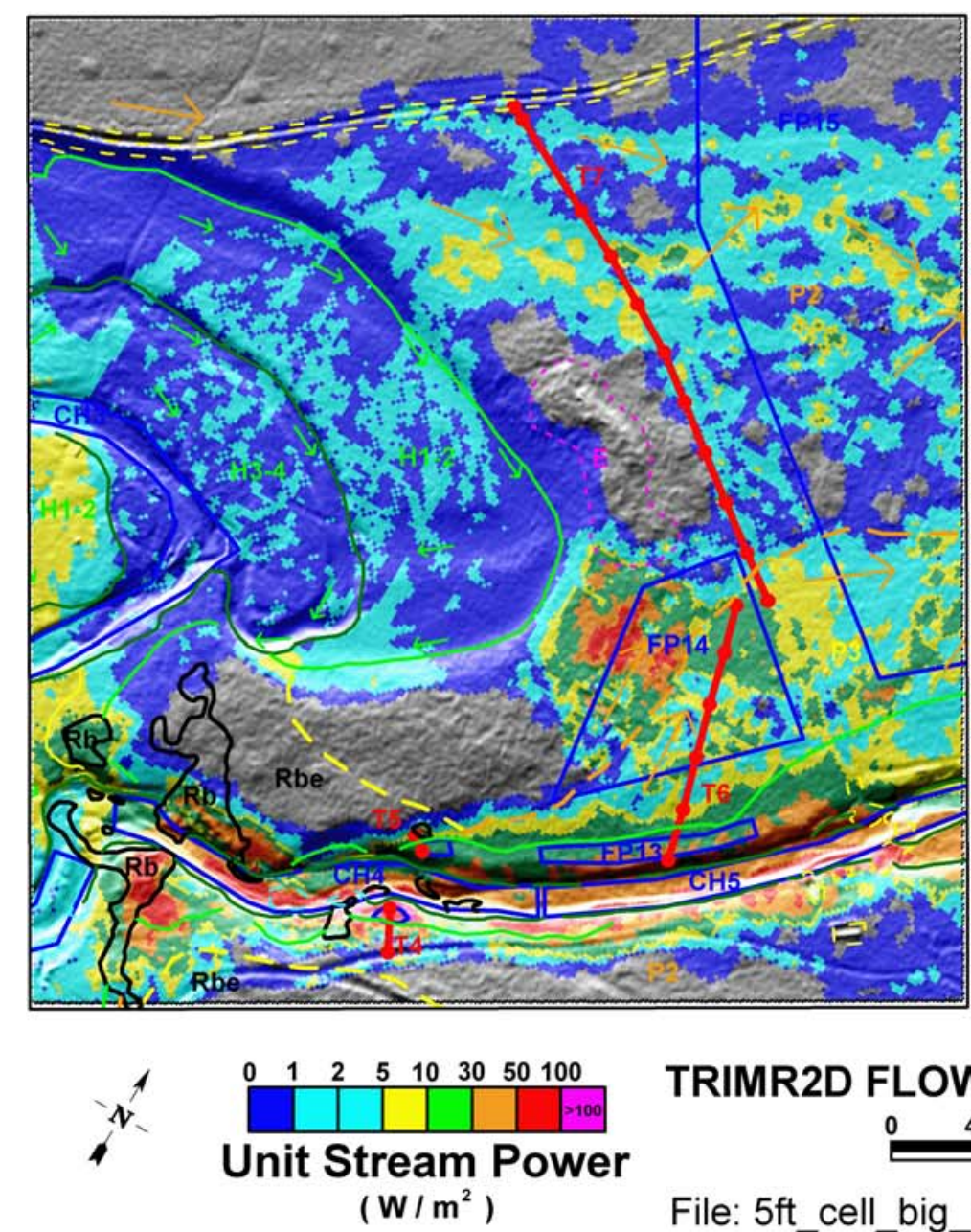

TRIMR2D FLOW MODEL $250 \mathrm{cms}(\sim 8,830 \mathrm{cfs})$ $\stackrel{40 \quad 80 \quad 120 \quad 160 \quad 200}{=}$

File: $5 \mathrm{ft} \_c e l l$ big_paleo_250cms_n_p038_dt_3s.txt
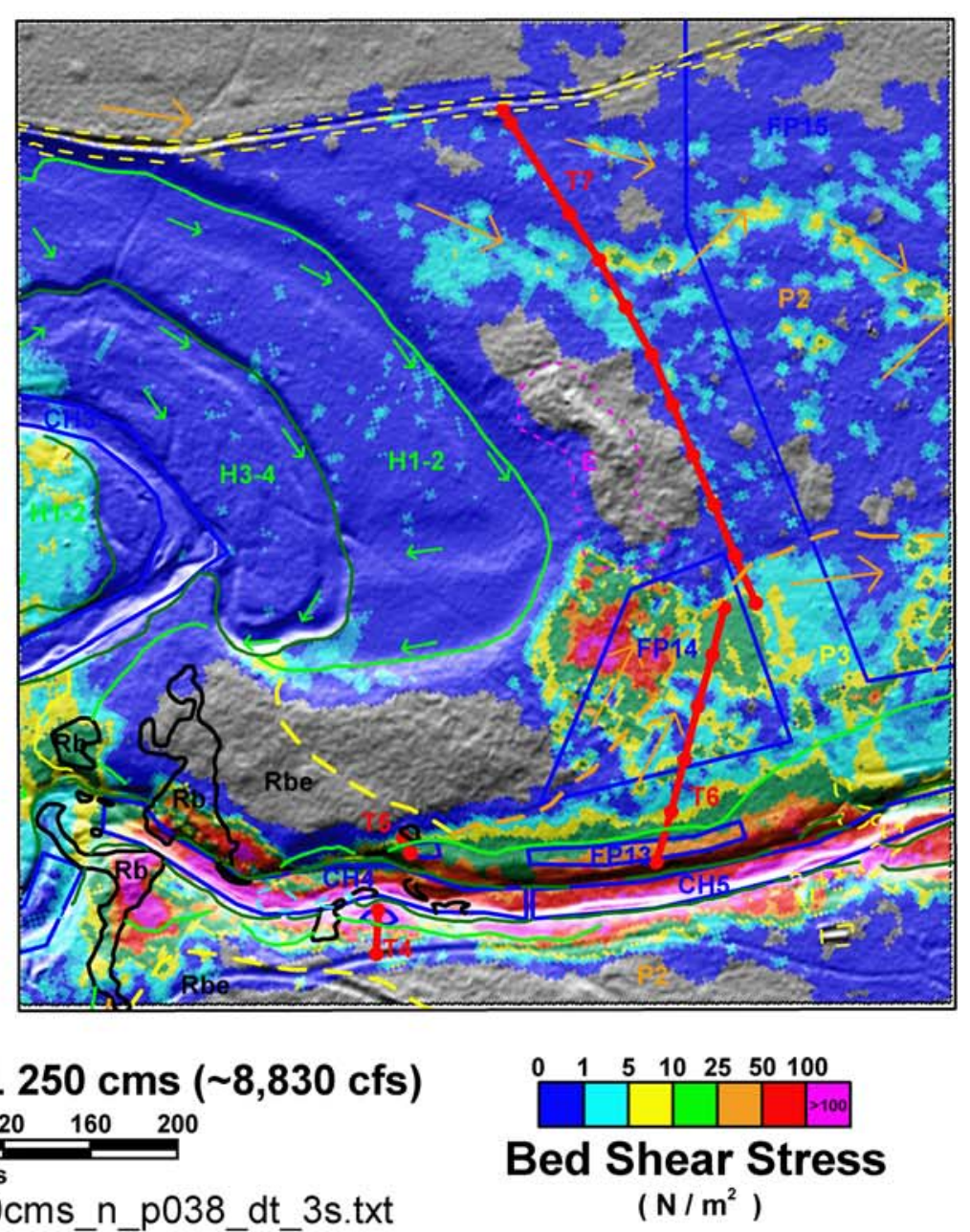

Figure 2-27 5-ft flow model results for $250 \mathrm{~m}^{3} / \mathrm{s}$ in the Saddle constriction study area. Base map symbology is from Figure 2-3 and Plate 2. 

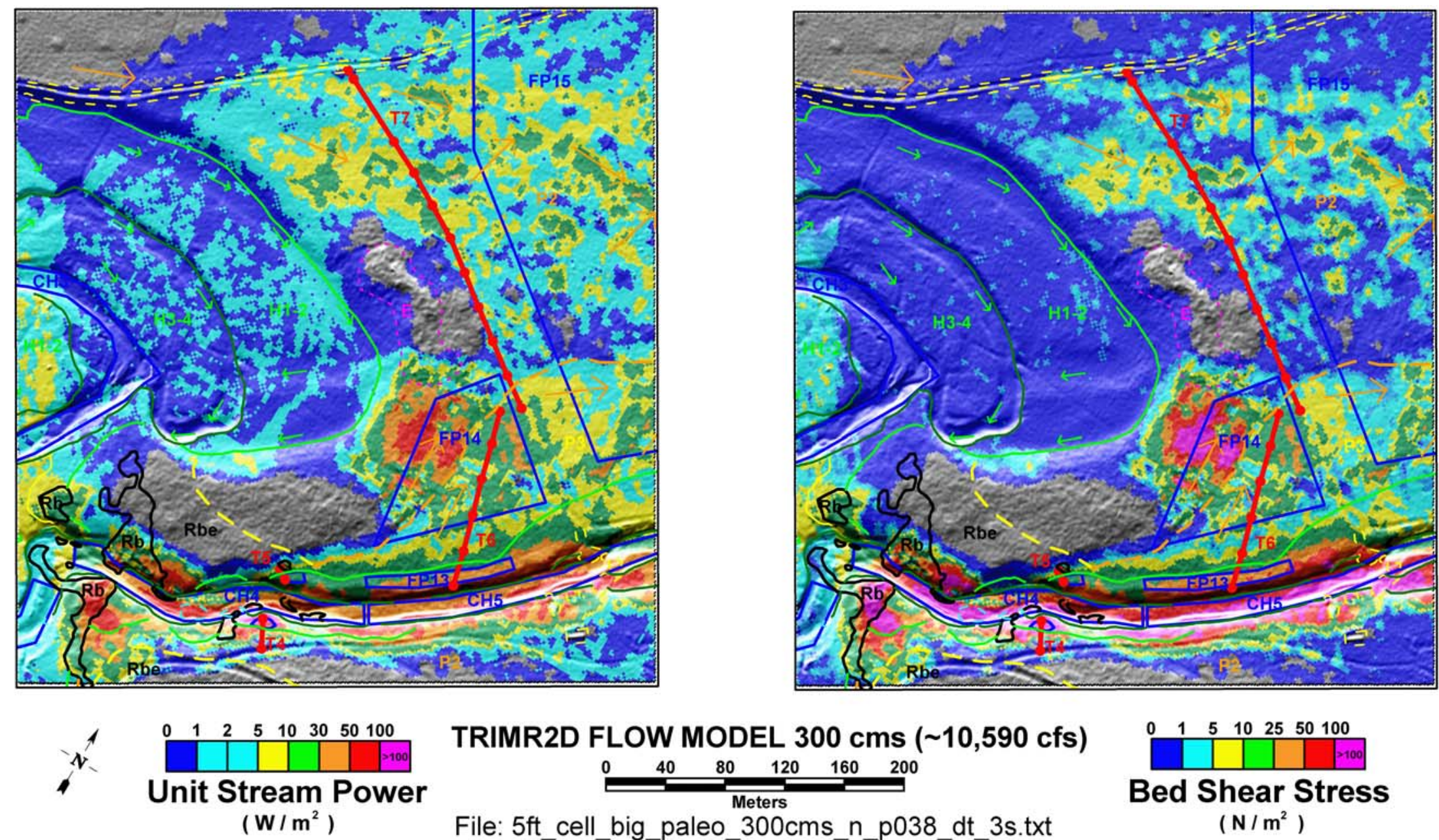

TRIMR2D FLOW MODEL $300 \mathrm{cms}(\sim 10,590 \mathrm{cfs})$ $\begin{array}{llllll}0 \quad 40 \quad 80 & 120 & 160 \quad 200\end{array}$

File: 5ft_cell_big_paleo_300cms_n_p038_dt_3s.txt

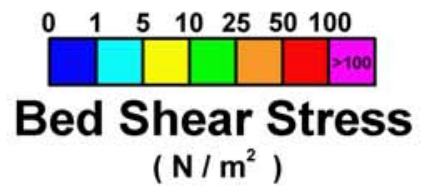

$\left(\mathrm{N} / \mathrm{m}^{2}\right)$

Figure 2-28 5-ft flow model results for $300 \mathrm{~m}^{3} / \mathrm{s}$ in the Saddle constriction study area. Base map symbology is from Figure 2-3 and Plate 2. 

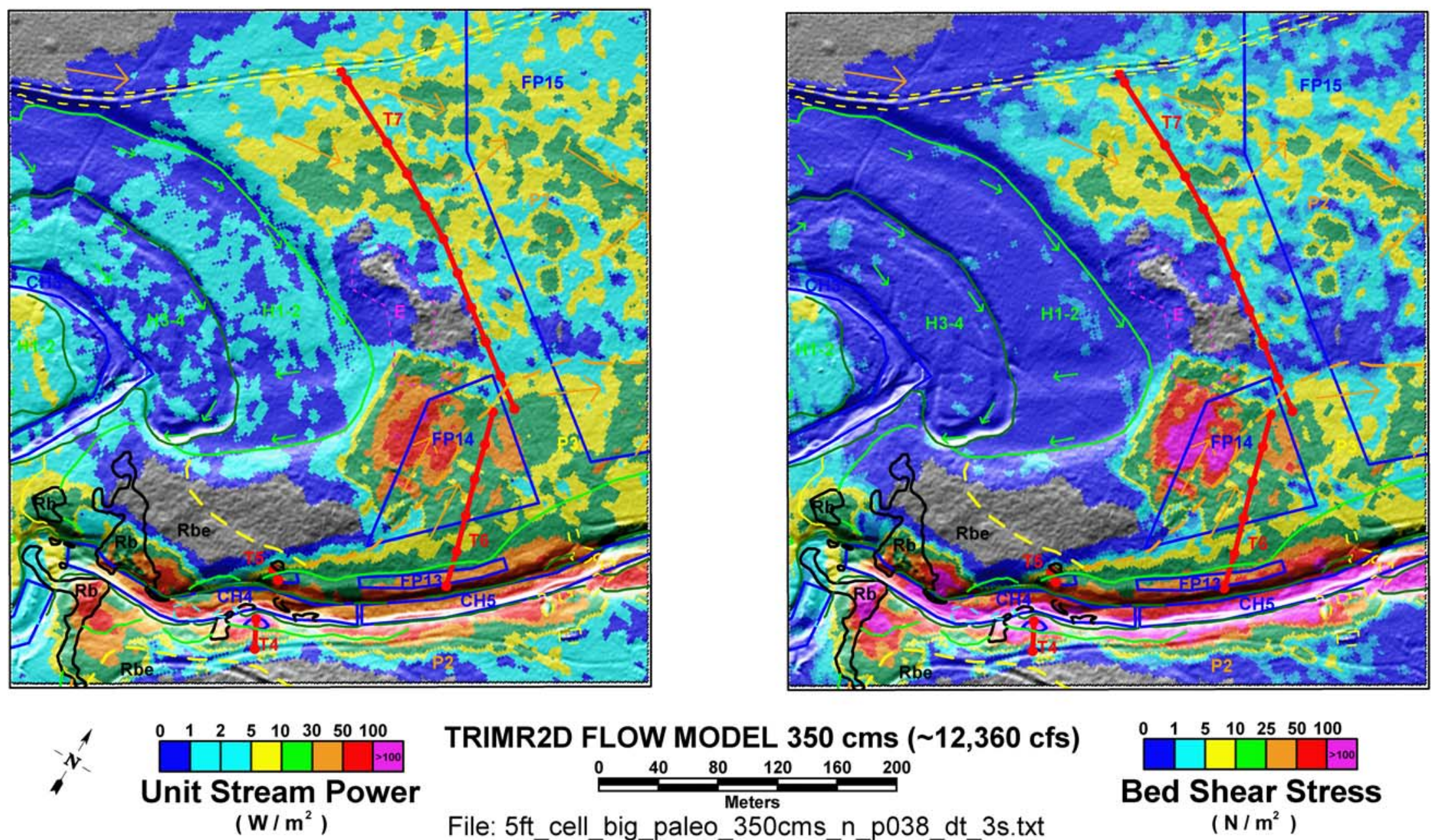

TRIMR2D FLOW MODEL $350 \mathrm{cms}(\sim 12,360 \mathrm{cfs})$

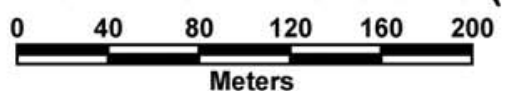

File: $5 \mathrm{ft}$ cell_big_paleo_350cms_n_p038_dt_3s.txt

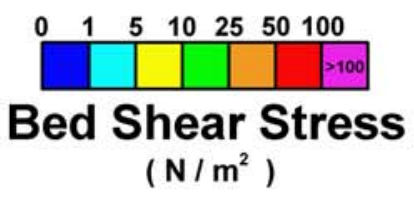

Figure 2-29 5-ft flow model results for $350 \mathrm{~m}^{3} / \mathrm{s}$ in the Saddle constriction study area. Base map symbology is from Figure 2-3 and Plate 2. 

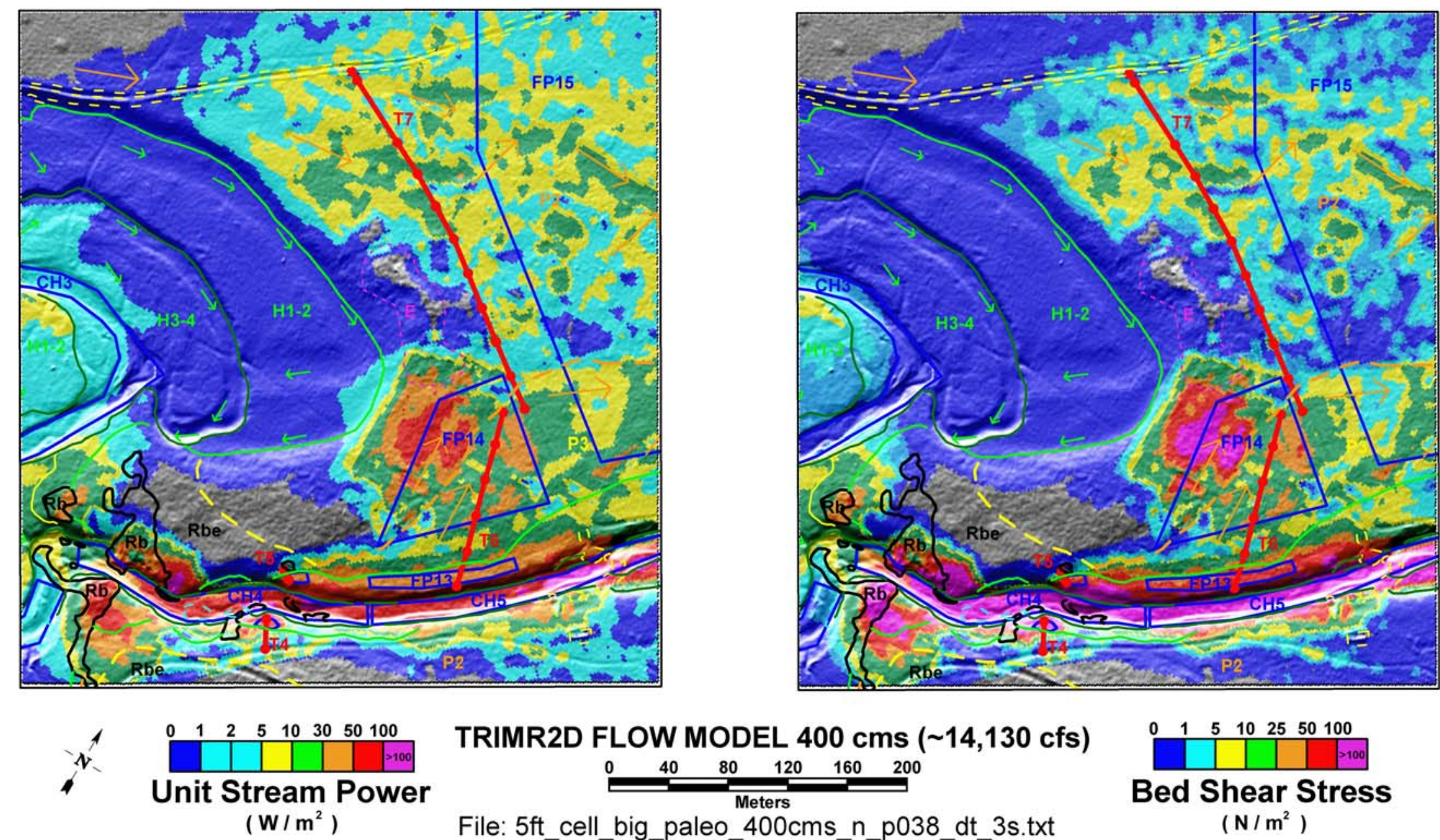

\section{TRIMR2D FLOW MODEL $400 \mathrm{cms}(\sim 14,130 \mathrm{cfs})$

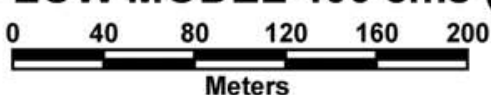

File: 5ft_cell_big_paleo_400cms_n_p038_dt_3s.txt

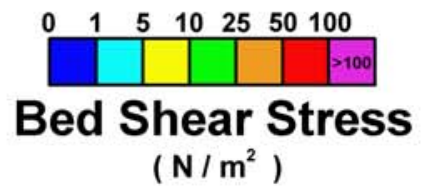

$\left(\mathrm{N} / \mathrm{m}^{2}\right)$

Figure 2-30 5-ft flow model results for $400 \mathrm{~m}^{3} / \mathrm{s}$ in the Saddle constriction study area. Base map symbology is from Figure 2-3 and Plate 2. 

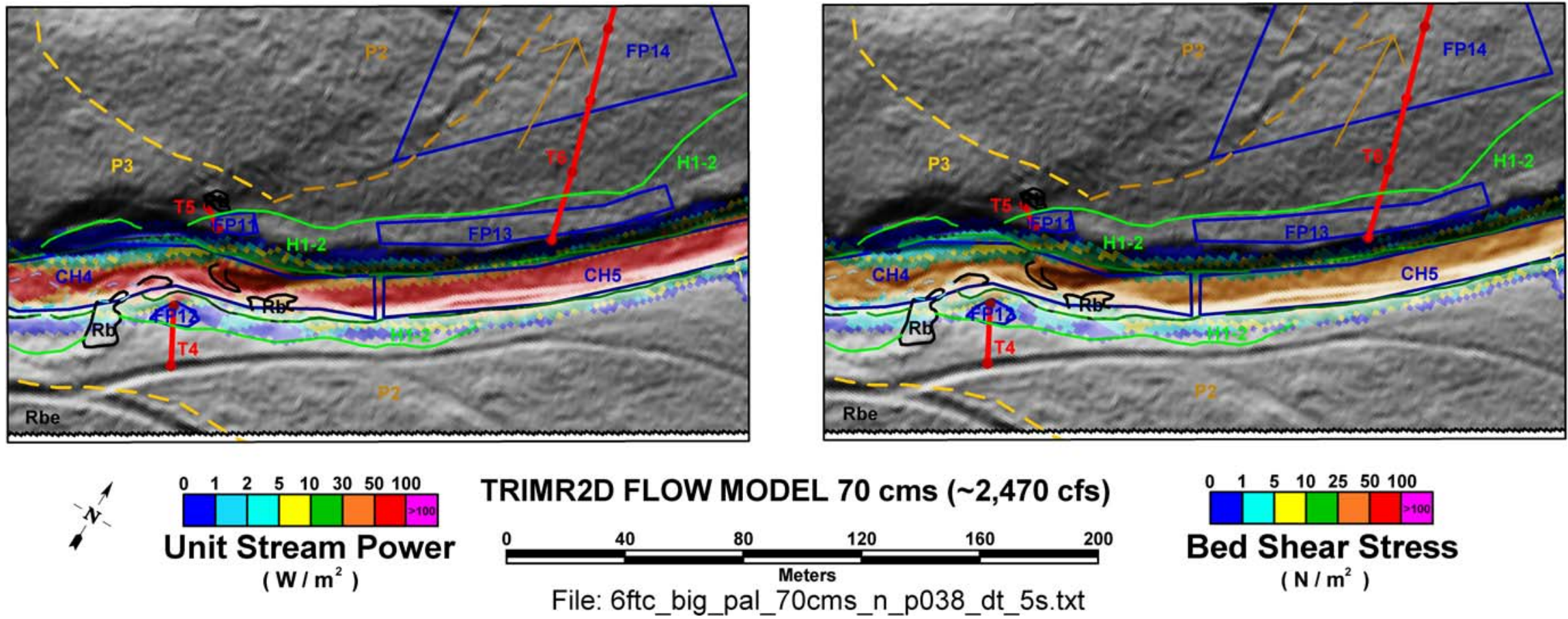

Figure 2-31 6-ft flow model results for $70 \mathrm{~m}^{3} / \mathrm{s}$ in the T4/T5/T6 study area. Base map symbology is from Figure 2-3 and Plate 2. 


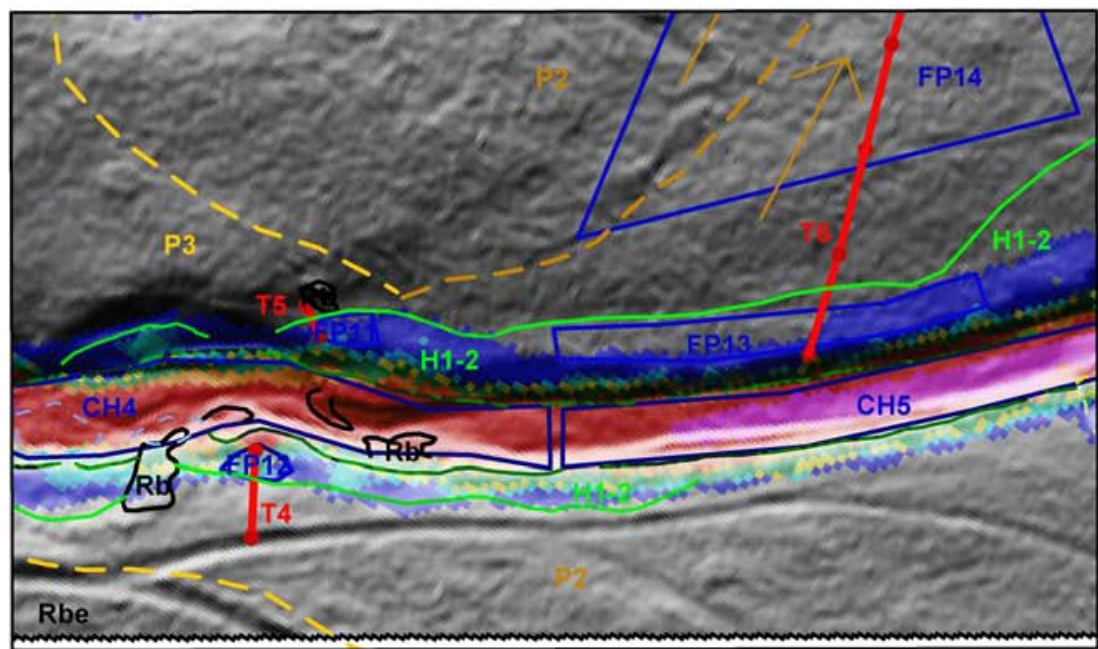

TRIMR2D FLOW MODEL $100 \mathrm{cms}$ ( 3,530 cfs)

\begin{tabular}{l|lll|l|l|l|l|}
0 & 1 & 2 & 5 & 10 & 30 & 50 & 100 \\
\hline & & & & & & & \\
Unit Stream Power
\end{tabular} $\left(\mathrm{W} / \mathrm{m}^{2}\right)$
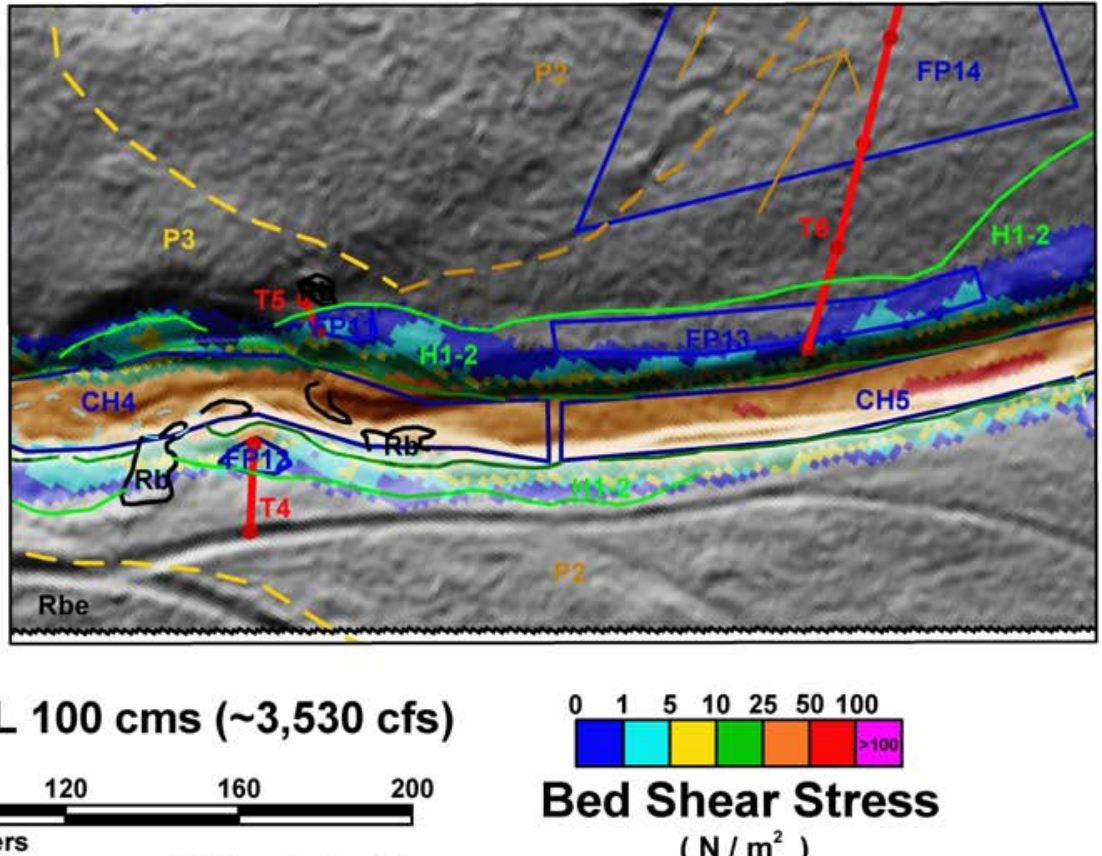

File: 6ftc_big_pal_100cms_n_p038_dt_5s.txt

Figure 2-32 6-ft flow model results for $100 \mathrm{~m}^{3} / \mathrm{s}$ in the T4/T5/T6 study area. Base map symbology is from Figure 2-3 and Plate 2. 

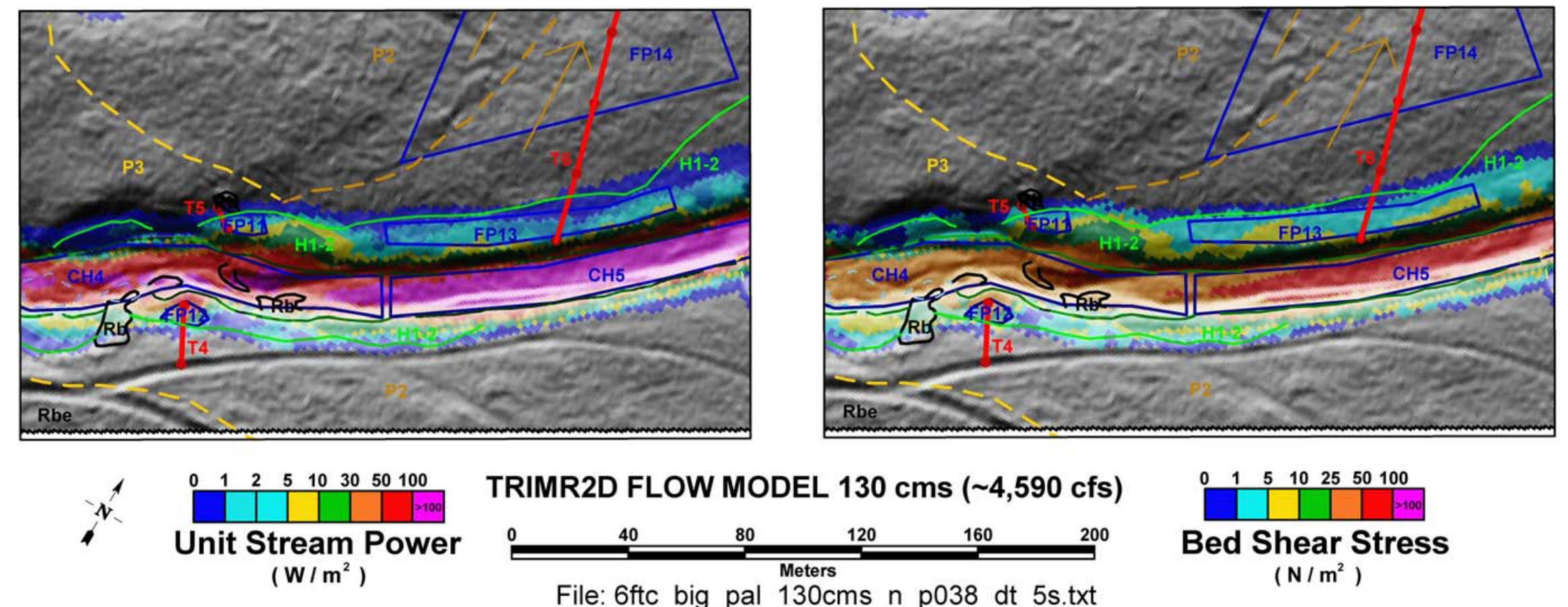

Figure 2-33 6-ft flow model results for $130 \mathrm{~m}^{3} / \mathrm{s}$ in the T4/T5/T6 study area. Base map symbology is from Figure 2-3 and Plate 2. 

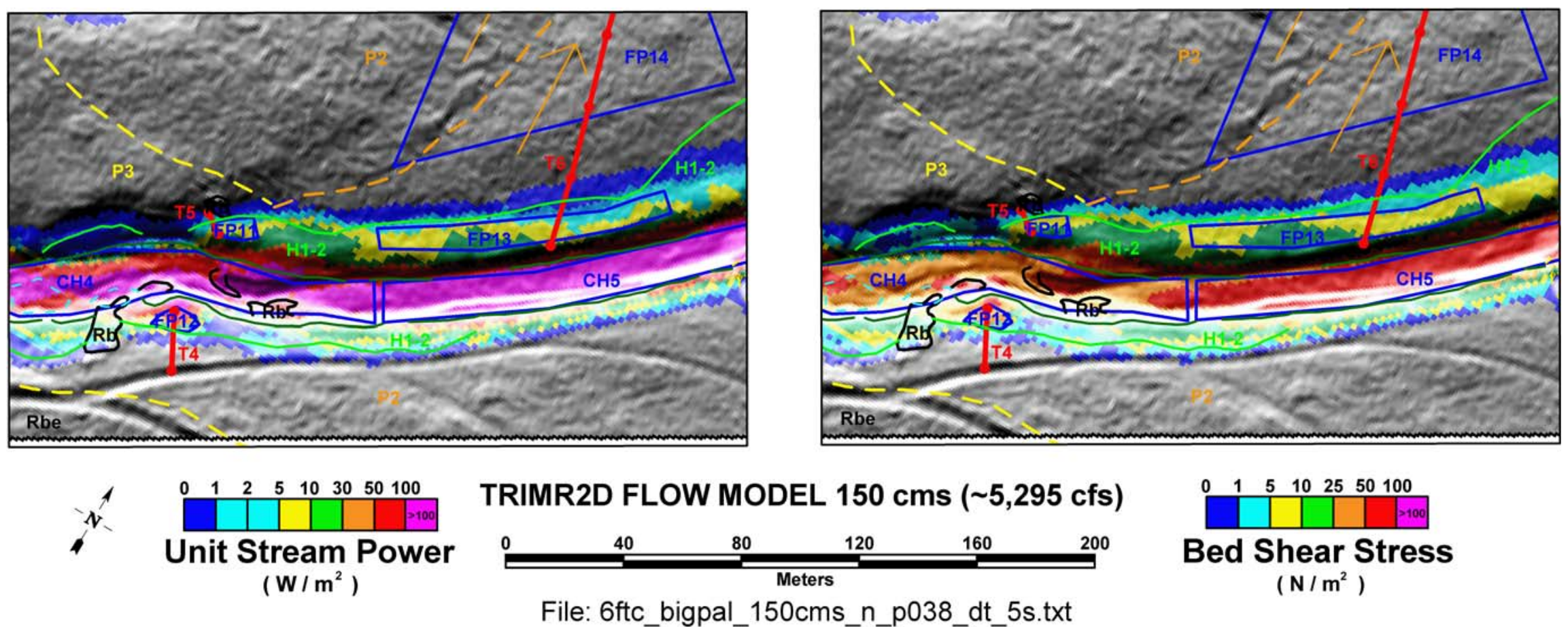

Figure 2-34 6-ft flow model results for $150 \mathrm{~m}^{3} / \mathrm{s}$ in the T4/T5/T6 study area. Base map symbology is from Figure 2-3 and Plate 2. 

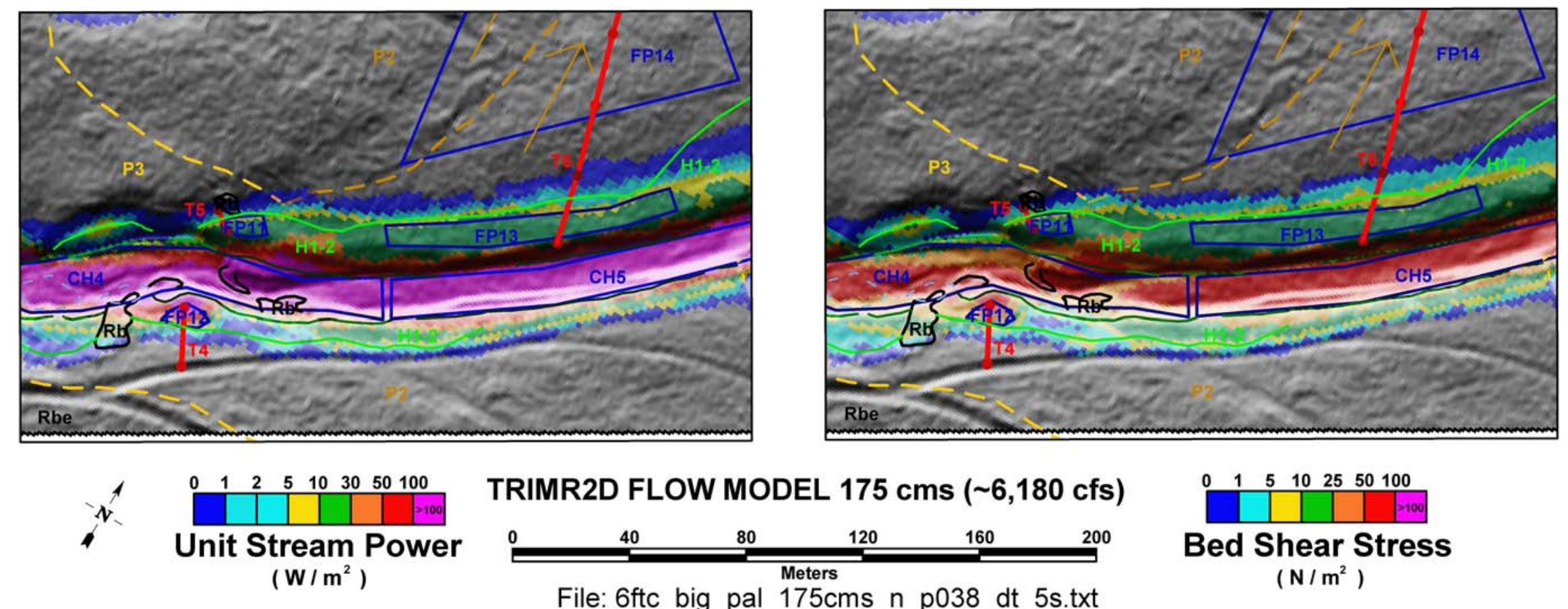

Figure 2-35 6-ft flow model results for $175 \mathrm{~m}^{3} / \mathrm{s}$ in the T4/T5/T6 study area. Base map symbology is from Figure 2-3 and Plate 2. 

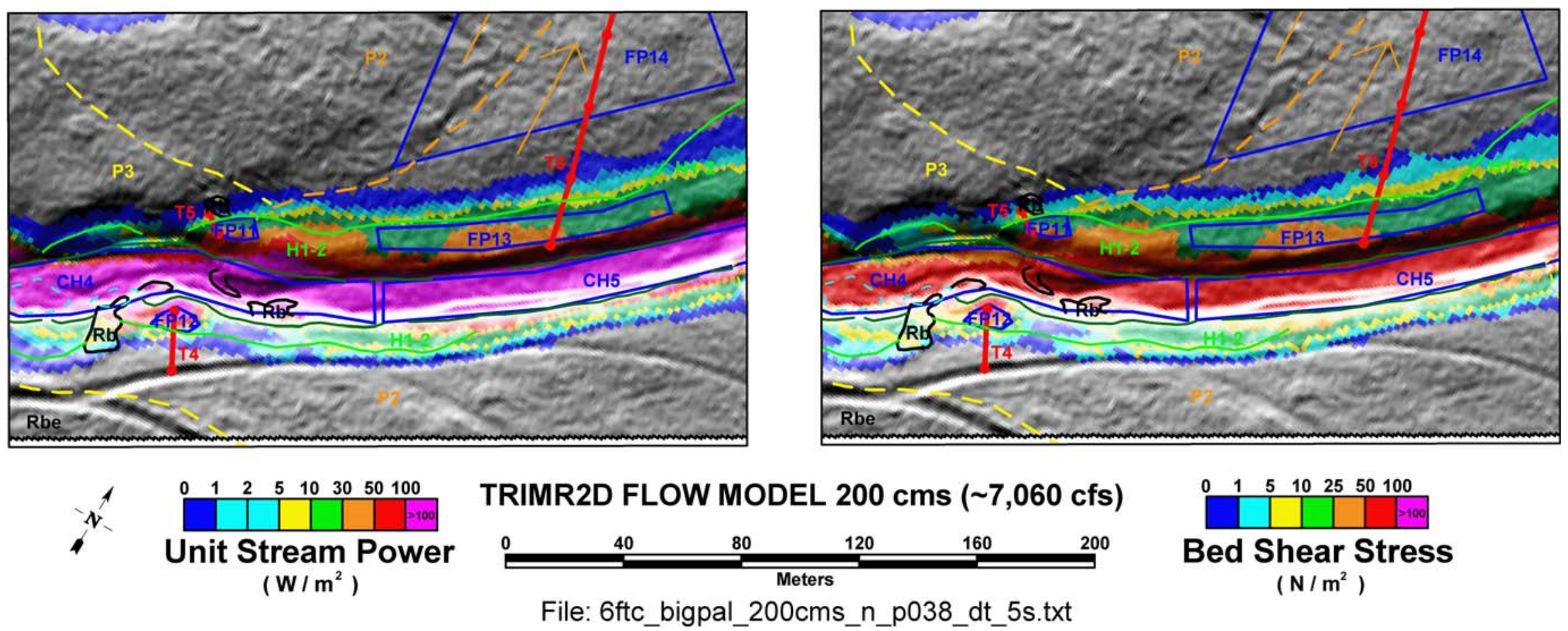

Figure 2-36 6-ft flow model results for $200 \mathrm{~m}^{3} / \mathrm{s}$ in the T4/T5/T6 study area. Base map symbology is from Figure 2-3 and Plate 2. 

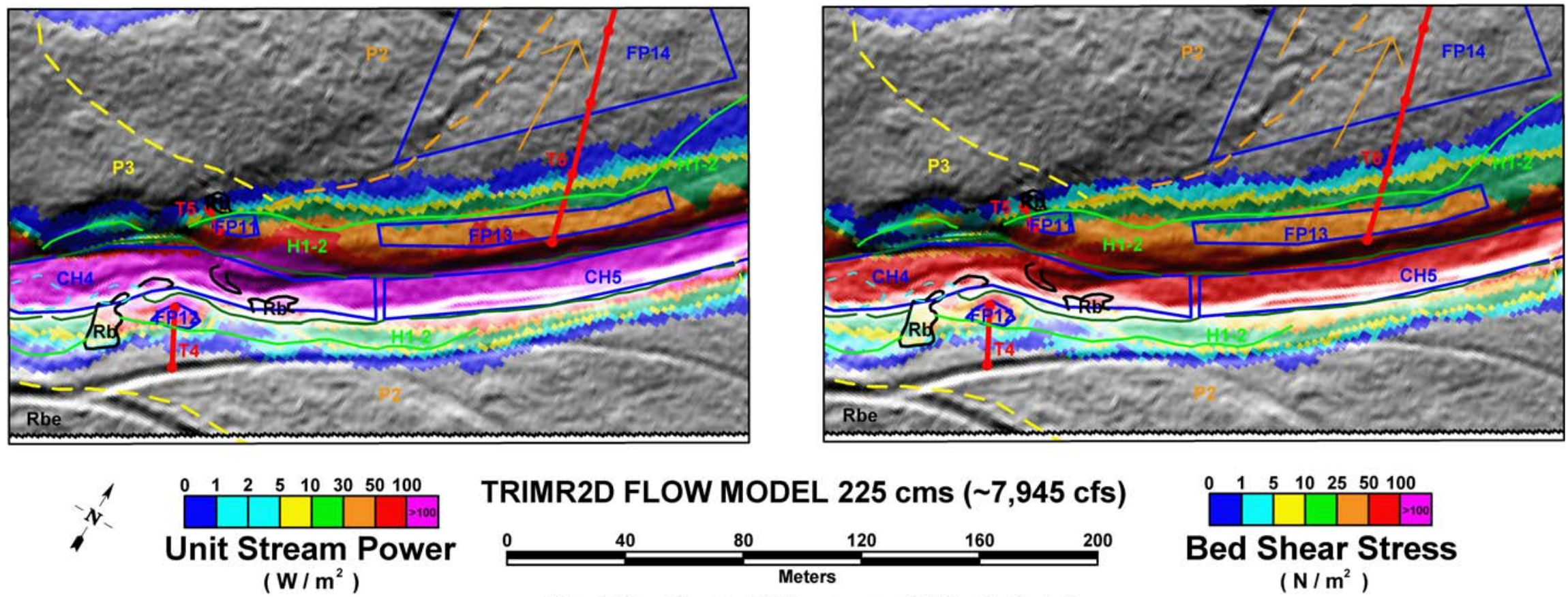

TRIMR2D FLOW MODEL $225 \mathrm{cms}(\sim 7,945 \mathrm{cfs})$
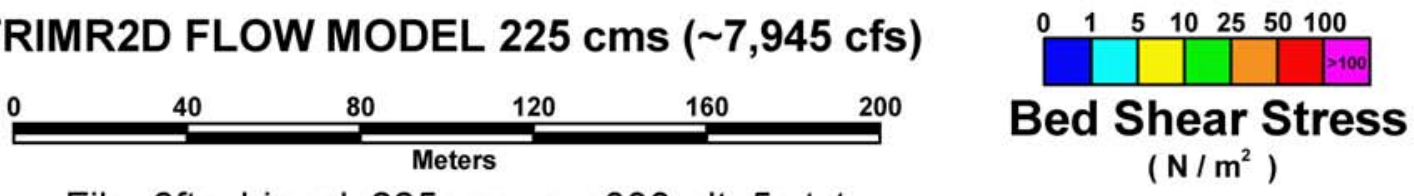

File: 6ftc_bigpal_225cms_n_p038_dt_5s.txt

$\left(\mathrm{N} / \mathrm{m}^{2}\right)$

Figure 2-37 6-ft flow model results for $225 \mathrm{~m}^{3} / \mathrm{s}$ in the T4/T5/T6 study area. Base map symbology is from Figure 2-3 and Plate 2. 

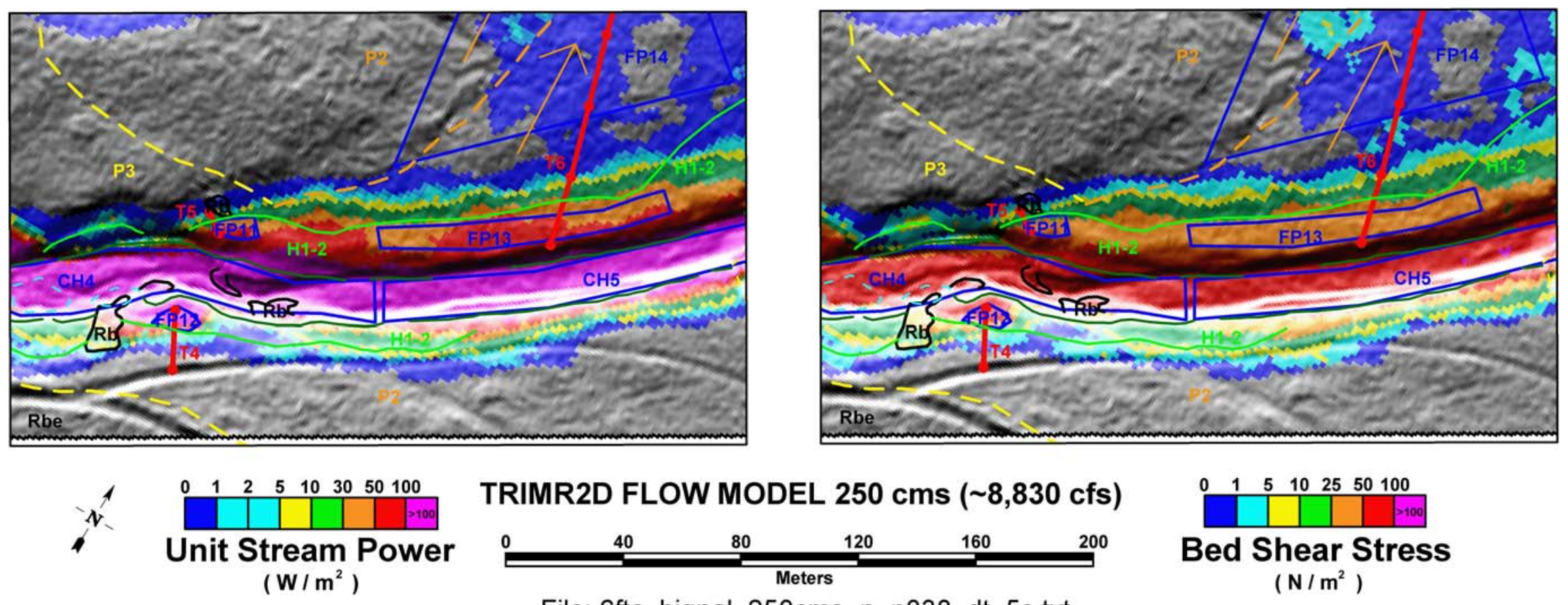

TRIMR2D FLOW MODEL $250 \mathrm{cms}(\sim 8,830 \mathrm{cfs})$

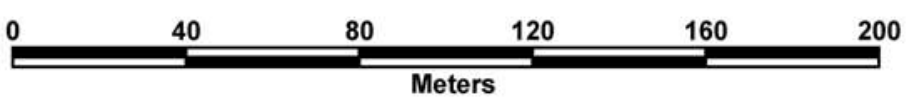

File: 6ftc_bigpal_250cms_n_p038_dt_5s.txt

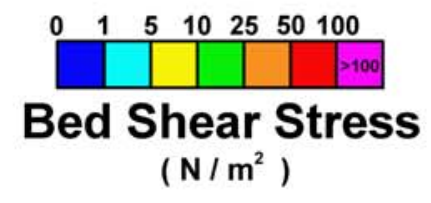

Figure 2-38 6-ft flow model results for $250 \mathrm{~m}^{3} / \mathrm{s}$ in the T4/T5/T6 study area. Base map symbology is from Figure 2-3 and Plate 2. 

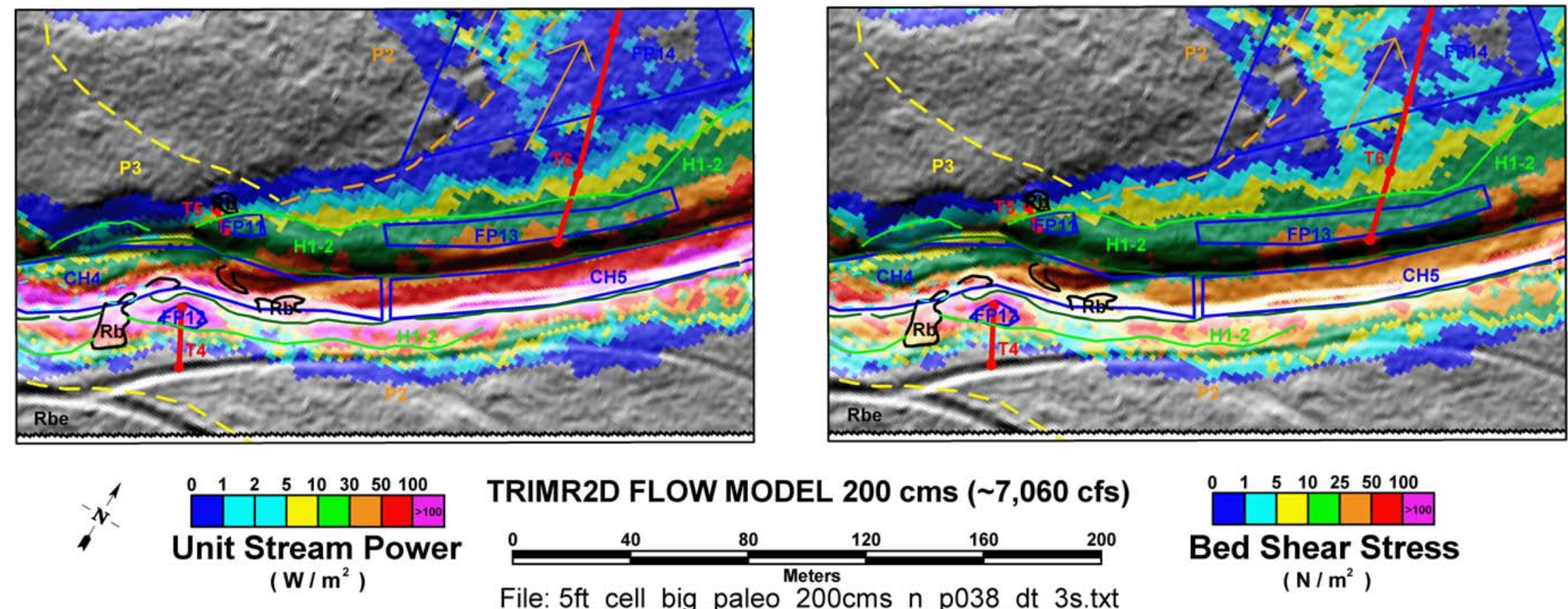

File: 5ft_cell_big_paleo_200cms_n_p038_dt_3s.txt

$\left(\mathrm{N} / \mathrm{m}^{2}\right)$

Figure 2-39 5-ft flow model results for $200 \mathrm{~m}^{3} / \mathrm{s}$ in the T4/T5/T6 constriction study area. Base map symbology is from Figure 2-3 and Plate 2. 

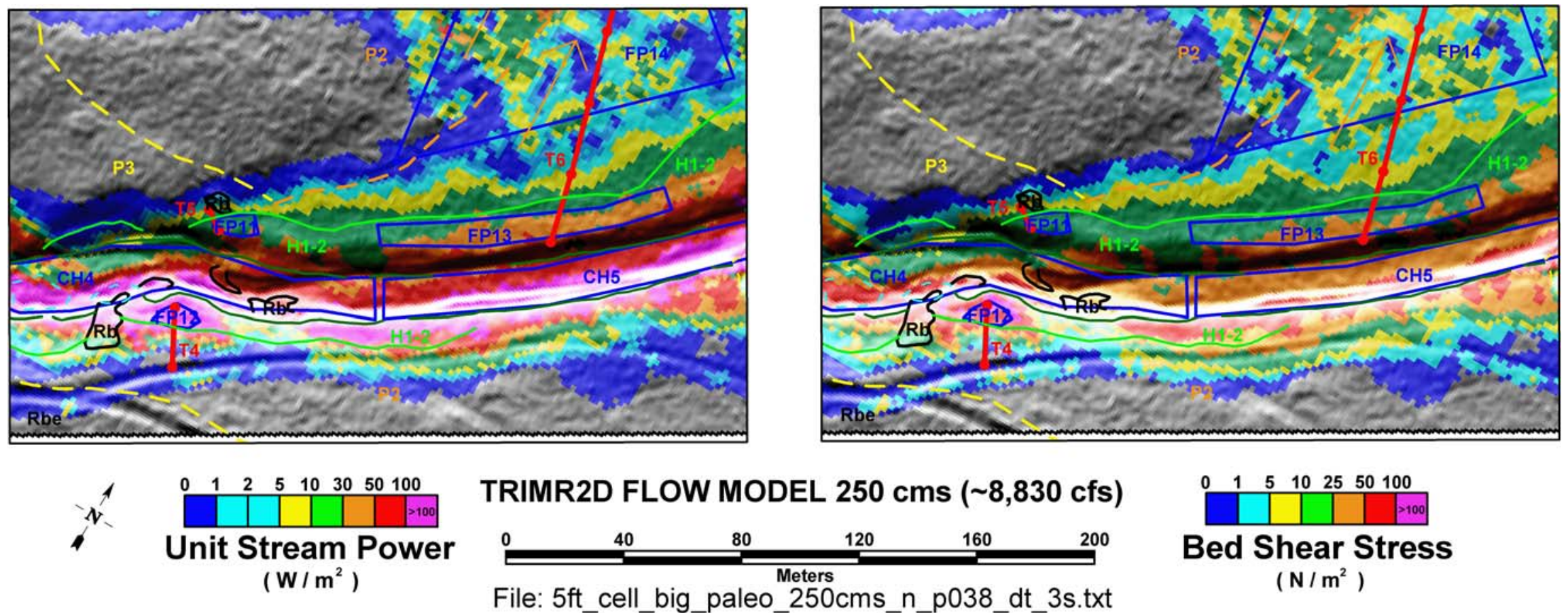

Figure 2-40 5-ft flow model results for $250 \mathrm{~m}^{3} / \mathrm{s}$ in the T4/T5/T6 constriction study area. Base map symbology is from Figure 2-3 and Plate 2 . 

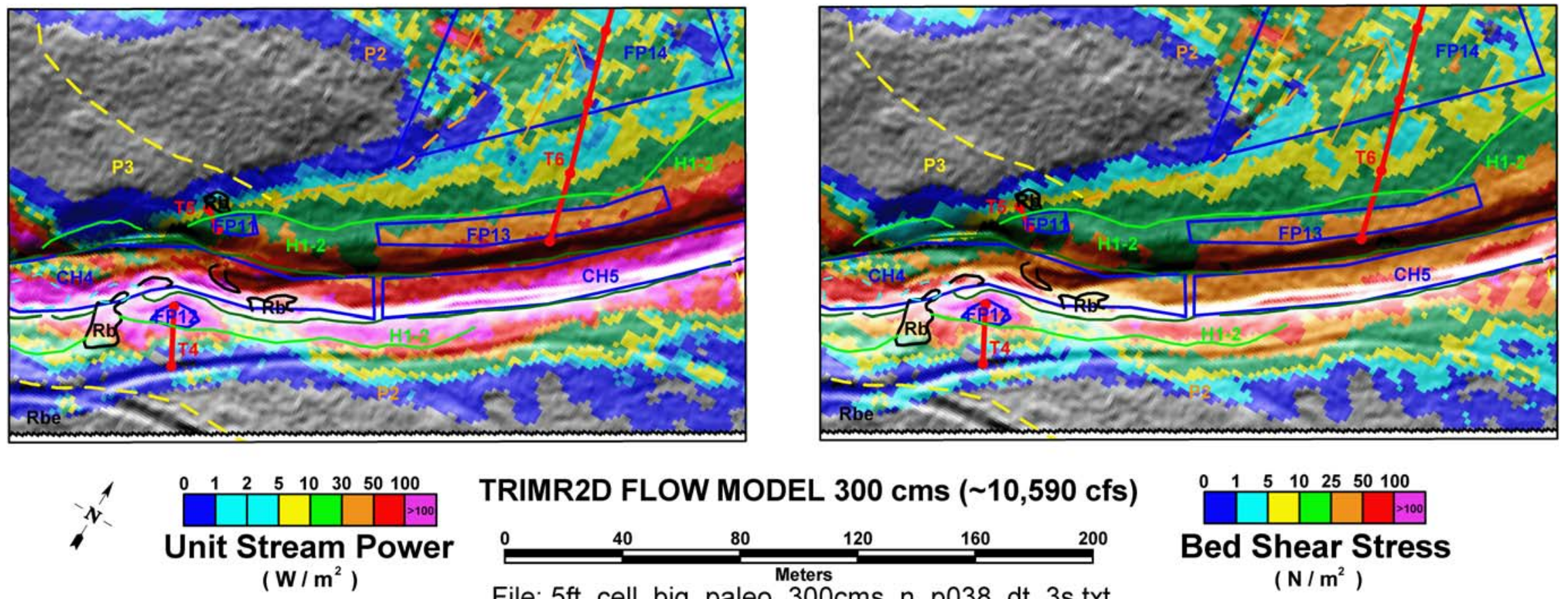

TRIMR2D FLOW MODEL $300 \mathrm{cms}(\sim 10,590 \mathrm{cfs})$

$\left(\mathrm{W} / \mathrm{m}^{2}\right)$

File: 5ft_cell_big_paleo 300cms n n p038 dt 3s.txt

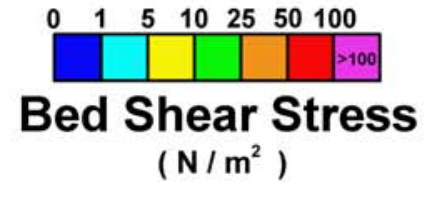

Figure 2-41 5-ft flow model results for $300 \mathrm{~m}^{3} / \mathrm{s}$ in the T4/T5/T6 constriction study area. Base map symbology is from Figure 2-3 and Plate 2. 

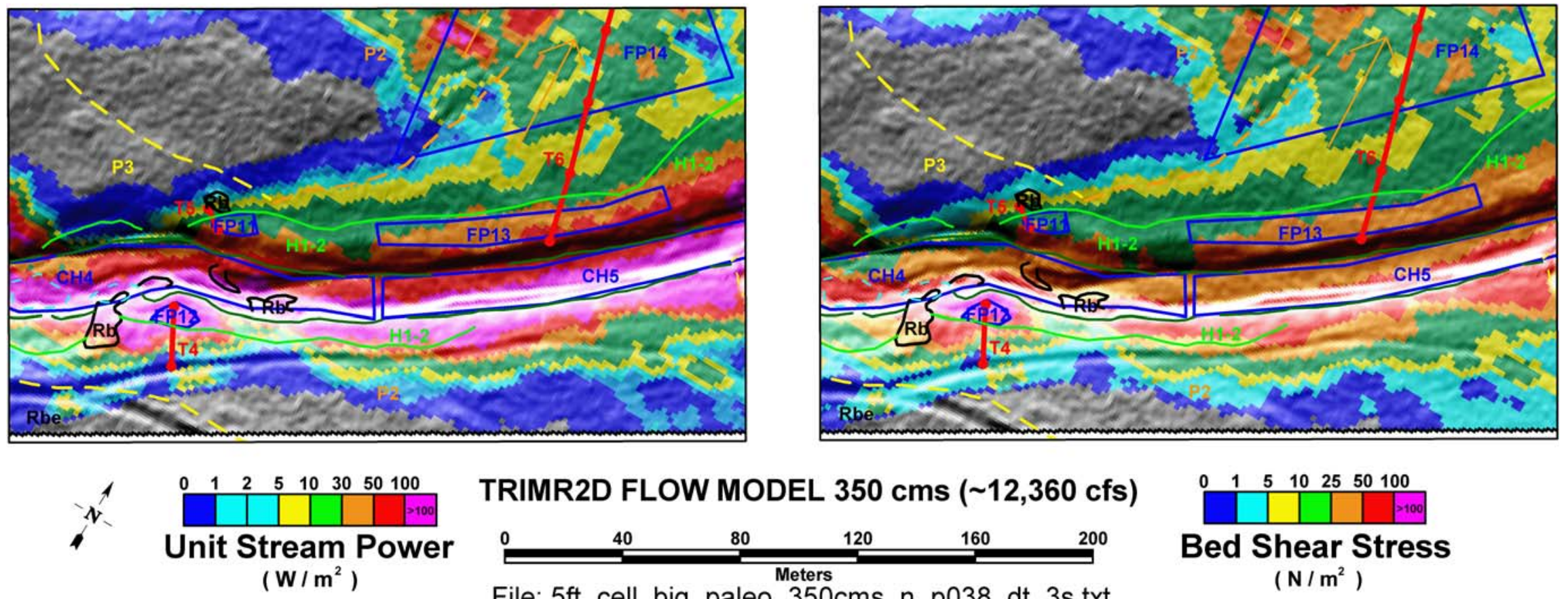

TRIMR2D FLOW MODEL $350 \mathrm{cms}(\sim 12,360 \mathrm{cfs})$

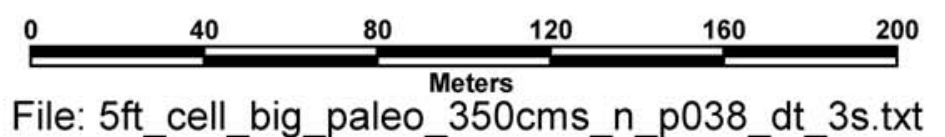

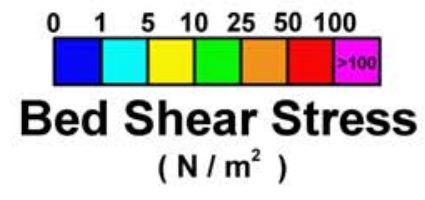

Figure 2-42 5-ft flow model results for $350 \mathrm{~m}^{3} / \mathrm{s}$ in the T4/T5/T6 constriction study area. Base map symbology is from Figure 2-3 and Plate 2. 

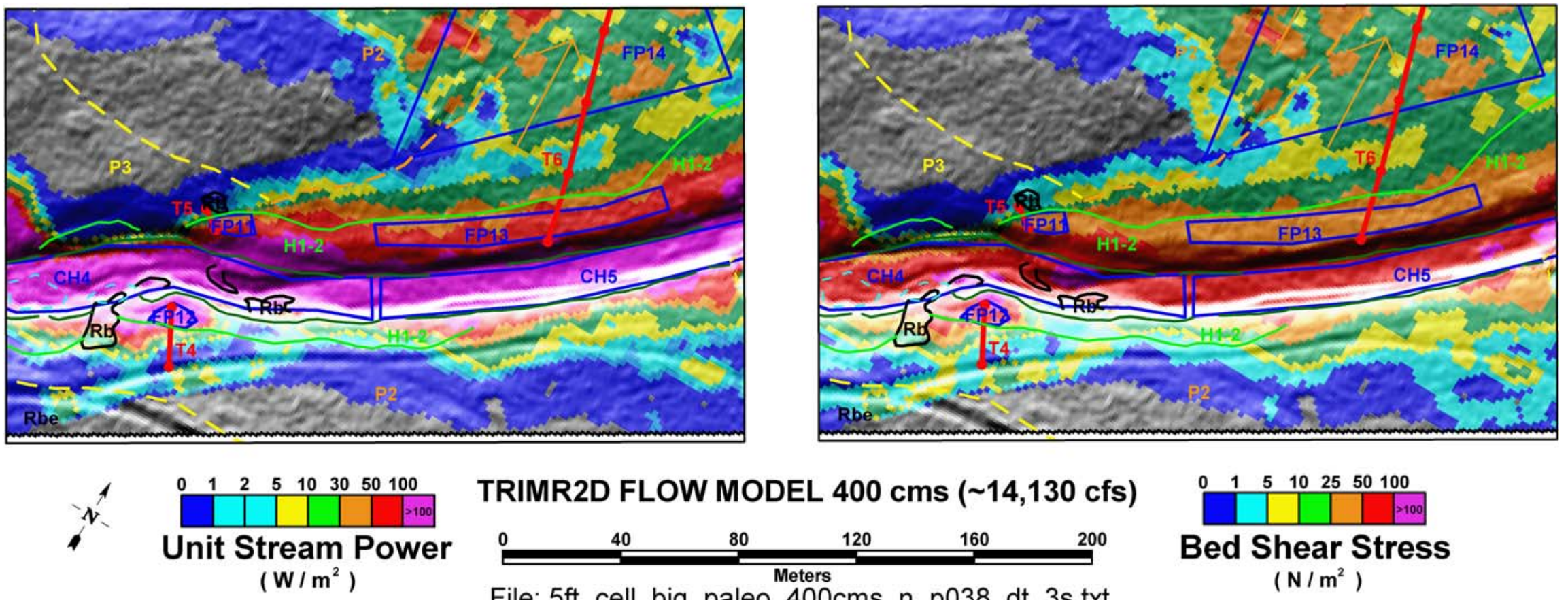

TRIMR2D FLOW MODEL $400 \mathrm{cms}(\sim 14,130 \mathrm{cfs})$

File: 5ft_cell_big_paleo_400cms_n_p038_dt_3s.txt

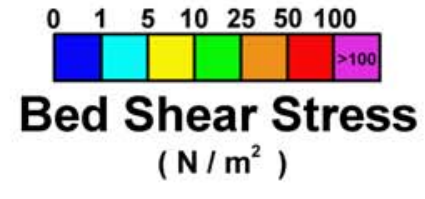

Figure 2-43 5-ft flow model results for $400 \mathrm{~m}^{3} / \mathrm{s}$ in the T4/T5/T6 constriction study area. Base map symbology is from Figure 2-3 and Plate 2. 

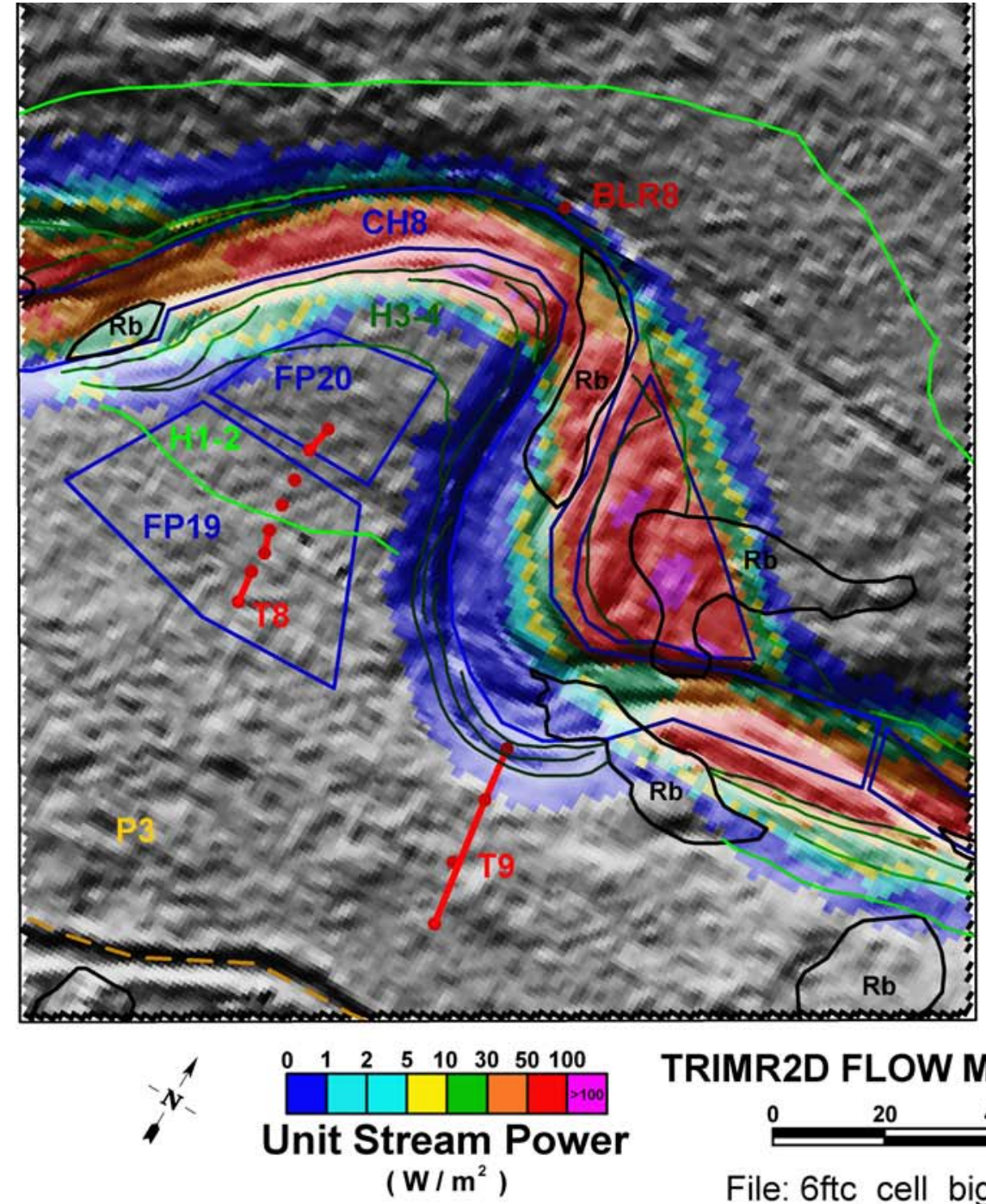

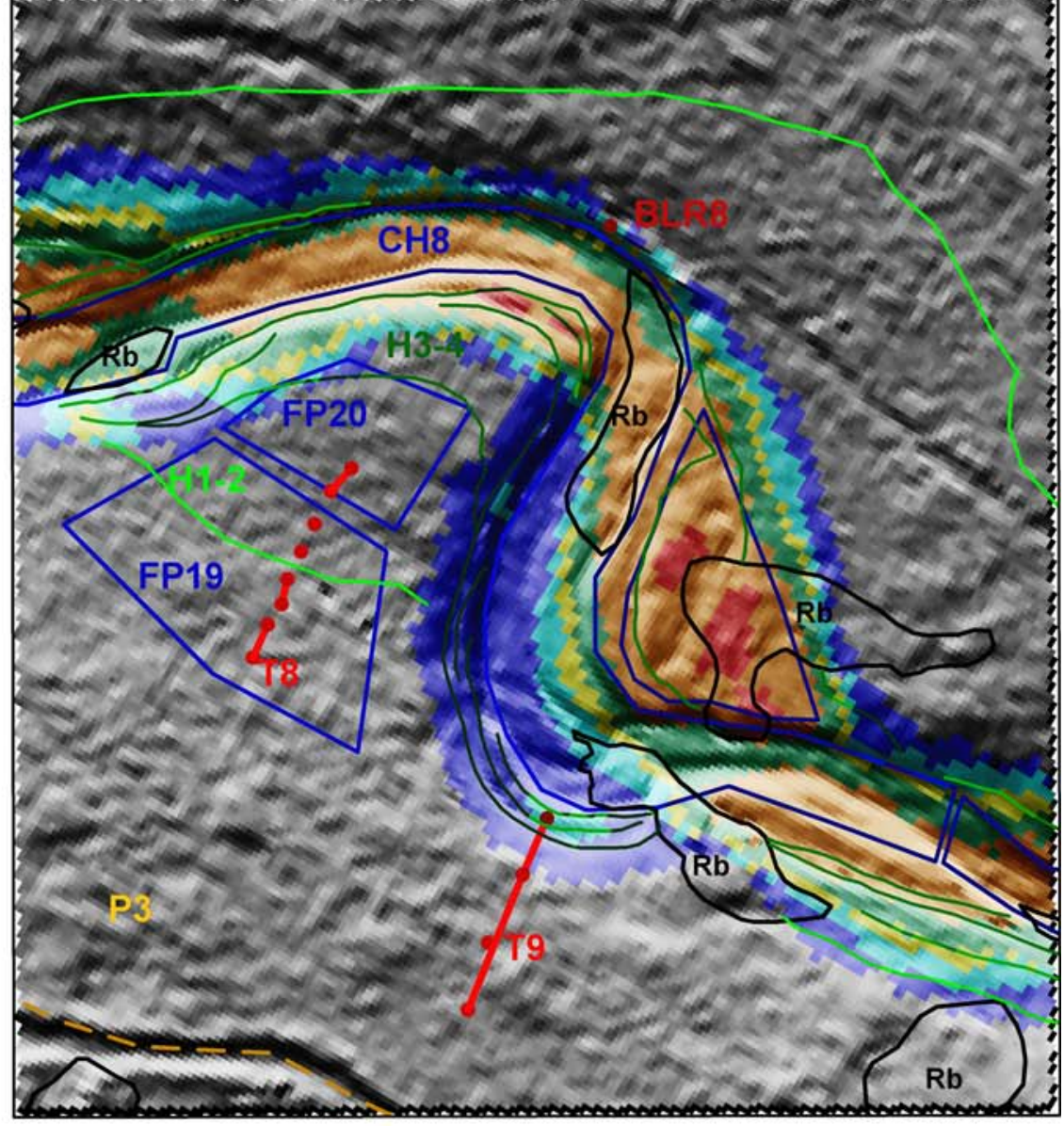

TRIMR2D FLOW MODEL $70 \mathrm{cms}$ ( $2470 \mathrm{cfs})$

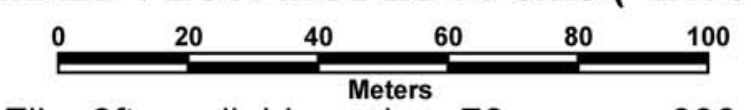

File: 6ftc_cell_big_paleo_70cms_n_p038_dt_5s.txt

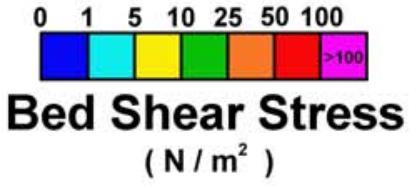

$\left(\mathrm{N} / \mathrm{m}^{2}\right)$

Figure 2-44 6-ft flow model results for $70 \mathrm{~m}^{3} / \mathrm{s}$ in the BLR8 study area. Base map symbology is from Figure 2-3 and Plate 2. 

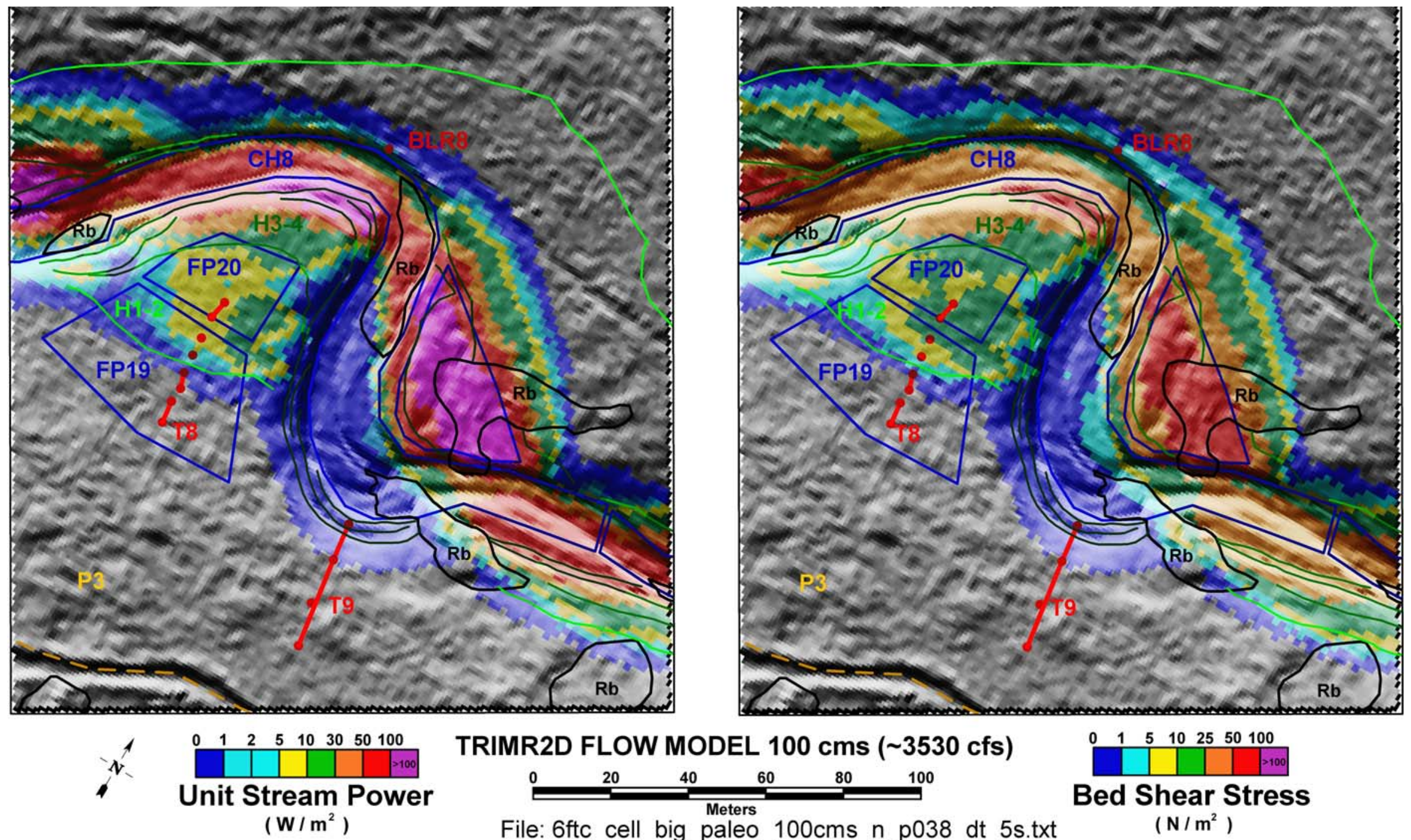

File: 6ftc_cell_big_paleo_100cms_n_p038_dt_5s.txt

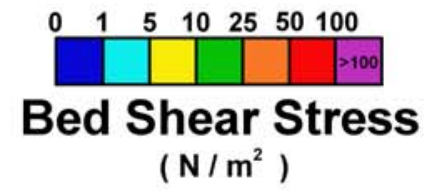

Figure 2-45 6-ft flow model results for $100 \mathrm{~m}^{3} / \mathrm{s}$ in the BLR8 study area. Base map symbology is from Figure 2-3 and Plate 2. 

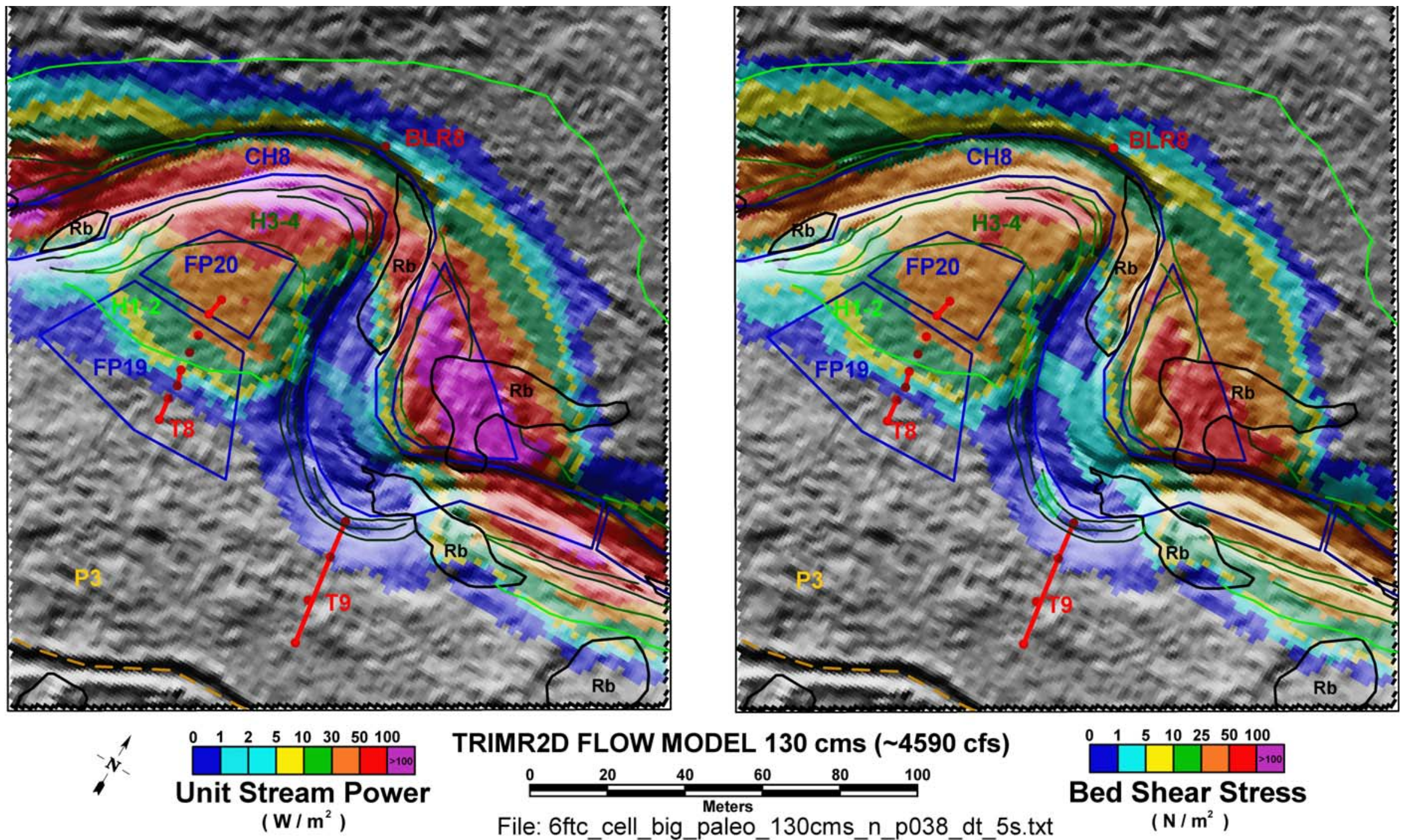

File: 6ftc_cell_big_paleo_130cms_n_p038_dt_5s.txt

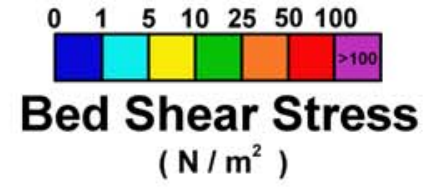

Figure 2-46 6-ft flow model results for $130 \mathrm{~m}^{3} / \mathrm{s}$ in the BLR8 study area. Base map symbology is from Figure 2-3 and Plate 2. 

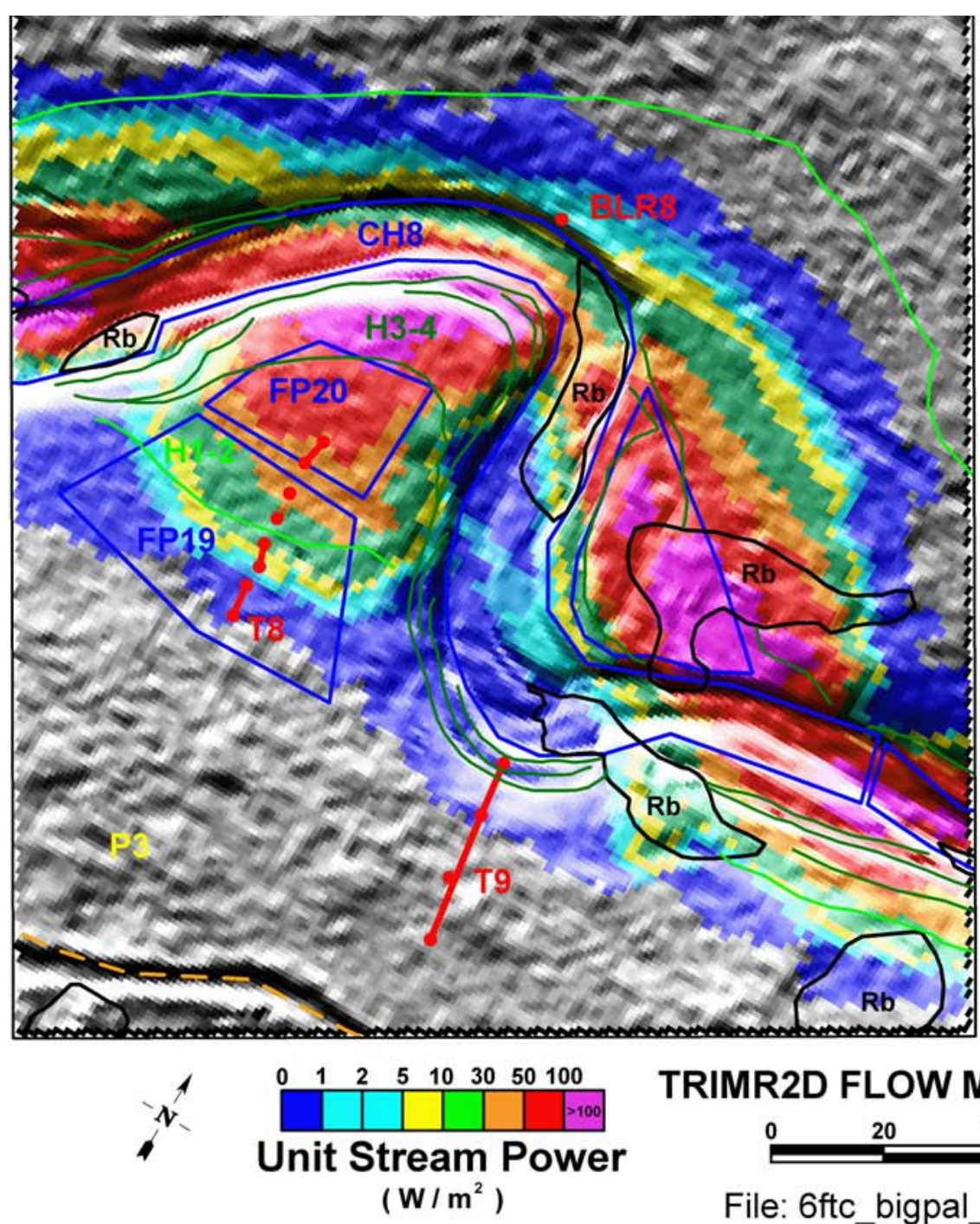

TRIMR2D FLOW MODEL $150 \mathrm{cms}$ ( 5,295 cfs)

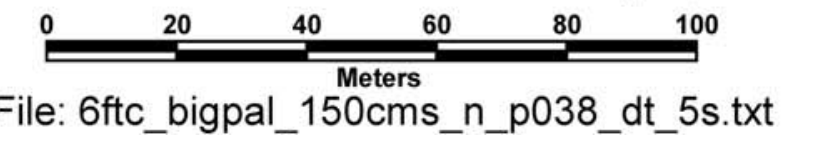

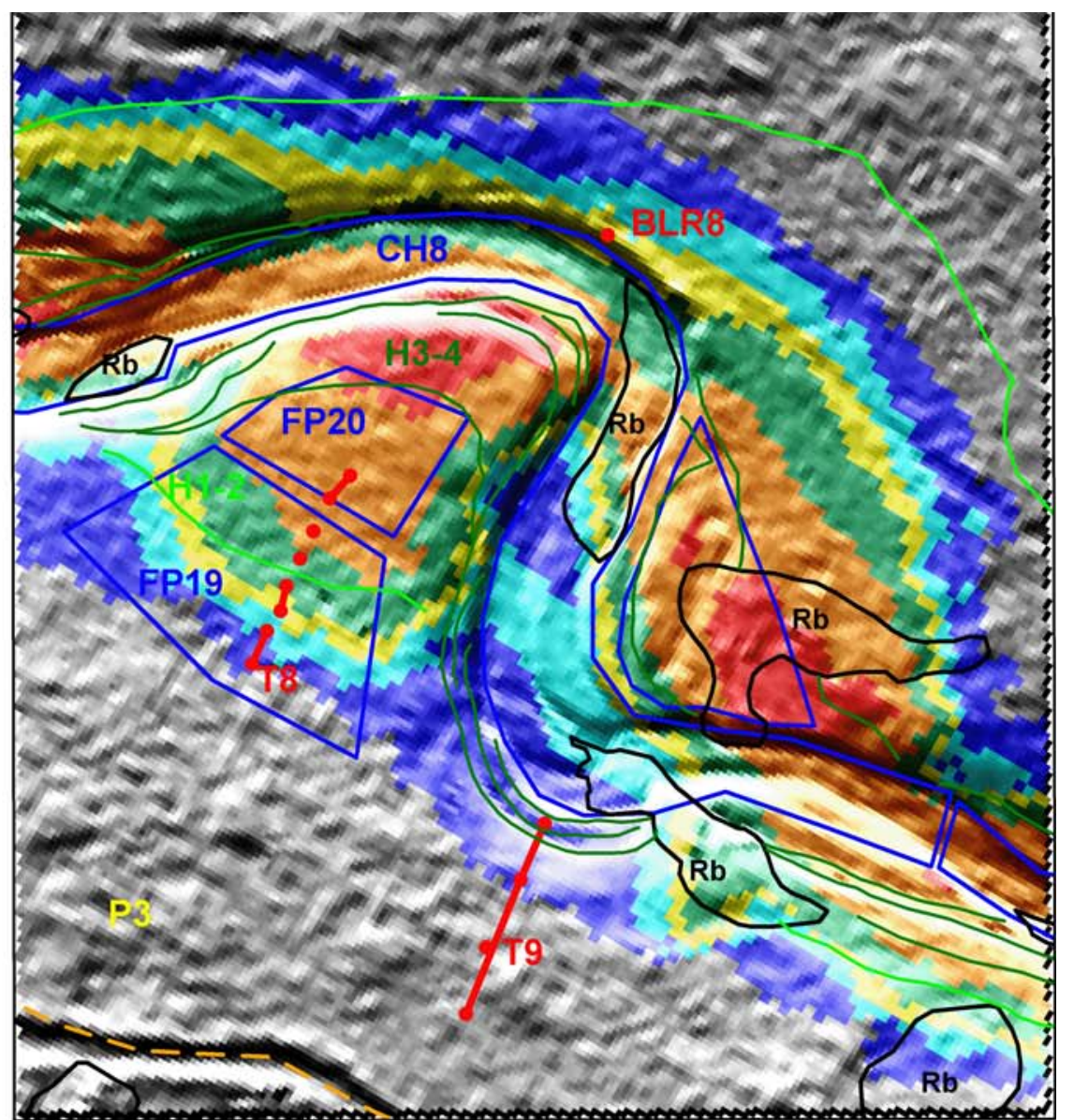

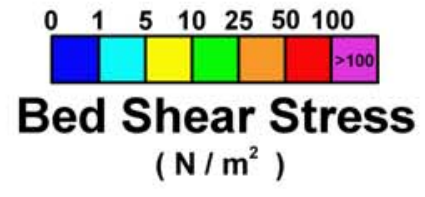

Figure 2-47 6-ft flow model results for $150 \mathrm{~m}^{3} / \mathrm{s}$ in the BLR8 study area. Base map symbology is from Figure 2-3 and Plate 2. 

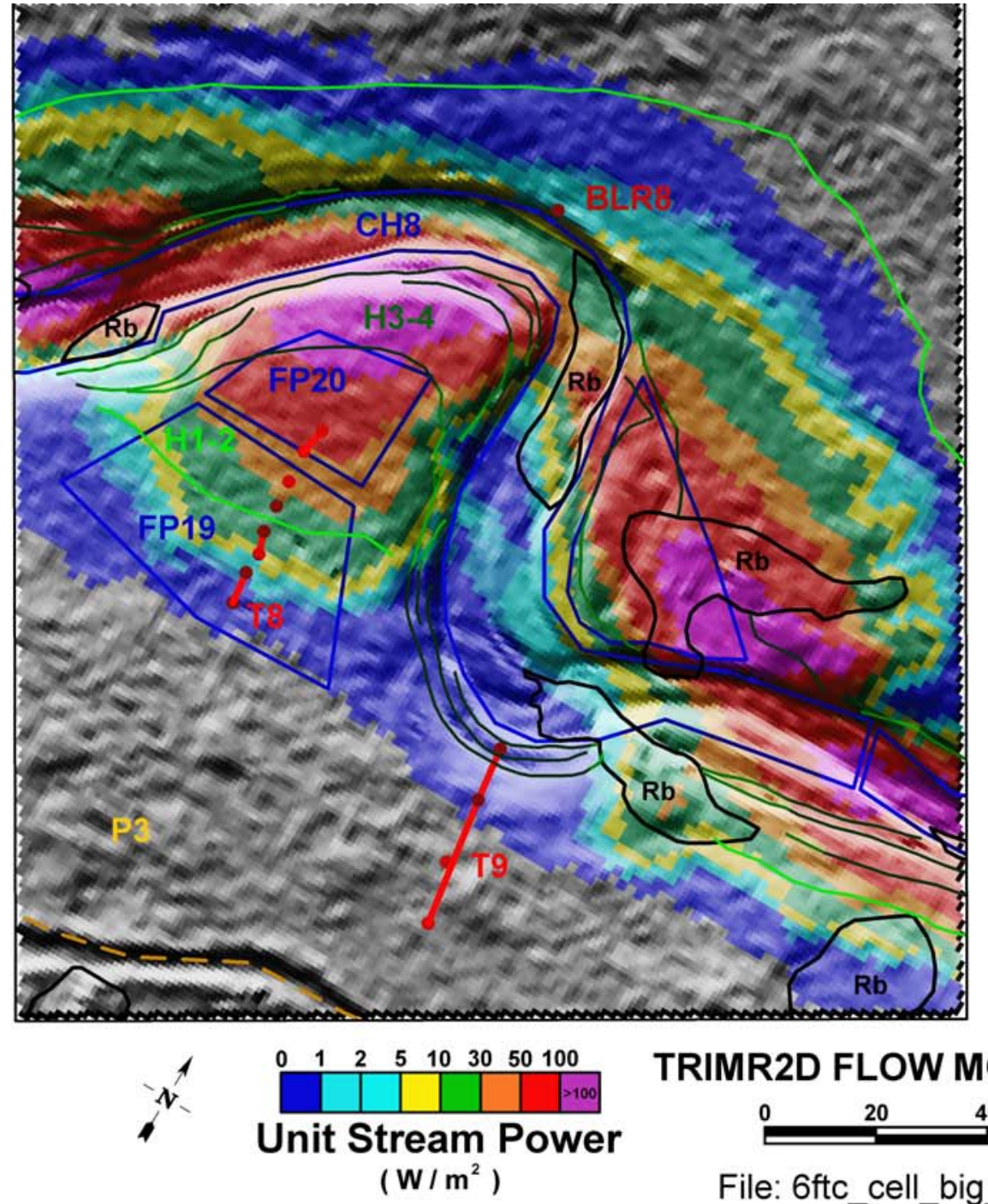

TRIMR2D FLOW MODEL $175 \mathrm{cms}$ ( $6180 \mathrm{cfs}$ )

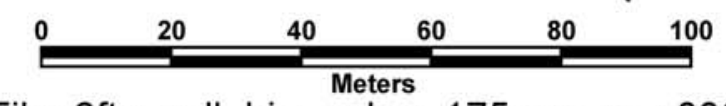

File: 6ftc_cell_big_paleo_175cms_n_p038_dt_5s.txt
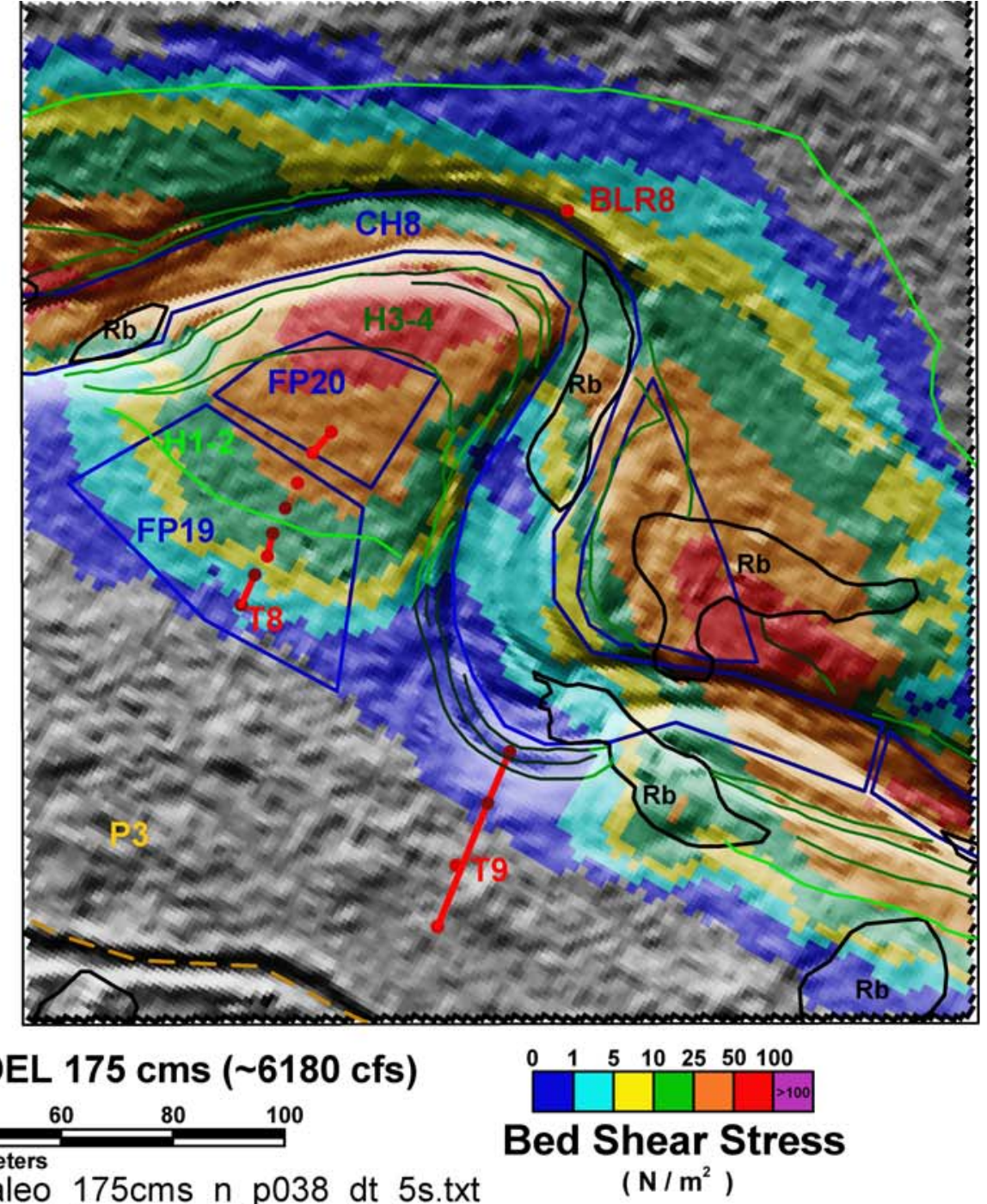

Figure 2-48 6-ft flow model results for $175 \mathrm{~m}^{3} / \mathrm{s}$ in the BLR8 study area. Base map symbology is from Figure 2-3 and Plate 2. 

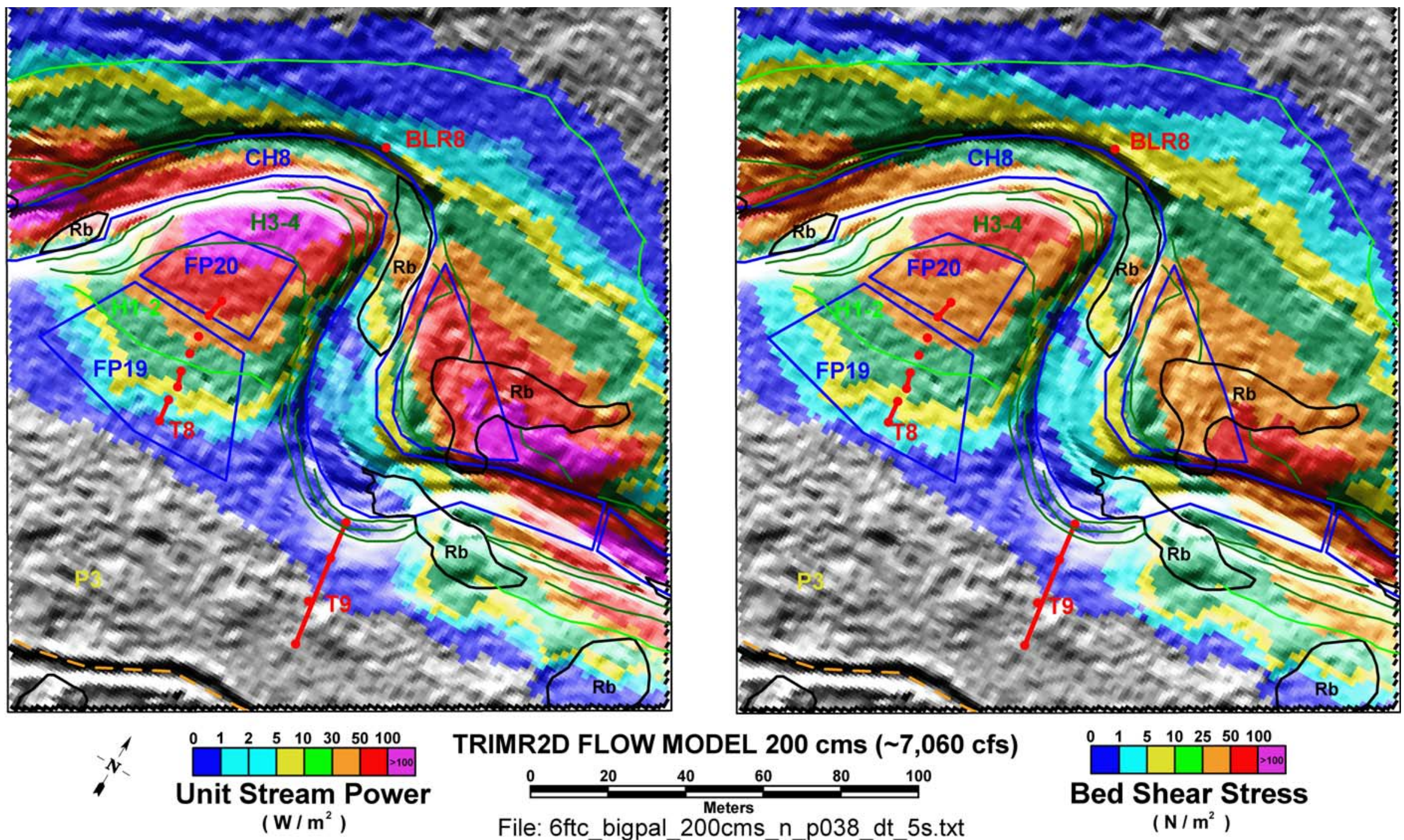

Figure 2-49 6-ft flow model results for $200 \mathrm{~m}^{3} / \mathrm{s}$ in the BLR8 study area. Base map symbology is from Figure 2-3 and Plate 2. 

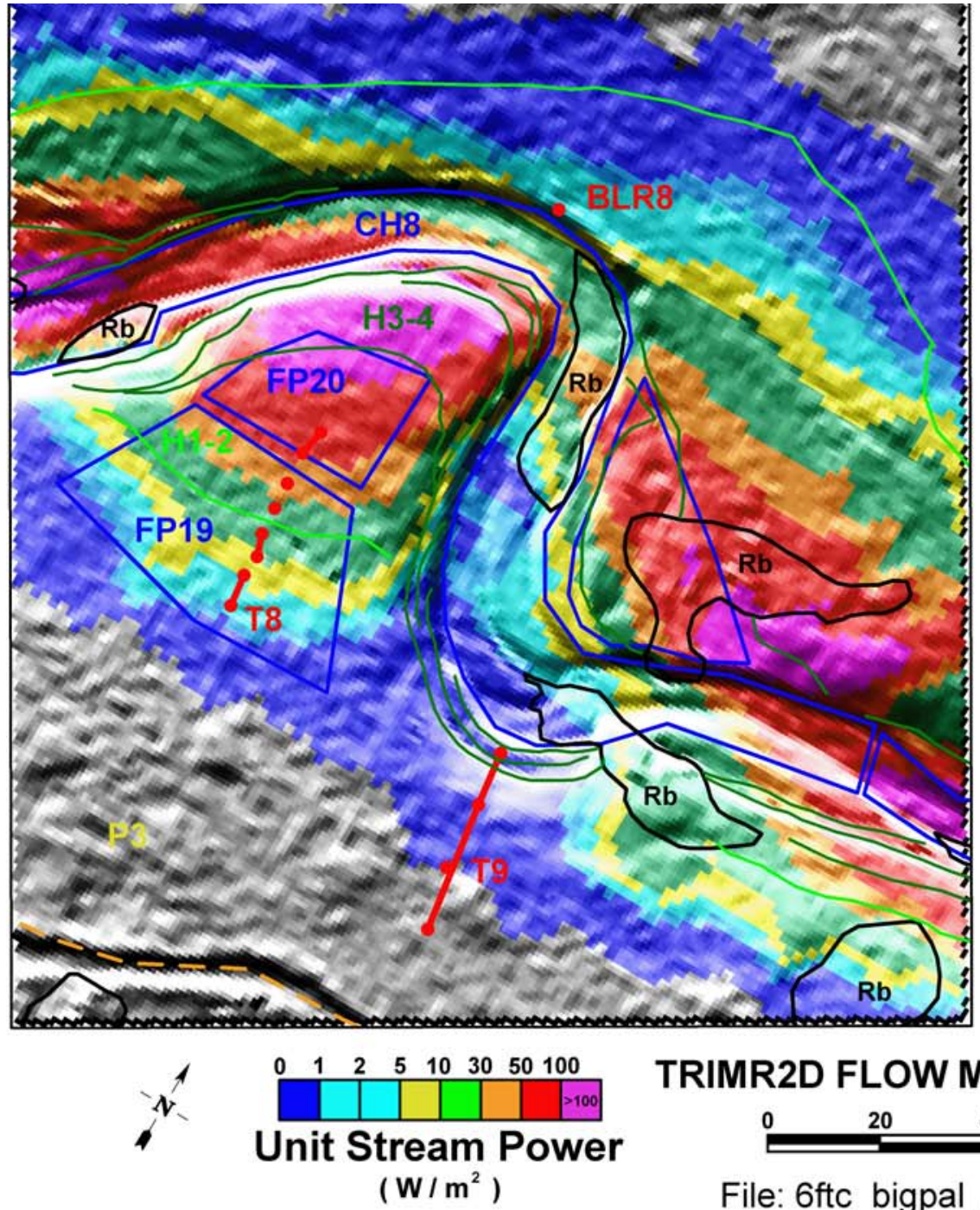

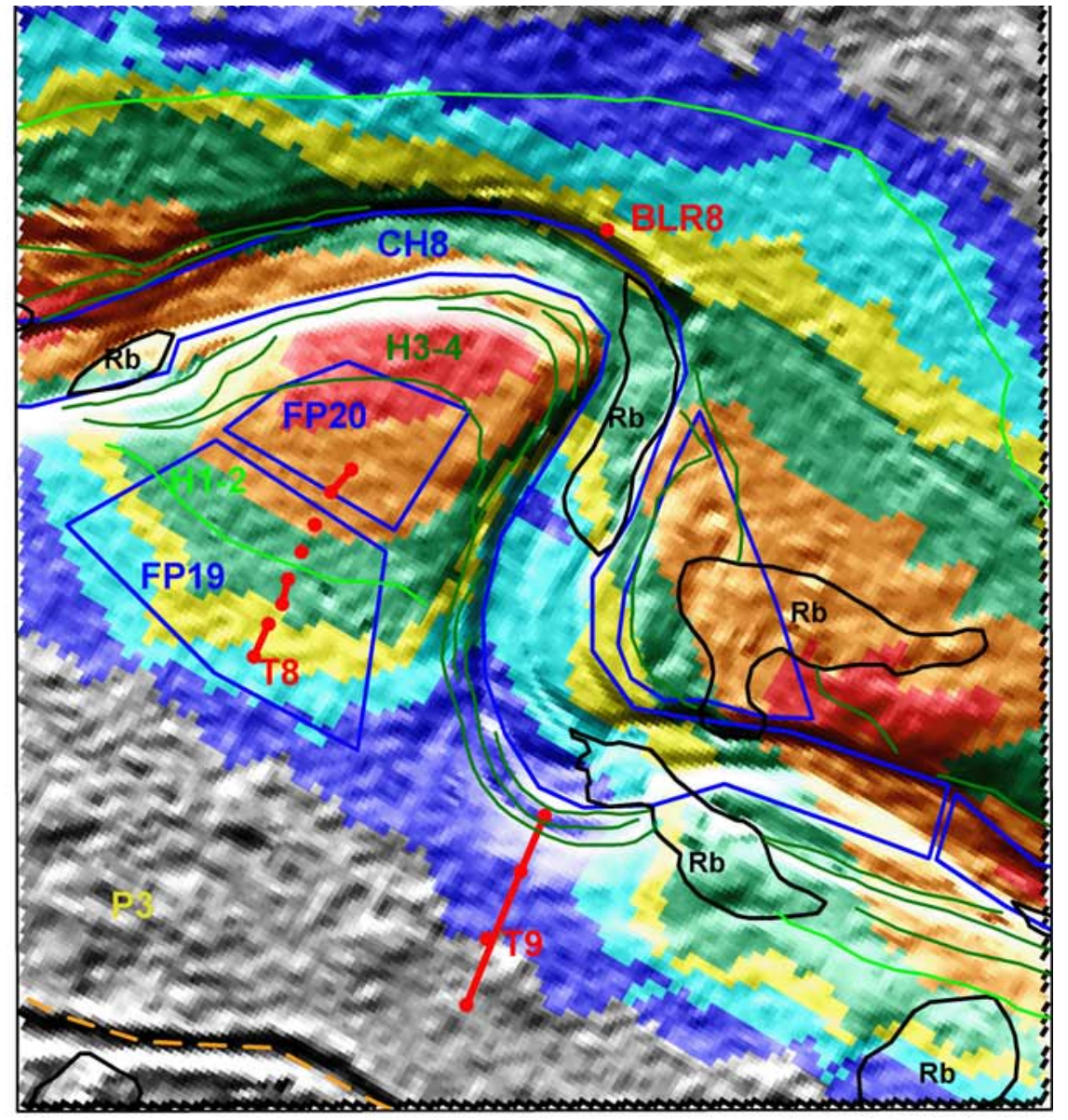

TRIMR2D FLOW MODEL 225 cms ( 7,945 cfs)

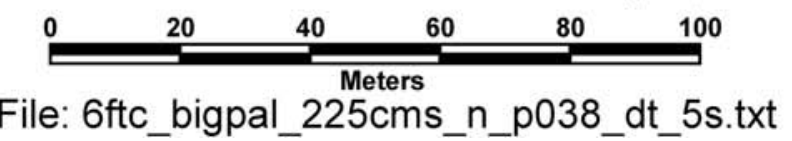

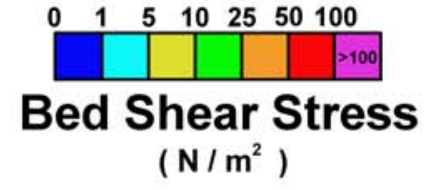

Figure 2-50 6-ft flow model results for $225 \mathrm{~m}^{3} / \mathrm{s}$ in the BLR8 study area. Base map symbology is from Figure 2-3 and Plate 2. 

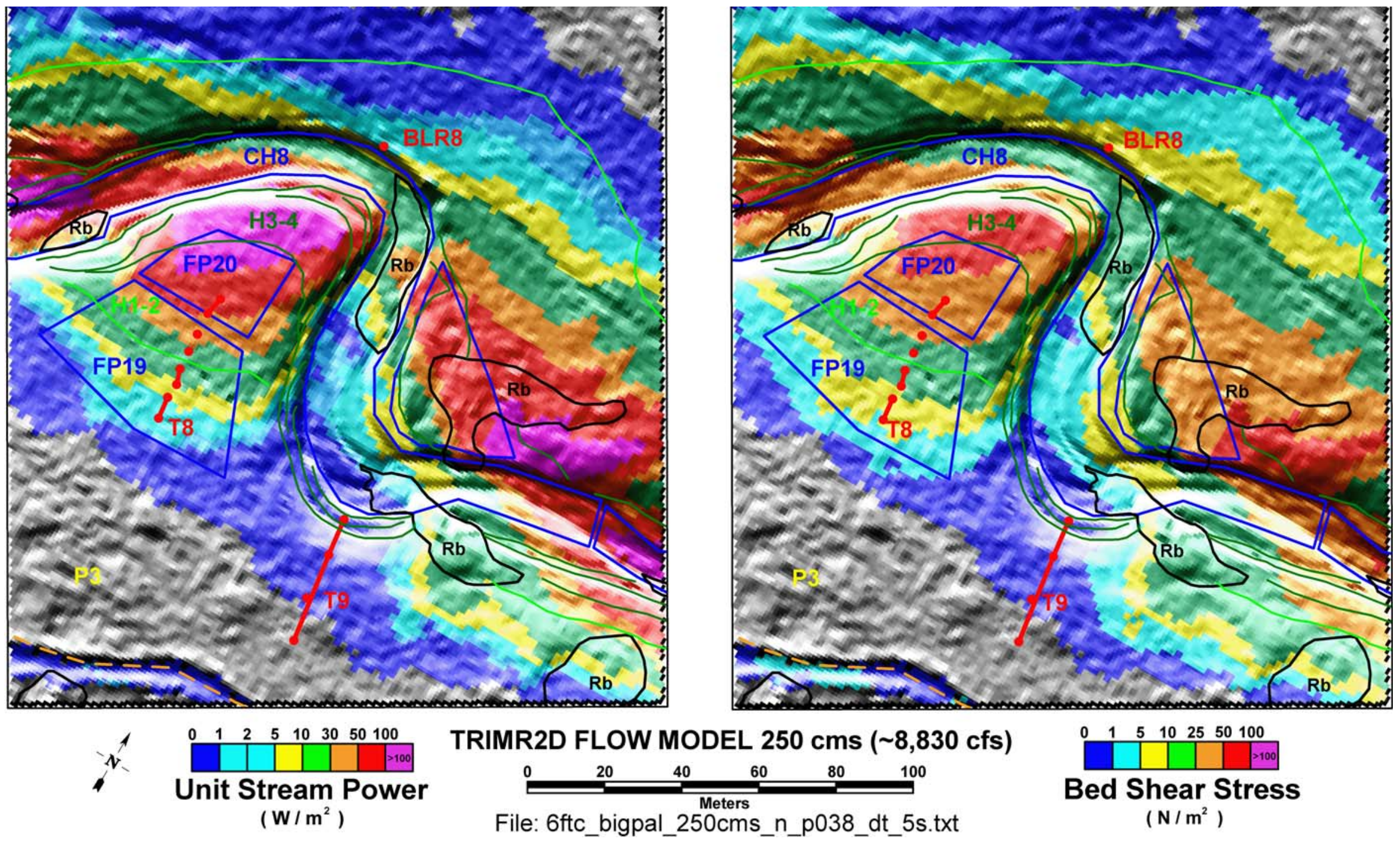

Figure 2-51 6-ft flow model results for $250 \mathrm{~m}^{3} / \mathrm{s}$ in the BLR8 study area. Base map symbology is from Figure 2-3 and Plate 2. 

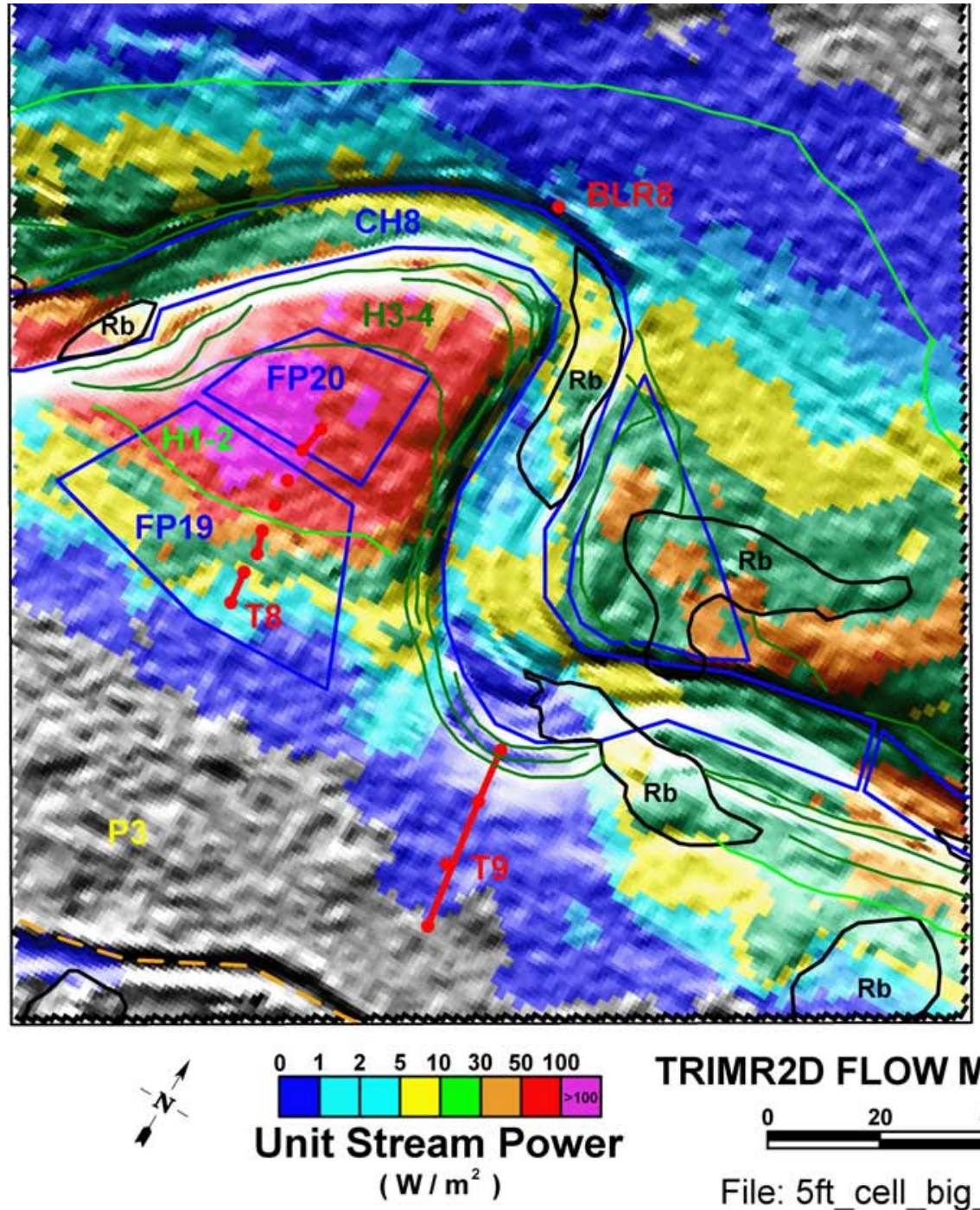

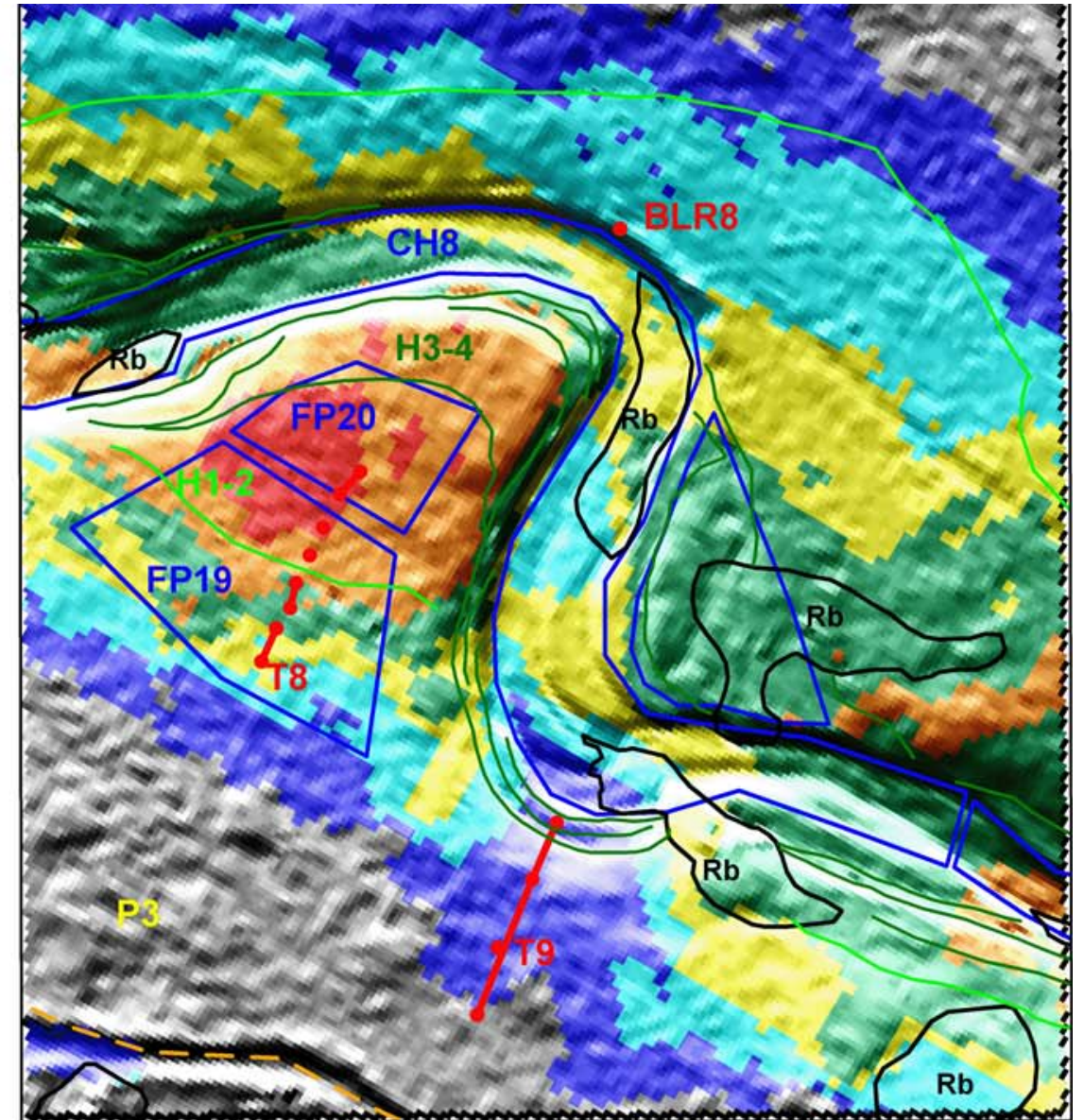

TRIMR2D FLOW MODEL $200 \mathrm{cms}$ ( 7,060 cfs)

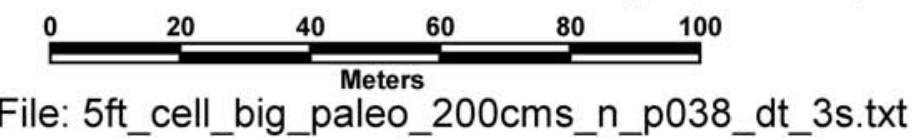

Figure 2-52 5-ft flow model results for $200 \mathrm{~m}^{3} / \mathrm{s}$ in the BLR8 constriction study area. Base map symbology is from Figure 2-3 and Plate 2. 

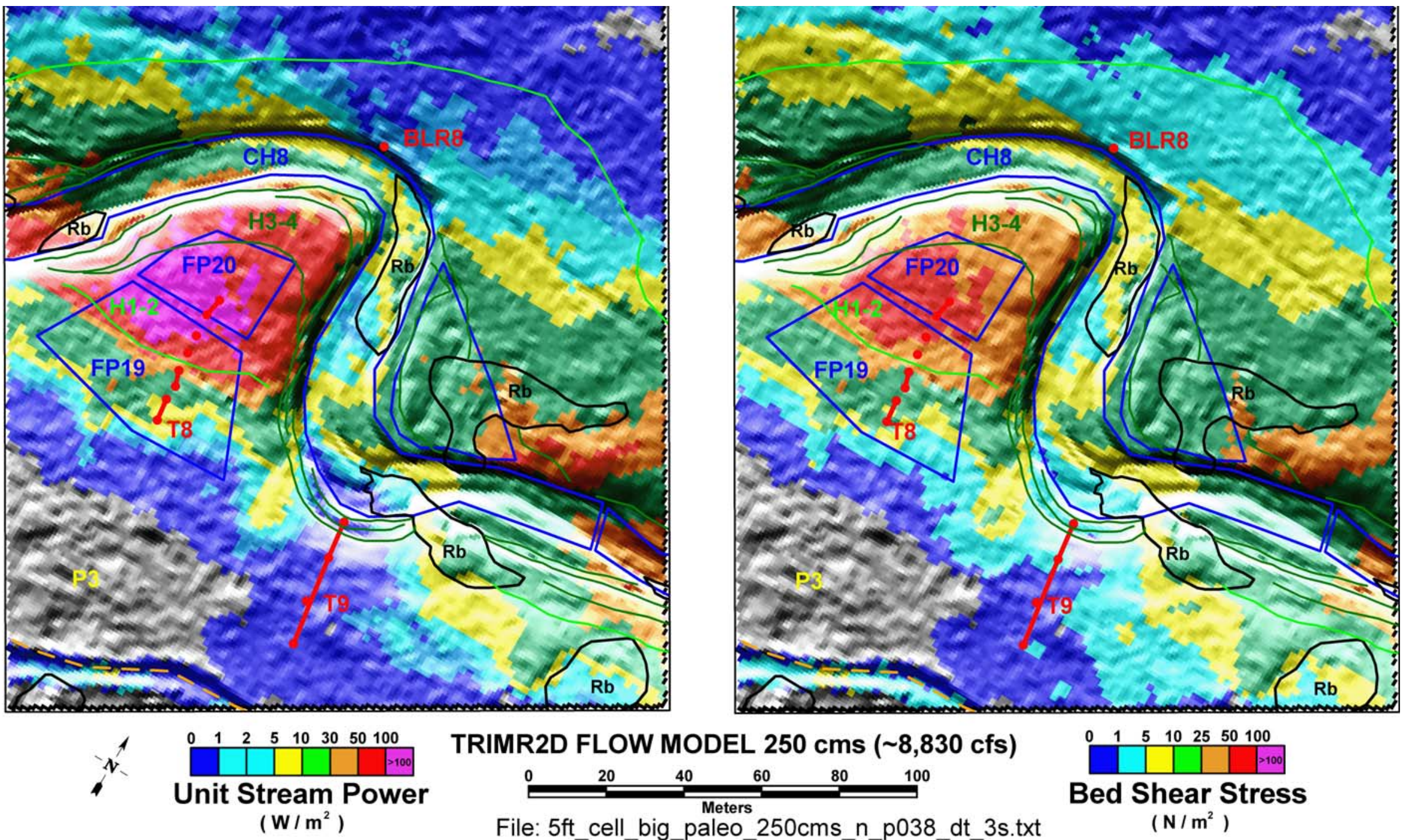

TRIMR2D FLOW MODEL $250 \mathrm{cms}(\sim 8,830 \mathrm{cfs})$

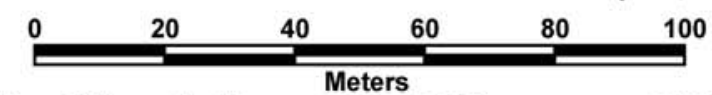

File: 5ft_cell_big_paleo_250cms_n_p038_dt_3s.txt

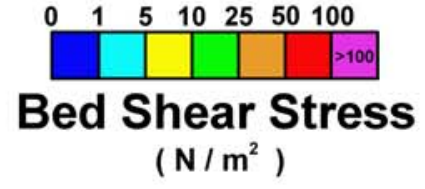

Figure 2-53 5-ft flow model results for $250 \mathrm{~m}^{3} / \mathrm{s}$ in the BLR8 constriction study area. Base map symbology is from Figure 2-3 and Plate 2 . 

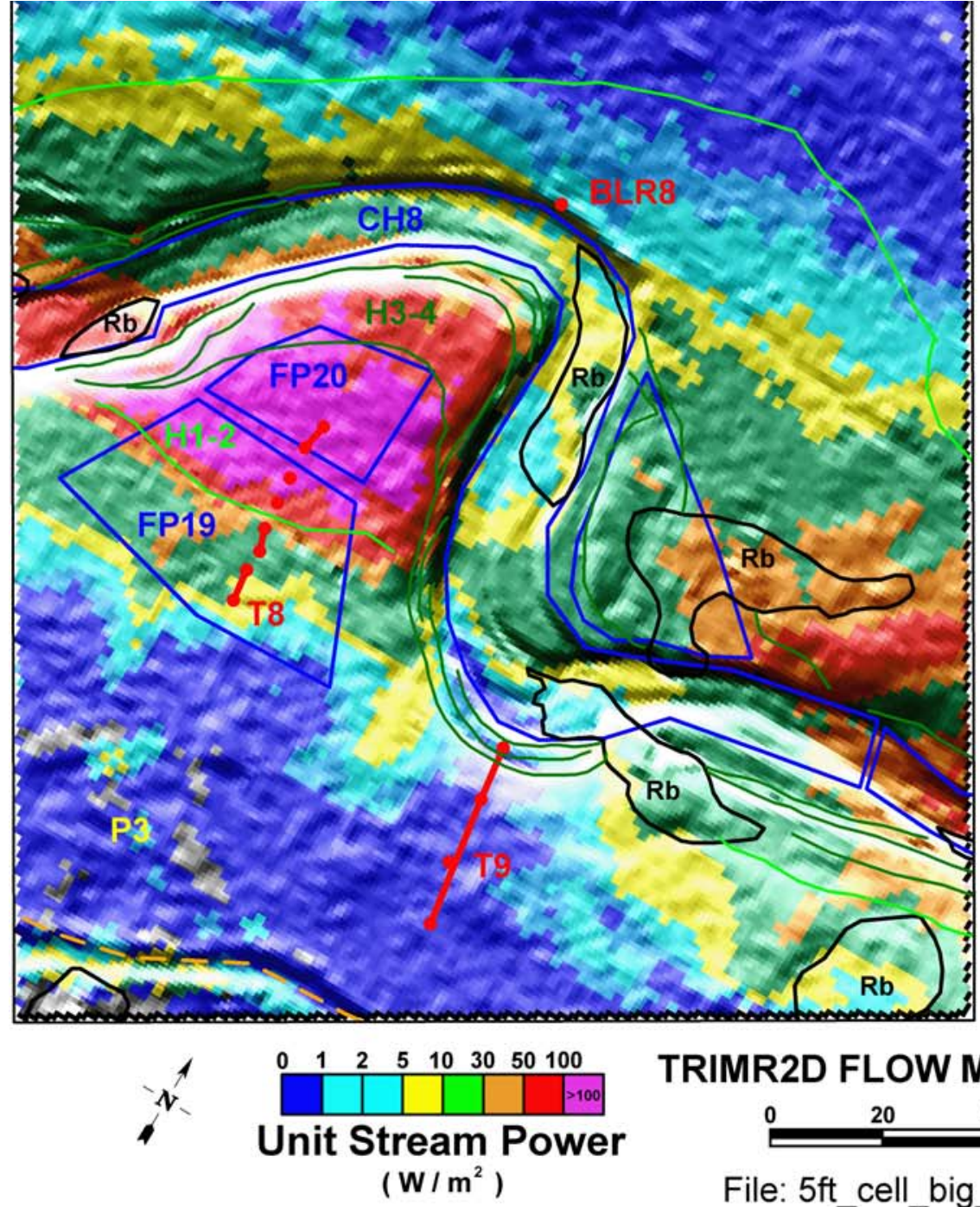

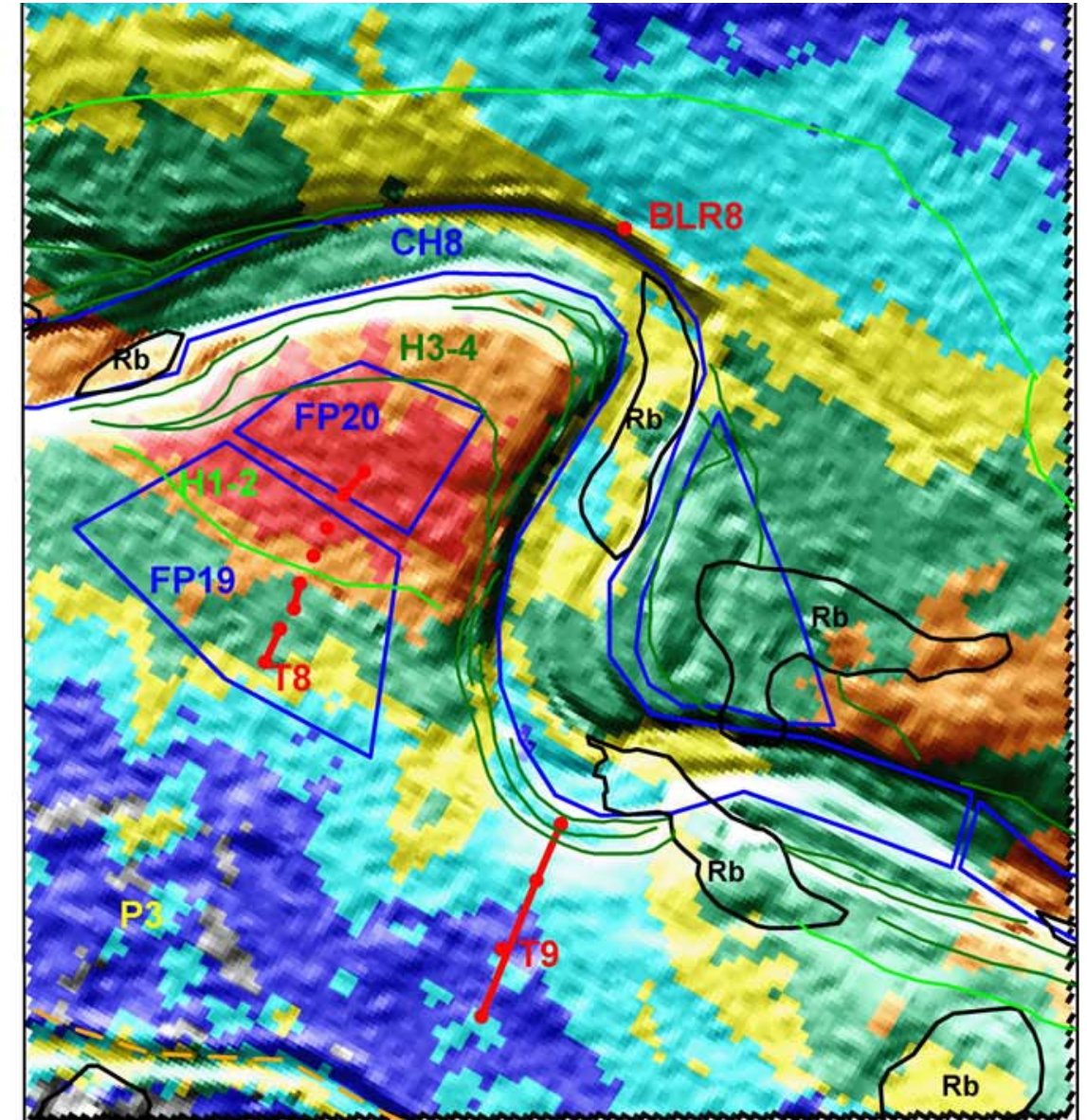

TRIMR2D FLOW MODEL $300 \mathrm{cms}$ ( 10,590 cfs)

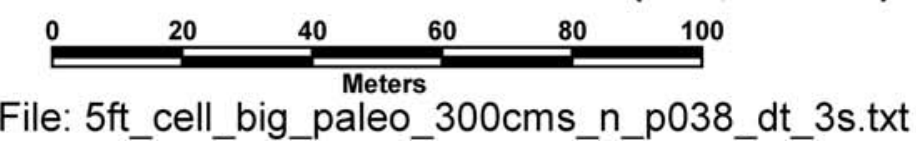

Figure 2-54 5-ft flow model results for $300 \mathrm{~m}^{3} / \mathrm{s}$ in the BLR8 constriction study area. Base map symbology is from Figure 2-3 and Plate 2. 

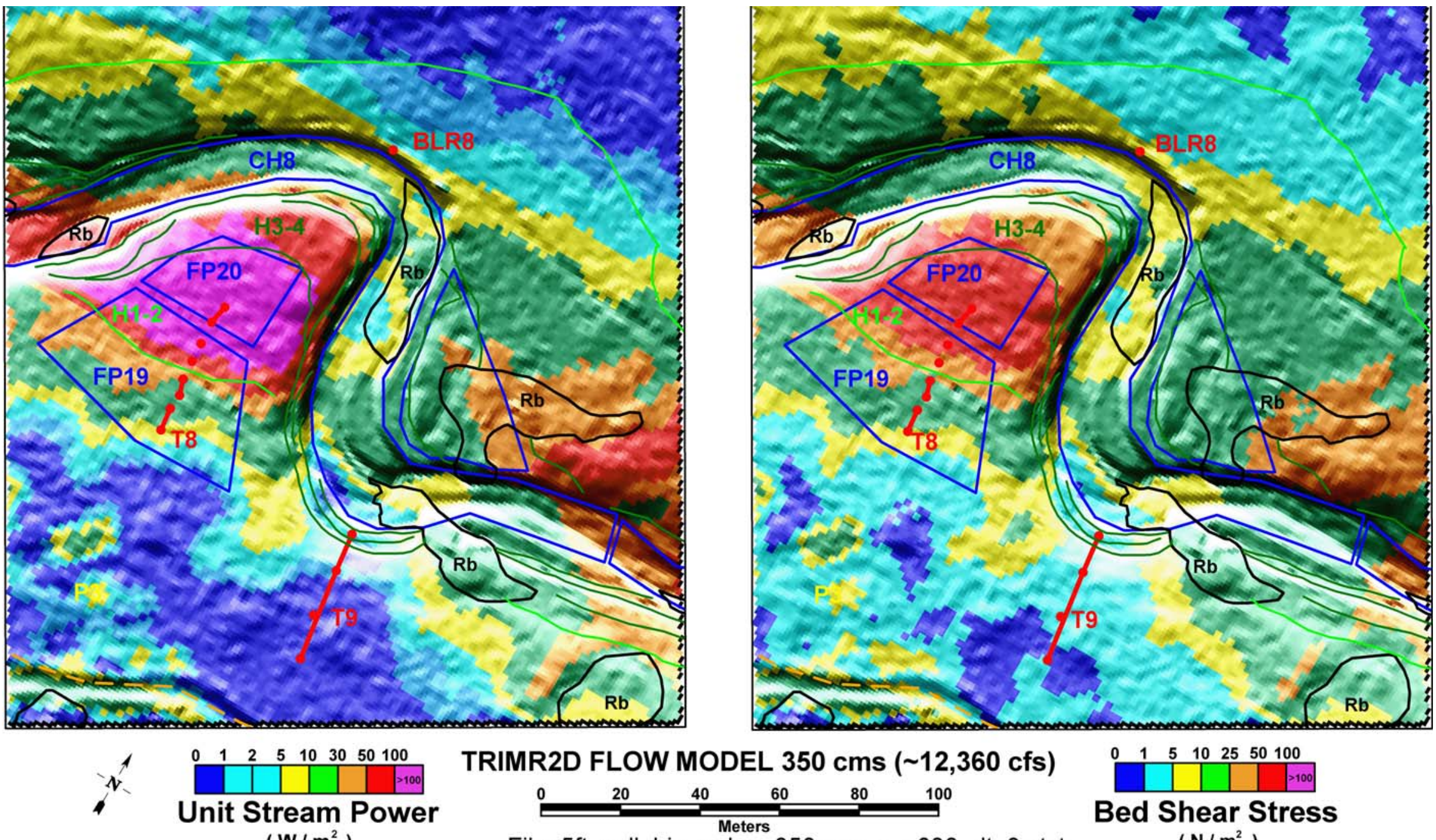

TRIMR2D FLOW MODEL $350 \mathrm{cms}$ ( $12,360 \mathrm{cfs})$ $\left(\mathrm{W} / \mathrm{m}^{2}\right)$

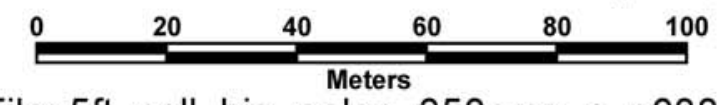

File: 5ft_cell_big_paleo_350cms_n_p038_dt_3s.txt

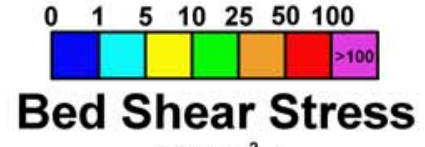

$\left(\mathrm{N} / \mathrm{m}^{2}\right)$

Figure 2-55 5-ft flow model results for $350 \mathrm{~m}^{3} / \mathrm{s}$ in the BLR8 constriction study area. Base map symbology is from Figure 2-3 and Plate 2. 

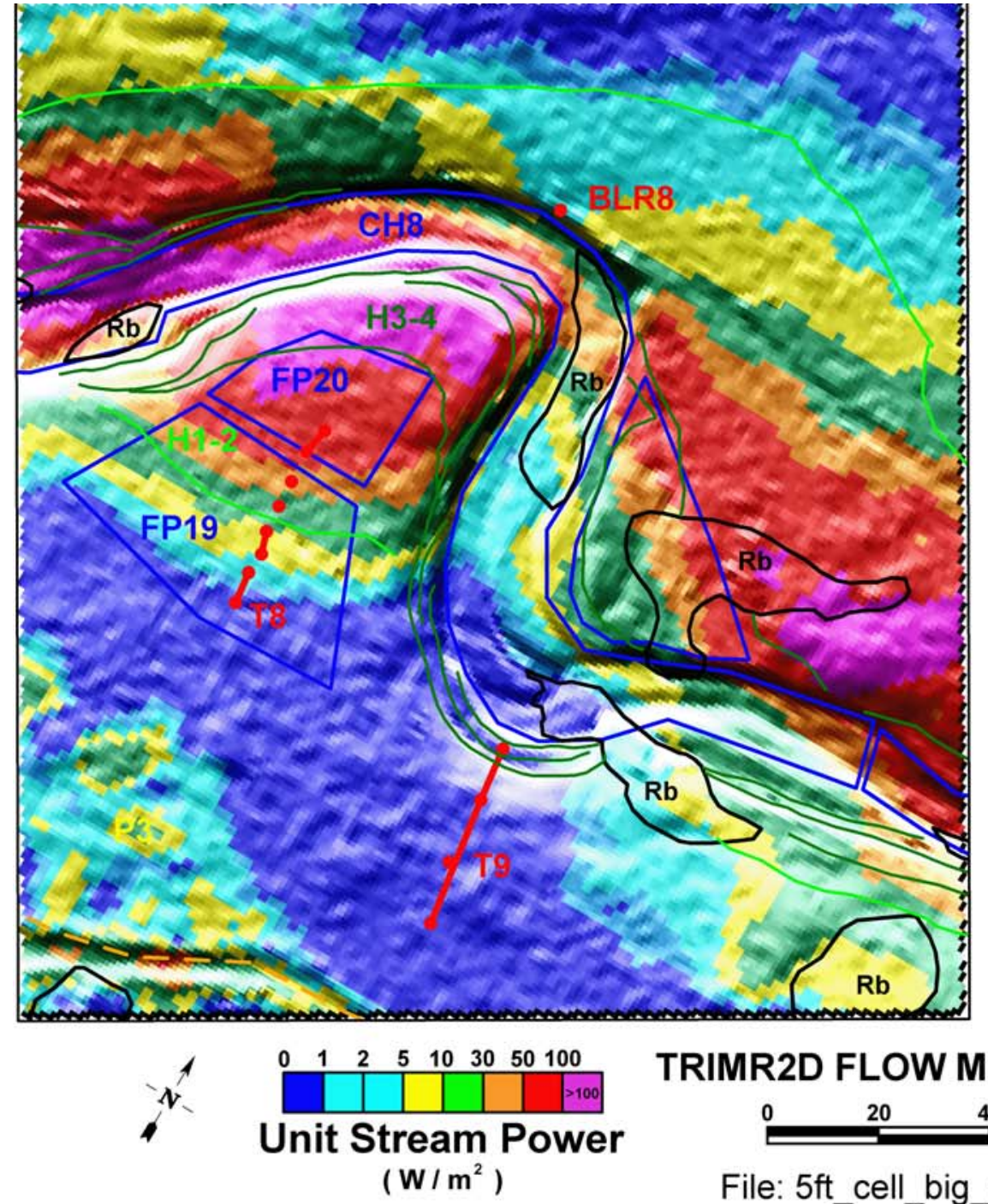

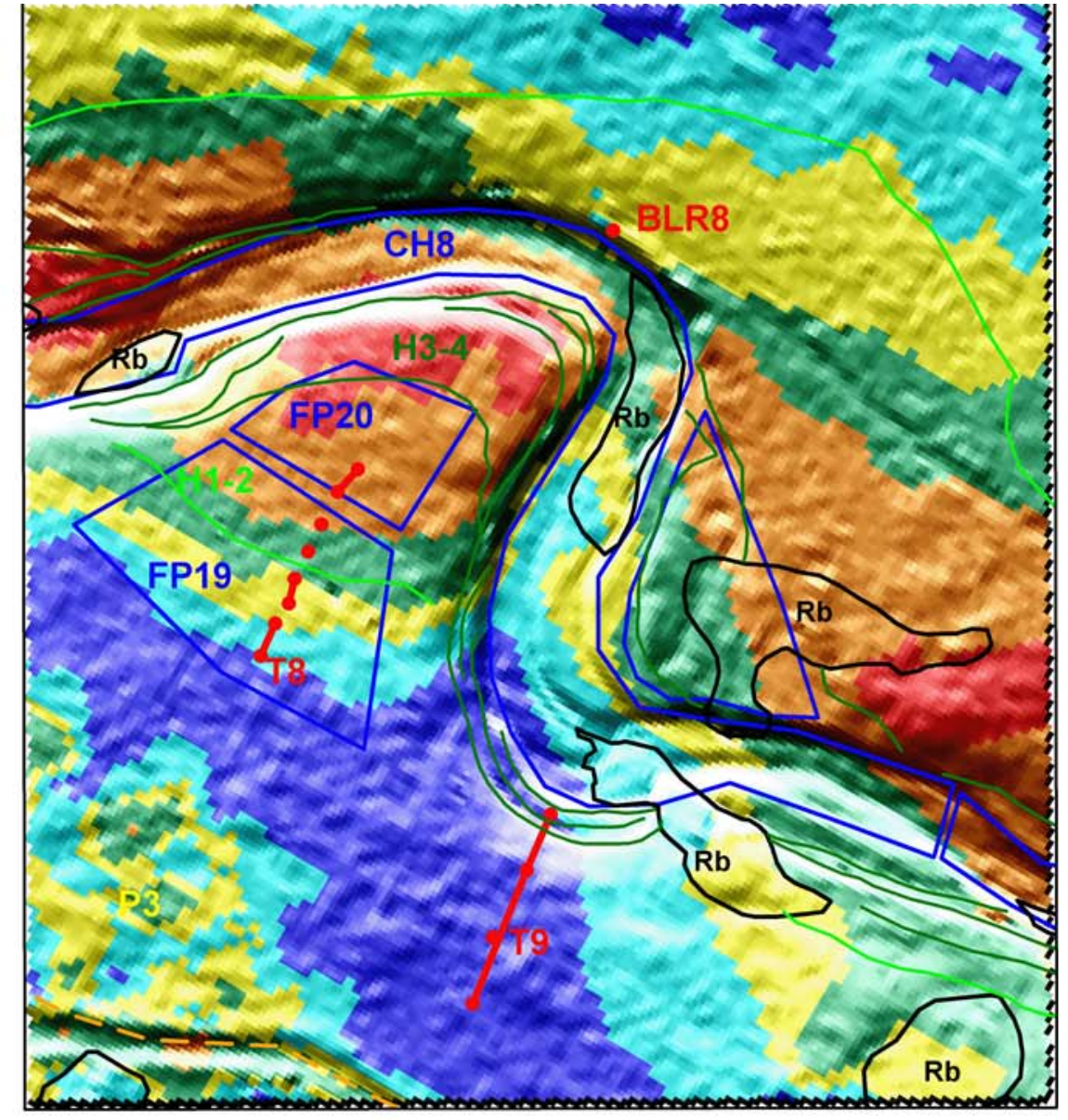

TRIMR2D FLOW MODEL $400 \mathrm{cms}(\sim 14,130 \mathrm{cfs})$

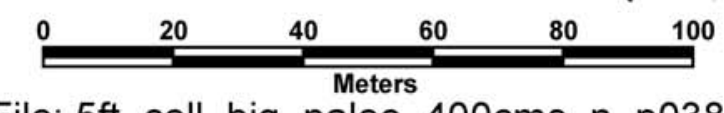

File: $5 \mathrm{ft} \_$cell_big_paleo_400cms_n_p038_dt_3s.txt

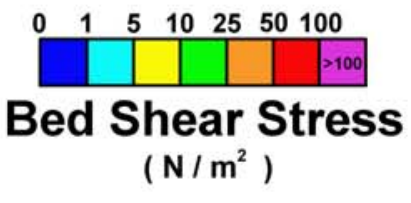

Figure 2-56 5-ft flow model results for $400 \mathrm{~m}^{3} / \mathrm{s}$ in the BLR8 constriction study area. Base map symbology is from Figure 2-3 and Plate 2 . 
Tables for Section 2.0 
Table 2-1 Discharge and modeling scenarios for the INEEL Diversion Dam study reach

\begin{tabular}{|c|c|c|c|c|}
\hline \multirow{3}{*}{$\begin{array}{l}\text { Modeled } \\
\text { Discharge } 1 \\
\mathrm{~m}^{3} / \mathrm{s}\left(\mathrm{ft}^{3} / \mathrm{s}\right)\end{array}$} & \multicolumn{3}{|c|}{ Topography ${ }^{2}$} & \multirow{3}{*}{ Potential Significance of Modeled Discharge } \\
\hline & \multicolumn{2}{|c|}{2000 6-ft grid } & \multirow{2}{*}{$\begin{array}{c}\text { Reprocessed } \\
1993 \text { 5-ft grid } \\
n=0.038\end{array}$} & \\
\hline & $n=0.030$ & $n=0.038$ & & \\
\hline $10(\sim 355)$ & $\mathrm{X}$ & $\mathrm{X}$ & & $\begin{array}{l}\text { Approximate maximum gaged flow downstream of } \\
\text { INEEL Diversion (since } 1984\end{array}$ \\
\hline $12(\sim 425)$ & $\mathrm{X}$ & $\mathrm{X}$ & & \\
\hline $15(\sim 530)$ & $\mathrm{X}$ & $\mathrm{X}$ & & \\
\hline $25(\sim 885)$ & $\mathrm{X}$ & $\mathrm{X}$ & & Approximate INEEL Diversion Dam release capacity \\
\hline $50(\sim 1765)$ & $\mathrm{X}$ & $\mathrm{X}$ & & Range for largest estimated historic floods near INEEL \\
\hline $70(\sim 2470)$ & $\mathrm{X}$ & $\mathrm{X}$ & & Diversion Dam \\
\hline $100(\sim 3530)$ & $\mathrm{X}$ & $\mathrm{X}$ & & $\begin{array}{l}\text { Revised USGS 100-yr flood is } 106 \mathrm{~m}^{3} / \mathrm{s}\left(\sim 3740 \mathrm{ft}^{3} / \mathrm{s}\right) \\
\text { (Hortness and Rousseau, 2002) }\end{array}$ \\
\hline $130(\sim 4590)$ & $\mathrm{X}$ & $\mathrm{X}$ & & \\
\hline $150(\sim 5295)$ & $\mathrm{X}$ & $\mathrm{X}$ & & $\begin{array}{l}\text { Median value for 10,000 yr paleohydrologic bound } \\
\text { (Ostenaa and others, 1999) }\end{array}$ \\
\hline $175(\sim 6180)$ & $\mathrm{X}$ & $\mathrm{X}$ & & $\begin{array}{c}\text { Approximate USGS 100-yr flood downstream of INEEL } \\
\text { Diversion Dam (Kjelstrom and Berenbrock, 1998) }\end{array}$ \\
\hline $200(\sim 7060)$ & $\mathrm{X}$ & $X$ & $\mathrm{X}$ & \\
\hline $225(\sim 7945)$ & $\mathrm{X}$ & $\mathrm{X}$ & & \\
\hline $250(\sim 8830)$ & $\mathrm{X}$ & $\mathrm{X}$ & $X$ & \\
\hline $300(\sim 10,590)$ & & & $\mathrm{X}$ & \\
\hline $350(\sim 12,360)$ & & & $\mathrm{X}$ & \\
\hline $400(\sim 14,130)$ & & & $\mathrm{X}$ & \\
\hline $\begin{array}{l}\text { Notes: } \\
{ }^{1} \text { Steady-s } \\
{ }^{2} \text { All scen }\end{array}$ & $\begin{array}{l}\text { e dischar } \\
\text { os model }\end{array}$ & $\begin{array}{l}\text { input at } \\
\text { with TR }\end{array}$ & $\begin{array}{l}\text { stream end of } \\
\text { MR2D with } 5-0\end{array}$ & $\begin{array}{l}\text { ach, downstream of the INEEL Diversion Dam } \\
\text { 6-ft rectangular grid with input topography as noted. }\end{array}$ \\
\hline
\end{tabular}


Table 2-2 Soils and Radiocarbon Summary

\begin{tabular}{|c|c|c|c|c|c|c|}
\hline $\begin{array}{l}\text { Trench } \\
\text { No. }\end{array}$ & $\begin{array}{c}\text { Field } \\
\text { Sample No. }\end{array}$ & $\begin{array}{c}\text { Sample } \\
\text { Depth } \\
\text { (cm) }\end{array}$ & Material dated & $\begin{array}{l}\text { Laboratory } \\
\text { number }\end{array}$ & $\begin{array}{l}\text { Radiocarbo } \\
\text { n age } \\
\left({ }^{14} \mathrm{C} \text { yr }\right. \\
\text { B.P. }) \pm 1 \sigma\end{array}$ & $\begin{array}{c}\text { Calibrated age } \\
\text { range } \\
\text { (cal yr B.P.) } \\
\pm 2 \sigma\end{array}$ \\
\hline \multirow[t]{5}{*}{$\mathrm{T} 4$} & T4-20-1AR & $20-25$ & Artemisia charcoal & Beta - 174101 & $520 \pm 40$ & 630-600; 560-510 \\
\hline & T4-20-2AR & $38-51$ & Artemisia charcoal & Beta - 174102 & $1070 \pm 40$ & $1060-930$ \\
\hline & T4-19-1AR & $50-60$ & Artemisia charcoal & Beta - 174099 & $1130 \pm 40$ & $1160-950$ \\
\hline & T4-19-1CO & $50-60$ & Conifer charcoal & Beta - 174100 & $1980 \pm 40$ & $2000-1860$ \\
\hline & T4-19-3CH & $140-155$ & $\begin{array}{l}\text { Chrysothamnus } \\
\text { charcoal }\end{array}$ & Beta - 172812 & $6330 \pm 40$ & $7320-7200$ \\
\hline \multirow[t]{2}{*}{ T5 } & T5-0-1AR & $22-32$ & Artemisia charcoal & Beta - 174103 & $780 \pm 40$ & $760-660$ \\
\hline & $\mathrm{T} 5-0-2 \mathrm{CO}$ & $110-130$ & Conifer charcoal & Beta - 174104 & $1880 \pm 40$ & $1900-1720$ \\
\hline \multirow[t]{6}{*}{ T6 } & T6-4-1SA & $12-25$ & Salicaceae charcoal & Beta - 174106 & $630 \pm 40$ & $660-540$ \\
\hline & T6-4-1AR & $12-25$ & Artemisia charcoal & Beta - 174105 & $830 \pm 40$ & $790-680$ \\
\hline & T6-6-1YS & $95-105$ & snail shell & Beta - 183387 & $10390 \pm 50$ & $12800-11940$ \\
\hline & T6-4-2MIX & $103-121$ & charcoal fragments & Beta - 172813 & $3210 \pm 40$ & $3480-3360$ \\
\hline & T6-20-2MIX & $110-140$ & charcoal fragments & Beta - 183388 & $2710 \pm 40$ & $2870-2760$ \\
\hline & T6-68-1AR & $30-40$ & Artemisia charcoal & Beta - 174107 & $620 \pm 40$ & $660-540$ \\
\hline \multirow[t]{3}{*}{ T9 } & T9-32-1PO & $35-45$ & Populus charcoal & Beta - 183391 & $170 \pm 40$ & $\begin{array}{c}290-250 ; 230-130 \\
\quad 110-70 ; 30-0\end{array}$ \\
\hline & T9-32-2CM & $105-115$ & $\begin{array}{l}\text { Chrysothamnus } \\
\text { charcoal }\end{array}$ & Beta - 183392 & $130 \pm 40$ & $290-0$ \\
\hline & T9-2-2AR & $105-115$ & Artemisia charcoal & Beta - 183389 & $2610 \pm 40$ & $2730-2780$ \\
\hline
\end{tabular}


Table 2-3 Geologic and Geomorphic Summary for Big Lost River Paleofloods and Paleohydrologic Bounds

\begin{tabular}{|c|c|c|}
\hline $\begin{array}{l}\text { Event } \\
\text { name }\end{array}$ & $\begin{array}{l}\text { Age or time } \\
\text { span } \\
\text { (Cal yrs or } \\
\text { Cal yr } \\
\text { B.P })^{1}\end{array}$ & Summary of Evidence \\
\hline \multicolumn{3}{|r|}{ Paleofloods } \\
\hline $\begin{array}{l}\text { "white } \\
\text { flood" }\end{array}$ & $\begin{array}{l}>100 \mathrm{yr} \\
\text { (pre- } \\
\text { gaging) but } \\
\text { less than } \\
400-600 \mathrm{yr}\end{array}$ & $\begin{array}{l}\text { Based on thin deposit in T4. Not recognized in T5 or T6 (slightly higher sites). } \\
\text { Possible correlative in T9(?). Age - most likely } 100 \text { to } 150 \text { years based on absence of } \\
\text { soil development }\end{array}$ \\
\hline $\begin{array}{l}\text { "400-yr" } \\
\text { flood }\end{array}$ & $\begin{array}{l}400 \text { to } 600 \\
\text { years }\end{array}$ & $\begin{array}{l}\text { Apparently correlative deposits in T4, T5, T6 (also BLR2, BLR7 \& BLR8) with } \\
\text { similar soils, stratigraphic setting, and radiocarbon ages. Soil has stage I- Bk horizon. } \\
\text { Stripping of A and AB/Bw horizons at T8c, partial stripping at T8b; May represent } \\
\text { more than one flood. }\end{array}$ \\
\hline $\begin{array}{l}\text { "older } \\
\text { flood" }\end{array}$ & $\begin{array}{c}1000 \text { to } \\
2000 \text { years }\end{array}$ & $\begin{array}{l}\text { Deposits with Stage I to I+ Bk horizon that underlie "400-yr flood" deposits in T4, T5, } \\
\text { T6 and T9. Appears to indicate long period of stability with little or no deposition at } \\
\text { these sites before deposition of deposits associated with "400-yr" flood. Similar } \\
\text { stratigraphy at BLR2 and BLR8. Likely represents multiple floods of similar or } \\
\text { smaller maximum discharge. Minimum discharge must inundate FP1-FP4, FP6-8, } \\
\text { most of FP7, FP11-13, FP17-18, and FP19-21, which are areas with H1-2 geomorphic } \\
\text { surfaces that appear to indicate Holocene flooding. }\end{array}$ \\
\hline \multicolumn{3}{|r|}{ Paleohydrologic Bounds } \\
\hline 400-yr \#1 & $400-600$ & $\begin{array}{l}\text { Preservation of recognizable stratigraphy at T4 and T6. No stripping of A-horizons } \\
\text { from the youngest deposits at T4 and T6. Apparently correlative H1-2 geomorphic } \\
\text { surfaces at FP1, FP3-4, FP7, FP11-13, FP17, and FP19-20. }\end{array}$ \\
\hline $\begin{array}{l}\text { early } \\
\text { Holocene } \\
\quad \text { (H1 } \\
\text { surfaces) }\end{array}$ & $\begin{array}{c}6000 \text { to } \\
8000\end{array}$ & $\begin{array}{l}\text { Preservation of stratigraphy in T6, T4, and T8a,b,c. Banks at BLR6 and continuity of } \\
\text { H1-2 geomorphic surfaces along BLR. }\end{array}$ \\
\hline Pleistocene & $>10000$ & $\begin{array}{l}\text { Preservation of Pleistocene gravel surfaces throughout the study reach. Actual age of } \\
\text { the underlying deposits is older than } 12-15 \mathrm{ka} \text { (minimum age of deglaciation) and } \\
\text { some may be older than } 20-25 \mathrm{ka} \text { (Last glacial maximum). Length of time span for } \\
\text { paleohydrologic bound is limited by post-glacial, warmer climate more similar to } \\
\text { present. }\end{array}$ \\
\hline
\end{tabular}




\subsection{PALEOFLOODS AND PALEOHYDROLOGIC BOUNDS FOR THE BIG LOST RIVER}

\subsection{Background to the Use of Paleohydrologic Bounds}

The approach taken for this paleohydrologic analysis is similar to that used for the previous paleohydrologic studies at INL (Ostenaa et al., 1999, 2002) as well as several Bureau of Reclamation flood hazard evaluations for dams throughout the western United States (e.g., Ostenaa et al., 1996, 1997; Ostenaa and Levish, 1997). Flood frequency analyses for these studies incorporate paleoflood estimates and paleohydrologic bounds (Levish, 2002; Levish et al., 1994, 1996, 1997; Ostenaa and Levish, 1996) into nonparametric Bayesian analyses that use likelihood functions that incorporate both parameter and data (discharge and geologic age) measurement uncertainties (O’Connell et al., 1996, 1998; O’Connell, 2005).

A paleohydrologic bound is the time interval during which a given discharge has not been exceeded. Paleohydrologic bounds are not actual floods, but instead are limits on paleostage over a measured time interval. These bounds represent stages and discharges that have not been exceeded since a geomorphic surface stabilized. Through hydraulic modeling, discharge for a paleohydrologic bound can be derived from stage, just as a discharge is derived from the paleostage indicators of past floods. Used appropriately, paleohydrologic bounds are powerful constraints in flood frequency analyses, even if the number, timing, and magnitude of individual paleofloods are uncertain (Stedinger and Cohn, 1986).

In this context, the present analysis only assumes that for extreme floods, upstream regulatory structures and diversions do not increase flood magnitudes downstream compared to the unregulated natural flows, except for cases where upstream regulating structures might fail. Flood probabilities for such scenarios should be evaluated separately, and account for the overall failure probability of the structure under all conditions. The impacts of regulation and variations in smaller flows, such as those of historical experience, on frequency estimates of extreme floods are addressed through sensitivity analyses.

3.1.1 Geologic and geomorphic evidence of flooding. There are many different types of geologic and geomorphic information in fluvial systems that provide a direct indication of the 
magnitude and frequency of floods (e.g., Baker et al., 1988). Gravel bars and slackwater terraces indicate the minimum stage of past floods. Likewise, evidence for past erosion such as channels on terrace surfaces and truncated soil profiles also indicates the minimum stage of past floods. The age and frequency of the floods that produced these features can be determined by the degree of soil development, the morphology and extent of weathering on surface features, and radiocarbon analysis of organic material within the deposits. For historical or more recent paleofloods, floated debris and subtle erosional scars are a shorter-lived record of the maximum stage.

A complementary indication of the limits of past floods is the recognition of the amount of time during which floods have not modified geomorphic features or deposits. Soil development and the geomorphic evolution of deposits and surfaces are time-dependent processes (e.g., Birkeland, 1999). Thus, the age of stable, non-flood-modified geomorphic surfaces adjacent to streams is an indication of the minimum length of time since last flooding (Costa, 1978). Evidence of modification of these surfaces by floods includes the deposition of sediment resulting in burial of soils, erosion and truncation of soils, erosion of channels on the surfaces, or erosion of the deposits themselves. Estimates of the stage required to modify these surfaces can come from empirical comparisons to data from historical floods or by comparison to hydraulic model results of observed flows. The minimum depth of flow required for the initiation of large-scale erosion or deposition on geomorphic surfaces can also be evaluated formally in terms of shear stress or stream power (e.g., Parker, 1978; Andrews, 1984; Baker and Costa, 1987). This type of approach is expanded upon here based on the criteria discussed below and in Appendix $\mathbf{D}$.

\subsection{Criteria and Approach for Evaluating Paleohydrologic Information}

In evaluating discharge estimates for paleohydrologic bounds, the focus is on developing an estimate of the flood discharge required to modify or erode a geomorphic surface for which stability can be demonstrated for some prior length of time (e.g. Levish, 2002). Evidence of surface stability is primarily shown by the consistency of soil development and stratigraphy that underlie the surface. These geomorphic surfaces are most often terraces, adjacent to the main stream channel. Many geomorphologists have used stream power as a measure of the potential for channel and landscape modification with a focus on channel power or average cross section 
power (e.g., Baker and Costa, 1987; Magiligan, 1992). For engineering applications of erosion, channel stability, and sediment transport studies, many empirical and semi-theoretical relationships have been developed for hydraulic parameters such as depth, velocity, shear stress and stream power (e.g., see Carson and Griffiths, 1987 for a summary). However, in neither body of literature are there many examples of sites which might be considered long existing paleohydrologic bounds which have been overtopped by historical floods, and associated model estimates of the flow parameters associated with this overtopping developed. As noted by Jarrett and England (2002), documentation for the relationships between HWM (high water marks) and the estimated stage required to modify a geomorphic surface and thus define a paleohydrologic bound is lacking in the general literature.

Previous paleohydrologic studies of the Big Lost River recognized the value of using stream power or shear stress as quantitative measures of the erosional potential of stream flow across geomorphic surfaces that might be considered as paleohydrologic bounds (Ostenaa et al., 1999, 2002). However, no quantitative criteria for application of these measures to evaluating discharge and associated uncertainty estimates for paleohydrologic bounds were proposed. Ostenaa et al. (1999) noted the presence of "high" stream power and inundation depths typically in the range of 25-90 cm (1-3 ft) as a justification for establishing bounds. Ostenaa et al. (2002) compared modeled channel stream power for a discharge that had significant gravel bedload transport to modeled power on Pleistocene surfaces downstream of a site termed the Saddle. Power in both cases was noted to be in the range of 50 to $>100 \mathrm{~W} / \mathrm{m}^{2}$. Ranges of inundation depths were noted along with observations that shear stress calculations would indicate potential mobility of $2 \mathrm{~mm}$ particles for flow depths as shallow as $5-18 \mathrm{~cm}$.

In the present study, we develop a more formal framework for the application of shear stress and stream power to the problem of specification of discharge estimates for paleohydrologic bounds. The difficulties associated with developing conclusions within this framework are similar to those faced in seismic hazard assessment (e.g., SSHAC, 1995), in that uncertainty of the estimates is derived from several sources including limited data, imperfect knowledge and models of salient physical processes, and legitimate differences of scientific opinion. 
Three major types of information are used to estimate the discharge range associated with a paleohydrologic bound: 1) stratigraphic and geomorphic data, 2) hydraulic modeling results of depth, stream power, and shear stress for differing input parameters, and 3) a criterion for erosion/modification of geomorphic surfaces based on empirical data compilations of unit stream power and bed shear stress. Results of the geologic/geomorphic investigations were described and compiled in Section 2.4, Plate 2, and Appendix B. The hydraulic modeling approach and results were discussed in Section 2.5 and portrayed on plots in Appendix D. A criterion for erosion/modification of geomorphic surfaces based on stream power and shear stress is developed in Appendix D and implemented below.

Geomorphic map units define the spatial extent of areas with similar geologic/geomorphic processes and history. Individual map units are characterized by similarity in relative and absolute age, geomorphic processes and history over broad areas. Differences in age, process, and history between different areas define different geomorphic units. Thus, based on detailed mapping and trenching investigations along the Diversion Dam study reach of the Big Lost River (Plate 2, Appendix B, and Section 2.4), three major geomorphic map groups, H1-2, H3-4, and P2-3, are of primary importance to the issues of specifying paleohydrologic bounds. The similarities and differences within these broad map units are highlighted and defined through "point" investigations with trenches or soil description sites where stratigraphic details are described in detail. These detailed site descriptions provide the basis for areal extrapolation represented by the areal extent of the geomorphic map units. Individual geomorphic map unit areas naturally define the spatial limits of areas within which the variability of hydraulic parameters such as stream power and shear stress can be evaluated when that geomorphic unit is inundated by a modeled flow.

Two-dimensional hydraulic modeling based on relatively small grid cells is used to develop detailed information on the extent and spatial variability of flow for each modeled discharge. From the model results, shear stress and stream power are calculated for each grid cell providing a detailed depiction of the magnitude and spatial variability of these parameters over the inundated areas. This information can then be compared to the spatial extent and characteristics of differing geologic/geomorphic units. Results from the two-dimensional modeling of each discharge that are 
used to evaluate paleohydrologic information are 1) depth and spatial extent of inundation over a particular stratigraphic site or geomorphic surface, 2) magnitude and spatial extent of shear stress and/or stream power over a site or geomorphic surface, and 3) magnitude and spatial extent of shear stress and stream power in channel reaches. Evaluation based on depth and extent of inundation primarily considers whether or not a particular site or surface area is inundated by a given flow. For many sites, as a greater percentage of a given site or geomorphic surface is inundated, to progessively greater depths, the probability of surface modification and development of a preservable geologic record increases. Likewise, as the extent and depth of inundation increase, the magnitude and distribution of stream power and shear stress change across the geomorphic surface as well.

The hydraulic conditions associated with flow across a geomorphic surface are varied and nonuniform due to topography, small- and large-scale roughness, turbulence, and mixing. Thus, actual and calculated values of stream power and shear stress vary spatially in magnitude across a given cross section and throughout the area of flow. The results or conclusions drawn from application of any criteria for surface modification is therefore dependent on the location chosen for evaluation. One advantage of the use of high-resolution, two-dimensional hydraulic models is that these models provide outputs that show the spatial variability of flow characteristics. Ideally, the spatial variability shown by hydraulic modeling can be evaluated separately for each geomorphic surface of interest.

The third major type of information used to estimate discharge associated with a paleohydrologic bound are empirical criteria and observational data on the magnitudes of stream power and shear stress that are likely associated with modification or erosion of differing geomorphic surfaces (Appendix D). From these data, limiting values for the estimated erosion or modification of differing surfaces can be subjectively estimated for the specific surface conditions and physical properties (e.g., vegetation, soil, and grain size) of each site or geomorphic surface. Because estimates of paleohydrologic bounds will ultimately have a probabilistic description for use in the flood frequency analyses (Section 4.0), these criteria are formulated as Probability Density Functions (PDF) that relate the relative probability of surface modification to particular values of shear stress or stream power. In general, the PDF's that describe the probability of surface 
modification are triangular distributions based on 3 estimated values. A lower value of shear stress or stream power represents a limit for which there is judged to be a reasonable possibility based on the existing empirical data that significant erosion or surface modification will occur. A central or preferred value represents a large body of data with high confidence. For some PDF's, the central values include a range of equal relative likelihood. An upper value limit defines a boundary beyond which there is virtual certainty of significant erosion or modification based on the available data. For application to the Diversion Dam reach of the Big Lost River, three separate criteria have been developed for stream power and shear stress, respectively (Figure 3-2 and Figure 3-3) and Appendix D). Two of the criteria are for application to differing site, soil, and geologic conditions associated the geomorphic surfaces along the Big Lost River (Figure 3-2). The third criteria describes the more general conditions under which significant geomorphic modification of portions of the Big Lost River channel might result from various discharge levels (Figure 3-3).

Soils and geologic data from the Big Lost River lead to two general categories for erosion and surface modification, termed soil erosion and terrace erosion, based on the contrasting physical and vegetative characteristics of the soils and terrace deposits. Most of the alluvial soils have an upper horizon(s), usually less than $30 \mathrm{~cm}$ thick, composed of silt and sand which is generally loose and unconsolidated. These horizons, usually designated as $\mathrm{A}, \mathrm{AB}$, and sometimes $\mathrm{Bw}$ in soil descriptions (Section 2.1 and Appendix B), lack carbonate cementation, are often bioturbated, and may include in their upper portions some component of recently active eolian sand. Some small grasses and plants have shallow roots in these horizons. In contrast, at most stream terrace sites, below a depth of more than 20-30 cm in most profiles, there is either carbonate cementation or gravel. In deposits that are mostly fine-grained, i.e., silty and sandy, soils with carbonate accumulation are stage I to II. In the gravel deposits maximum clast sizes are generally less than $200 \mathrm{~mm}$, and carbonate stages range from Stage I to III. Larger plants, such as sage, have widely scattered roots that extend into the gravel horizons. Based on the carbonate cementation and generally larger clast size associated with the terrace deposits, larger values of stream power and shear stress are required to initiate erosion relative to the alluvial soils. 
The criteria developed for channel stability (Figure 3-3) is mainly derived from geomorphic study observations of major channel widening or change following floods (Appendix D). This criteria is only applicable to channels where banks are cut in alluvium. Most channel banks along the Big Lost River Diversion Dam study reach are composed of fine-grained alluvium with weakly to moderately developed carbonate soils similar to sections exposed in T4, T5, T6, BLR2, BLR6, BLR7 and BLR8. Gravel, in Holocene fluvial deposits, is not present more than about $1 \mathrm{~m}$ above the present channel floor at these exposures. Based on geomorphic mapping (Plate 2), only very scattered sections of the channel banks are cut directly in the gravelly Pleistocene alluvium without an inset fine-grained fill terrace. More commonly, scattered basalt outcrops confine one or both channel banks.

\subsubsection{Evaluating Spatial Extent and Variability.}

The geomorphic maps and the hydraulic modeling results are both two-dimensional datasets that can be overlain and evaluated jointly. This approach allows the spatial extent of geomorphic surfaces and inundation to be evaluated along with the spatial variability of hydraulic modeling results for specific sets of geomorphic surfaces. This type of evaluation could be done in a strict GIS-style, where the full extent of each map unit is evaluated separately, but that approach has not been used here because the mapped geomorphic units include many transitional slopes and areas that are not ideally representative of sites that would be suitable for evaluating paleohydrologic bounds. Specifically, this includes areas such as broad slopes on risers between terraces where some slope erosion and deposition is ongoing, irrespective of the paleoflood and fluvial processes of the Big Lost River. Long-term geomorphic stability cannot generally be demonstrated for these types of transitional areas. For that reason, a more restricted subset of the key geomorphic surfaces were selected for evaluation. Within the Big Lost River Diversion Dam reach, 30 subareas were defined based on geomorphic characteristics (Figure 3-4). The boundaries of each subarea were drawn to generally lie within the extent of a single geomorphic map unit along the Big Lost River. Most of the subareas are of sufficient size to include hundreds of computational cells from the hydraulic modeling results and include thousands of square meters of individual geomorphic surfaces. One way of reducing uncertainty associated with paleohydrologic conclusions is to expand the spatial extent of that data throughout a study reach. 
The detailed geomorphic and spatial characteristics of the subareas are summarized in Table 3-1 and Table 3-2. Twenty-one subareas, FP1 to FP21, are located on the Holocene and Pleistocene geomorphic surfaces adjacent to the Big Lost River. These subareas range from small areas surrounding the individual trenches, (e.g., FP12 near T4) to subareas which encompass extensive areas of the Pleistocene surfaces flanking the Big Lost River (e.g., FP5 and FP15). Nine subareas, CH1 through CH9, were defined within the channel of the Big Lost River. These channel reaches differ in sinuosity, bed and bank materials, and hydraulic characteristics.

Within each subarea, values for inundation, stream power, and shear stress from each flow simulation are plotted relative to the threshold values for modification defined by empirical data (e.g., end points and peaks on Figure 3-2 and Figure 3-3). From the resulting plots (e.g., Figure 35 and remaining plots in Appendix D) a range of discharge values can be defined for each subarea that corresponds to the subjective probability thresholds for modification based on stream power or shear stress. A minimum discharge level for these values is first imposed by the requirement that 90-100 percent of the subarea is inundated by the simulated discharge. This is imposed to assure the uniformity of geomorphic processes within each subarea. Because the subarea boundaries are primarily defined by geomorphic boundaries, and because the age of geomorphic surfaces within each subarea are interpreted to be constrained by similar geologic factors, for flood modification of these surfaces nearly complete inundation is generally a minimum requirement. Inundation extent that is less than 100 percent is allowed for surfaces that include original depositional or erosional relief unrelated to flood modification. This would include transitional areas such as terrace risers that exist between surfaces of differing ages, or constructional relief associated with abandoned bars and channel features. Discharge values that correspond to the erosion/modification thresholds (i.e., PDF of Figure 3-2 and Figure 3-3) are then estimated by choosing a percentage of the subarea that must exceed the threshold value for erosion/modification. The two-dimensional hydraulic modeling demonstrates the spatial variability of hydraulic conditions across individual surfaces. Because the subareas are very large (see Table 3-1 for sizes), and the scale of geomorphic mapping and observation is also large, geomorphic change that is detectable within the scale of this investigation should result when threshold values are exceeded over much less than 100 per cent of most of the subareas. For the present scale of mapping along the Big Lost River, geomorphic features that are less than about 
$10 \mathrm{~m}^{2}\left(108 \mathrm{ft}^{2}\right)$, such as outcrops, dunes, mounds, and small channels, are readily observable and detectable. Thus, even for the smallest of the subareas, use of a value of 50 percent area for exceedence of the threshold values of stream power or shear stress corresponds to minimum areas of $35 \mathrm{~m}^{2}\left(377 \mathrm{ft}^{2}\right)$, and for most subareas, it is hundreds or thousands of square meters. The subarea percentages and the discharge ranges derived from analysis of each of the subareas are tabulated in Table 3-3.

\subsubsection{Uncertainty in Discharge Estimates of Modification for each Subarea.}

Overall, the uncertainty in the discharge ranges estimated from each subarea is mostly derived from three main sources. The first is the variability in calculated stream power and shear stress that results from changes in the input hydraulic model parameters such as discharge, roughness, or topographic model. This uncertainty is displayed for each subarea by comparison of the curves based on similar discharge, but varied roughness or topographic input, or comparing changes resulting from successive discharge values (e.g. Figure 3-5 and plots in Appendix D). As such, the ranges compiled in Table 3-3 directly incorporate this uncertainty for range of input parameters used in the simulations.

The second source of uncertainty lies in the PDF's (e.g., Figure 3-2) that describe the relative probability of erosion or modification associated with variation in stream power or shear stress. This source of uncertainty is directly linked to the choices and relevance of threshold values from empirical data to associate with surface modification (Appendix D). The tabulated empirical data on which these thresholds are based were collected according to a wide variety of scientific and engineering protocols. It is therefore difficult to directly link all of these results directly to the present framework of flow simulation and calculation used in the present study. Further research and data compilation, conducted specifically within the framework of modern two- and threedimensional flow modeling, is needed to rigorously evaluate whether the present range of values chosen to characterize the erosion/modification thresholds are appropriate, or not. Determining the proper basis for describing and characterizing the spatial variability of flow parameters and erosion over extent varied geomorphic surfaces is a critical component of this uncertainty.

The third source of uncertainty lies in the delineation and choices for the areal extent of a subarea or geomorphic surface which must meet the threshold criteria. This latter factor is somewhat 
minimized because stream power and shear stress values develop rapidly over most of the individual subareas with increases in discharge. Thus, the curves on Figure 3-5 and the additional plots in Appendix D are generally very steep, meaning that for most subareas, changing the required percentage that must exceed the threshold does not substantially change the estimate of discharge. Additional small uncertainty is derived directly from the delineation of the subarea boundaries from the geomorphic and geologic data. The extent to which the subareas are reasonable subdivisions or groupings of the geomorphic units can be judged subjectively by comparison of the subareas and geomorphic mapping. As noted above, use of the presently mapped geomorphic boundaries in lieu of the subareas would result in inclusion of larger percentages of transitional topography with increased geologic complexity and variability.

3.2.1.2 Combining Estimates from Multiple Subareas. Sample subareas for stream power and shear stress are located throughout the Diversion Dam study reach (Figure 3-4). Hydraulic conditions vary throughout the study reach and although many subareas are located on geomorphic surfaces of similar age where there will be variability within a subarea (Section 3.2.1), estimates of unit stream power and bed shear stress are expected to vary between subareas as well. Thus, a consistent approach for combining results from multiple subarea sites is required. For paleofloods, the observed geologic or geomorphic evidence should relate to a pattern of modeling results that is consistent with a single discharge range throughout the study reach. Thus, the estimated discharge for the paleoflood must 1) inundate all sites where correlative flood deposits are observed; and 2) have stream power and shear stress distributions that are consistent with the observed distributions of fine- and coarse-grained deposits of the paleoflood as well as any evidence of erosion that can be associated with the flood. Estimates from multiple sites should be generally consistent if all the sites are associated with a common paleoflood discharge. In contrast, because a paleohydrologic bound represents an exceedence of prior events, and is possibly a hypothetical event that was not associated with deposition of the preserved deposits or geomorphic surfaces, modeled hydraulic conditions may vary greatly between sites of similar age within a reach. Some sites will inevitably be much more strongly limiting than other sites even though they may be of the same general age. This is perhaps most easily illustrated by considering the broad areas of the Pleistocene P2 surfaces that flank the Big Lost River. As the hydraulic modeling results show, these surfaces are slowly and variably inundated over a broad range of 
discharge (Section 2.5 and Section 3.2.1). Thus, the estimated discharge required to modify any subsection of the P2 surfaces will vary substantially and for some sites, the criteria for modification (e.g., Figure 3-2) may never be met, regardless of discharge. In contrast, some areas of the Pleistocene surfaces may be sites where modification is highly likely at very shallow inundation. These types of sites are more strongly limiting as a basis for evaluating a paleohydrologic bound.

Comparison of possible discharge estimates from several subareas for any group of similar-age surfaces might yield a broad range of discharge values for a paleohydrologic bound, but the final choice of values to describe the bound can be limited to a more narrow range that best describes the uncertainty associated with estimates for a subset of the most strongly limiting sites. Limiting the range based on fewer sites may still be conservative depending on the number and characteristics of the initial group of subareas evaluated. There is no assurance that the subareas chosen include the most strongly limiting site for any age group. On the other hand, initial delineation of the subareas (Section 3.2.1) is based on a requirement that the subareas be large enough to include a geologic/geomorphic record or deposit that could be preserved and recognized over geologic time scales.

\subsection{Age and Discharge Estimates for Paleofloods}

The geologic investigations summarized in Section 2.4 identified stratigraphic evidence for at least three paleofloods along the Big Lost River that exceeded the stage and discharge of floods in the historic record (Table 3-5). Stratigraphic data from trenches and exposures defines the number, relative sizes, and relative ages of these paleofloods. Geologic age-dating methods provide the absolute ages and uncertainty ranges (Section 2.3 and Figure 2-8). Estimates of discharge ranges for the paleofloods are based on the hydraulic modeling results (Section 2.5) and the approaches discussed above in Section 3.2. The basis for reaching age and discharge conclusions for each of the paleofloods is discussed separately below. Summary data for discharge limits from each subarea are compiled in Table 3-3. Table 3-4 summarizes the applicability of each subarea to evaluation of the individual paleofloods and paleohydrologic bounds. 
3.3.1 "White Flood". Stratigraphic evidence for this flood is recognized at a single site, Trench T4 (Section 2.3.2.1). A thin, $\sim 7 \mathrm{~cm}$, deposit of silty sand caps the sequence of flood deposits in lowest portion of trench T4, stations 19-21, and appears to bury the soil formed on deposits of the underlying "400-yr" flood. Soil descriptions (Appendix B) designate this unit as the A1-horizon of the present soil and soil development is weak in comparison to other sites. The deposit is not associated with historic floods because no historic floods would have been large enough to inundate the site (Section 2.1.1 and Figure 2-6). No similar deposit is present or recognized in trenches $\mathrm{T} 5$ or $\mathrm{T} 6$, both of which are only slightly higher relative to discharge at which they are inundated (e.g. Figure 2-6) and it does not appear that soils in deposits of the "400yr" flood are eroded more recently at these sites (Section 2.3.2.2 and Section 2.3.2.3). A radiocarbon age from the underlying A2 horizon at T4 has a calibrated age range between 630510 cal yr B.P. (Table 2-2 and Appendix B). Deposits in lowest portions of trench T9 have young radiocarbon ages (Section 2.3.3.2 and Table 2-2), but are also inundated by discharges that might have occurred prior to construction of the INEEL Diversion Dam (Figure 2-7). Thus, the age of a paleoflood associated with this deposit is constrained to be prior to the beginning of streamgaging records (A.D.1903) by the minimum discharge required to reach the site. The deposit is younger than the 630-510 cal yr B.P. age from the underlying soil, and is most likely about 100150 years based on the relative soil development.

The discharge range for this flood is narrowly constrained by modeling results at the site. A minimum discharge of $70-80 \mathrm{~m}^{3} / \mathrm{s}$ is required to inundate the deposit (Figure 2-6). As discharge increases, unit stream power and bed shear stress increase very rapidly at trench T4 (Figure 2-31, Figure 2-32, and subarea FP12 in Table 3-3 and Appendix D - Figure D3-17). This constraint indicates that a discharge of more than $100 \mathrm{~m}^{3} / \mathrm{s}$ would have been very likely to have resulted in erosion of the underlying deposits between stations 20-21 of trench T4. Discharges larger than $100 \mathrm{~m}^{3} / \mathrm{s}$ (Figure 2-32) would also result in inundation of the "400-yr" deposits in the lower elevation portions of trenches T5 and T6. Discharge less than $100 \mathrm{~m}$ \% $/ \mathrm{s}$ is consistent with the lack of evidence for very young erosion at the Big Loop subarea FP9 (Appendix D - Figure D3-14) and at the BLR8 study area (subarea 20 - Appendix D - Figure D3-25 and trench T8c - Section 2.3.3.1). These constraints lead to limiting the estimated discharge for this paleoflood to a range of 80-100 $\mathrm{m}^{3} / \mathrm{s}$ (Table 3-5). 
3.3.2 "400-yr Flood". Stratigraphic evidence for this paleoflood was recognized in the earlier paleoflood study by Ostenaa et al. $(1999,2002)$ at four sites in the Diversion Dam study reach (Figure 2-11). Deposits with similar soils and stratigraphy that are apparently correlative are present in trenches T4, T5 and T6 (Figure 2-8 and Section 2.3.2). These deposits appear to be associated with the prominent geomorphic expression of the $\mathrm{H} 2$ surface that can be mapped throughout the study reach (Plate 2 and Section 2.2.3). Soil development in these deposits, and radiocarbon ages from these deposits and from underlying deposits constrain the age to about 600 - 400 cal yr B.P. (Figure 2-8).

Because the flood deposits recognized by Ostenaa et al. $(1999,2002)$ and in the trenches for this study appear to be associated with $\mathrm{H} 2$ geomorphic surface, one constraint for the discharge of this paleoflood is that the discharge be large enough to inundate the full extent of this surface throughout the study reach. As shown by the plots in Appendix D - Electronic Supplement that cover the entire study reach and the individual study area plots (Figure 2-12 through Figure 2-56) this constraint is met for modeled discharges between 100 to $130 \mathrm{~m}^{3} / \mathrm{s}$. The most strongly limiting sites for the lower discharge limit of this flood appear to be the H1-2 surface in the vicinity of trench T6 (Figure 2-33) and at the BLR8 study site near trench T8a (Figure 2-46). Modeled discharges of only slightly less than $130 \mathrm{~m}^{3} / \mathrm{s}$ are required at both of these sites to inundate the extent of flood deposits (T6 - Section 2.3.2.3) or young erosion (T8a,b - Section 2.3.3.1).

An upper limiting discharge for this paleoflood is derived from the observation that in trenches T4, T5, and T6 (Section 2.3.2) deposits of the "400-year" paleoflood overlie only slightly eroded soils formed in older flood deposits. At T8a,b (Section 2.3.3.1), preservation of Bk horizons in older flood deposits suggests that the primary record of the "400-yr" paleoflood at that site is only limited erosion of upper-most soil horizons. Comparison of unit stream power and bed shear stress values from the subareas that include these sites, and other H1-2 surfaces in the study reach indicates that once discharge exceeds about $175 \mathrm{~m}^{3} / \mathrm{s}$, the criteria for terrace erosion is being exceeded at multiple sites throughout the reach (Table 3-3 and Figure 3-6). Thus, if the paleoflood discharge exceeded $175 \mathrm{~m}^{3} / \mathrm{s}$, much more extensive erosion should have been associated with these deposits in the trench exposures. Discharge in the range of $130-175 \mathrm{~m}^{3} / \mathrm{s}$ is consistent with the muted expression of earth mounds on the large area of P3 surface northwest of trench T1 
(Plate 2 and subarea FP 6, Figure 3-4). In this discharge range, unit stream power and bed shear stress criteria for soil erosion are exceeded over most of this surface (Appendix D - Figure D3-11 and Figure 3-6). In the same discharge range, minor flow is initiated through the braid channel traversed by trench $\mathrm{T} 1$, consistent with soils and stratigraphy in the trench and nearby geomorphology (Section 2.3.1.1). However, for discharge greater than $175 \mathrm{~m}^{3} / \mathrm{s}$, unit stream power and bed shear stress increase in this channel (e.g., Figure 2-15) implying that significant erosion would be expected.

3.3.3 "Older Flood". Trench and bank exposures along the H1-2 surface all demonstrate that the deposits of the "400-yr" paleoflood overlie eroded soils developed in slightly older, similar flood deposits (Ostenaa et al., 1999, 2002; and Section 2.3). The soils in these deposits are generally similar, or slightly more developed than soils developed in the past 400-600 years. This implies a similar length of time over which no flood either eroded or resulted in significant deposition over these deposits. Likewise, the limited extent of the deposits of the "400yr" flood relative to the H1-2 surface indicate that overall, the surface must be a composite of deposits with similar origins, but differing ages. The significant scatter in radiocarbon ages from site to site, and the variability in soils that underlie the "400-yr" flood deposits appear to support this concept. As shown on Figure 2-8, there is much less correlation of the potential time brackets for a single older flood than for the "400-yr" paleoflood and some possibility that multiple floods may have occurred in the time interval since about 3000 cal yr B.P. However, both the stratigraphic and the chronologic resolution to define multiple floods in this time period are lacking in the present exposures. The existing age constraints appear to indicate that a conservative age range for this flood would lie in the range of 2000 to $1000 \mathrm{Cal}$ yr B.P.

The discharge range estimate (Table 3-5) for older flood(s) represented within deposits that underlie the H1-2 surface is similar to that for the "400-yr" flood. A minimum discharge must inundate the full extent of the H1-2 surface; an upper limiting discharge must not impose unit stream power and bed shear stress loads that would result in erosion of underlying and adjacent deposits. For these reasons, the same range of discharge, $130-175 \mathrm{~m}^{3} / \mathrm{s}$, is judged to be appropriate for possible "older" paleofloods as for the "400-yr" paleoflood. The spatial extent, and depth of flow, associated with this range of discharge envelopes all of the stratigraphic and 
geomorphic evidence of Holocene paleofloods that has been observed along the Diversion Dam study reach (Section 2.4).

\subsection{Age and Discharge Estimates for Paleohydrologic Bounds}

The geologic data show that over different time intervals and areas along the Big Lost River, there is evidence of relative geomorphic stability. Thus, the preservation of paleoflood deposits as the surface units on portions of the H1-2 geomorphic surfaces shows that no floods large enough to modify or remove these deposits have occurred since the time of those paleofloods. As summarized in Section 2.4, there is stratigraphic and geologic data along the Big Lost River that allows for defining three paleohydrologic bounds that span differing time intervals over the past 10,000 years (Table 3-5). Geomorphic mapping delineates the characteristics and extent of surfaces of similar age that are potentially useful as paleohydrologic bounds (Section 2.1.2). Stratigraphic data from trenches and exposures defines the characteristics of the surfaces and the evidence for relative surface stability over time. Geologic age-dating methods provide the absolute ages and uncertainty ranges (Section 2.3 and Figure 2-8). Estimates of discharge ranges for the paleohydrologic bounds are based on the hydraulic modeling results (Section 2.5) and the approaches discussed above in Section 3.2. The basis for reaching age and discharge conclusions for each of the paleohydrologic bounds is discussed separately below. Summary data for discharge limits from each subarea are compiled in Table 3-3. Table 3-4 summarizes the applicability of each subarea to evaluation of the individual paleofloods and paleohydrologic bounds.

3.4.1 400-yr Flood Bound. In trenches at the Saddle Constriction study area, deposits of a paleoflood with an age of 400- to 600- years are the parent materials of the surface soils (Section 2.3.2). Weakly developed soils developed in the flood deposits at these sites indicate that no significant erosion or deposition by other floods or other geomorphic processes have disrupted these surfaces in that time span. Similar relationships, preserved at multiple sites, demonstrate stability of these surfaces since the time of the "400-yr" flood, approximately 400 - to 600 -years ago (Section 3.3.2). Even at trench T4, where the "400-yr" deposits are buried by thin deposit of a younger paleoflood, the soil profile in the underlying deposits is intact, indicating that this site was not significantly eroded by that flood (Section 3.3.1), and hence has been stable since 
deposition 400-600 years ago. Throughout the reach, the H1-2 surfaces which include these deposits are unmodified by younger erosion (Section 2.2.3 and Plate 2).

The H1-2 surfaces and deposits of the "400-yr" flood are preserved in many differing hydraulic settings throughout the Diversion Dam study reach. Thus, for use as a paleohydrologic bound, some of these sites are much more strongly limiting than others (Section 3.2.1.2). In particular, at Trench T4, unit stream power and bed shear stress increase very rapidly with increasing discharge (Figure 2-31, Figure 2-32, and subarea FP12 in Table 3-3 and Appendix D - Figure D3-17). These data indicate that this site would be likely be subject to significant soil erosion at a discharge exceeding about $100 \mathrm{~m}^{3} / \mathrm{s}$, and terrace erosion once discharge exceeded 110-120 m³. Modeled values of unit stream power and bed shear stress in this discharge range increase even more rapidly near trench T8c in subarea 20 at the BLR8 study area (Figure 2-45 and Figure 2-46, Table 3-3 and Appendix D - Figure D3-25), where no deposits clearly younger than 400- to 600years are present (Section 2.3.3.1). Unit stream power and bed shear stress values from subarea 17, located on an unmodified H1-2 surface midway between the Saddle Constriction and BLR8 study areas (Figure 3-4), also increase rapidly (Appendix D - Figure D3-22). Compiled unit stream power and bed shear stress results from subareas throughout the reach show that large areas of the "400-yr" flood deposits would likely be subject to significant soil erosion at relatively low discharges (Figure 3-6). In contrast to estimating the discharge for the paleoflood, no requirement to inundate the entire H1-2 surface is imposed. Preservation and demonstration of stability at multiple sites which provide strongest limits on the discharge which might modify these sites is sufficient basis to establish the paleohydrologic bound (Section 3.2.1.2). Thus, the discharge limits for the paleohydrologic bound based on the deposits of the "400-year" paleoflood can be somewhat smaller than the discharge estimated for the paleoflood, because even a smaller flood would have a high likelihood of modifying extensive areas of the "400-year" deposits (Table 3-5). As discussed above, there are several sites where modification of the "400-year" flood deposits becomes increasingly certain for discharges above $110 \mathrm{~m}^{3} / \mathrm{s}$. To characterize the discharge range of the paleohydrologic bound, a modified triangular distribution of relative likelihood is used, with a lower discharge limit of $110 \mathrm{~m}^{3} / \mathrm{s}$. A peak is chosen at $130 \mathrm{~m}^{3} / \mathrm{s}$, with uniform likelihood extended to $150 \mathrm{~m}^{3} / \mathrm{s}$ (see Figure 4-1). 
3.4.2 Early Holocene (H1 surfaces) Bound. The stratigraphic evidence to support this paleohydrologic bound is the preservation of extensive areas of generally fine-grained fluvial sediments with well-developed carbonate soils that underlie the H1-2 surfaces. The most extensive exposures of these sediments and soils are in trench T6, stations 1 to $\sim 30$, and in the disconnected sequence of trenches at BLR8 study area, T8a,b,c (Section 2.3.2.3, Section 2.3.3.1, and Appendix B - Electronic Supplement). Smaller remnants are present at T4, stations 16 to 20 (Section 2.3.2.1 and Appendix B - Electronic Supplement), and at BLR6 (Ostenaa et al., 1999, 2002). These deposits and soils apparently are part of an aggradational fill of latest Pleistocene to early Holocene age (Section 2.2.3). Stage II carbonate soil horizons in these deposits are generally 50- to $100 \mathrm{~cm}$ thick, indicative of an early Holocene age for stabilization of the surface, and radiocarbon ages from these deposits ranging from about 7200 to 12,800 cal yr B.P support this age (Section 2.2.3 and Section Table 2-2). Based on these data, a conservative time interval of 6000 to 8000 years has been chosen for use as a paleohydrologic bound. Most of radiocarbon ages from these sites are older than this range, but the shorter time interval reflects the possible interpretation that aggradation of the sequence continued and the surfaces did not stabilize and begin forming soils until later.

There are fewer sites that constrain discharge estimates for this paleohydrologic bound than for the bound based on the "400-yr" flood (Table 3-4, compare Figure 3-6 and Figure 3-7). Discharge constraints based on the exposures at trenches T6 (subarea FP13) and T8a,b (subarea 20) (Figure 3-7) indicate that unit stream power and bed shear stress at these sites are high enough and extensive enough to indicate significant terrace erosion at these sites for discharges of $175 \mathrm{~m}^{3} / \mathrm{s}$ and larger. The H1-2 surface at FP17 (Figure 3-4) is similarly impacted. Many sites on Pleistocene P3 surfaces (Section 2.2.2) are significantly affected by modeled flows of $175 \mathrm{~m}^{3} / \mathrm{s}$ and larger as well. Terrace erosion is likely initiated in extensive areas of subareas FP6 and FP8 (Figure 3-4 and Figure 3-7), both sites that show geomorphic evidence of the "400-yr" flood (Section 3.3.2 and Plate 1). Results also indicate the initiation of soil erosion at sites on the older Pleistocene P2 surfaces (Section 2.2.2), such as in subareas FP5 and FP16 (Figure 3-4 and Figure 3-7). The geomorphology in these areas indicates that they are beyond the limits of any Holocene floods (Section 2.4 and Plate 1). For discharges larger than $250 \mathrm{~m}^{3} / \mathrm{s}$, judged to be the upper confidence limit for this paleohydrologic bound, significant terrace erosion is indicated for all the 
subareas (Figure 3-7). At larger discharges, flow also overtops the saddle area (Section 2.5.1.4) and impacts significant areas in, and adjacent to, subareas FP14 and FP15.

The paleohydrologic bound based on the early Holocene deposits (Table 3-5) potentially includes some conservatism in the time estimates for the bound, 6000 to 8000 years, in that most of the dating results indicate these deposits are likely somewhat older. The discharge range used for this bound, 175 to $250 \mathrm{~m}^{3} / \mathrm{s}$, is a range of values beyond any observed evidence for Holocene floods in the Diversion Dam study reach of the Big Lost River.

3.4.3 Pleistocene Bound. The extensive areas of unmodified Pleistocene surfaces that flank the Big Lost River are the stratigraphic and geomorphic basis for this paleohydrologic bound (Table 3-5). The Pleistocene P2 surfaces have a braid-channel morphology that is inherited from Pleistocene gravel deposition and unrelated to present flows in the Big Lost River (Section 2.2.2). The more limited areas of Pleistocene $P 3$ surfaces generally follow the present river channel and are also underlain by gravels, and likely represent the last episode of Pleistocene deglaciation (Section 2.2.2). Trench exposures in T6, T7, T8 and T9 indicate that the last phase of deposition on these surfaces was aggradation of fines in small channels on the P3 surfaces (Section 2.2.2, Section 2.3.2, and Section 2.3.3). Subsequent deposition, shown by the inset deposits that underlie the Holocene surfaces has been dominated by fines. Soils on the Pleistocene surfaces are characterized by an upper loess cap, generally less than 0.5-m-thick in the Diversion Dam study reach and well-developed carbonate morphology (Section 2.2.2). The Pleistocene age of both the P2 and P3 surfaces is established regionally by depositional links to regional glaciation, and in a local context by radiocarbons ages of $\sim 10,000$ to $12,800 \mathrm{cal}$ yr B.P. obtained from the inset fine-grained deposits (Section 2.2.2 and Table 2-2).

The lower discharge limits for the Pleistocene bound are based on discharges at which significant terrace erosion is indicated on the P3 surfaces, mostly in areas that are slightly modified by the "400-yr" paleoflood (Figure 3-8). Within subareas FP6, FP8, and FP19, discharges of 225 m³ and larger result in unit stream power and bed shear stress values over extensive areas that exceed upper limits for soil erosion and indicate significant potential for terrace erosion. In addition, near this discharge, model results indicate that flow is initiated over multiple locations near the Saddle area (Section 2.5.1.4), which produces localized areas with large values of unit stream power and 
bed shear stress on the Pleistocene surfaces just downstream. Over broad areas of the Pleistocene surfaces, increasing discharge leads to progressive increases in the extent of significant soil erosion and localized channeling. As discharge approaches $400 \mathrm{~m}^{3} / \mathrm{s}$, considered the upper discharge limit for this bound, unit stream power and bed shear stress values reach or exceed the preferred values for terrace erosion over significant portions of all the subareas located on the Pleistocene surfaces. The majority of these exceedences are concentrated braid channels such as those traversed by trenches T1, T2, T3, and T7 where the Pleistocene deposits and soils demonstrate long-term stability of these surfaces and channels (Section 2.4).

3.4.3.1 Catastrophic Channel Change. An alternative approach to determine discharge estimates for bounds over long, but non-specific time frames is to estimate the discharge which might result in "catastrophic" channel change (Appendix D and Figure 3-3). Unlike other estimates, this approach is not specific to the conditions of the Big Lost River, with the caveat that only in reaches where the channel banks are mostly composed of alluvium does this approach apply.

For each of the channel subareas (Figure 3-4), a range of values for catastrophic channel change is evaluated based on the subarea results, (Figure 3-9; derived from Appendix D - Figures D3-29 to D3-37), and the channel profile plots (Figure 2-9). A minimum discharge range for bounds has been estimated from the plots based on approximately 10 percent of the channel subarea exceeding the minimum criteria for either unit stream power $>200 \mathrm{~W} / \mathrm{m}^{2}$ or bed shear stress $>100$ $\mathrm{N} / \mathrm{m}^{2}$, realizing that some subareas have sections with rock channels and minimum values should be higher in those subreaches (see Table 3-2 for descriptions of individual channel subareas). A preferred value is taken when there is significant exceedence on the plots (Appendix D - Figures D3-29 to D3-37), of the $400 \mathrm{~W} / \mathrm{m}^{2}$ or $200 \mathrm{~N} / \mathrm{m}^{2}$, and these exceedences are apparent as well on the channel profile plots (Figure 2-9). The existence of large areas of rock outcrops in the channel is a factor that will make this approach non-conservative, but is hard to quantify. Modeling does not extend to large enough discharges to estimate a true upper bound; and this approach is inherently subjective, but we do expect these values to have a degree of consistency with the estimates of paleohydrologic bounds that have durations of thousands of years. 
Results from each subarea combined are shown on Figure 3-9. A bounding range of discharge that would be associated with catastrophic channel change on this reach of the Big Lost River is judged to be $250-450 \mathrm{~m}^{3} / \mathrm{s}$ based on the compiled results. Within this range five of the subreaches exceed the basis for reaching preferred values. Subarea CH1 is largely discounted because it may include some effects due to flow initiation in the upstream portion of the model, especially for larger flows and because long portions of this subreach include rock channels. Subareas $\mathrm{CH} 4$ and $\mathrm{CH} 7$ also include significant sections of rock outcrop, but are also representative of the types of sites where empirical data on which this approach is based might have been collected (Appendix D). The absence of higher values of unit stream power or bed shear stress in subareas $\mathrm{CH} 3, \mathrm{CH} 6$, and $\mathrm{CH} 8$ results from flow stagnation due to downstream channel constrictions (Section 2.5.1.4).

Evaluation based on catastrophic channel change is not linked directly to a time period associated with a specific paleohydrologic bound or used subsequently in the flood frequency analyses. For the Big Lost River, these results appear to qualitatively support the range of bounds independently evaluated for periods of 1000's to 10,000 years. Thus, the occurrence of floods with discharges that appear likely to significantly modify the Pleistocene surfaces (Section 3.4.3), would also be considered "catastrophic" in a geomorphic sense. 
Figures for Section 3.0 


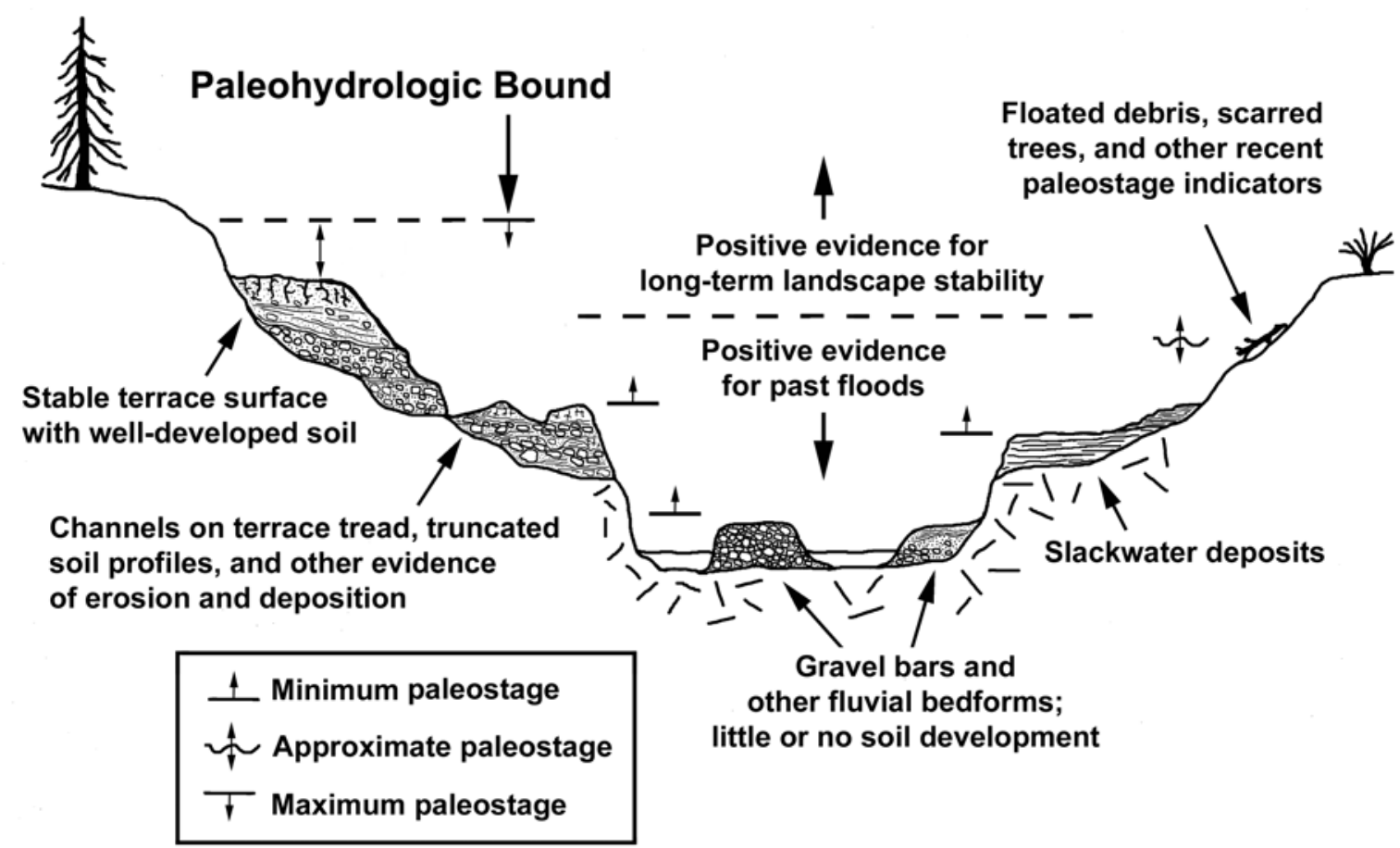

Figure 3-1 Schematic representation of different types of geomorphic and stratigraphic evidence for paleofloods and paleohydrologic bounds. 

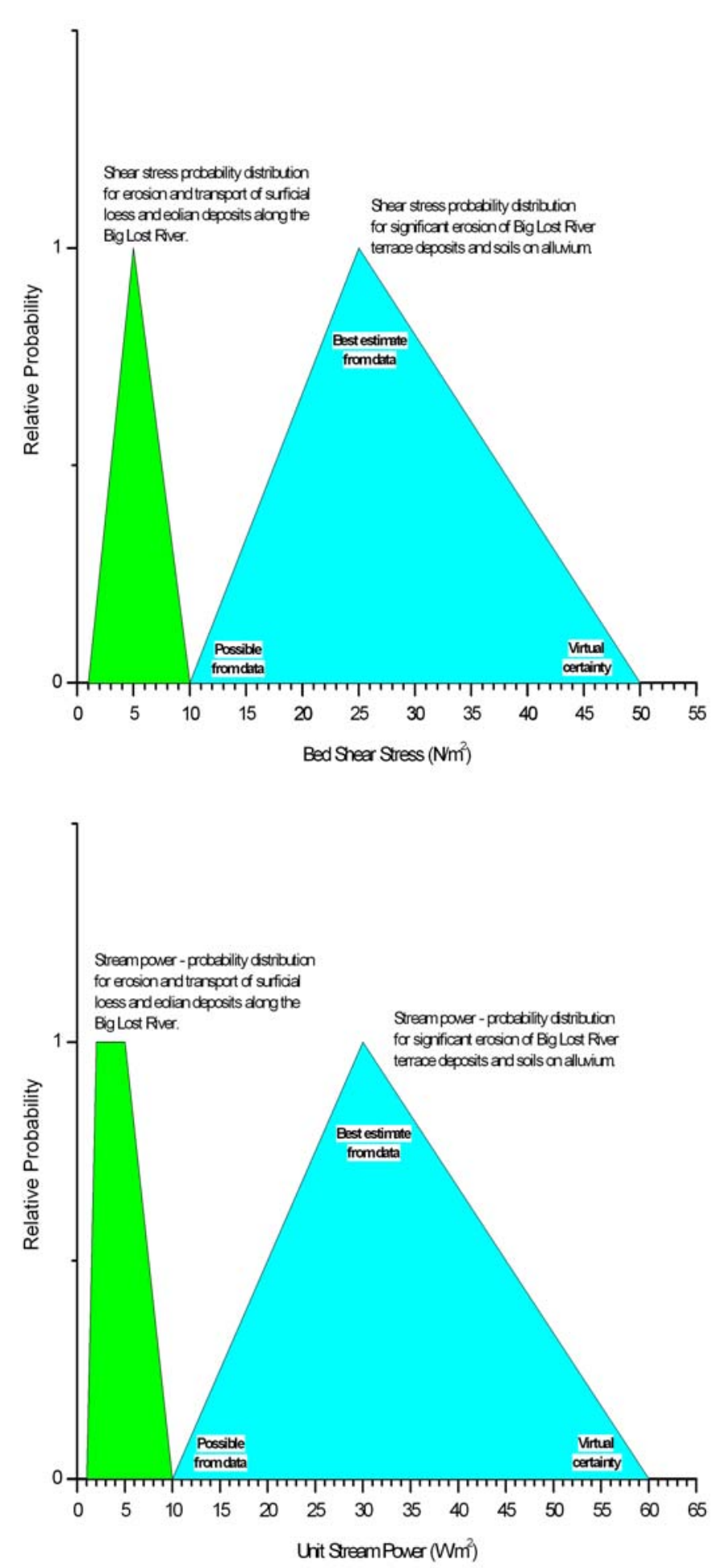

Figure 3-2 Probability density functions for erosion based on shear stress and stream power for Big Lost River applications. See Appendix D for discussion of data used to define these distributions 


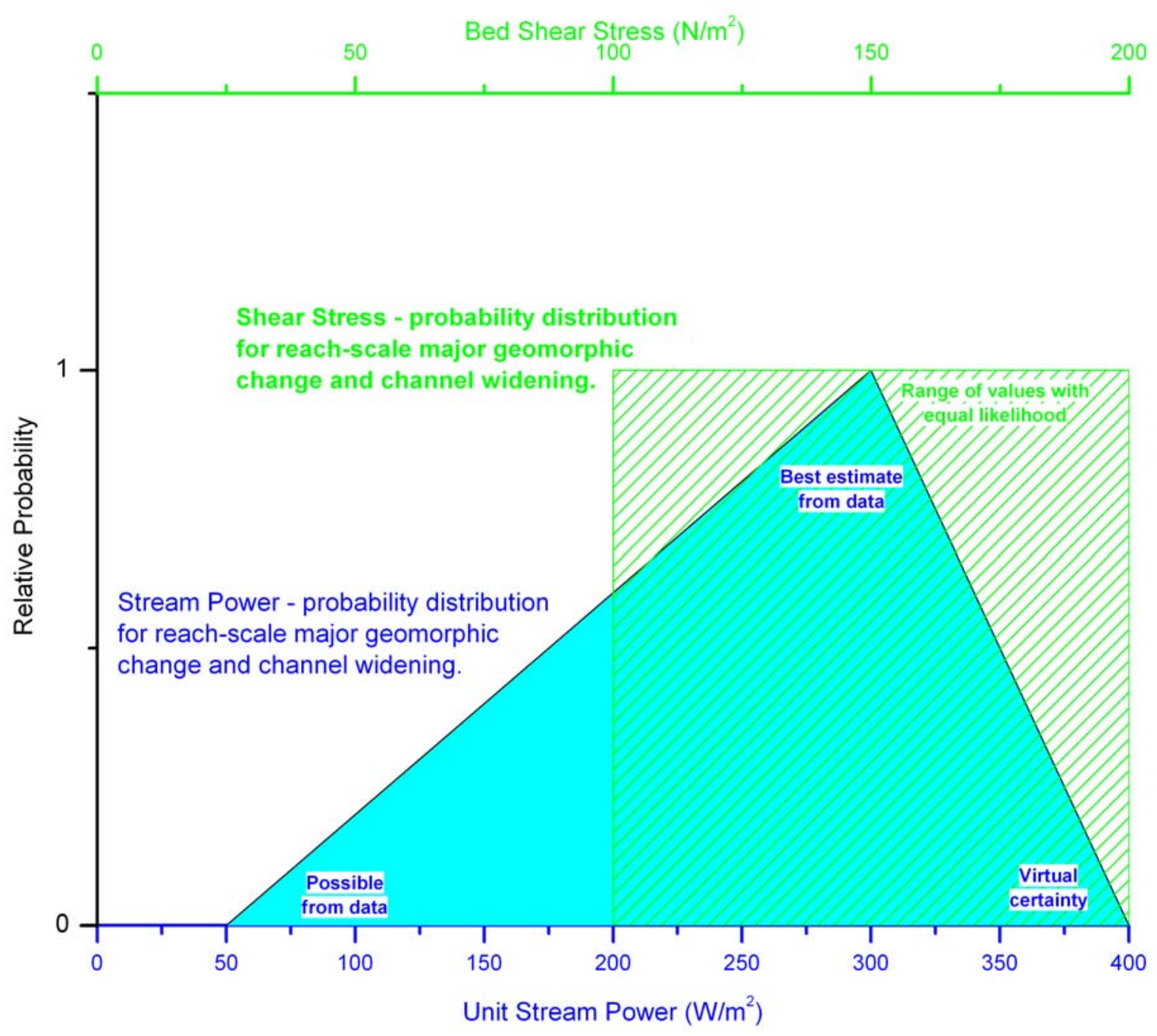

Figure 3-3 Probability distributions for major channel modifications based on channel averaged stream power and shear stress values. See Appendix D for discussion of data used to define these distributions 


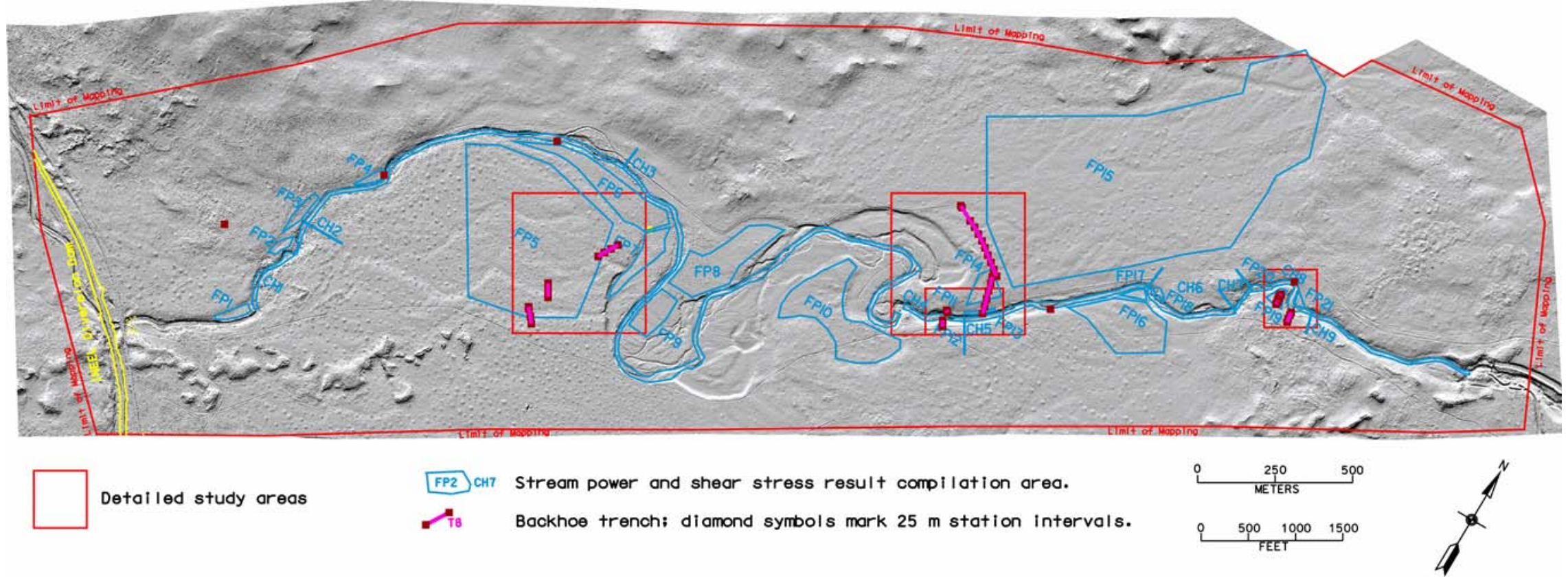

Figure 3-4 Stream power and shear stress sample areas along Big Lost River Diversion Dam study reach. See Table 3-1and Table 3-2 for summary of characteristics of each subarea. 

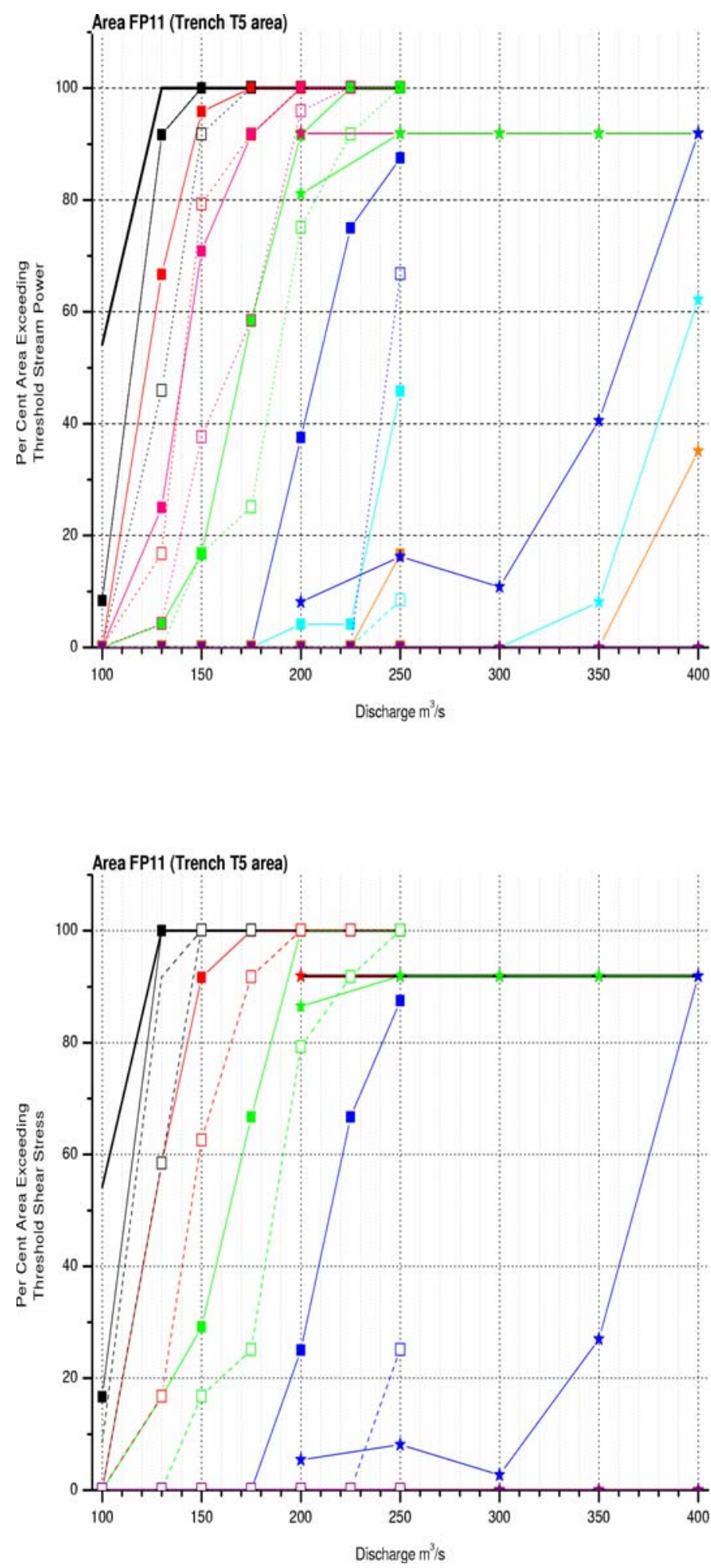

Power Legend

- Per cent of sample area inundated by modeled flow

- - Per cent of area with power $>1 \mathrm{~W} / \mathrm{m}^{2}$; Low bound of soil erosion

- - Per cent of area with power $>2 \mathrm{~W} / \mathrm{m}^{2}$; Low end of preferred value range for soil erosion

-- Per cent of area with power $>5 \mathrm{~W} / \mathrm{m}^{2} ;$ High end of preferred value range for soil erosion

- - - Per cent of area with power $>10 \mathrm{~W} / \mathrm{m}^{2}$; High bound of soll erosion; Low bound of terrace erosion

- - Per cent of area with power $>30 \mathrm{~W} / \mathrm{m}^{2}$; Preferred value of terrace erosion

- - Per cent of area with power $>50 \mathrm{~W} / \mathrm{m}^{2}$

- - - Per cent of area with power $>60 \mathrm{~W} / \mathrm{m}^{2}$; High bound of terrace erosion; Low bound of catastrophic channel erosion

$-1-$ Per cent of area with power $>200 \mathrm{~W} / \mathrm{m}^{2}$; Preferred value for catastrophic channel erosion

- - Per cent of area with power $>400 \mathrm{~W} / \mathrm{m}^{2}$; High bound of catastropic channel erosion

* Star symbols show results from models on 5-tt grid derived from 1993 photography Filled symbols/solid lines are $n=0.038$; Open symboisidashed lines are $n=0.030$

Shear Stress Legend

- Per cent of sample area inundated by modeled flow

- - Per cent of area with shear stress $>1 \mathrm{~N}^{2} \mathrm{~m}^{2}$; Low bound of soil erosion

- - Per cent of area with shear stress $>5 \mathrm{~N}^{2} \mathrm{~m}^{2}$; Low bound of soil erosion

-n-Per cent of area with shear stress $>10 \mathrm{~N} / \mathrm{m}^{2} ;$ Preferred value of soil erosion; Low bound of terrace erosion

- - - Per cent of area with shear stress $>25 \mathrm{~N} / \mathrm{m}^{2}$; Preferred value of terrace erosion

- - - Per cent of area with shear stress $>50 \mathrm{~N} / \mathrm{m}^{2}$; High bound of terrace erosion

- - - Per cent of area with shear stress $>100 \mathrm{~N}^{2} \mathrm{~m}^{2}$; Low bound of preferred range for catastrophic channel change

- - Per cent of area with shear stress $>200 \mathrm{~N}^{2}{ }^{2}$; High bound of preferred range for catastropic channel change

* Star symbols show results from models on 5 -ft grid derived from 1993 photography Filled symbols/solid lines are $r=0.038$; Open symbois/dashed lines are $n=0.030$

Figure 3-5 Example of stream power and shear stress results for subarea FP11. Colored lines and symbols correspond to key values (listed in legend above) on the PDF of Figure 3-2. Each symbol represents the percent area exceeding the threshold values for a single flow simulation. Colored lines between symbols represent change between simulations of different discharge. Lines with colored stars are data from models on 5-ft grid derived from 1993 photography. 


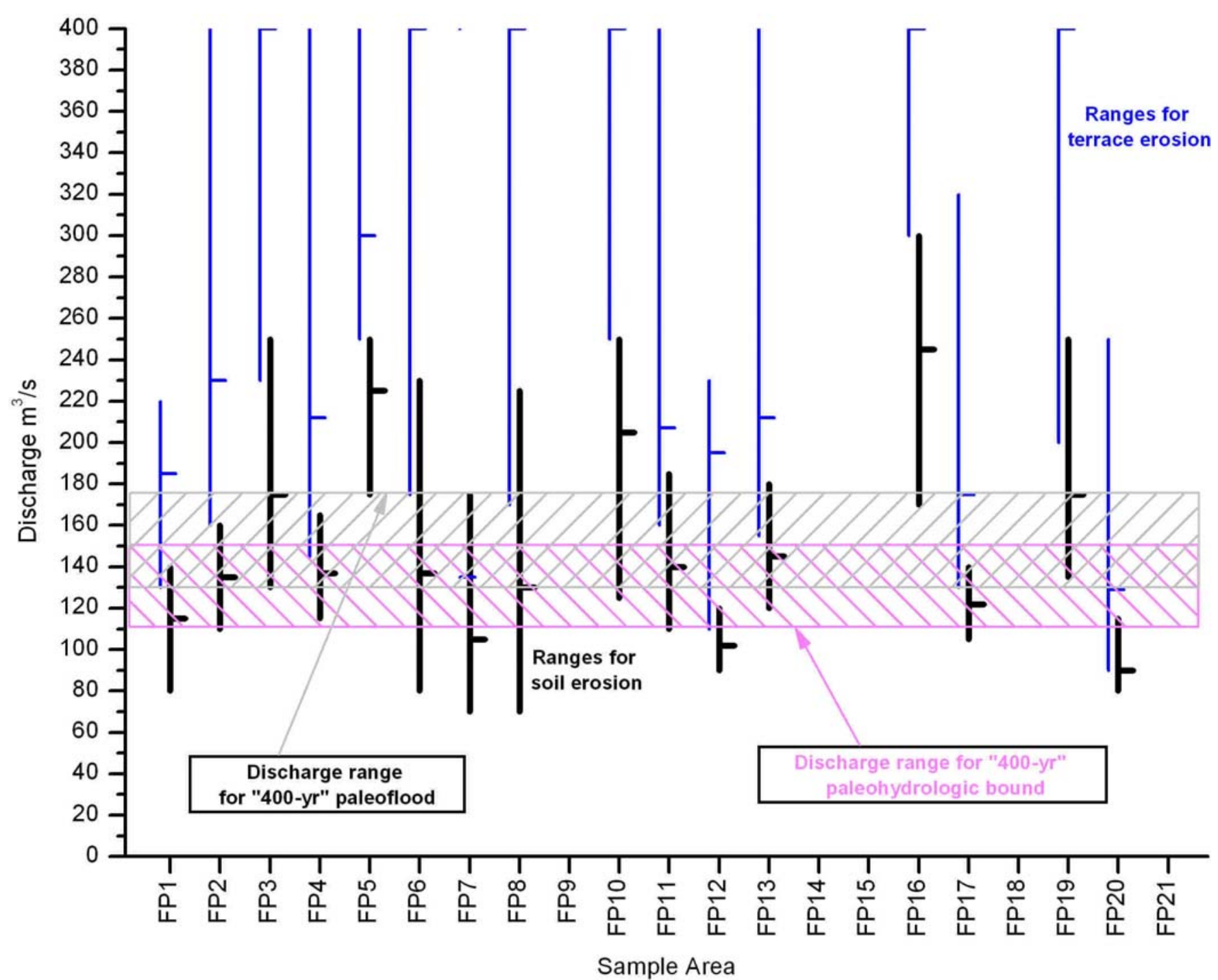

Figure 3-6 Combined discharge limits for late Holocene paleofloods and paleohydrologic bounds. Estimated discharge ranges for soil erosion, black bars and terrace erosion, blue bars are from (Table 3-3). Gray cross-hatching shows discharge range for paleofloods; magenta cross-hatch shows range for paleohydrologic bound (Table 3-5). See (Figure 3-4) for sample area locations, (Table 3-4) for applicability, and (Table 3-1) for sample area descriptions. 


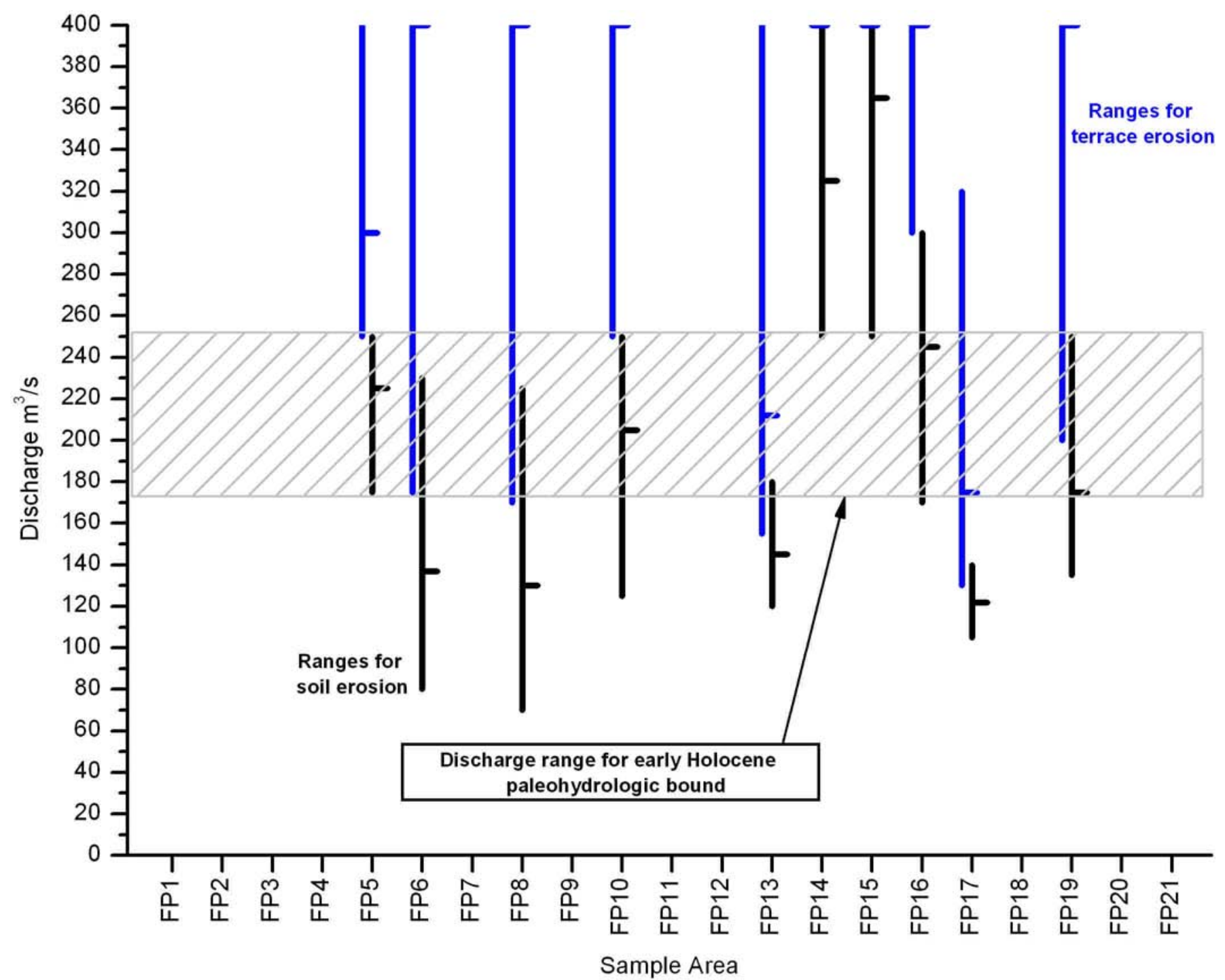

Figure 3-7 Combined discharge limits for early Holocene paleohydrologic bound. Cross hatching shows discharge range for early Holocene (T1) paleohydrologic bound (Table 3-5). See (Figure 3-6) for additional explanation of symbols. 


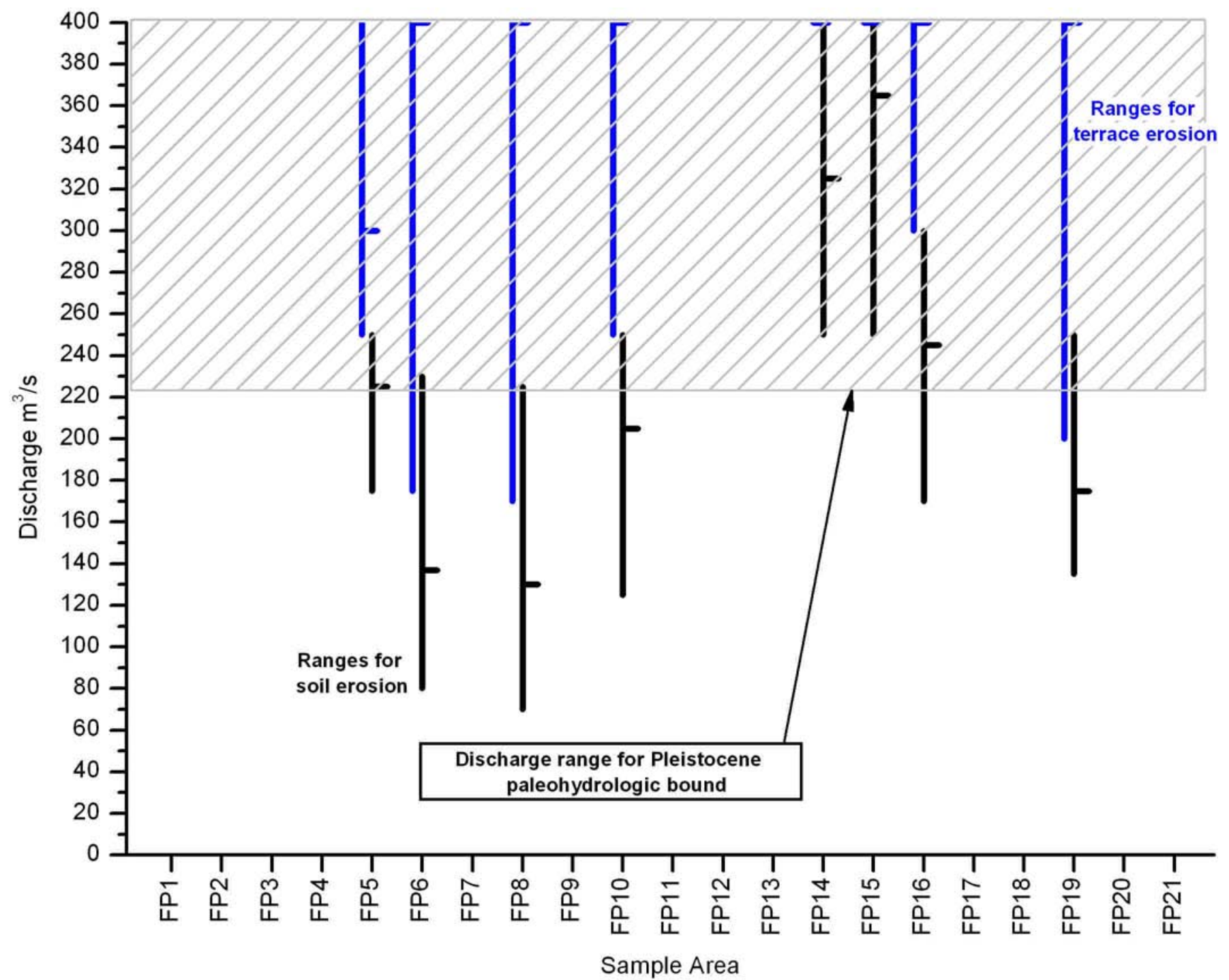

Figure 3-8 Combined discharge limits for Pleistocene paleohydrologic bound. Cross hatching shows discharge range for Pleistocene paleohydrologic bound (Table 3-5). See (Figure 3-6) for additional explanation of symbols. 


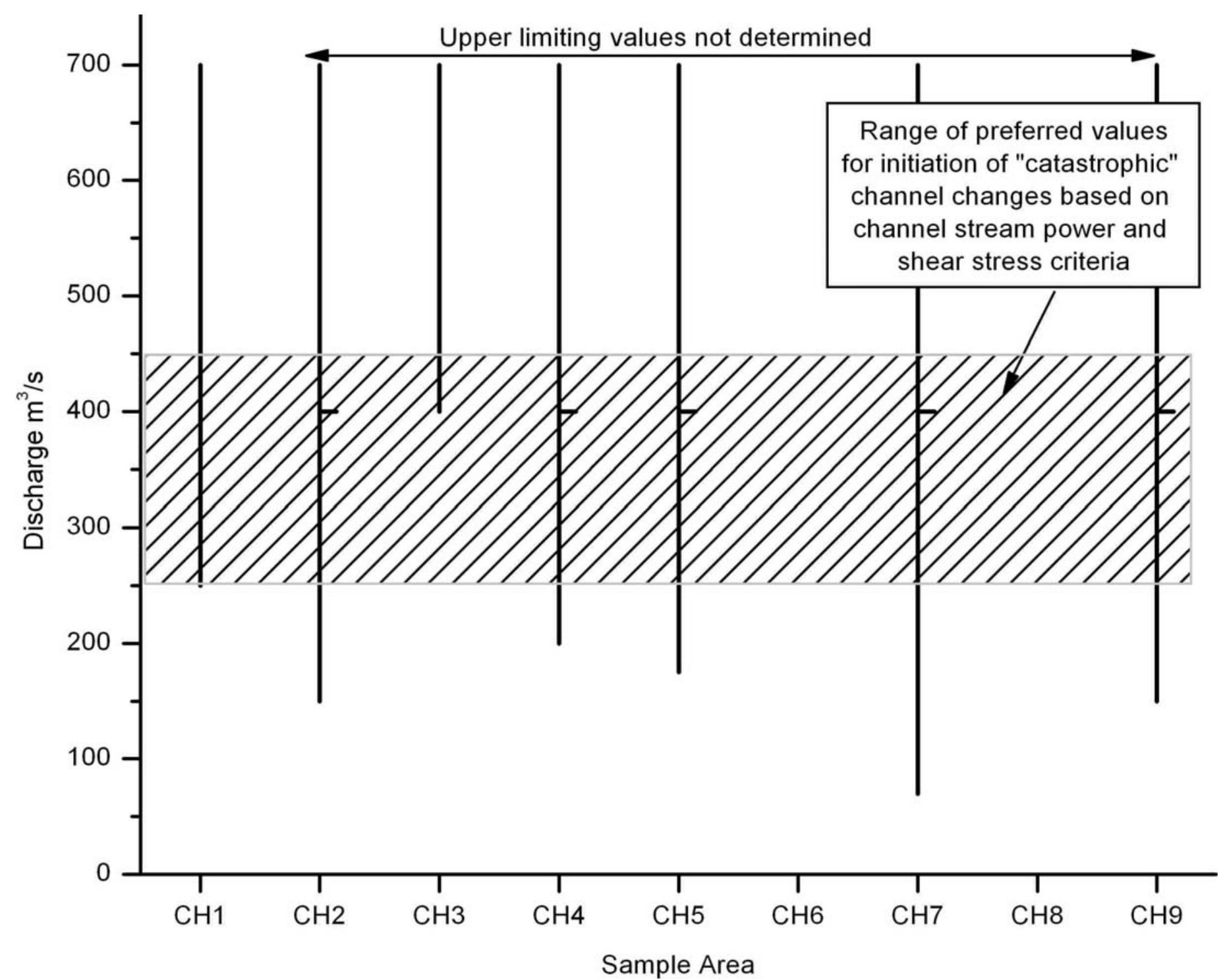

Figure 3-9 Combined discharge limits for catastrophic channel change. Upper limiting values are arbitrarily plotted at $700 \mathrm{~m}^{3} / \mathrm{s}$. See Figure 3-6 for additional explanation of symbols. Sample area descriptions are in Table 3-2. Subarea data from Appendix D, Figure D3-27 through D3-37. 
Tables for Section 3.0 
Table 3-1 Hydraulic modeling sample area characteristics - floodplain subareas

\begin{tabular}{|c|c|c|c|c|c|c|c|c|}
\hline \multirow{3}{*}{$\begin{array}{l}\text { Sub- } \\
\text { area }\end{array}$} & \multicolumn{3}{|c|}{ Area and Number of Cells } & \multicolumn{5}{|c|}{ Geomorphic and Geologic Characteristics } \\
\hline & \multirow{2}{*}{$\begin{array}{l}\text { Number } \\
\text { of } 6-\mathrm{ft} \\
\text { cells }^{1}\end{array}$} & \multicolumn{2}{|c|}{ Area } & \multirow{2}{*}{$\begin{array}{l}\text { Map unit and surface } \\
\text { morphology }\end{array}$} & \multirow{2}{*}{$\begin{array}{l}\text { Surficial deposits } \\
\text { /soil }\end{array}$} & \multirow[t]{2}{*}{ Underlying deposits } & \multirow{2}{*}{$\begin{array}{l}\text { Trenches } \\
\text { or sites }\end{array}$} & \multirow[t]{2}{*}{ Other } \\
\hline & & $\begin{array}{c}\mathrm{ft}^{2} \\
\left(\mathrm{~m}^{2}\right)\end{array}$ & $\begin{array}{c}\text { acres } \\
\text { (hectare) }\end{array}$ & & & & & \\
\hline FP1 & 902 & $\begin{array}{l}32472 \\
(3017)\end{array}$ & $\begin{array}{c}0.74 \\
(0.30)\end{array}$ & H1-2; smooth terrace surface & silt and sand & not exposed & n.a & Beginning of model reach \\
\hline FP2 & 595 & $\begin{array}{l}21420 \\
(1990)\end{array}$ & $\begin{array}{c}0.49 \\
(0.20)\end{array}$ & $\begin{array}{c}\text { H3 and Rd; overflow } \\
\text { channel; and basalt outcrop }\end{array}$ & $\begin{array}{l}\text { silt and sand in } \\
\text { channel; rock } \\
\text { outcrop }\end{array}$ & basalt(?) & $\begin{array}{c}\text { n.a.; } \\
\text { Juniper } \\
\text { Bends site }\end{array}$ & $\begin{array}{l}\text { Probable flow in channel } \\
\text { from pre-INEEL Diversion } \\
\text { floods }\end{array}$ \\
\hline FP3 & 1068 & $\begin{array}{l}38448 \\
(3572)\end{array}$ & $\begin{array}{c}0.88 \\
(0.36)\end{array}$ & $\begin{array}{l}\text { H1-2 onlap onto Qbd } \\
\text { outcrops }\end{array}$ & $\begin{array}{l}\text { silt and sand; minor } \\
\text { areas of basalt }\end{array}$ & $\begin{array}{l}\text { Thin(?) veneer of } \\
\text { fluvial sediment over } \\
\text { basalt }\end{array}$ & $\begin{array}{c}\text { n.a.; } \\
\text { Juniper } \\
\text { Bends site }\end{array}$ & \\
\hline FP4 & 538 & $\begin{array}{l}19368 \\
(1799)\end{array}$ & $\begin{array}{c}0.44 \\
(0.18)\end{array}$ & H2; smooth terrace surface & silt and sand & $\begin{array}{l}>1 \mathrm{~m} \text { of fine } \\
\text { sediment }\end{array}$ & $\begin{array}{l}\text { BLR7 on } \\
\text { d/s edge }\end{array}$ & \\
\hline FP5 & 60286 & $\begin{array}{l}2170296 \\
(201627)\end{array}$ & $\begin{array}{c}49.69 \\
(20.11)\end{array}$ & $\begin{array}{l}\text { P2; subdued braided channels } \\
\text { with large earth mounds }\end{array}$ & $\begin{array}{l}\text { silt and sand with } \\
\text { local pavement }\end{array}$ & $\begin{array}{l} \pm 0.5 \mathrm{~m} \text { silt and sand } \\
\text { overlying gravel }\end{array}$ & $\begin{array}{l}\text { T1, T2, } \\
\text { T3 }\end{array}$ & \\
\hline FP6 & 9435 & $\begin{array}{l}339660 \\
(31555)\end{array}$ & $\begin{array}{c}7.78 \\
(3.15)\end{array}$ & $\begin{array}{l}\text { P3/H1-2; smooth terrace; few } \\
\text { muted earth mounds }\end{array}$ & silt and sand & gravel(?) & n.a. & $\begin{array}{l}\text { BLR2 is on inset terrace at } \\
\text { upstream end of FP6 area }\end{array}$ \\
\hline FP7 & 3390 & $\begin{array}{l}122040 \\
(11338)\end{array}$ & $\begin{array}{c}2.79 \\
(1.13)\end{array}$ & $\begin{array}{l}\text { H1-2; mostly smooth surface; } \\
\text { minor channels }\end{array}$ & silt and sand & (?) & n.a. & \\
\hline FP8 & 10401 & $\begin{array}{l}374436 \\
(34786)\end{array}$ & $\begin{array}{c}8.57 \\
(3.47)\end{array}$ & $\begin{array}{l}\text { P3/H1; smooth terrace; few } \\
\text { muted earth mounds }\end{array}$ & silt and sand & $\begin{array}{l}\text { thin silt and sand } \\
\text { gravel(?) }\end{array}$ & n.a. & $\begin{array}{l}\text { Historical irrigation ditch on } \\
\mathrm{u} / \mathrm{s} \text { side is not eroded; } \\
\text { historical use as field or } \\
\text { pasture }\end{array}$ \\
\hline FP9 & 3469 & $\begin{array}{l}124884 \\
(11602)\end{array}$ & $\begin{array}{c}2.86 \\
(1.16)\end{array}$ & $\begin{array}{l}\mathrm{H} 2 / \mathrm{H} 3 \text {; mostly smooth } \\
\text { terrace with channels on } \\
\text { lower portion }\end{array}$ & silt and sand & (?) & n.a. & $\begin{array}{l}\text { Historical irrigation ditch on } \\
\text { u/s side is not eroded; } \\
\text { historical use as field or } \\
\text { pasture }\end{array}$ \\
\hline
\end{tabular}


Table 3-1 Hydraulic modeling sample area characteristics - floodplain subareas

\begin{tabular}{|c|c|c|c|c|c|c|c|c|}
\hline \multirow{3}{*}{$\begin{array}{l}\text { Sub- } \\
\text { area }\end{array}$} & \multicolumn{3}{|c|}{ Area and Number of Cells } & \multicolumn{5}{|c|}{ Geomorphic and Geologic Characteristics } \\
\hline & \multirow{2}{*}{$\begin{array}{l}\text { Number } \\
\text { of } 6-\mathrm{ft} \\
\text { cells }{ }^{1}\end{array}$} & \multicolumn{2}{|c|}{ Area } & \multirow{2}{*}{$\begin{array}{l}\text { Map unit and surface } \\
\text { morphology }\end{array}$} & \multirow{2}{*}{$\begin{array}{l}\text { Surficial deposits } \\
\text { /soil }\end{array}$} & \multirow[t]{2}{*}{ Underlying deposits } & \multirow{2}{*}{$\begin{array}{l}\text { Trenches } \\
\text { or sites }\end{array}$} & \multirow[t]{2}{*}{ Other } \\
\hline & & $\begin{array}{c}\mathrm{ft}^{2} \\
\left(\mathrm{~m}^{2}\right)\end{array}$ & $\begin{array}{c}\text { acres } \\
\text { (hectare) }\end{array}$ & & & & & \\
\hline FP10 & 15504 & $\begin{array}{l}558144 \\
(51853)\end{array}$ & $\begin{array}{l}12.78 \\
(5.17)\end{array}$ & $\begin{array}{l}\text { P3/H1; smooth terrace; few } \\
\text { muted earth mounds; eroded } \\
\text { d/s margin }\end{array}$ & silt and sand & $\begin{array}{c}\text { silt and sand } \\
\text { overlying gravel(?) }\end{array}$ & n.a. & $\begin{array}{l}\text { Western portion eroded; earth } \\
\text { mounds more prevalent in } \\
\text { eastern half; Affected by } \\
\text { backwater from saddle } \\
\text { constriction }\end{array}$ \\
\hline FP11 & 24 & $864(80)$ & $\begin{array}{c}0.02 \\
(0.01)\end{array}$ & $\begin{array}{l}\text { H1-2; smooth terrace and } \\
\text { riser to P2 surface }\end{array}$ & silt and sand & $\begin{array}{l}\text { basalt outcrops in } \\
\text { stream bank }\end{array}$ & T5 & \\
\hline FP12 & 23 & $828(77)$ & $\begin{array}{c}0.02 \\
(0.01)\end{array}$ & $\begin{array}{l}\text { H1-2; small area between } \\
\text { basalt outcrops }\end{array}$ & silt and sand & $\begin{array}{l}\text { basalt outcrops in } \\
\text { banks; gravel on } \\
\text { higher surface }\end{array}$ & $\mathrm{T} 4$ & \\
\hline FP13 & 236 & $\begin{array}{l}8496 \\
(789)\end{array}$ & $\begin{array}{c}0.19 \\
(0.08)\end{array}$ & $\begin{array}{c}\text { H1-2; long, narrow, smooth } \\
\text { terrace }\end{array}$ & silt and sand & $>1 \mathrm{~m}$ fine sediments & T6 & \\
\hline FP14 & 2095 & $\begin{array}{l}75420 \\
(7007)\end{array}$ & $\begin{array}{c}1.73 \\
(0.70)\end{array}$ & $\begin{array}{l}\text { P3; minor eolian sand; } \\
\text { smooth terrace surface }\end{array}$ & silt and sand & $\begin{array}{c}<0.5 \mathrm{~m} \text { silt and sand } \\
\text { overlying gravel }\end{array}$ & T6 & \\
\hline FP15 & 152753 & $\begin{array}{l}5499108 \\
(510884)\end{array}$ & $\begin{array}{l}125.90 \\
(50.95)\end{array}$ & $\begin{array}{l}\text { P1-2; subdued braided } \\
\text { channels with large earth } \\
\text { mounds; minor areas of } \\
\text { eolian sand sheets }\end{array}$ & silt and sand & $\begin{array}{c} \pm 0.5 \mathrm{~m} \text { silt and sand } \\
\text { overlying gravel }\end{array}$ & $\mathrm{T} 7$ & $\begin{array}{c}\text { Several wheel tracks; } \\
\text { includes circular area cleared } \\
\text { as target for old bombing } \\
\text { range }\end{array}$ \\
\hline
\end{tabular}


Table 3-1 Hydraulic modeling sample area characteristics - floodplain subareas

\begin{tabular}{|c|c|c|c|c|c|c|c|c|}
\hline \multirow{3}{*}{$\begin{array}{l}\text { Sub- } \\
\text { area }\end{array}$} & \multicolumn{3}{|c|}{ Area and Number of Cells } & \multicolumn{5}{|c|}{ Geomorphic and Geologic Characteristics } \\
\hline & \multirow{2}{*}{$\begin{array}{l}\text { Number } \\
\text { of 6-ft } \\
\text { cells }^{1}\end{array}$} & \multicolumn{2}{|c|}{ Area } & \multirow{2}{*}{$\begin{array}{l}\text { Map unit and surface } \\
\text { morphology }\end{array}$} & \multirow{2}{*}{$\begin{array}{l}\text { Surficial deposits } \\
\text { /soil }\end{array}$} & \multirow[t]{2}{*}{ Underlying deposits } & \multirow{2}{*}{$\begin{array}{l}\text { Trenches } \\
\text { or sites }\end{array}$} & \multirow[t]{2}{*}{ Other } \\
\hline & & $\begin{array}{c}\mathrm{ft}^{2} \\
\left(\mathrm{~m}^{2}\right)\end{array}$ & $\begin{array}{c}\text { acres } \\
\text { (hectare) }\end{array}$ & & & & & \\
\hline FP16 & 10913 & $\begin{array}{l}392868 \\
(36499)\end{array}$ & $\begin{array}{c}8.99 \\
(3.64)\end{array}$ & $\begin{array}{l}\text { P2/P3; braided channels with } \\
\text { large earth mounds }\end{array}$ & silt and sand & $\begin{array}{l} \pm 0.5 \mathrm{~m} \text { silt and sand } \\
\text { overlying gravel(?) }\end{array}$ & n.a. & $\begin{array}{l}\text { T6 is on inset terrace near } \\
\text { upper end of area }\end{array}$ \\
\hline FP17 & 477 & $\begin{array}{l}17172 \\
(1595)\end{array}$ & $\begin{array}{c}0.39 \\
(0.16)\end{array}$ & H1-2; smooth terrace & silt and sand & (?) & n.a. & \\
\hline FP18 & 199 & $\begin{array}{l}7164 \\
(666)\end{array}$ & $\begin{array}{c}0.16 \\
(0.07)\end{array}$ & Rb; scoured basalt outcrop & $\begin{array}{l}\text { basalt; minor sand } \\
\text { and silt }\end{array}$ & basalt & n.a. & \\
\hline FP19 & 427 & $\begin{array}{l}15372 \\
(1428)\end{array}$ & $\begin{array}{c}0.35 \\
(0.14)\end{array}$ & H1; smooth terrace surface & silt and sand & $\begin{array}{l}\text { silt and sand; minor } \\
\text { fine gravel }\end{array}$ & T8b,c & \\
\hline FP20 & 178 & $\begin{array}{l}6408 \\
(595)\end{array}$ & $\begin{array}{c}0.15 \\
(0.06)\end{array}$ & H2; smooth terrace surface & silt and sand & $\begin{array}{c}\text { silt and sand; } \\
\text { increasing gravel } \\
\text { away from channel }\end{array}$ & T8a,b & $\begin{array}{l}\text { BLR8 on similar inset surface } \\
\text { across channel }\end{array}$ \\
\hline FP21 & 266 & $\begin{array}{l}9576 \\
(890)\end{array}$ & $\begin{array}{c}0.22 \\
(0.09)\end{array}$ & Rb; scoured basalt outcrop & $\begin{array}{l}\text { basalt; minor silt and } \\
\text { sand }\end{array}$ & basalt & n.a. & \\
\hline
\end{tabular}


Table 3-2 Hydraulic modeling sample area characteristics - channel subareas

\begin{tabular}{|c|c|c|c|c|c|c|c|}
\hline \multirow{3}{*}{$\begin{array}{l}\text { Sub- } \\
\text { area }\end{array}$} & \multicolumn{4}{|c|}{ Number of Cells ${ }^{1}$, Area ${ }^{2}$ and Length } & \multicolumn{3}{|c|}{ Geomorphic and Geologic Characteristics } \\
\hline & \multirow{2}{*}{$\begin{array}{l}\text { Number } \\
\text { of 6-ft } \\
\text { cells }\end{array}$} & \multicolumn{2}{|c|}{ Area } & \multirow{2}{*}{$\begin{array}{c}\text { Length } \\
\mathrm{ft} \\
(\mathrm{m})\end{array}$} & \multirow[t]{2}{*}{ Channel form } & \multirow[t]{2}{*}{ Bed/bank materials } & \multirow[t]{2}{*}{ Notes } \\
\hline & & $\begin{array}{l}\mathrm{ft}^{2} \\
\left(\mathrm{~m}^{2}\right)\end{array}$ & $\begin{array}{c}\text { acres } \\
\text { (hectare) }\end{array}$ & & & & \\
\hline CH1 & 1305 & $\begin{array}{l}46980 \\
(4365)\end{array}$ & $\begin{array}{c}1.08 \\
(0.44)\end{array}$ & $\begin{array}{l}1154 \\
(352)\end{array}$ & $\begin{array}{l}\text { Mostly straight with } \\
\text { small amplitude bends. } \\
\text { Single thread; rock } \\
\text { controlled. }\end{array}$ & $\begin{array}{l}\text { Common rock outcrops in bed and banks with rock } \\
\text { constrictions; long section of fluted and scoured } \\
\text { rock bed. Some banks of P2 gravels and fine- } \\
\text { grained lateral accretion deposits (H1/H2/H3). }\end{array}$ & "Juniper Bends area" \\
\hline $\mathrm{CH} 2$ & 4533 & $\begin{array}{l}163188 \\
(15161)\end{array}$ & $\begin{array}{c}3.74 \\
(1.51)\end{array}$ & $\begin{array}{c}3773 \\
(1150)\end{array}$ & $\begin{array}{l}\text { Gently curving; one sharp } \\
\text { bend at BLR2 (FP4). } \\
\text { Single thread. }\end{array}$ & $\begin{array}{l}\text { Scattered rock outcrops in bed throughout length; } \\
\text { some rock in banks near and upstream of BLR2 } \\
\text { (FP4). Bed mostly sand and fine gravel. Right bank } \\
\text { mostly fine-grained lateral accretion deposit (H1- } \\
\text { 2) against P2 gravel. Left bank mostly H2/H3 fine- } \\
\text { grained deposits. }\end{array}$ & $\begin{array}{c}\text { BLR2 and BLR7 bank exposures } \\
\text { are in this reach. }\end{array}$ \\
\hline CH3 & 9920 & $\begin{array}{l}357120 \\
(33178)\end{array}$ & $\begin{array}{c}8.18 \\
(3.31)\end{array}$ & $\begin{array}{c}7830 \\
(2387)\end{array}$ & $\begin{array}{l}\text { Large amplitude s-bends; } \\
\text { tighter radius at } \\
\text { downstream end. Single } \\
\text { thread at upstream end, } \\
\text { multi thread in central } \\
\text { portion of meanders. }\end{array}$ & $\begin{array}{l}\text { Sand and gravel in bed and banks. Rock outcrops } \\
\text { in bed and banks are limited to scattered } \\
\text { occurrences at downstream end of sample area just } \\
\text { upstream of Saddle constriction. Bank materials } \\
\text { are heterogeneous mix of silty/sandy alluvium and } \\
\text { gravel of all ages. }\end{array}$ & "Big Loop" \\
\hline & ${ }^{1}$ For & rid mo & averao & mher & lls is $\sim 145 \%$ of number o & -ft grid cells. & w channel. At most sections, \\
\hline
\end{tabular}


Table 3-2 Hydraulic modeling sample area characteristics - channel subareas

\begin{tabular}{|c|c|c|c|c|c|c|c|}
\hline \multirow{3}{*}{$\begin{array}{l}\text { Sub- } \\
\text { area }\end{array}$} & \multicolumn{4}{|c|}{ Number of Cells ${ }^{1}$, Area ${ }^{2}$ and Length } & \multicolumn{3}{|c|}{ Geomorphic and Geologic Characteristics } \\
\hline & \multirow{2}{*}{$\begin{array}{l}\text { Number } \\
\text { of 6-ft } \\
\text { cells }\end{array}$} & \multicolumn{2}{|c|}{ Area } & \multirow{2}{*}{\begin{tabular}{c|} 
Length \\
$\mathrm{ft}$ \\
$(\mathrm{m})$
\end{tabular}} & \multirow[t]{2}{*}{ Channel form } & \multirow[t]{2}{*}{ Bed/bank materials } & \multirow[t]{2}{*}{ Notes } \\
\hline & & $\begin{array}{c}\mathrm{ft}^{2} \\
\left(\mathrm{~m}^{2}\right)\end{array}$ & $\begin{array}{c}\text { acres } \\
\text { (hectare) }\end{array}$ & & & & \\
\hline $\mathrm{CH} 4$ & 877 & $\begin{array}{l}31572 \\
(2933)\end{array}$ & $\begin{array}{c}0.72 \\
(0.29)\end{array}$ & $\begin{array}{l}668 \\
(204)\end{array}$ & $\begin{array}{l}\text { Straight reach with very } \\
\text { gentle s-bend and large } \\
\text { rock constrictions. Single } \\
\text { thread, rock controlled. }\end{array}$ & $\begin{array}{l}\text { Bed is mostly sand and gravel with scattered rock } \\
\text { outcrops. Rock section in bed just upstream. Banks } \\
\text { are controlled by rock outcrops. Intervening bank } \\
\text { areas are H1/H2 lateral accretion terraces. }\end{array}$ & $\begin{array}{l}\text { "Saddle constriction". Trench } \\
\text { sites T4 and T5 (FP11 and FP12) } \\
\text { are adjacent to the downstream } \\
\text { portion of this reach. }\end{array}$ \\
\hline CH5 & 2444 & $\begin{array}{l}87984 \\
(8174)\end{array}$ & $\begin{array}{c}2.01 \\
(0.82)\end{array}$ & $\begin{array}{l}1965 \\
(599)\end{array}$ & $\begin{array}{l}\text { Mostly straight reach. } \\
\text { Single thread. }\end{array}$ & $\begin{array}{l}\text { Bed is gravel. Right bank mostly P2/P3 gravel with } \\
\text { narrow H1/H2 lateral accretion terrace and few } \\
\text { rock outcrops. Left bank is wider H1/H2 terrace. }\end{array}$ & $\begin{array}{l}\text { Trench T6 is on left bank in } \\
\text { upstream section; BLR6 is on } \\
\text { right bank, mid-reach. }\end{array}$ \\
\hline CH6 & 1322 & $\begin{array}{l}47592 \\
(4421)\end{array}$ & $\begin{array}{l}1.09 \\
(0.44)\end{array}$ & $\begin{array}{l}1030 \\
(314)\end{array}$ & $\begin{array}{l}90^{\circ} \text { bend at upstream end; } \\
\text { mostly straight with } \\
\text { gentle left bends. Single } \\
\text { thread with rock control. }\end{array}$ & $\begin{array}{c}\text { Rock in bed near upstream portion. Scattered } \\
\text { outcrops in bed downstream, otherwise gravel. } \\
\text { Scattered rock outcrops along banks; most banks } \\
\text { H1/H2/H3 terraces. }\end{array}$ & \\
\hline $\mathrm{CH} 7$ & 198 & $\begin{array}{l}7128 \\
(662)\end{array}$ & $\begin{array}{c}0.16 \\
(0.07)\end{array}$ & $\begin{array}{l}260 \\
(79)\end{array}$ & $\begin{array}{l}\text { Rock constriction. } \\
\text { Straight, single thread. }\end{array}$ & $\begin{array}{l}\text { Gravel bed. Banks are rock, with small areas of } \\
\text { fine-grained H1/H2 deposits between outcrops. }\end{array}$ & "Bridge constriction" \\
\hline CH8 & 1195 & $\begin{array}{l}43020 \\
(3997)\end{array}$ & $\begin{array}{c}0.98 \\
(0.40)\end{array}$ & $\begin{array}{c}934 \\
(285)\end{array}$ & $\begin{array}{l}\text { Tight s-bend with rock } \\
\text { controls. Single thread. }\end{array}$ & $\begin{array}{l}\text { Mostly gravel bed with many rock outcrops. Large } \\
\text { areas of rock control in middle of reach. Rock } \\
\text { banks and constriction on middle/downstream } \\
\text { portion. Upstream banks are H2/H3 fine-grained } \\
\text { deposits. }\end{array}$ & $\begin{array}{l}\text { BLR8 on right bank mid-reach. } \\
\text { T8 and T9 trenches on right banks } \\
\text { in middle portion of reach. }\end{array}$ \\
\hline CH9 & 1444 & $\begin{array}{l}51984 \\
(4829)\end{array}$ & $\begin{array}{l}1.19 \\
(0.48)\end{array}$ & $\begin{array}{l}1852 \\
(564)\end{array}$ & $\begin{array}{l}\text { Mostly straight with } \\
\text { gentle bends. Single } \\
\text { thread with rock control. }\end{array}$ & $\begin{array}{l}\text { Bed is gravel with several rock outcrops. Right } \\
\text { bank has narrow H4 fine-grained terrace along } \\
\text { most of length with scattered rock outcrops. Left } \\
\text { bank is H2/H3/H4 fine-grained terrace with } \\
\text { scattered rock outcrops. }\end{array}$ & \\
\hline
\end{tabular}


Table 3-3 Summary of limiting discharge values from hydraulic modeling sample areas

\begin{tabular}{|c|c|c|c|c|c|c|c|}
\hline \multirow{3}{*}{$\begin{array}{c}\text { Sample } \\
\text { Area }\end{array}$} & \multirow{3}{*}{$\begin{array}{l}\text { Per Cent } \\
\text { Area } \\
\text { Meeting } \\
\text { Erosion } \\
\text { Criteria }\end{array}$} & \multicolumn{6}{|c|}{ Discharge $\left(\mathrm{m}^{3} / \mathrm{s}\right)$} \\
\hline & & \multicolumn{3}{|c|}{ Soil Erosion } & \multicolumn{3}{|c|}{ Terrace Erosion } \\
\hline & & $\begin{array}{l}\text { Low } \\
\text { Bound }\end{array}$ & $\begin{array}{l}\text { Preferred } \\
\text { Value }\end{array}$ & $\begin{array}{l}\text { High } \\
\text { Bound }\end{array}$ & $\begin{array}{l}\text { Low } \\
\text { Bound }\end{array}$ & $\begin{array}{l}\text { Preferred } \\
\text { Value }\end{array}$ & High Bound \\
\hline FP1 & 50 & $80-110$ & 115 & $130-140$ & $130-140$ & $170-200$ & 220 \\
\hline FP2 & 50 & 110 & $120-150$ & 160 & 160 & $220-240$ & $>400(?)$ \\
\hline FP3 & 50 & $130-140$ & $160-190$ & $230-250$ & $230-250$ & $>400(?)$ & $>400(?)$ \\
\hline FP4 & 50 & 115 & $120-145$ & $145-165$ & $145-165$ & $205-220$ & $350-400(?)$ \\
\hline FP5 & n.a.* & 175 & 225 & 250 & 250 & 300 & 400 \\
\hline FP6 & 50 & $80-100$ & $115-160$ & $175-230$ & $175-230$ & >400(?) & $>400(?)$ \\
\hline FP7 & 50 & $<70$ & $<90-125$ & $135-175$ & $135-175$ & $>400(?)$ & $>400(?)$ \\
\hline FP8 & 50 & $<70$ & $95-160$ & $170-225$ & $170-225$ & $>400(?)$ & $>400(?)$ \\
\hline FP9 & 50 & $<70$ & $<70$ & $80-100$ & $80-100$ & 250 & $>400(?)$ \\
\hline FP10 & n.a.* & $125-160$ & $160-250$ & 250 & 250 & $>400(?)$ & $>400(?)$ \\
\hline FP11 & 50 & 110 & $120-160$ & $160-185$ & 160-185 & 200-215 & $>400(?)$ \\
\hline FP12 & 50 & 90 & $95-110$ & $110-120$ & $110-120$ & $130-160$ & $160-230$ \\
\hline FP13 & 50 & $115-120$ & $130-160$ & $155-180$ & $155-180$ & $205-220$ & $270->400(?)$ \\
\hline FP14 & n.a.* & 250 & $300-350$ & $400-450$ & $400-450$ & >400(?) & $>400(?)$ \\
\hline FP15 & n.a.* & 250 & $330-400$ & $>400(?)$ & $>400(?)$ & $>400(?)$ & $>400(?)$ \\
\hline FP16 & n.a.* & $170-220$ & $220-270$ & 300 & 300 & $>400(?)$ & $>400(?)$ \\
\hline FP17 & 50 & $105-110$ & $115-130$ & $130-140$ & $130-140$ & 165-185 & $220-320$ \\
\hline FP18 & 50 & 60 & $65-70$ & 80 & 80 & $100-110$ & $130-190$ \\
\hline FP19 & 50 & $135-140$ & $150-200$ & $200-250$ & $200-250$ & $>400(?)$ & $>400(?)$ \\
\hline FP20 & 50 & 80 & 90 & $90-115$ & $90-115$ & $120-140$ & $155-250$ \\
\hline FP21 & 50 & 30 & 35 & 40 & 40 & $45-60$ & $60-90$ \\
\hline
\end{tabular}


Table 3-4 Applicability of hydraulic modeling sample areas to paleofloods and paleohydrologic bounds estimates

\begin{tabular}{|c|c|c|c|c|c|c|}
\hline \multirow{3}{*}{$\begin{array}{c}\text { Sample } \\
\text { Area }\end{array}$} & \multicolumn{6}{|c|}{ Event Name } \\
\hline & \multicolumn{3}{|c|}{ Paleofloods } & \multicolumn{3}{|c|}{ Paleohydrologic Bounds } \\
\hline & $\begin{array}{l}\text { "white } \\
\text { flood" }\end{array}$ & $\begin{array}{l}\text { "400-yr" } \\
\text { flood }\end{array}$ & $\begin{array}{c}\text { "older } \\
\text { flood(s)" }\end{array}$ & $400-\mathrm{yr} \# 1$ & $\begin{array}{l}\text { early Holocene } \\
\text { (H1 surfaces) }\end{array}$ & Pleistocene \\
\hline FP1 & & G & & $\mathrm{G}$ & & \\
\hline FP2 & & G & & & & \\
\hline FP3 & & & G & $\mathrm{G}$ & & \\
\hline FP4 & & $S$ & G & G,S & & \\
\hline FP5 & & & G,S & & $\mathrm{G}$ & G,S \\
\hline FP6 & & G,S & G,S & G,S & G & G \\
\hline FP7 & & G & & $\mathrm{G}$ & & \\
\hline FP8 & & $\mathrm{G}$ & G & $\mathrm{G}$ & G & G \\
\hline FP9 & G & & & & & \\
\hline FP10 & & G & G & $\mathrm{G}$ & $\mathrm{G}$ & $\mathrm{G}$ \\
\hline FP11 & S & G,S & G,S & G,S & & \\
\hline FP12 & S & G,S & G,S & G,S & & \\
\hline FP13 & $S$ & G,S & G,S & G,S & G,S & \\
\hline FP14 & & & & & & G,S \\
\hline FP15 & & & & & & G,S \\
\hline FP16 & & G & G & G & G,S & G \\
\hline FP17 & & G & G & G & G & \\
\hline FP18 & G & & & & & \\
\hline FP19 & & $S$ & $S$ & G,S & G,S & G,S \\
\hline FP20 & & $\mathrm{S}$ & $\mathrm{S}$ & G,S & & \\
\hline FP21 & G & & & & & \\
\hline
\end{tabular}


Table 3-5 Big Lost River Paleofloods and Paleohydrologic Bounds

\begin{tabular}{|c|c|c|c|}
\hline Event name & $\begin{array}{l}\text { Age or time span } \\
\text { (Cal yrs or Cal yr } \\
\text { B.P })^{1}\end{array}$ & $\begin{array}{l}\text { Discharge } \\
\left(\mathrm{m}^{3} / \mathrm{s}\right) \text { and type } \\
\text { of distribution }\end{array}$ & Summary of Evidence \\
\hline \multicolumn{4}{|r|}{ Paleofloods } \\
\hline "white flood" & $\begin{array}{l}>100 y r \text { (pre- } \\
\text { gaging) but less } \\
\text { than } 400-600 y r\end{array}$ & $\begin{array}{l}90(80-100) \\
\text { uniform }\end{array}$ & $\begin{array}{l}\text { Based on thin deposit in T4. Not recognized in T5 or T6 (slightly higher sites). Possible correlative in T9(?). Age - } \\
\text { most likely } 100 \text { to } 150 \text { years based on absence of soil development. Discharge - Upper limit based on rapid } \\
\text { increase in power/shear stress at T4 and lack of deposit in T5/T6. }\end{array}$ \\
\hline "400-yr" flood & 400 to 600 years & $\begin{array}{l}150(130-175) \\
\text { triangular }\end{array}$ & $\begin{array}{l}\text { Apparently correlative deposits in T4, T5, T6 (also BLR2, BLR7 \& BLR8) with similar soils, stratigraphic setting, } \\
\text { and radiocarbon ages. Soil has stage I- Bk horizon. Stripping of A- and AB/Bw horizons at T8c, partial stripping at } \\
\text { T8b; lack of erosion at T8a. May represent more than one flood. }\end{array}$ \\
\hline "older flood" & $\begin{array}{l}1000 \text { to } 2000 \\
\text { years }\end{array}$ & $\begin{array}{l}150(130-175) \\
\text { triangular }\end{array}$ & $\begin{array}{l}\text { Deposits with Stage I to I+ Bk horizon that underlie "400-yr flood" deposits in T4, T5, T6 and T9. Appears to } \\
\text { indicate long period of stability with little or no deposition at these sites before deposition of deposits associated } \\
\text { with "400-yr" flood. Similar stratigraphy at BLR2 and BLR8. Likely represents multiple floods of similar or } \\
\text { smaller maximum discharge. Minimum discharge must inundate FP1-FP4, FP6-8, most of FP7, FP11-13, FP17- } \\
\text { 18, and FP19-21, which are areas with H1-2 geomorphic surfaces that appear to indicate Holocene flooding. }\end{array}$ \\
\hline \multicolumn{4}{|r|}{ Paleohydrologic Bounds } \\
\hline 400-yr \#1 & $400-600$ & $\begin{array}{l}130(110-150) \\
\text { triangular }\end{array}$ & $\begin{array}{l}\text { Preservation of recognizable stratigraphy at T4 and T6. No stripping of A-horizons from the youngest deposits at } \\
\text { T4 and T6. Apparently correlative H1-2 geomorphic surfaces at FP1, FP3-4, FP7, FP11-13, FP17, and FP19-20. }\end{array}$ \\
\hline $\begin{array}{l}\text { early Holocene } \\
\text { (H1 surfaces) }\end{array}$ & 6000 to 8000 & $\begin{array}{l}225(175-250) \\
\text { triangular }\end{array}$ & $\begin{array}{l}\text { Preservation of stratigraphy in T6, T4, and T8a,b,c. Banks at BLR6 and continuity of H1-2 geomorphic surfaces } \\
\text { along BLR. }\end{array}$ \\
\hline Pleistocene & $>10000$ & $\begin{array}{c}250(225-400) \\
\text { triangular }\end{array}$ & $\begin{array}{l}\text { Preservation of Pleistocene gravel surfaces throughout the study reach. Actual age of the underlying deposits is } \\
\text { older than } 12-15 \mathrm{ka} \text { (minimum age of deglaciation) and some may be older than } 20-25 \mathrm{ka} \text { (Last glacial maximum). } \\
\text { Length of time span for paleohydrologic bound is limited by post-glacial, warmer climate more similar to present. }\end{array}$ \\
\hline
\end{tabular}




\subsection{REVISED FLOOD FREQUENCY FOR THE BIG LOST RIVER AT THE INEEL DIVERSION DAM}

It is necessary to revise flood frequency estimates for two reasons. First, peak discharge values have been slightly modified for several data points, including the paleohydrologic nonexceedence bounds. Second, the distribution of observed peak discharges and paleohydrologic information is sufficiently complex that parametric flood frequency functions are ill-suited to determine statistical quantities, such as credible or "confidence" limits for flood frequency estimates. Consequently, a newly-published nonparametric Bayesian flood frequency estimation approach (O’Connell, 2005) is used to obtain probabilistic minimum-bias estimates of flood frequency.

\subsection{Nonparametric Flood Frequency for the Big Lost River at INL}

The nonparametric Bayesian Monte Carlo method of O’Connell (2005) is used to estimate flood frequency. This method accommodates complex flood behaviors such as event clustering (repeated instances of similar magnitude floods) and can use varied data, such as gage and historical peak discharges, and paleohydrologic upper and lower bounds on peak discharge, while rigorously accounting for a wide variety of measurement uncertainties. In contrast to nonparametric kernel estimation approaches, the stochastic assumption is used to generate flood frequency models that span the data and provide about twice the number of degrees of freedom of the data. Each generated flood frequency model is scored using likelihoods that account for data measurement uncertainties. A parametric estimation approach ensures high precision because posterior sampling is known. However, parametric approaches can produce substantial biases because the classes of allowed flood frequency models are restricted. These biases are completely undetectable within a parametric paradigm. The minimize these types of biases, the nonparametric approach used here surrenders some precision, but produces greater overall accuracy and assurance; it reveals the annual probabilities where discharge becomes unconstrained by the data, thereby eliminating unsubstantiated extrapolation. Parametric flood frequency estimation introduces strong extrapolation priors that make it difficult, if not impossible, to determine when flood frequency is no longer constrained by the data. These 
problems are apparent in the parametric method of O'Connell et al. (2002) used in the previous INL flood-frequency analyses (Ostenaa et al., 1999).

Measurement uncertainty is included using discrete pdf's. Gaussian measurement uncertainties of $2 \sigma=25 \%$ are used for the gage data (see Figure 4-1 for an example for the largest gage flood). The smaller (historical) paleoflood is assigned a uniform likelihood for discharges from $80 \mathrm{~m}^{3} / \mathrm{s}$ (cms) to $105 \mathrm{cms}$ and its corresponding non-exceedence bound is assigned a uniform likelihood for discharges from $80 \mathrm{cms}$ to $110 \mathrm{cms}$. The non-uniform measurement uncertainties for the rest of the nonexceedence bounds and paleofloods are shown in Figure 4-1.

Monte Carlo integration is used with a total of 320,000 randomly-created flood-frequency models to produce posterior estimates of probability density for peak discharge at target annual exceedence probabilities (AEP) and for cumulative probability (which is transformed to AEP for plotting) associated with target peak discharges. The 25 least frequent AEP positions used to randomly generate peak discharge values are shown in Table 4-1 which reflect about twice the number of degrees of freedom represented by the data for AEP's $<0.1$.

Peak discharges were randomly generated at all data points plotted in Figure 4-2, with the caveat that the peak discharges for $T<10$ years were rescaled to a maximum of half their values to avoid having the reordering of small flows influence the distribution of the large flows of interest. The cumulative frequency ( $c f$ ) node positions at $T=30,000$ years and $T=40,000$ years were added to provide an extrapolation limit for the computation. As shown in Figure 4-2 non-informative peak discharge priors were selected for AEP's $<0.1$ by expanding the prior to include discharges much larger than the observed data. These priors adequately represent an ignorance function relative to the magnitude of floods and bounds in the input data. Construction of such a prior is essential for determining the AEP limit where observed data no longer provide any meaningful constraints on flood frequency. The range of peak discharges included in the Bayesian estimation of flood frequency as a function of AEP and return period are shown in Figure 4-2 by the yellow region. The maximum number of peak discharge resorting operations allowed before rejecting a random flood frequency model was set to seven and represented less than a third of the total number of degrees of freedom. 
Monte Carlo nonparametric flood frequency results using 320,000 random models are shown in Figure 4-2. Formal Monte Carlo relative errors are 2.7\% based on the approach used in O’Connell (2005), but actual convergence appears to be much faster, because flood frequency estimates obtained using 8000, 40,000 and 320,000 random models are virtually the same. Sampling density functions are substantially broader than the nonzero regions of posterior density (Figure 4-2). The best-fitting models reproduce all the observed data well (Figure 4-2). This result is expected since arbitrary flood frequency shapes can be generated by the nonparametric process. It is instructive to inspect sampling functions, posterior pdf's and $c f$ 's for individual return periods that show more detail than can be portrayed in Figure 4-2.

The cluster of floods in the 80-90 cms range (Figure 4-2) places strong constraints on the $T=100$ year and $T=150$ year discharges, although the $T=150$-year pdf begins to develop a longer tail at maximum discharges (Figure 4-3). The increased uncertainty in estimated discharges for AEP's < 0.01 is apparent in the expanding upper tail in the discharge pdf's for $T=200$ years and $T=350$ years (Figure 4-4) which is also clearly apparent in Figure 4-2. Since the only definite information available about the occurrence of floods in this region are the historical and paleoflood, a wide range of peak discharge scenarios are consistent with the flood and nonexceedence bound data for $T=150$ years to $T=500$ years, as indicated by the wide region of blue curves in Figure 4-2 and the expanding upper tails in Figure 4-3, Figure 4-4, and Figure 4-5.

While the discharge mode is dominated by the largest paleoflood for $T=1000$ years and $T=2000$ years (Figure 4-6) a relatively large range of discharges are allowed because there is little density information in the form of actual floods (only the historical and paleoflood). Consequently, the higher likelihood discharges vary over a wide range constrained mostly by the nonexceedence bounds and the single paleoflood for AEP's < 1/1000 (Figure 4-2). This is particularly evident for $T=3500$ years and $T=5000$ years, where discharges from slightly the lower limit of the largest paleoflood discharge up to the upper limits of the early Holocene nonexceedence bound are allowed (Figure 4-7). For $\mathrm{T}=7500$ years and $\mathrm{T}=10,000$ years, the only constraints are that discharge be as large as the largest paleoflood, but smaller than the late Holocene nonexceedence bound (Figure 4-8). As T extends beyond 10,000 years, the available data provide diminishing constraints with increasing $\mathrm{T}$ (Figure 4-9). Once $\mathrm{T}$ is about twice the length of record ( $\mathrm{T}=20,000$ 
years), constraints on the upper bound for discharge become weak, while the constraint that discharge must be as large as the largest paleoflood remain (Figure 4-9). This is evident in the large discharge ranges of high likelihood models for AEP's $<0.0001$ (shown as blue lines in Figure 4-2).

For discharges $>100 \mathrm{cms}$ credible intervals for AEP can be quite large because there is only positive evidence for the actual occurrence of one such discharge (P in Figure 4-2). Consequently, AEP's for discharges $>100 \mathrm{cms}$ are only weakly bounded to the right in Figure 4-2 and in fact become virtually unbounded to the right (are not required to ever occur) for discharges significantly exceeding the largest observed discharge. This means that the right credible limit for discharges $>\sim 300 \mathrm{cms}$ becomes a cumulative frequency of one or AEP of zero (Figure 4-2, Figure 4-10, and Figure 4-11). Thus for discharges $>\sim 300 \mathrm{cms}$ the most meaningful statistic are bounds to the left in Figure 4-2 which limit the maximum frequencies of occurrence. Central tendency measures like the mean or median lose statistical significance in these situations. However, for all discharges, the nonexceedence discharge bounds place strong limits on the maximum AEP's that can be associated with particular discharges (Figure 4-2).

The densities in Figure 4-10, Figure 4-11, Figure 4-12, and Figure 4-13 look peculiar relative to the cumulative frequencies because all density/cumulative frequencies calculations are performed in cumulative frequency space and then transformed to AEP/T for plotting. This is why it appears that there is more density to the right (small AEP's) than indicated by the cumulative frequency curves or credible limits in Figure 4-10, Figure 4-11, Figure 4-12, and Figure 4-13. For example, the AEP density distribution for a discharge of $106 \mathrm{cms}$ appears unbounded to the right, but the cumulative frequency density is well behaved and provides a useful right credible limit (Figure 412). When the right credible limits are significant (discharges $<\sim 300 \mathrm{cms}$ ), they indicate a $90 \%$ probability that the AEP is greater than the right credible limit AEP. The wide ranges of AEP's represented between the $10 \%$ and $90 \%$ credible limits for discharges $<300 \mathrm{cms}$ (Figure 4-11, Figure 4-12, and Figure 4-13) indicate the large range of recurrence uncertainties that result from the lack of strong density information, i.e., multiple observed discharges or discharge exceedences $>100 \mathrm{cms}$. 
As discussed above for this particular dataset there is more statistical significance to the left credible limits, than the mean or right credible limits for discharges $>\sim 300 \mathrm{cms}$. For discharges $>$ $\sim 300$ cms right credible limits may just as easily extend to $\mathrm{AEP}=0$ as the values reported in the nonparametric flood frequency calculations, and the shape of the densities are generally not compatible with a measure of central tendency, such as a mean. Consequently, mean flood frequency estimates for AEP's $<0.0001$ are flagged with stars in Table 4-2. 
Figures for Section 4.0 

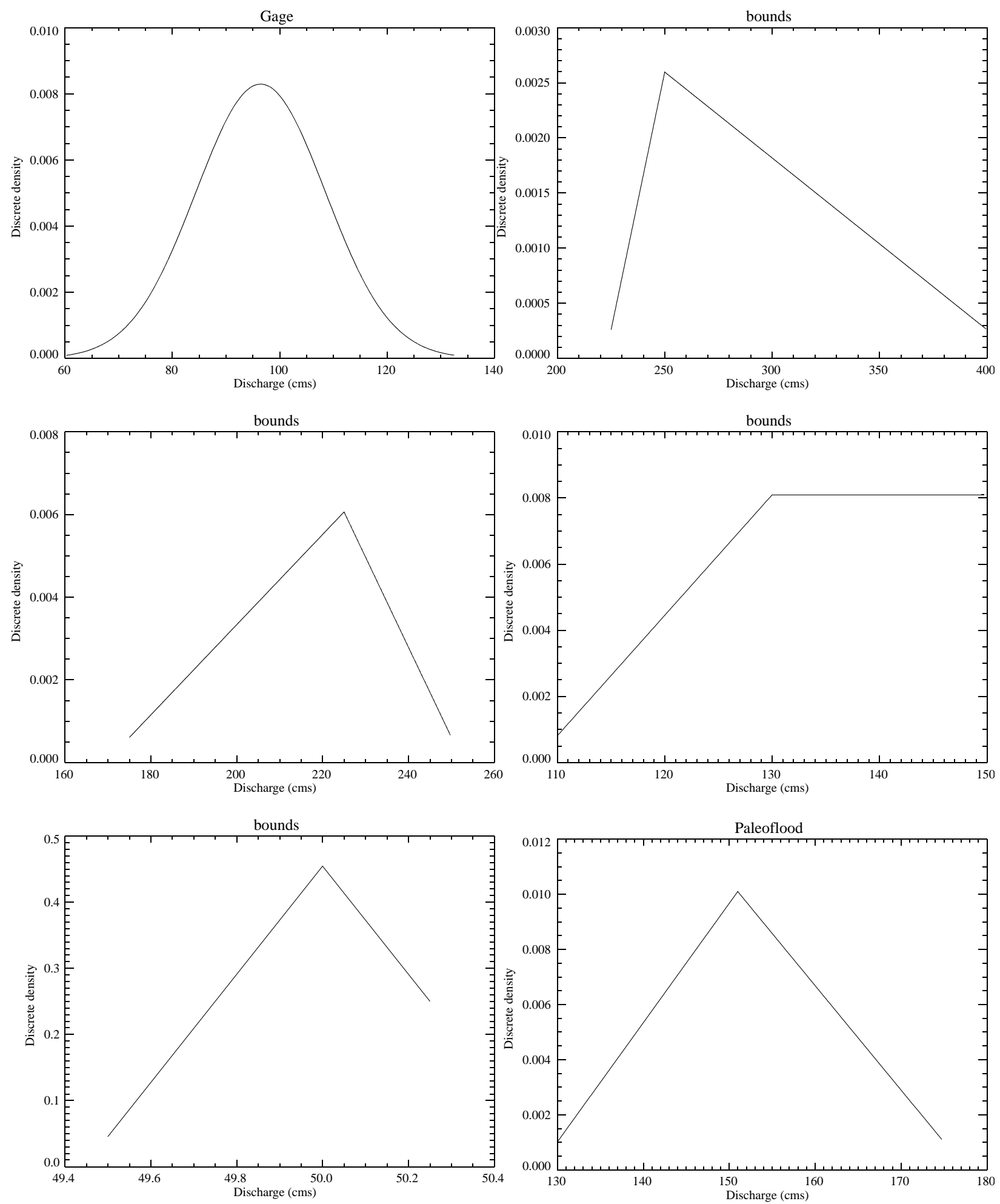

Figure 4-1 Measurement uncertainties for gage, bound, and paleoflood discharges on the Big Lost River at the INEEL Diversion Dam.. 


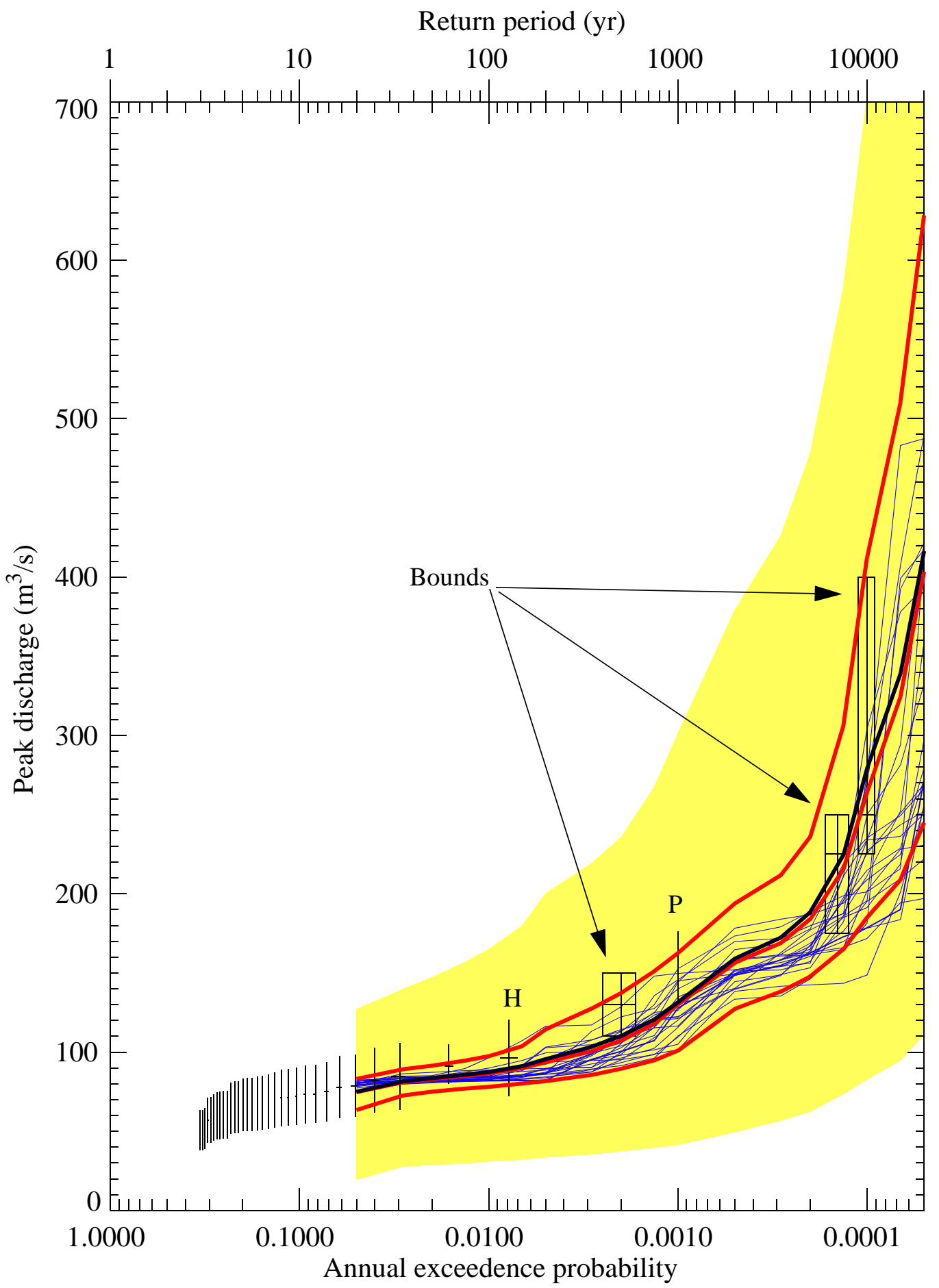

Figure 4-2 Revised flood frequency for Big Lost River at the INEEL Diversion Dam. Gaged flows (vertical black lines, with short horizontal lines indicating preferred discharge and plotting position uncertainty) are from Big Lost River at Howell Ranch (94 years) attenuated to the INEEL Diversion Dam based on methods of Hortness and Rousseau (2002). Geologic data includes two paleofloods (largest discharges labeled $\mathrm{H}$ and $\mathrm{P}$ ) and three paleohydrologic bounds (black boxes - vertical lines indicate discharge range, horizontal lines indicate duration range). Lower and upper red curves are 5\% and 95\% credible limits (middle red is median, and middle black is mean). Blue curves are models with relative likelihoods $>0.25$ of the maximum likelihood. Yellow region indicates the limits of sampling. 

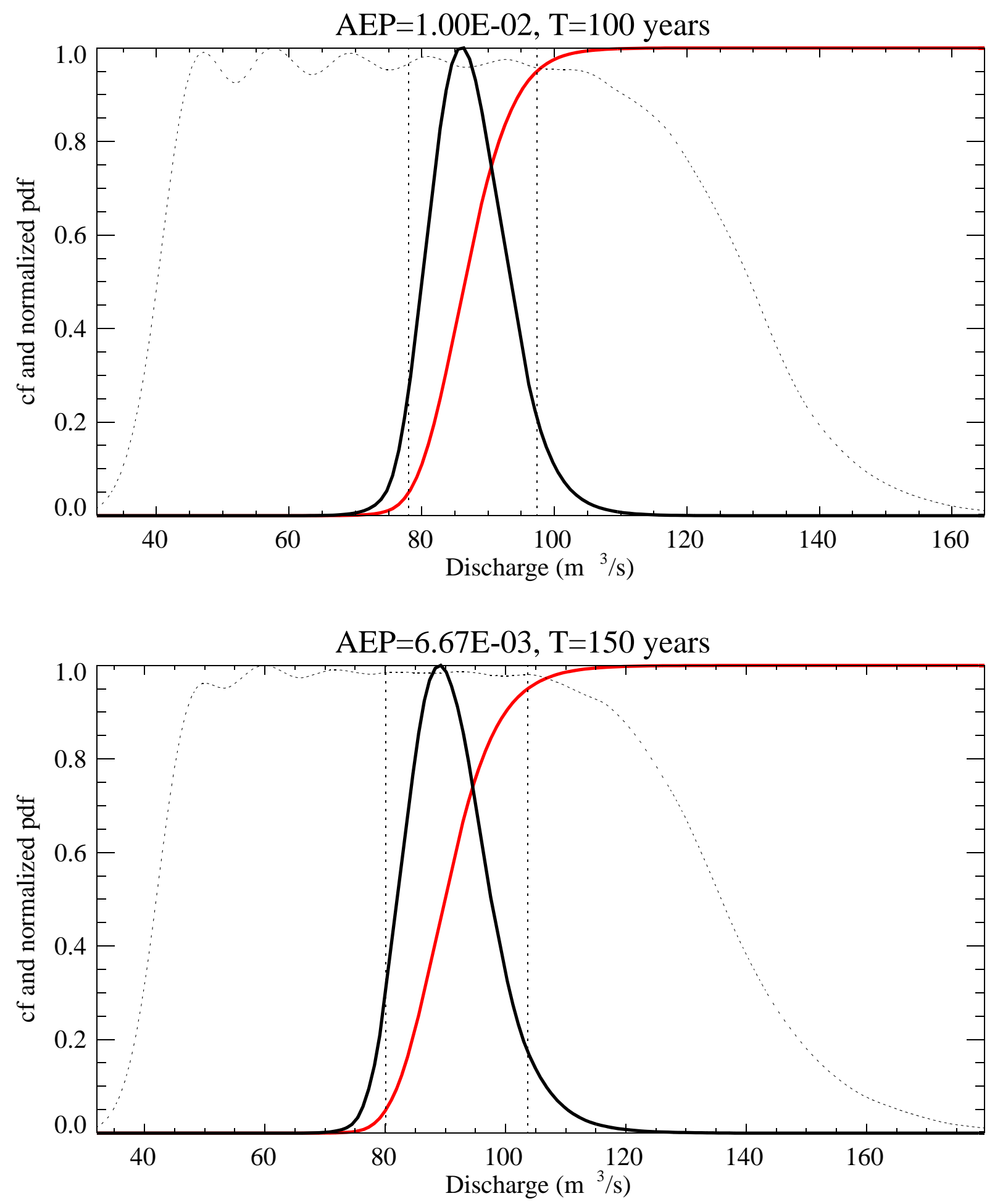

Figure 4-3 Peak discharges distributions for AEP's 0.01 and 0.00667 on the Big Lost River at the INEEL Diversion Dam. Red curves are cumulative probability, dotted curves are sampling density, and black curves are probability density. Vertical dotted lines represent 5\% and 95\% credible limits. 

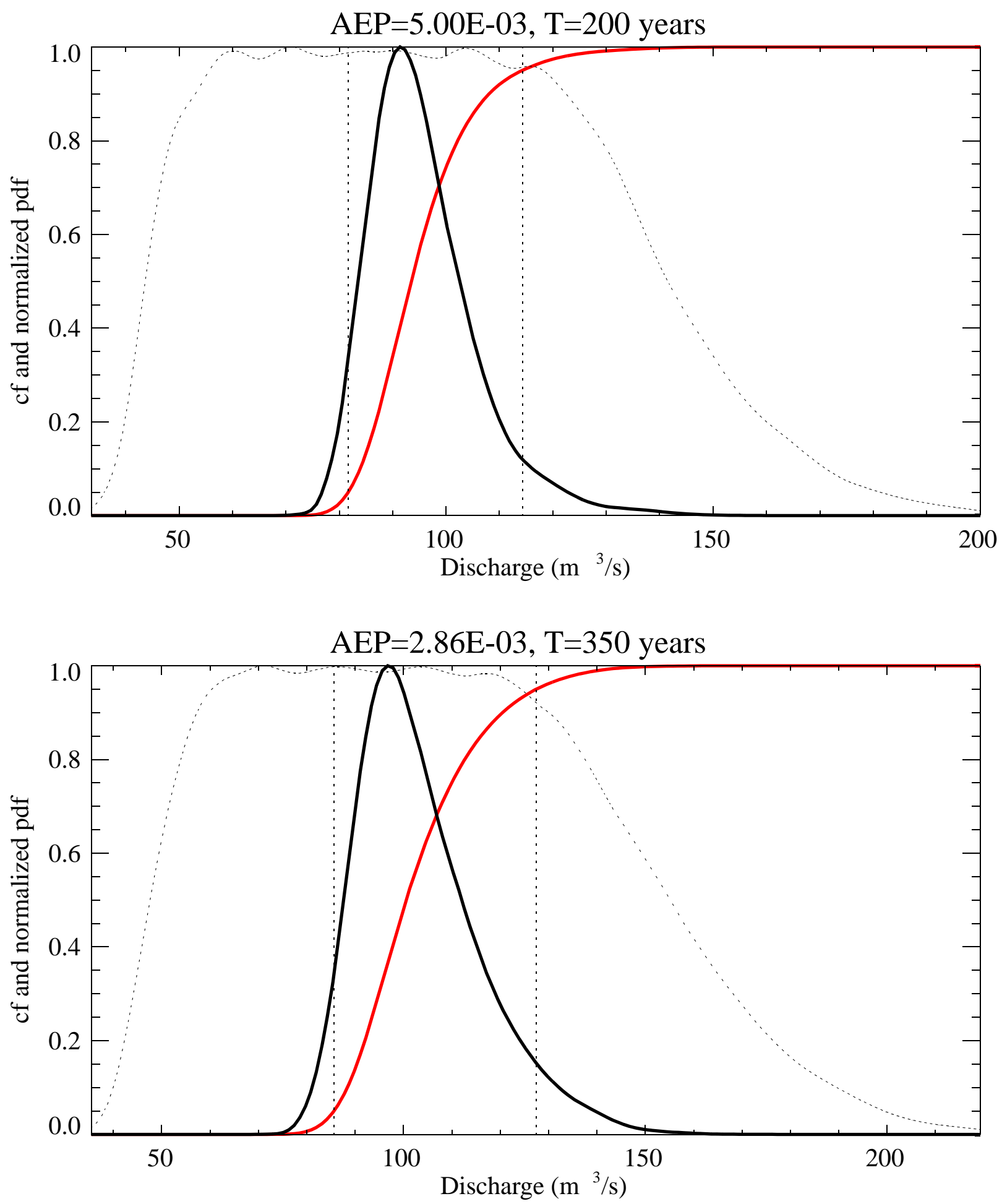

Figure 4-4 Peak discharges distributions for AEP's 0.005 and 0.00286 on the Big Lost River at the INEEL Diversion Dam. Red curves are cumulative probability, dotted curves are sampling density, and black curves are probability density. Vertical dotted lines represent 5\% and 95\% credible limits. 

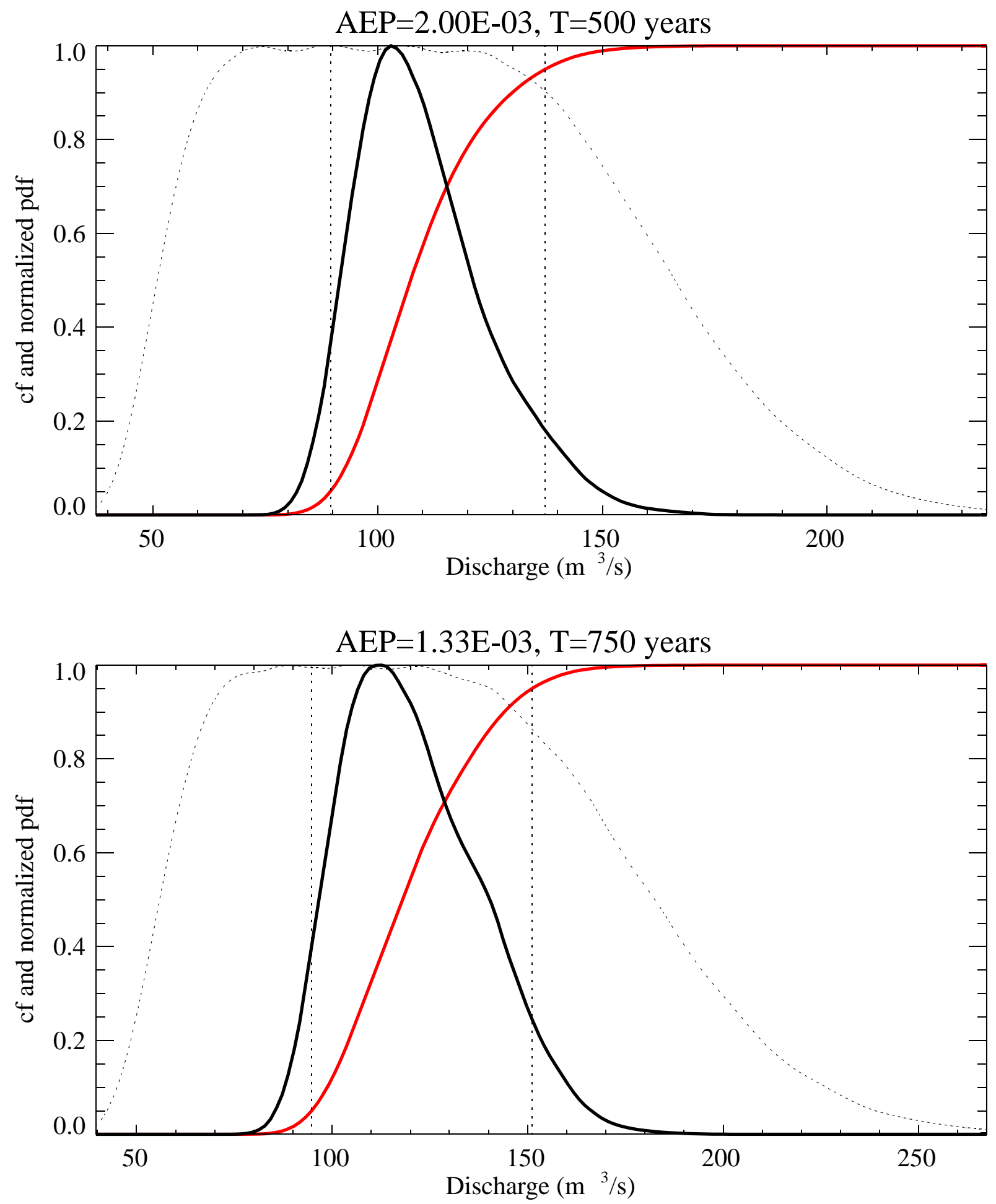

Figure 4-5 Peak discharges distributions for AEP's 0.002 and 0.00133 on the Big Lost River at the INEEL Diversion Dam. Red curves are cumulative probability, dotted curves are sampling density, and black curves are probability density. Vertical dotted lines represent 5\% and 95\% credible limits. 

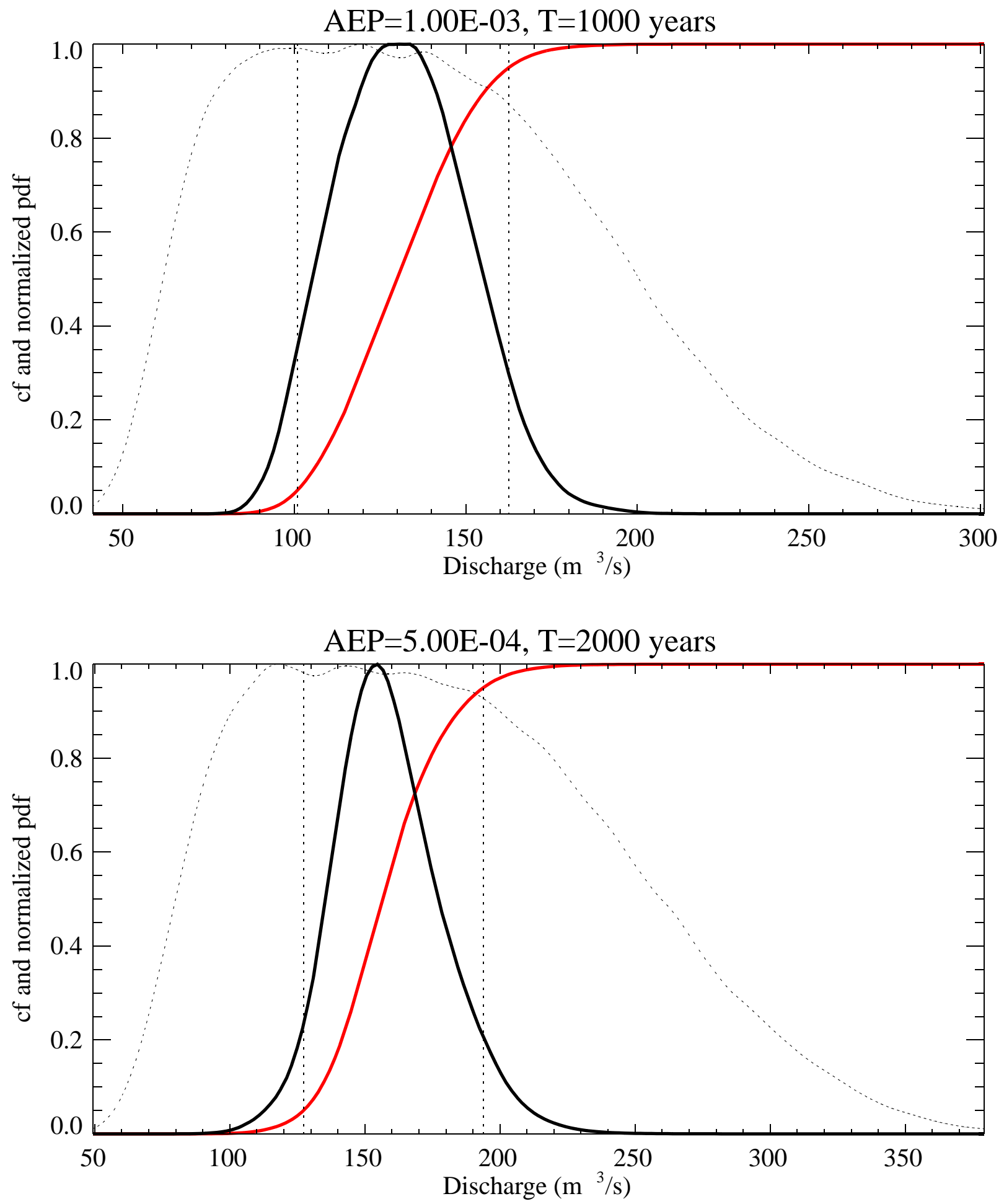

Figure 4-6 Peak discharges distributions for AEP's 0.001 and 0.0005 on the Big Lost River at the INEEL Diversion Dam. Red curves are cumulative probability, dotted curves are sampling density, and black curves are probability density. Vertical dotted lines represent 5\% and 95\% credible limits. 

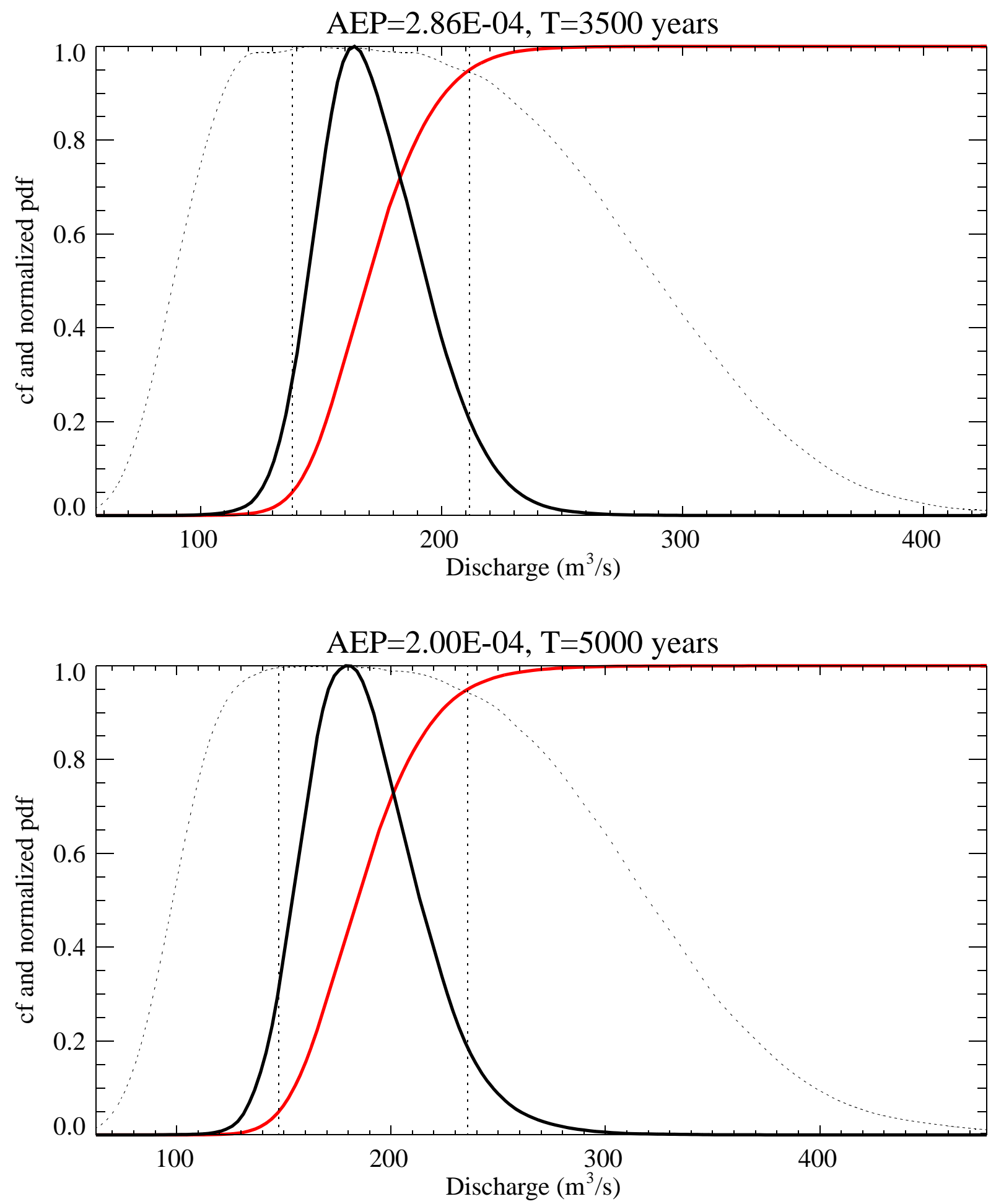

Figure 4-7 Peak discharges distributions for AEP's 0.000286 and 0.00002 on the Big Lost River at the INEEL Diversion Dam. Red curves are cumulative probability, dotted curves are sampling density, and black curves are probability density. Vertical dotted lines represent 5\% and 95\% credible limits. 

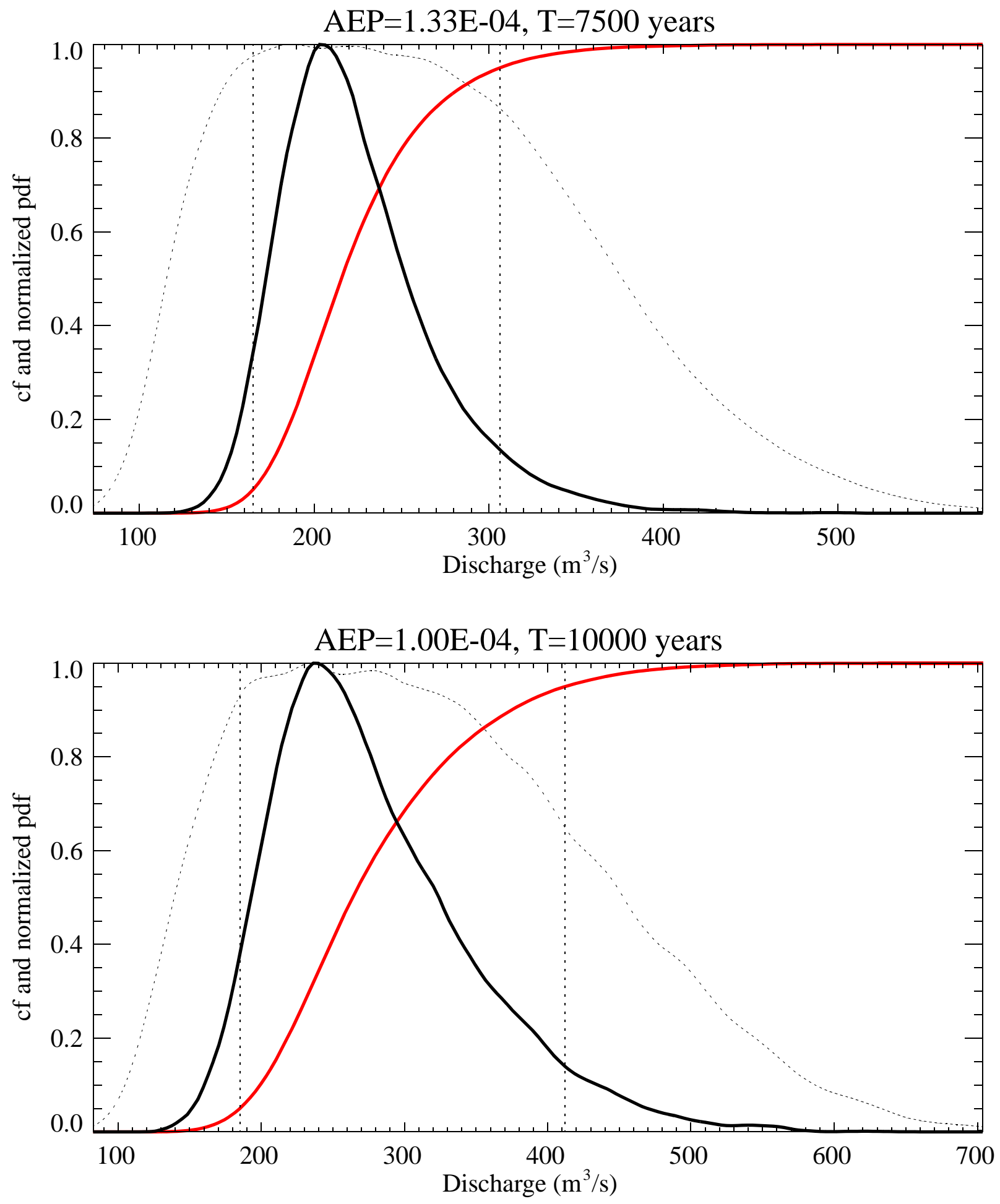

Figure 4-8 Peak discharges distributions for AEP's 0.000133 and 0.00001 on the Big Lost River at the INEEL Diversion Dam. Red curves are cumulative probability, dotted curves are sampling density, and black curves are probability density. Vertical dotted lines represent 5\% and 95\% credible limits. 

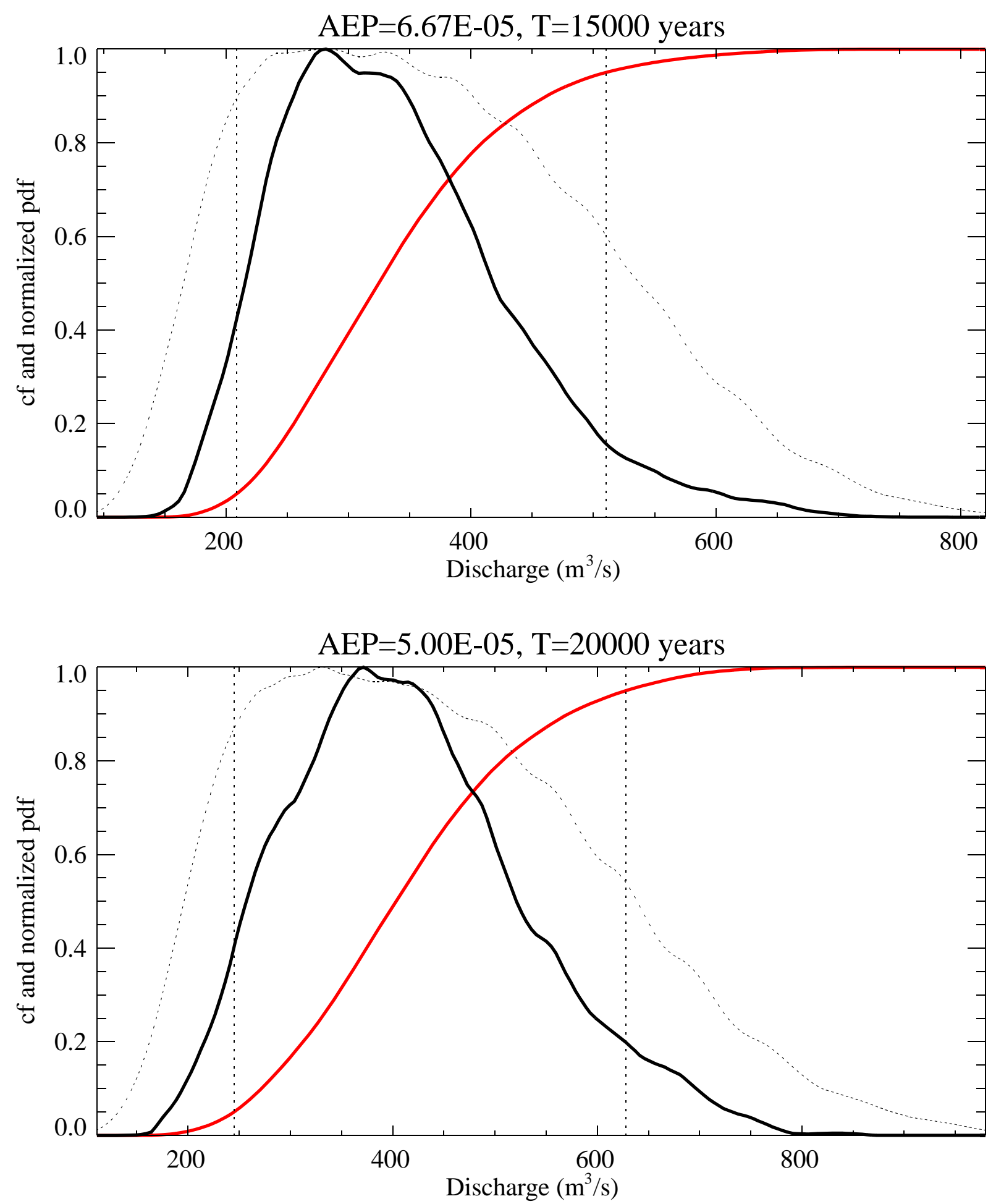

Figure 4-9 Peak discharges distributions for AEP's 0.0000667 and 0.000005 on the Big Lost River at the INEEL Diversion Dam. Red curves are cumulative probability, dotted curves are sampling density, and black curves are probability density. Vertical dotted lines represent $5 \%$ and 95\% credible limits. 

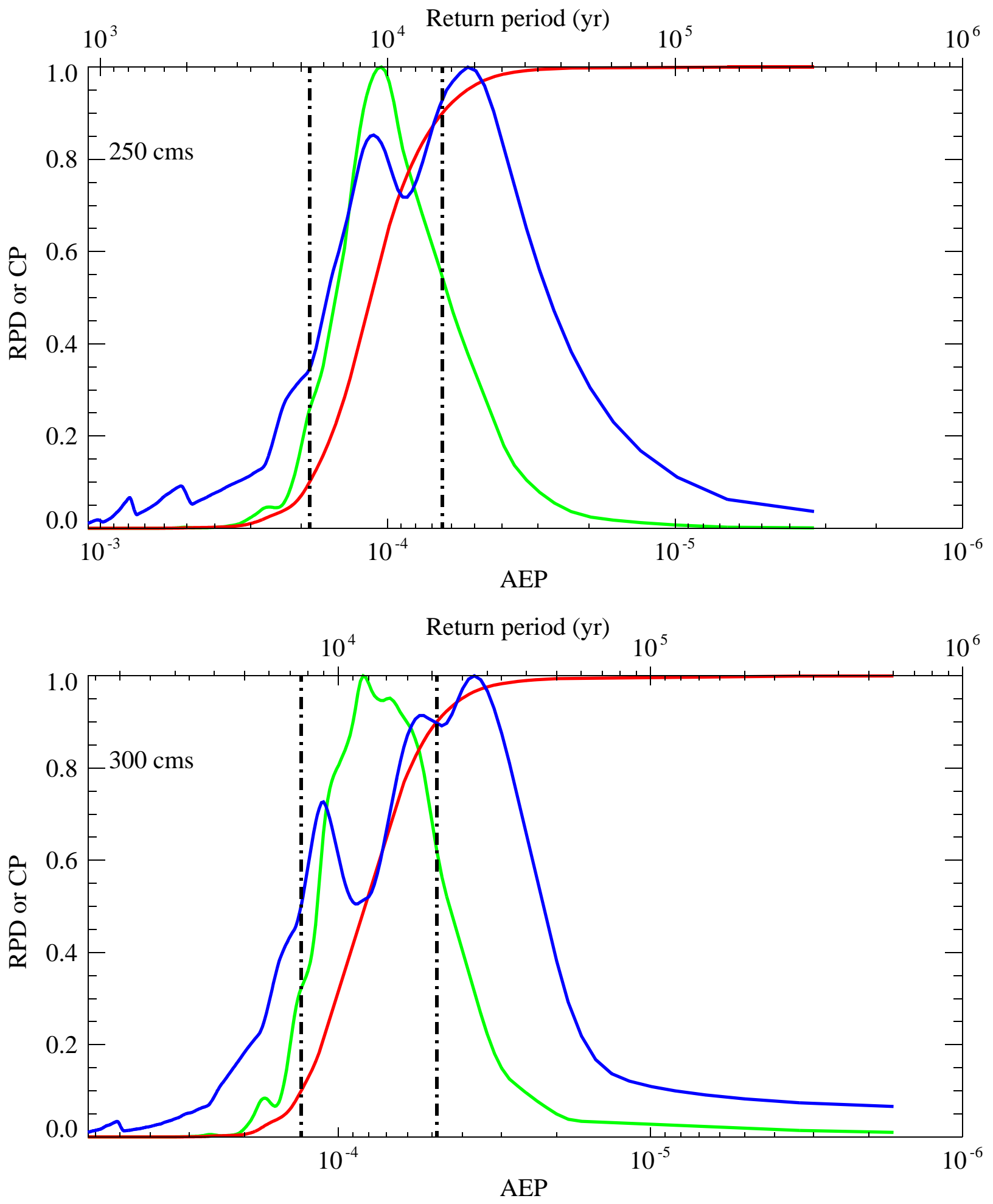

Figure 4-10 AEP distributions for $250 \mathrm{~m}^{3} / \mathrm{s}$ and $300 \mathrm{~m}^{3} / \mathrm{s}$ on the Big Lost River at the INEEL

Diversion Dam. Red curves are cumulative probability, blue curves are sampling density, and green curves are probability density (from cumulative probability and transformed to AEP). Vertical lines represent $10 \%$ and $90 \%$ credible limits on AEP, but are not really defined for $300 \mathrm{~m}^{3} / \mathrm{s}$ because nonzero density extends to $\mathrm{AEP}=0$. 

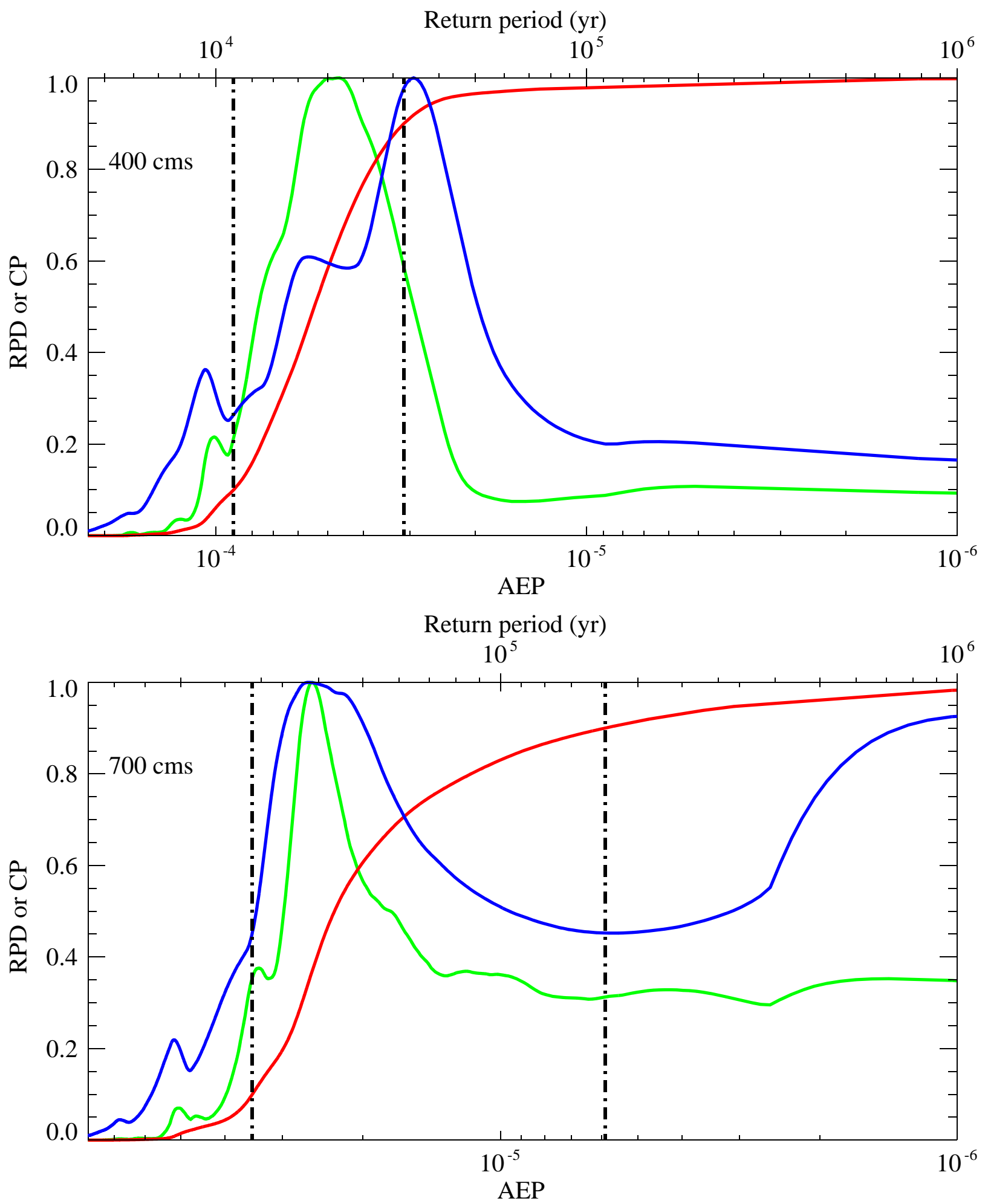

Figure 4-11 AEP distributions for $400 \mathrm{~m}^{3} / \mathrm{s}$ and $700 \mathrm{~m}^{3} / \mathrm{s}$ on the Big Lost River at the INEEL

Diversion Dam. Red curves are cumulative probability, blue curves are sampling density, and green curves are probability density (from cumulative probability and transformed to AEP). Vertical lines represent $10 \%$ and $90 \%$ credible limits on AEP, but are not really defined here because nonzero density extends to $\mathrm{AEP}=0$. 

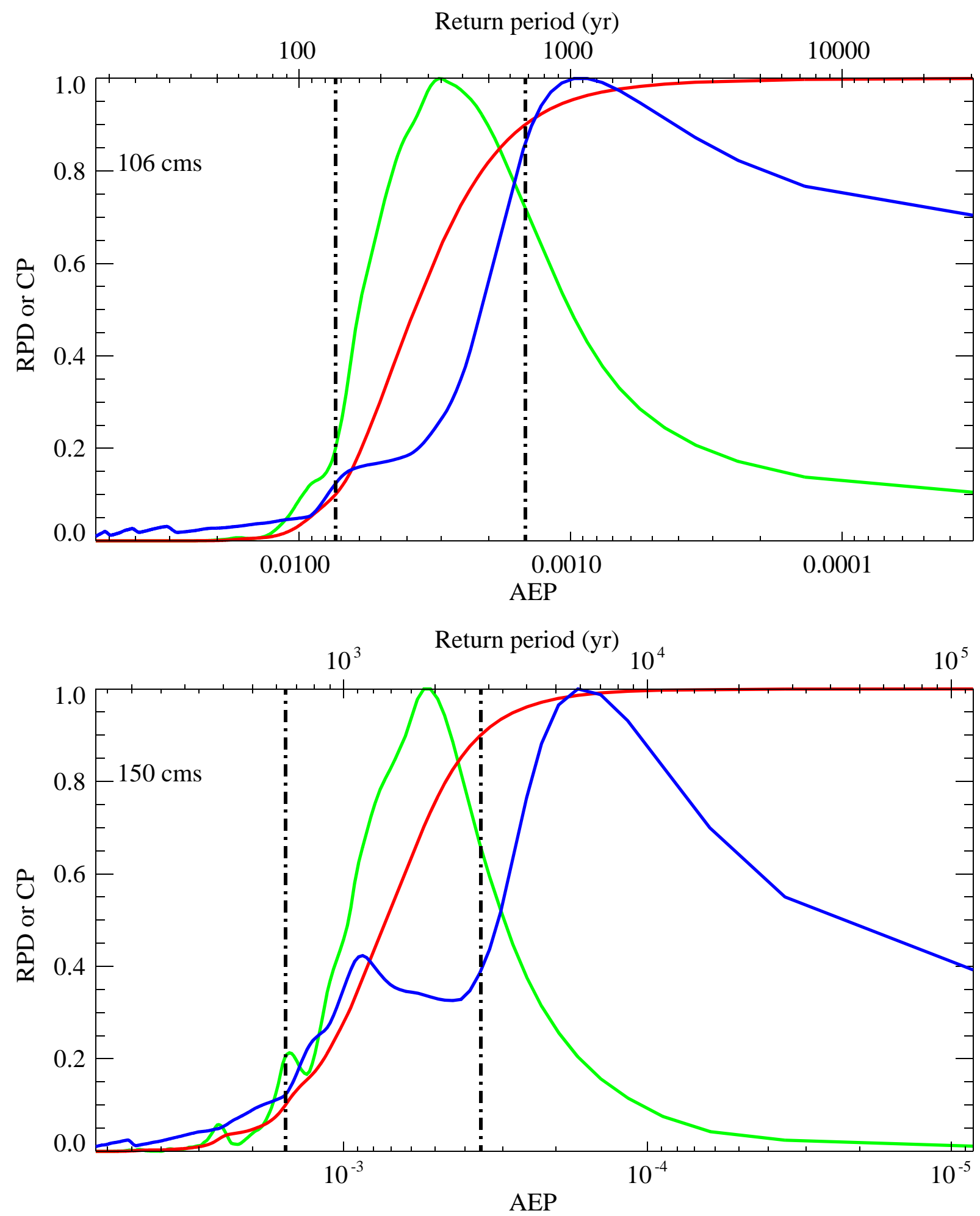

Figure 4-12 AEP distributions for $106 \mathrm{~m}^{3} / \mathrm{s}$ and $150 \mathrm{~m}^{3} / \mathrm{s}$ on the Big Lost River at the INEEL Diversion Dam. Red curves are cumulative probability, blue curves are sampling density, and green curves are probability density (from cumulative probability and transformed to AEP). Vertical lines represent $10 \%$ and $90 \%$ credible limits on AEP. 

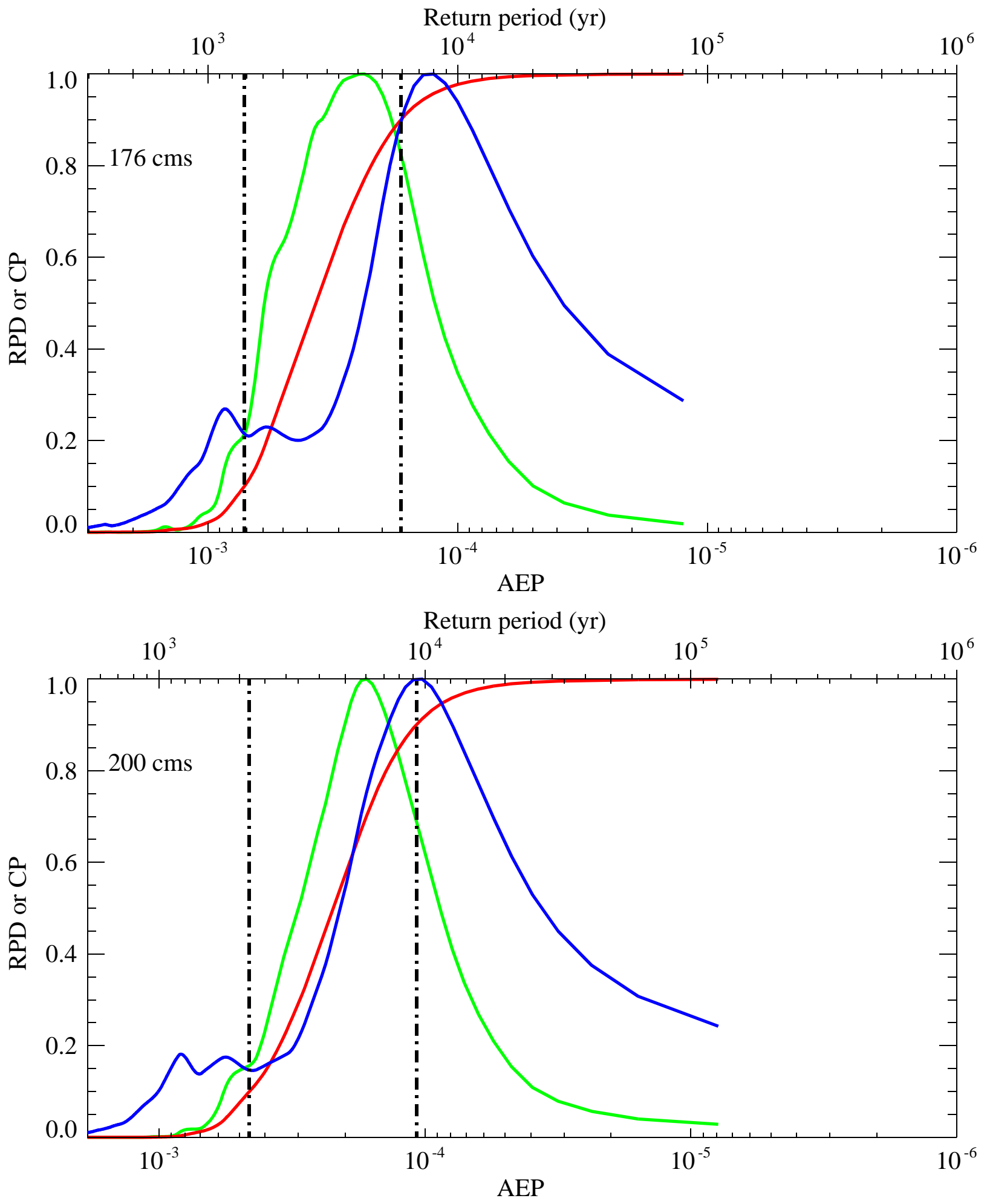

Figure 4-13 AEP distributions for $176 \mathrm{~m}^{3} / \mathrm{s}$ and $200 \mathrm{~m}^{3} / \mathrm{s}$ on the Big Lost River at the INEEL Diversion Dam. Red curves are cumulative probability, blue curves are sampling density, and green curves are probability density (from cumulative probability and transformed to AEP). Vertical lines represent $10 \%$ and $90 \%$ credible limits on AEP 
Tables for Section 4.0 
Table 4-1 Least frequent peak discharge generation nodes.

\begin{tabular}{|c|c|c|}
\hline$C f$ & AEP (1/yr) & $\begin{array}{c}\text { Return } \\
\text { period (yr) }\end{array}$ \\
\hline \hline 0.885662 & 0.114338 & 8.7 \\
\hline 0.896279 & 0.103721 & 9.6 \\
\hline 0.906895 & 0.093105 & 10.7 \\
\hline 0.917511 & 0.082489 & 12.1 \\
\hline 0.928128 & 0.071872 & 13.9 \\
\hline 0.938744 & 0.061256 & 16.3 \\
\hline 0.949360 & 0.050640 & 19.7 \\
\hline 0.959976 & 0.040024 & 25.0 \\
\hline 0.970593 & 0.029407 & 34.0 \\
\hline 0.983657 & 0.016343 & 61.2 \\
\hline 0.992182 & 0.007818 & 128. \\
\hline 0.995000 & 0.005000 & 200 \\
\hline 0.997500 & 0.002500 & 400 \\
\hline 0.998571 & 0.001429 & 700 \\
\hline 0.999000 & 0.001000 & 1000 \\
\hline 0.999231 & 0.000769 & 1300 \\
\hline 0.999500 & 0.000500 & 2000 \\
\hline 0.999750 & 0.000250 & 4000 \\
\hline 0.999833 & 0.000167 & 6000 \\
\hline 0.999875 & 0.000125 & 8000 \\
\hline 0.999900 & 0.000100 & 10000 \\
\hline 0.999933 & 0.000067 & 15000 \\
\hline 0.999950 & 0.000050 & 20000 \\
\hline 0.999967 & 0.000033 & 30000 \\
\hline 0.999975 & 0.000025 & 40000 \\
\hline \hline & & \\
\hline
\end{tabular}


Table 4-2 Nonparametric Flood Frequency for the Big Lost River at the Diversion Dam.

\begin{tabular}{|c|c|c|c|c|}
\hline $\begin{array}{c}\text { AEP } \\
(1 / \mathrm{yr})\end{array}$ & $\begin{array}{c}\text { Return } \\
\text { period (yr) }\end{array}$ & $\begin{array}{c}5 \% \\
\left(\mathrm{~m}^{3} / \mathrm{s}\right)\end{array}$ & $\begin{array}{c}\text { mean } \\
\left(\mathrm{m}^{3} / \mathrm{s}\right)\end{array}$ & $\begin{array}{c}95 \% \\
\left(\mathrm{~m}^{3} / \mathrm{s}\right)\end{array}$ \\
\hline \hline $5 \times 10^{-2}$ & 20 & 63 & 75 & 83 \\
\hline $2.86 \times 10^{-2}$ & 35 & 73 & 81 & 89 \\
\hline $2 \times 10^{-2}$ & 50 & 75 & 83 & 91 \\
\hline $1.33 \times 10^{-2}$ & 75 & 77 & 86 & 95 \\
\hline $10^{-2}$ & 100 & 78 & 87 & 97 \\
\hline $6.67 \times 10^{-3}$ & 150 & 80 & 91 & 104 \\
\hline $5 \times 10^{-3}$ & 200 & 82 & 96 & 114 \\
\hline $2.86 \times 10^{-3}$ & 350 & 86 & 103 & 127 \\
\hline $2 \times 10^{-3}$ & 500 & 89 & 110 & 137 \\
\hline $1.33 \times 10^{-3}$ & 750 & 95 & 121 & 151 \\
\hline $10^{-3}$ & 1000 & 101 & 131 & 163 \\
\hline $5 \times 10^{-4}$ & 2000 & 127 & 159 & 194 \\
\hline $2.86 \times 10^{-4}$ & 3500 & 138 & 172 & 212 \\
\hline $2 \times 10^{-4}$ & 5000 & 148 & 188 & 236 \\
\hline $1.33 \times 10^{-4}$ & 7500 & 165 & 224 & 306 \\
\hline $10^{-4}$ & 10,000 & 185 & 279 & 412 \\
\hline $6.67 \times 10^{-5}$ & 15,000 & 209 & $339 *$ & $510 *$ \\
\hline $5 \times 10^{-5}$ & 20,000 & 245 & $416 *$ & $628 *$ \\
\hline \hline Values with diminished or little statistical significance. & & \\
\hline \hline
\end{tabular}




\subsection{PROBABILISTIC FLOOD STAGE AT INTEC AND TRA}

Two-dimensional hydraulic modeling using a broad range of discharges conducted for the reach of the Big Lost River downstream of the INEEL Diversion Dam to approximately the INEEL railroad grade downstream of INTEC and TRA provide one element needed for probabilistic flood stage estimates at these facilities. A conceptual framework for evaluating the model results and flood frequency information was developed in the early stages of this study to guide the evaluations. Uncertainties in probabilistic flood stage estimates are discussed in the context of that framework. Based on this framework, results and uncertainties for stage - probability curves for fifteen specific sites within INTEC and TRA are discussed.

\subsection{Topographic Input to Two-Dimensional Models}

The 5-ft-spaced reprocessed topographic data from the 1993 aerial photography at INEEL (Appendix A) were used to construct the computational meshes for TrimR2D and RiCOM flow modeling of INL inundation. Construction of the TrimR2D grid was relatively straightforward and simply involved subsampling a subset of the rotated topographic data to produce a 10 -ftspacing input file. Details of this process are provided in Appendix C, Part A, Section 2. TrimR2D flow results were used to define regions that warranted increased spatial sampling afforded by the finite-element capabilities of RiCOM. The construction of the RiCOM computational mesh was quite involved and is documented in Appendix C, Part A, Section 2.

In both grids the minimum elevation in the grid was removed from all points in the grid to maximize numerical precision in quantities involving elevations. Coordinate transformation equations were constructed for both flow grids to convert the local grid coordinates to their original INEEL state-plane coordinates and elevations.

\subsection{Two Dimensional Hydraulic Modeling}

Discharges were selected for modeling over the full range of flow probabilities to provide representative data from which to construct the stage - probability curves. Specific discharge values were chosen for relevance to historical flood events, system capacities, and flood estimates from previous studies (Table 5-1). 
The TrimR2D grid consisted of approximately 3.3 million active cells. The RiCOM grid consisted of approximately 7.2 million active elements and nearly 14 million active sides and used a time step 1/5 of the TrimR2D time step. RiCOM calculations were much more computationally demanding than TrimR2D, with RiCOM calculations running at 1/10-1/20 real time, while TrimR2D ran at $1 / 2$ to $1 / 4$ real time. Consequently, TrimR2D was used to perform most of the sensitivity analyses concerning infiltration and culvert scenarios and RiCOM was used to concentrate calculations on the most important subset of flows identified from the TrimR2D flow calculations.

5.2.1 Infiltration Implementation and Scenarios. Infiltration was implemented in TrimR2D and RiCOM as discussed in Appendix C, Part A, Section 3. As discussed in Appendix E, infiltration estimates from Fiedler (2002) were modified to produce channel loss rates consistent with historical maximum channel discharge losses between the Diversion Dam and Lincoln Avenue of $\sim 15 \%$. The two scenarios in Table 5-1 represent logical infiltration endmembers of no infiltration and full infiltration consistent with the maximum observed historical channel losses between the Diversion Dam and Lincoln Avenue.

5.2.2 Culvert Implementation and Scenarios. As indicated in Table 5-1, TrimR2D was used to calculate flows for four scenarios for a full range of discharges. The four scenarios were constructed to determine the relative influence of infiltrations and culverts on estimated inundation. The scenarios represented in Table 5-1 all assume full Big Lost River conveyance through Lincoln Avenue, the railroad embankment downstream of INTEC, and Highway 20/26. As discussed in detail in Appendix C, Part A, Section 3, culvert flow information from Berenbrock and Doyle (2003) was used for all other culverts. Since the RiCOM calculations indicated that topographic grid resolution had a significant impact on estimated inundation in the vicinity of INTEC, RiCOM was also used to estimate the impact of complete blockage of flow by Lincoln Avenue on estimated inundation for the case of full infiltration and full operation of the remaining culverts.

5.2.3 Flow Initialization. The TrimR2D inundation grid was initially wetted with springs distributed along the Big Lost River channel that were activated for several minutes of flow to partially fill the channels. To produce steady-state flows for specific discharges, springs 
were activated immediately downstream of the Diversion Dam in the active channel with a total flux equal to the specific discharge. For the TrimR2D flows, 32 springs were used to minimize excess stages in the vicinity of the springs. Because RiCOM used 5-ft elements in the active channel, 886 springs were used to minimize excess stages in the vicinity of the springs. It is important to note, that despite these efforts to minimize excess stages in the vicinity of the input springs, stages near the springs may be up to $1 \mathrm{~m}$ higher than would occur if water flowed through the channel at typical velocities of 1-2 m/s. Consequently, inundation of areas immediately south of the channel downstream of the Diversion Dam are overestimated to some degree, particularly for discharges of $300 \mathrm{cms}$ or larger. TrimR2D flows for all discharges started from the same initial low-flow channel wetting conditions so that all discharges in Table 5-1 could be calculated in parallel. The TrimR2D stages upon completion of the flow simulations (about 40 hours of flow) were used as initial conditions to initialize the RiCOM flow calculations. The outlet flow boundary was located more than $1 \mathrm{~km}$ from any regions of interest. Consequently, a simple fixed water surface elevation boundary condition was imposed for simplicity, since the boundary condition had no impact on the interior points of interest in the grids.

5.2.4 Flow Parameters. Time steps were established at $20 \mathrm{~s}$ for the TrimR2D 20-ft grid to ensure Courant numbers of larger than 4 for main channel flow velocities for all discharges. A time step of $4 \mathrm{~s}$ was used for the RiCOM grid because all significant flow channels used 5-ft elements. This ensured Courant numbers larger than 4 in the main flow channels in the RiCOM flow calculations. Criteria for selection of time step and the impact of time step on computed flows are discussed in detail in Appendix C, Part A - Section 1 and Part B - Section 1. Semiimplicit weights were set to 0.7 for all calculations.

5.2.5 Flow Completion. A total of 15 hydrograph monitoring positions were established throughout inundation grids in both channel and out-of-bank positions. These hydrographs were monitored to determine when the flows had reached steady state. Typically, flow times of about 20-40 hours where required to achieve steady-state conditions throughout the TrimR2D grid, when starting from a modest channel inundation condition. Steady-state flow conditions were obtained in the RiCOM flow calculations in 6-7 hours of flow time, when starting with the TrimR2D inundations at the same discharge. Steady-state conditions were defined as attaining an 
essentially static water surface elevation at all the hydrograph monitoring positions (natural highfrequency water surface elevation oscillations, typically of several centimeters, were ignored).

5.2.6 Flow Output. Appendix E - Electronic Supplement presents maps depicting the results of two-dimensional hydraulic modeling conducted to estimate probabilistic flood stage at INTEC and TRA for the discharges listed in Table 5-1. These maps show results for both the entire reach downstream of the INEEL Diversion Dam as well as enlarged views in the immediate vicinity of the facilities. For TrimR2D, the output flow quantities included water surface elevations and vector flow velocities interpolated to the water surface elevation positions at cellcentered positions in the staggered grid. Using the known topography, derived quantities such as depth, shear stress, and power were obtained. For RiCOM, the output flow quantities included water surface elevations and vector flow velocities interpolated to the element vertices using the finite-element basis functions. The inverse transformation operators were then applied to produce flow quantities in the INEEL state-plane coordinate system. For most modeled discharges, results are presented for modeled flow depth, unit stream power, and bed shear stress based on the TrimR2D results. RiCOM results are presented mostly as plots showing the difference in watersurface elevation from TrimR2D results for the same input discharge. A full set of RiCOM results (depth, unit stream power, bed shear stress) are presented only for four quantile results of the 100and 500- yr discharges from the flood frequency analyses. Additional depth difference plots from TrimR2D models depict end member differences for infiltration and culvert scenarios.

\subsection{Conceptual Framework for Development of Probabilistic Inundation Maps and Flood Stage Estimates for Facility Sites at INL}

Each of the inundation maps for a specific discharge listed in Table 5-1 could be associated with mean and credible limits on AEP associated with that discharge from Section 4.0 and Table 5-2. However, such AEP's would not represent complete probabilistic inundation maps (PIM) for INL. There are additional probabilities (or weights) that must be assigned to aleatory (random-bynature) parameters, such as infiltration and culvert conveyance. A conceptual framework for evaluating these uncertainties that was developed in the early stages of this study to guide the investigations is illustrated in Figure 5-2. Epistemic uncertainties include factors such as flow model variability and appropriate scenario terrain models used in the simulations. Elicitation and 
assignments of weights to all aleatory and epistemic factors are required to produces comprehensive PIM’s. Each of the major elements will be briefly described below.

\subsubsection{Aleatory Uncertainties.}

5.3.1.1 Flood Frequency Analyses. The flood frequency analysis (FFA) can be viewed as the primary input to the PIM process. This is the element by which the annual probability of floods (and hence inundation) are incorporated into the process. Several sources of uncertainty are brought into the PIM process through the FFA, including discharge measurement uncertainties and statistical uncertainties in estimated AEP. The flood frequency results from Section 4.0 are used to establish probabilistic estimates of mean AEP, and 5\% and 95\% credible limits on AEP associated with the specific discharges in Table 5-1. For instance, a 5\% credible limit on AEP roughly represents a 95\% probability that the AEP is actually larger than the 5\% credible limit AEP (low confidence the AEP will not be exceeded). Conversely, a 95\% credible limit on AEP roughly represents a 5\% probability that the AEP is actually larger than the 95\% credible limit AEP (high confidence the AEP will not be exceeded). As these concepts may not be intuitive, it helps to remember than the conservative limits are represented by the upper hazard curves, which correspond to the 95\% credible limit for AEP.

If multiple and complete estimates of flood frequency exist for the site, each of the alternative estimates could be weighted and carried through the PIM process. Because of the wide variation of previous flood frequency estimates for the INL site ( Section 1.0), it was the original intent of this study to include alternative estimates and propagate this uncertainty through to the estimate of flood stage at the facilities. For example, flood frequency results based on earlier paleoflood studies of the Big Lost River (Ostenaa and others, 1999) would be weighted relative to present study results from Section 4.0 based on expert opinion. However, because the present study found that the topography used as inputs to earlier paleoflood studies was inadequate (Appendix A) making hydraulic model results unreliable, it is now clear that the earlier results must be discounted and effectively given zero weight. As there are no other existing flood frequency analyses for the Big Lost River that can be extended with uncertainties significantly beyond an AEP of $10^{-2}$, only the revised analyses described in Section 4.0 is used. Potential impacts of the differences associated with point estimates for floods of a specific AEP, such as the 100-yr flow 
estimate of Hortness and Rouseau (2002) are separately evaluated against the final stageprobability curves later in this section.

5.3.1.2 Hydrograph Shape. The current modeling effort uses a specific hydrograph shape based on an assumption of unregulated long-duration "natural” flow. Here long-duration means sufficient duration to inundate the entire INL inundation grid to the point of steady-state flow. The time required to achieve steady-state flow from initially near-dry conditions (flow confined to the Big Lost River channel) can be as long as about 20 hours. Steady-state flow can be achieved across the entire INL inundation grid in as little as 5-10 hours for modest ( 10\%) changes in discharge. For the purposes of the PIM, the probabilistic stage estimates correspond to peak flow durations of 20 hours. The effects of regulation and potential dam failure on hydrograph shape would require separate investigations, that would focus on modeling transient flow behavior.

5.3.1.3 Infiltration. The potential variability in inundation due to infiltration is currently evaluated by including two distinct end-member values for this parameter. Interpretation of available data suggests infiltration losses between 0 (no infiltration) and $15 \%$ for the study reach of the Big Lost River (Appendix E). These two end member values provide information to assess the sensitivity of results to this parameter. The uncertainty in this parameter is composed of the intrinsic spatial variability in infiltration as well as a lack of knowledge regarding methods for estimating the parameter (especially for out-of-bank flows and long durations).

5.3.1.4 Culverts. The probabilistic stage calculations for INL include a simplified representation of the effect of culverts on flow, and hence inundation at the site. Three scenarios are considered. In two scenarios full conveyance of the active Big Lost River channel is allowed through Lincoln Avenue and either, full conveyance, or zero conveyance, occurs through the other culverts. The third scenario involves zero conveyance through the Lincoln Avenue culverts on the active channel of the Big Lost River and full conveyance through the remaining culverts. 


\subsubsection{Epistemic Uncertainties.}

5.3.2.1 Topography and Flow Model Uncertainty. Uncertainties in the modeling of topography will exist in both the FFA results and in the PIM. Currently, these uncertainties are explicitly treated by calculating flow results using two grid resolutions to provide a first-order sensitivity analysis. Potential epistemic uncertainties associated with the two flow models are discussed in Appendix C, Part B, Section 1. These tests and output comparisons (difference plots in Appendix E - Electronic Supplement) show that negligible differences in water-surface elevation at most sites can be attributed to the choice of flow model. Much larger epistemic uncertainty is associated with the ability to accurately resolve subtle topographic features in the model inputs.

Efforts have been made to ensure that the topographic models will not have systematic biases (Appendix A). The observed sensitivity of the flow results to grid resolution suggest that the flow models are likely sensitive to random and transient variations in topography, particularly in regions near the Big Lost River channel and secondary channels associated with old diversions, roadways, ditches, and artificial barriers. These small-scale features play significant roles in determining the path of shallow flow across the broad Pleistocene surfaces near INTEC and TRA.

5.3.3 Scope of Results. Based on the study results, it was deemed unnecessary to attempt to assign weights to the various aleatory and epistemic uncertainty components to produce a comprehensive calculation of PIM. Hence, for this study, the conceptual framework portrayed in Figure 5-2 has essentially one primary input from which calculated uncertainty is carried forward, that being the revised flood frequency analyses. For the present analyses, the other aleatory components of uncertainty are either beyond the scope of the present study (e.g., hydrograph variability), or can be shown to be not significant based on the modeling results (e.g., effects of infiltration and most culverts). Difference plots of the end member scenarios of infiltration and secondary culvert blockage show that the change in water surface between these scenarios is less than $0.25 \mathrm{ft}$ except for isolated locations along the margin of the inundated area where a small increase in stage overtops a local threshold and leads to inundation of adjacent lower areas (Appendix E - Electronic Supplement). Examination of these results shows that in most cases the resulting stage differences are most typically on the order of $\sim 0.1 \mathrm{ft}$. 
Stage - AEP curves were constructed for fifteen TRA/INTEC sites of particular interest shown on Figure 5-1 and listed in Table 5-3. Example curves from two INTEC and two TRA sites are shown here as Figure 5-3 through Figure 5-6 and a complete set of curves is displayed in Appendix F. Curves show mean, 5\%, and 95\% fractiles based on the associated discharge probabilities derived from the flood frequency analyses in Section 4.0 and listed in Table 5-2 and the stage (water-surface elevations) from the TrimR2D and RiCOM hydraulic models. Differences in equivalent fractile curves due to infiltration and culvert scenarios are typically on the order of $\sim 0.1 \mathrm{ft}$. Differences due to discharge AEP are much larger. For AEP of 0.01 (100-yr) the typical range between the $5 \%$ and $95 \%$ curves is $~ 0.3 \mathrm{ft}$; for AEP of $0.0001(10,000-\mathrm{yr})$ the range is typically 0.5 - to $1.0 \mathrm{ft}$. These ranges thus depict the sensitivity of stage to uncertainty in input discharge AEP.

Epistemic uncertainty associated with the input topography for the hydraulic models is not quantified in a statistical sense, but is shown by the differences in stage hazard plots for TrimR2D compared to RiCOM. These effects are often largest for flows less than about $200 \mathrm{cms}$ where the differences the ability of the input grids to resolution subtle features of the input topography leads to areas inundated to higher or lower levels between the flow models (See TrimR2D minus RiCOM difference plots in Appendix E - Electronic Supplement). A full appreciation of the impact of these factors on inundation characteristics is best provided by the large-scale inundation maps. On the stage - AEP curves for the fifteen TRA/INTEC sites suggest these effects are mostly less than $~ 0.5 \mathrm{ft}$ (Appendix F), but it is the maps (Appendix E - Electronic Supplement) that provide the best illustrations of the strong sensitivity of portions of the inundation to topographic resolution and relatively subtle topographic features such as roads and old diversion structures.

\subsection{Evaluation of Results}

Flow patterns for the modeled flows near and through the facility sites are complex and strongly influenced by small-scale topographic features such as secondary channels, ditches, roads, berms, barriers, buildings and the overall topographic slope across each facility site. Water-surface elevations within the site areas are not always directly linked to the water-surface elevation in the main Big Lost River channel because flow reaches many areas of the site through channel networks that connect to the main Big Lost River as much as several kilometers upstream of the 
facilities. In other cases, some areas within each facility are effectively isolated from most flows by local topographic high areas of unknown permanence or integrity. Thus, within each facility, the water-surface elevation shown on the stage-probability plots for a given probability may differ across the facility by as much as $10 \mathrm{ft}$. Table 5-4 and Table 5-5 show the variations in watersurface elevation based on TrimR2D simulations at the fifteen monitoring sites within TRA and INTEC for AEP of 0.01 (100-yr), 0.02 (500-yr), 0.005 (2000-yr), and $0.0001(10,000)$.

5.4.1 Flood Stage - Probability at TRA. The situation at TRA illustrates that topographic features located far from TRA have the most profound impacts on potential inundation at TRA. For discharges of $225 \mathrm{cms}$ or larger, flow backwaters behind the constriction upstream of BLR8 (upstream of Hwy 20/26), flows proceed into a channel that extends $1 \mathrm{~km}$ north of the Big Lost River, and are entrained on the north side of an old Pioneer diversion canal (that starts 3-4 km upstream of TRA), which delivers the flow directly to the west edge of the TRA (see inundation maps in Appendix E - Electronic Supplement). Similarly, inundation hazards for the southern side of the TRA are dominated by flows that escape the primary Big Lost River channel about $3.2 \mathrm{~km}$ upstream of Monroe Avenue for discharges of $>100 \mathrm{cms}$ as illustrated in Figure 5-3 and the inundation maps (Appendix E - Electronic Supplement). Other sites in the TRA, like TRA-632 (map ref \#7), are influenced by large scale flow features and are almost completely insensitive to topographic resolution, infiltration, or culvert scenarios (Figure 5-4). Only topographic resolution (Figure 5-4a) has a non-negligible impact on the TRA-632 stage probabilities, but the effect is still small (compare Figure 5-4a to Figure 5-3b or Figure 5$5 a)$.

5.4.2 Flood Stage - Probability at INTEC. Topographic grid resolution also has a profound impact on estimated inundation at several sites at INTEC (Appendix E - Electronic Supplement; Figure 5-5) However, full versus blocked conveyance of the Big Lost River at Lincoln Avenue has the strongest impact on estimated inundation at INTEC map ref site \#13 (Figure 5-5). Similar results are obtained at the INTEC tank farm (map ref \#10, Figure 5-6) except that RiCOM inundation actually exceeds TrimR2D inundation for discharges larger than 100 cms (Figure 5-6a). The contrasts between Figure 5-5a and Figure 5-6a demonstrate some of the complex dependencies of inundation on topographic grid resolution at INTEC and serve to 
emphasize the importance of using the inundation maps (Appendix E - Electronic Supplement) to understand the primary factors influencing inundation at INL facilities.

\subsection{Inundation Discussion}

Stage hazard curves are provided in Appendix F for fifteen specific sites near TRA or INTEC as listed in Table 5-3 and shown on Figure 5-1. For each site there are four plots of flow simulation results: 1) TrimR2D, 2) RiCOM, 3) TrimR2D - RiCOM comparisons, and 4) RiCOM Lincoln Ave blockage scenarios. Comparisons within and between these four sets of plots isolate or compare specific factors that could influence estimated stages. The TrimR2D simulations are the primary suite of results for final estimate of stage hazard curves and isolate the effects of variations in infiltration and secondary culvert blockage. Generally, the secondary culverts have virtually no impact on inundation at most sites, with only minor impacts on inundation at sites outside TRA along Monroe Avenue. Infiltration has only a modest impact on inundation and generally does not change the hazard curves much. The RiCOM simulations and TrimR2D RiCOM simulations illustrate the impacts of topographic resolution and persistent topographic features such as roads, old diversions, etc. These factors have the strongest impacts on inundation over the entire site. The RiCOM simulations with blockage of the Big Lost River channel at Lincoln Avenue has the strongest impact on inundation for portions of INTEC, particularly for the simulations of discharges less than about $250 \mathrm{cms}$.

The inundation maps in Appendix E - Electronic Supplement provide an essential tool to understand the stage hazard curves in Appendix F. It is clear that small-scale (possibly transient) changes to topography can significantly impact inundation at TRA and INTEC. This is a consequence of the relatively flat terrain in the vicinity of the Big Lost River and these INL facilities. However, the maps also provide a tool to determine small-scale changes to topography that could substantially reduce inundation hazards at TRA and INTEC. For instance, flow along the northern side of the old diversion channel west of TRA could be blocked by rather small-scale topographic modifications about $3.2 \mathrm{~km}$ west of TRA near the western end of the old diversion channel. The inundation impacts of topographic modification scenarios could be easily investigated by running new flows with modifications to the detailed topographic RiCOM mesh. Clearly, the performance of the Big Lost River culverts at Lincoln Avenue have a profound 
influence on stage hazards for several sites at INTEC, especially for the lower end of the discharges simulated. Similarly, although an explicit culvert blocking scenario was not constructed for the railroad embankment bridge downstream of INTEC, blockage of conveyance through the railroad embankment may also significantly influence stage hazards for portions of INTEC.

The stage hazard curves contained in Appendix $\mathbf{F}$ have the same limitations for extrapolation to small AEP (AEP < 0.0001) as do the flood frequency results presented in Section 4.0. Because the flood frequency results are largely unconstrained for small AEP, no meaningful estimate of 95\% limits is contained in the revised flood frequency analyses to promulgate into the stage probability estimate. Given the nearly unlimited upper bounds of extrapolation that might be possible for small AEP from the present flood frequency analyses, development of stage hazard curves for smaller AEP would also require additional hydraulic modeling for discharges much larger than $700 \mathrm{cms}$, which is the largest discharge considered in the present study. 
Figures for Section 5.0 


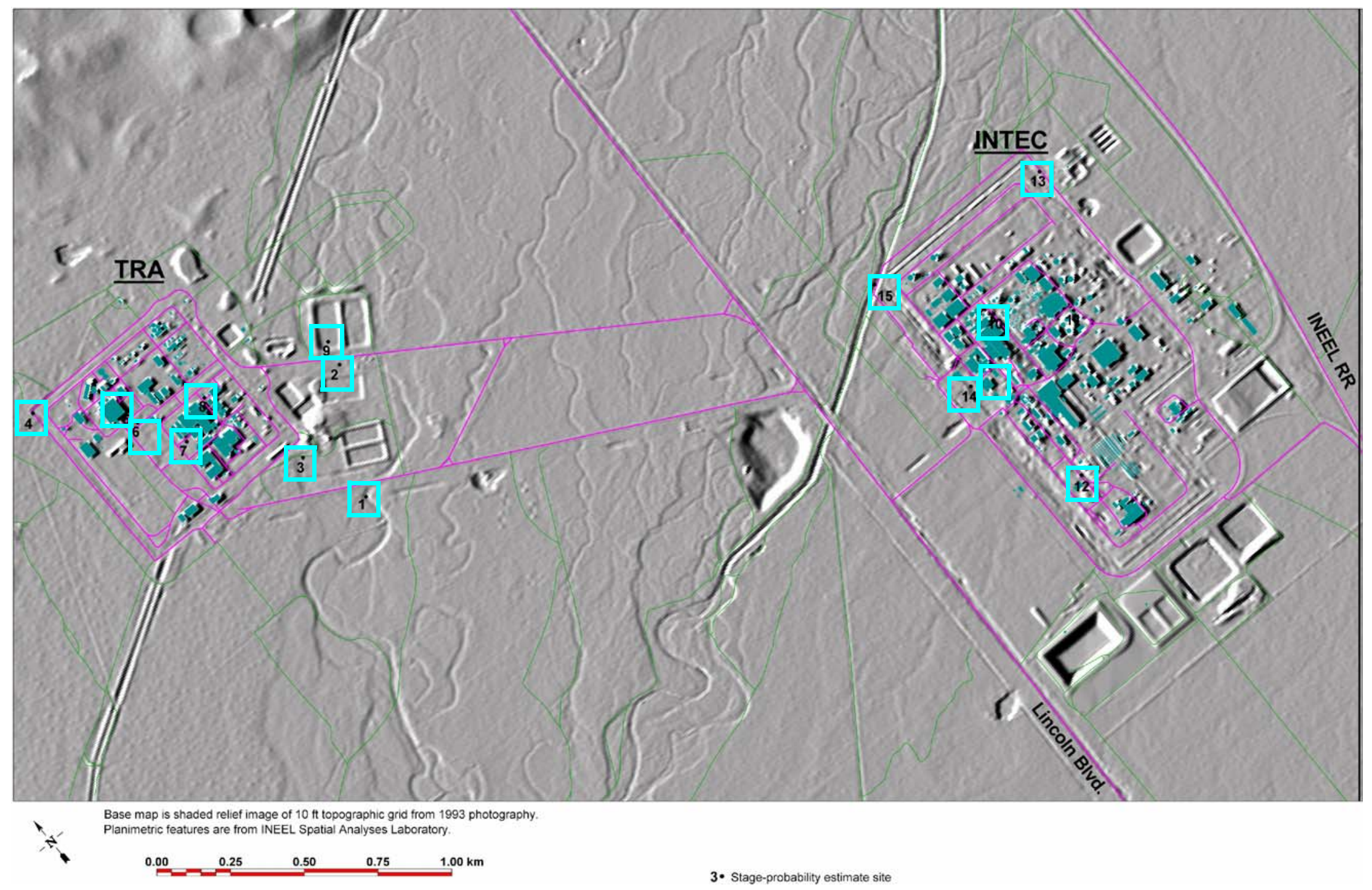

Figure 5-1 Map of monitoring site locations (numbered black squares within blue boxes) for inundation at TRA and INTEC.. Sites 1 through 9 are located within and around TRA; sites 10 through 15 are located within and around INTEC. Numbers by each square are "Map Ref \#" listed under "site" in Table 5-3 and in the headings of each stage-AEP plot. 
CONCEPTUAL LOGIC TREE FOR ESTIMATION OF PROBABILISTIC FLOOD STAGE

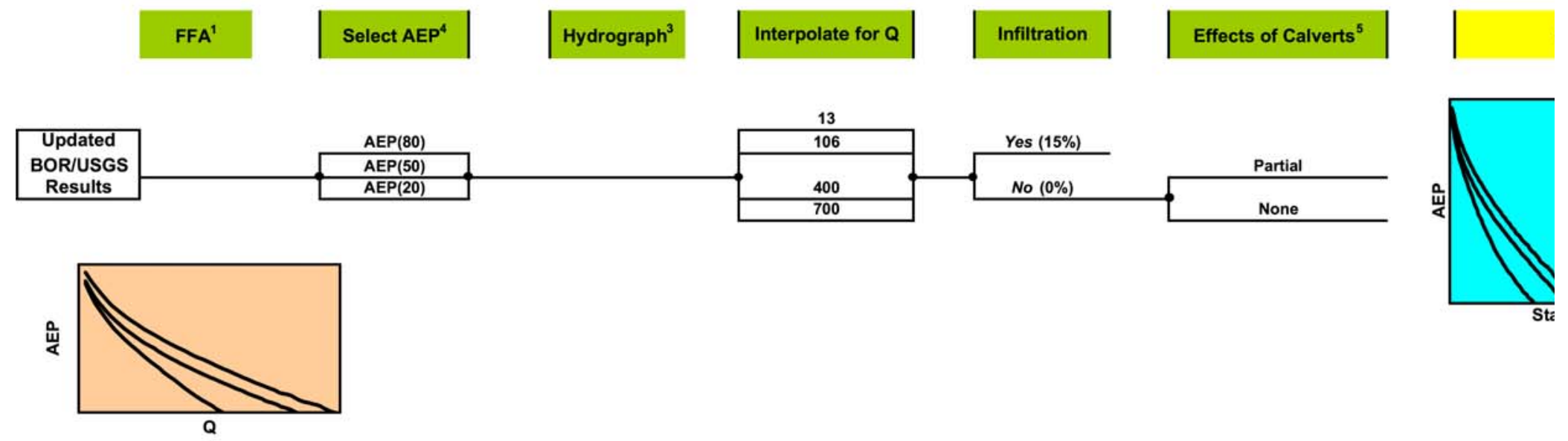

\footnotetext{
Alternative

FFA (similar to above for alternative FFA results)

Results $^{2}$

Notes: 'FFA - flood frequency analysis

'Could include regulated flow frequency and/or upstream dam failure probability estimates

Hydrographic Shapes are based on assumption of natural, unregulated flow

${ }^{4}$ Flow simulations have been run for $Q$ values $=13,25,63,106,150,200,250,300,400,700 \mathrm{hts}$

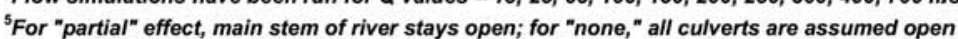

Figure 5-2 Conceptional logic tree for probabilistic INL inundation modeling. 
(a)

Map Ref \#1 - TRA - U/S Monroe Ave: $20 \mathrm{ft}$ cell indices x=2209 y=788 Depth (ft)

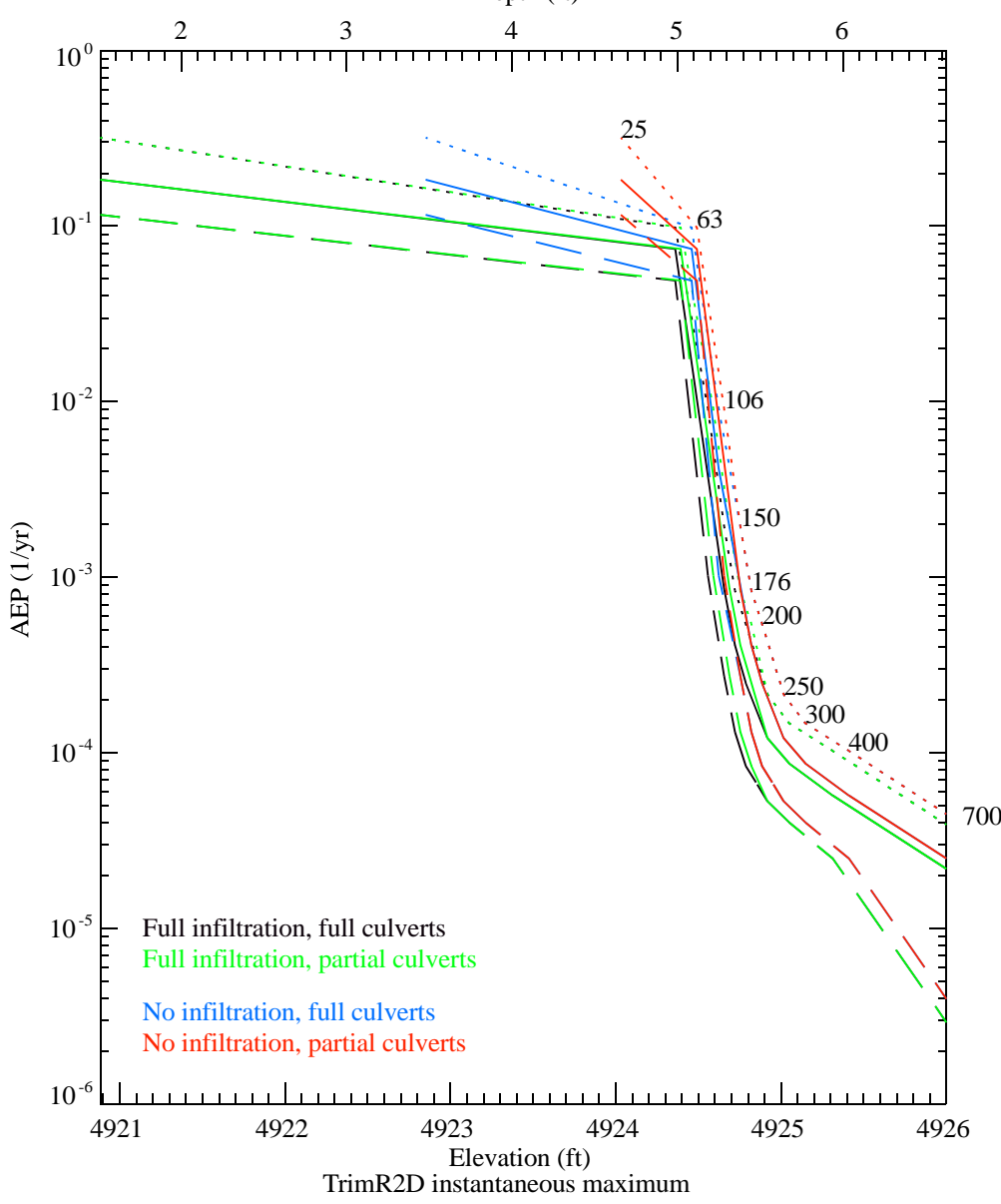

(b)

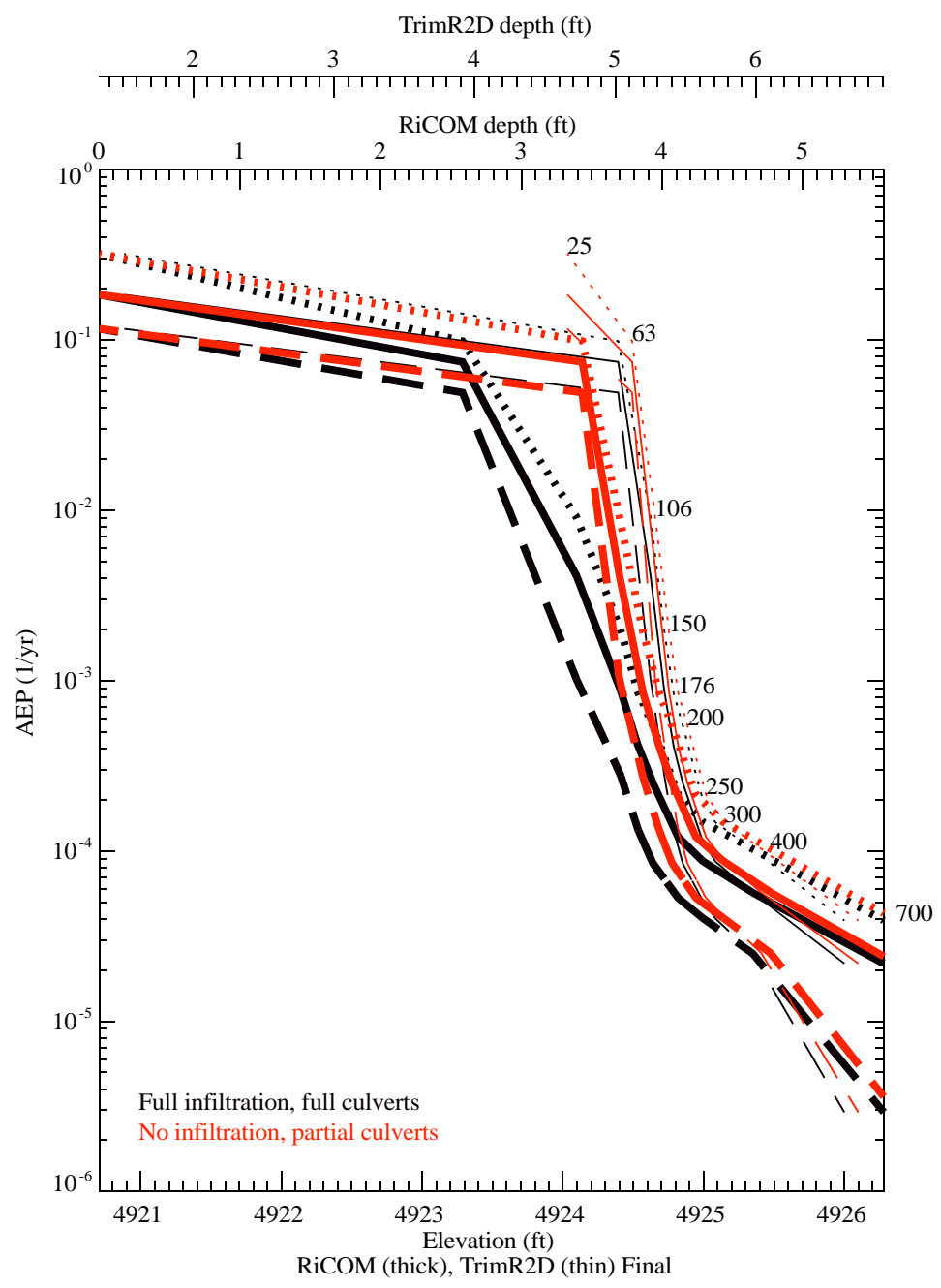

Map Ref \#1 - TRA - U/S Monroe Ave: FEM node index=4383878

Figure 5-3 Stage hazard curves for site TRA map ref \#1. TrimR2D results are shown in (a) and RiCOM results in (b). In the TrimR2D results (a) there are four color-coded infiltration-culvert scenarios (see legend) for fractiles of 5\% (dashed curves), mean (solid curves), and 95\% (dotted curves). When black or blue curves are not visible the inclusion of culverts outside the Big Lost River main channel had no influence at the site. In (b) comparison of TrimR2D (thin curves) and RicOM (thick curves) results demonstrate that topographic resolution has the strongest impact on the site inundation. Numbers indicate discharges (cms) for specific points along the rightmost 95\% curves. See Figure 5-1 for site location. 
(a)
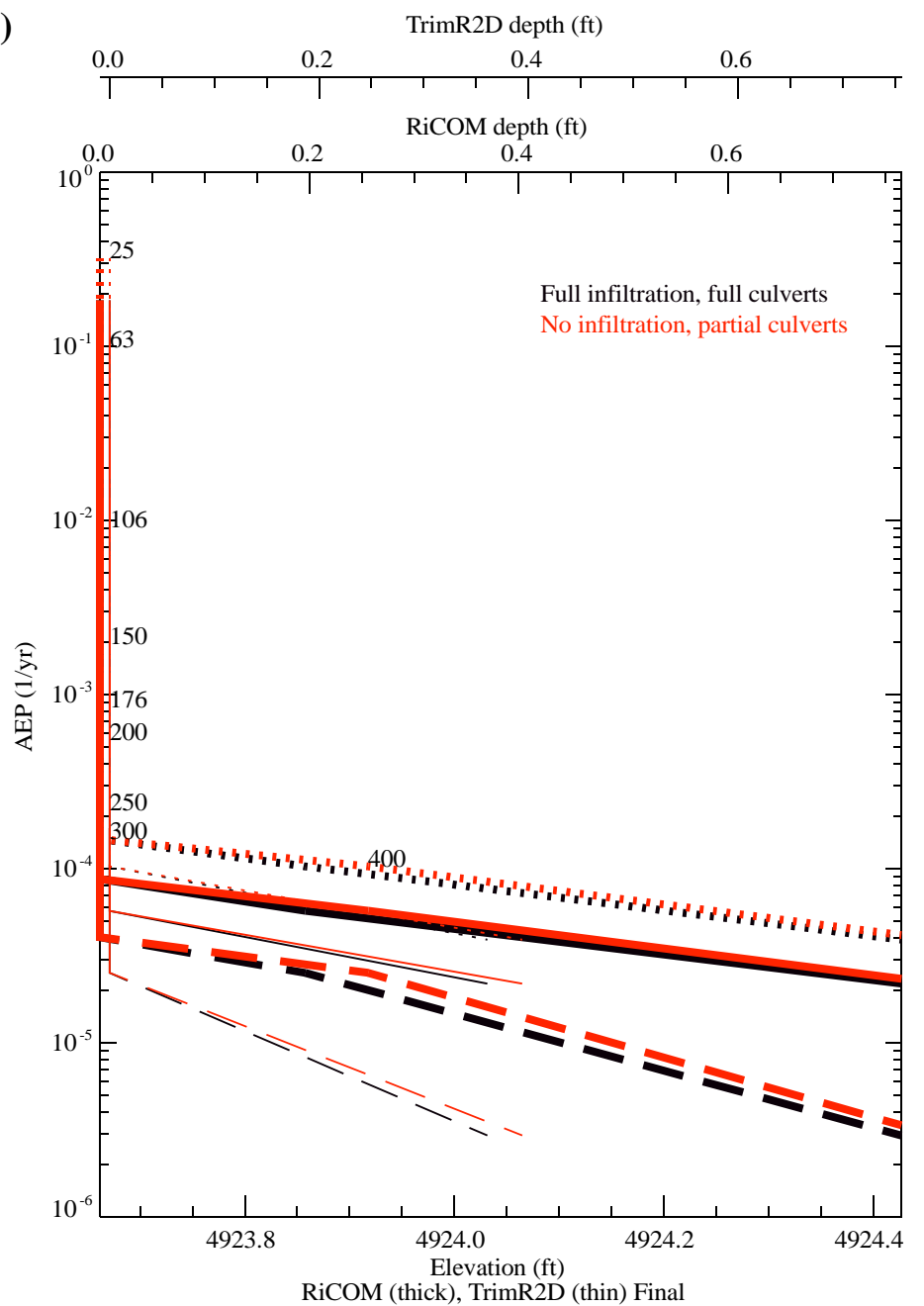

(b)

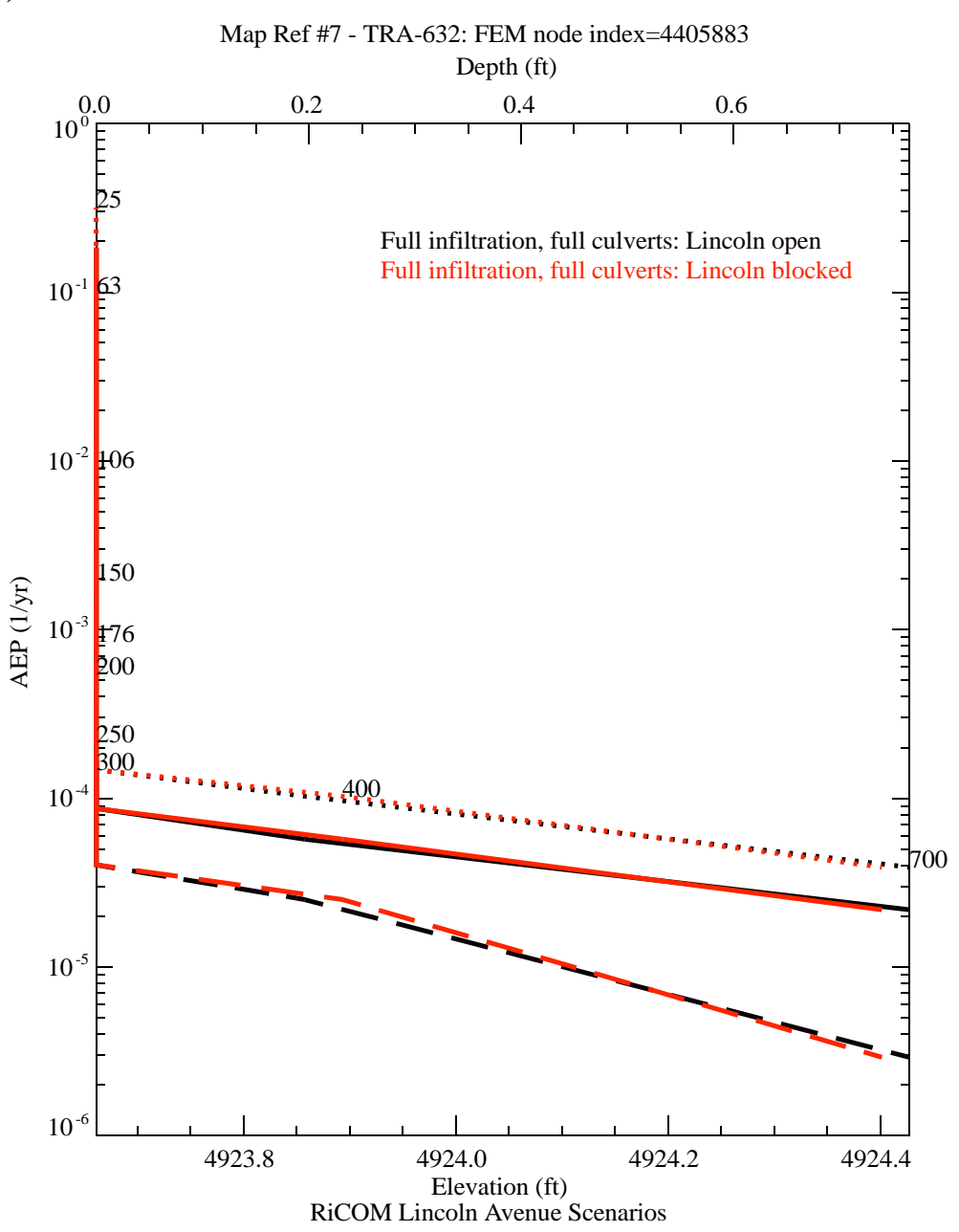

Map Ref \#7 - TRA-632: FEM node index=4405883

Figure 5-4 Stage hazard curves for TRA-632 map ref \#7. (a) comparison of TrimR2D (thin curves) and RiCOM (thick curves) results demonstrate that topographic resolution has a stronger impact on site inundation than infiltration or culverts when the main channel is open. (b) blocking the Big Lost

River at Lincoln Avenue (b) has virtually no impact on site inundation. Lines styles indicate fractiles of 5\% (dashed curves), mean (solid curves), and 95\% (dotted curves). Numbers indicate discharges (cms) for specific points along the rightmost 5\% curves. See Figure 5-1 for site location. 
(a)
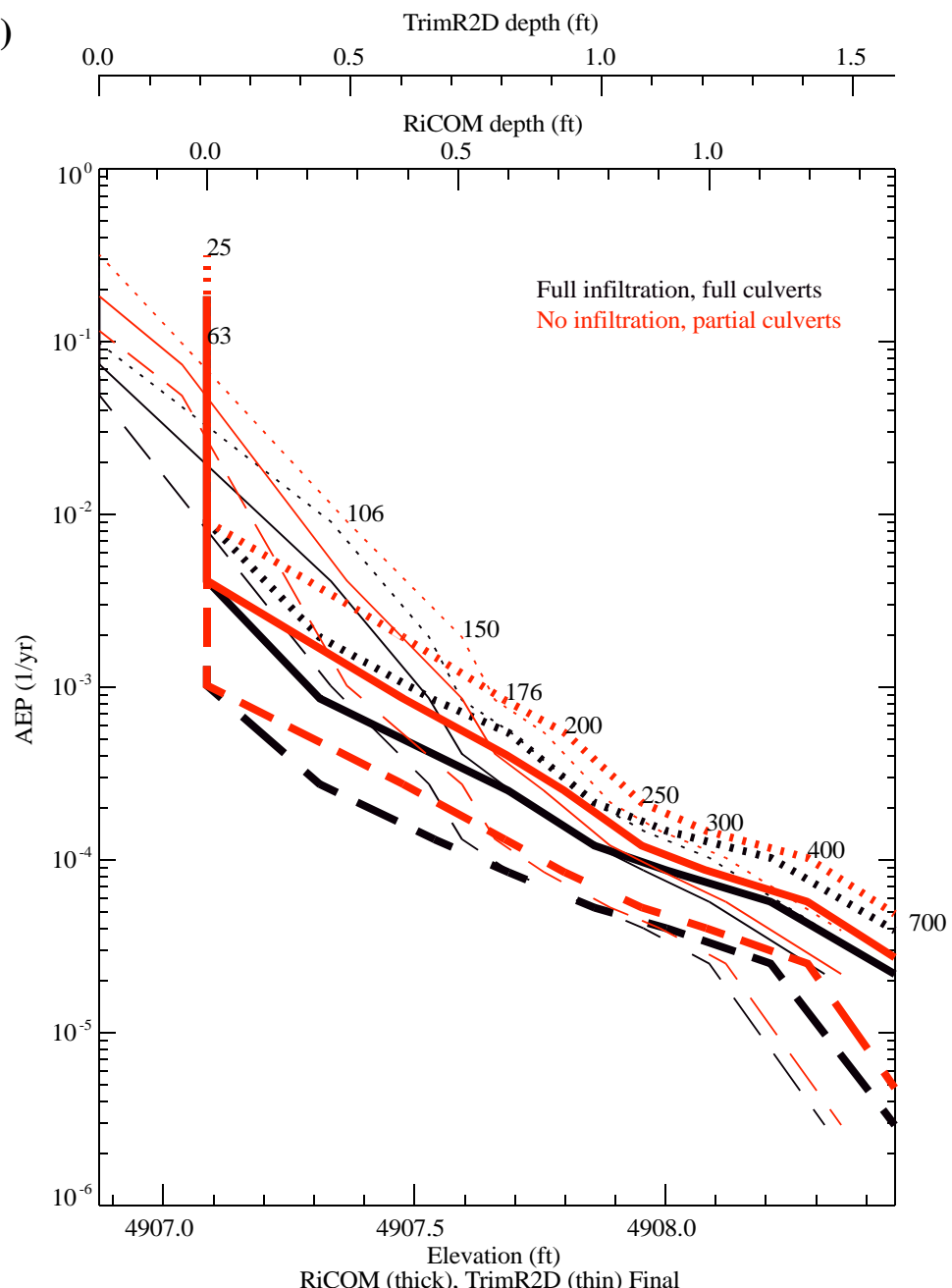

(b)

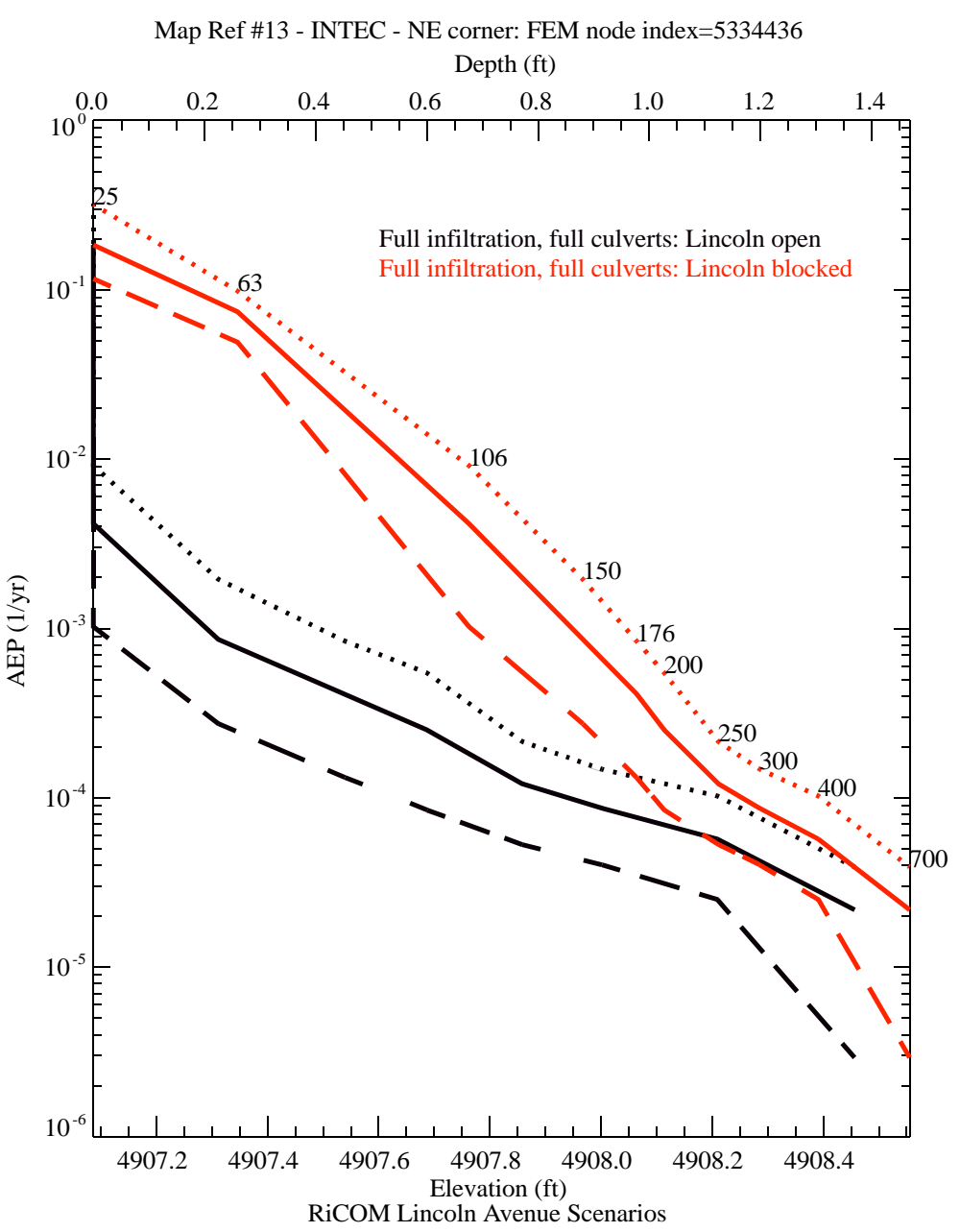

Map Ref \#13 - INTEC - NE corner: FEM node index=5334436

Figure 5-5 Stage hazard curves for INTEC map ref \#13. (a) comparison of TrimR2D (thin curves) and Ricom (thick curves) results demonstrate that topographic resolution has a stronger impact on site inundation than infiltration or culverts when the main channel is open. (b) blocking the Big Lost River at Lincoln Avenue has the strongest impact on site inundation. Lines styles indicate fractiles of 5\% (dashed curves), mean (solid curves), and 95\% (dotted curves). Numbers indicate discharges (cms) for specific points along the rightmost 95\% curves. See Figure 5-1 for site location. 
(a)
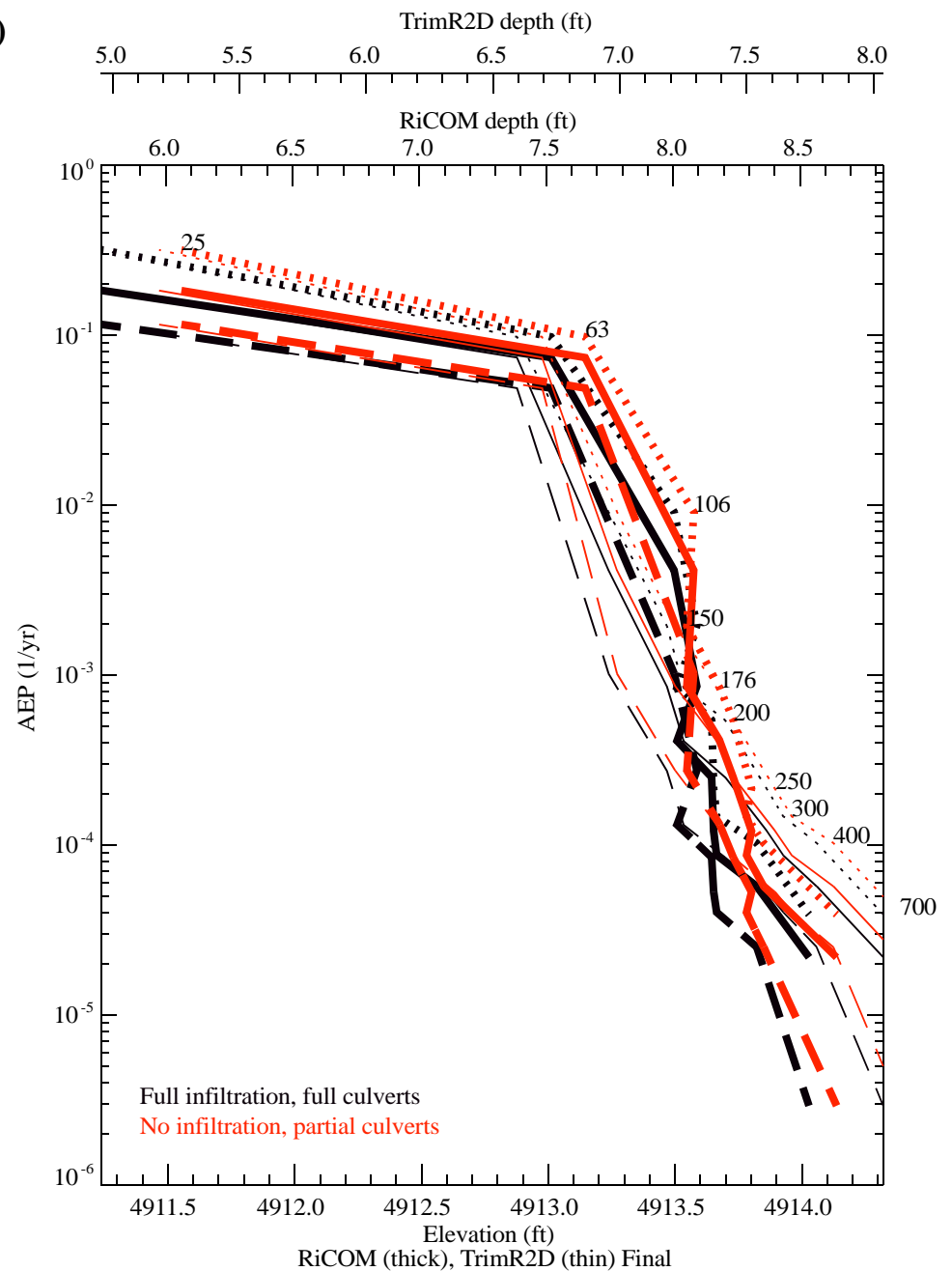

Map Ref \#15 - BLR - NW corner INTEC: FEM node index=5083832

Figure 5-6 Stage hazard curves for the INTEC tank farm map ref \#10. (a) comparison of TrimR2D (thin curves) and Ricom (thick curves) results demonstrate that topographic resolution has a stronger impact on site inundation than infiltration or culverts when the main channel is open. (b) blocking the Big Lost River at Lincoln Avenue has the strongest impact on site inundation. Lines styles indicate fractiles of 5\% (dashed curves), mean (solid curves), and 95\% (dotted curves). Numbers indicate discharges (cms) for specific points along the rightmost 95\% curves. See Figure 5-1 for site location. 
Tables for Section 5.0 
Table 5-1 Discharge and modeling scenarios used to construct the stage - probability estimates

\begin{tabular}{|c|c|c|c|c|c|}
\hline \multirow{3}{*}{$\begin{array}{l}\text { Modeled } \\
\text { Discharge } \\
\mathrm{m}^{3} / \mathrm{s}\left(\mathrm{ft}^{3} / \mathrm{s}\right)\end{array}$} & \multicolumn{4}{|c|}{ Infiltration $^{2}$} & \multirow{3}{*}{ Potential Significance of Modeled Discharge } \\
\hline & \multicolumn{2}{|c|}{ None } & \multicolumn{2}{|c|}{ Full } & \\
\hline & $\begin{array}{l}\text { Full } \\
\text { Culverts }\end{array}$ & $\begin{array}{c}\text { Partial } \\
\text { Culverts }\end{array}$ & $\begin{array}{c}\text { Partial } \\
\text { Culverts }\end{array}$ & $\begin{array}{l}\text { Full } \\
\text { Culverts }\end{array}$ & \\
\hline $13(\sim 460)$ & $\mathrm{T}$ & $\mathrm{T}$ & $\mathrm{T}$ & $\mathrm{T}$ & $\begin{array}{l}\text { Approximate maximum Big Lost River gaged flow } \\
\text { downstream of INEEL Diversion (since 1984) }\end{array}$ \\
\hline $25(\sim 885)$ & $\mathrm{T}$ & $\mathrm{T}, \mathrm{R}$ & $\mathrm{T}$ & $\mathrm{T}, \mathrm{R}$ & $\begin{array}{c}\text { Approximate INEEL Diversion Dam release } \\
\text { capacity }\end{array}$ \\
\hline $63(\sim 2225)$ & $\mathrm{T}$ & $\mathrm{T}, \mathrm{R}$ & $\mathrm{T}$ & $\mathrm{T}, \mathrm{R}$ & $\begin{array}{l}\text { Estimated maximum Big Lost River historic flood } \\
\text { (1965) upstream of INEEL Diversion Dam }\end{array}$ \\
\hline 87 & & $\mathrm{R}$ & & $\mathrm{R}$ & Revised Big Lost River 100-yr flood (this study) \\
\hline 97 & & $\mathrm{R}$ & & $\mathrm{R}$ & $\begin{array}{l}\text { 95\% bound on revised Big Lost River100-yr flood } \\
\text { (this study) }\end{array}$ \\
\hline $106(\sim 3740)$ & $\mathrm{T}$ & $\mathrm{T}, \mathrm{R}$ & $\mathrm{T}$ & $\mathrm{T}, \mathrm{R}$ & $\begin{array}{l}\text { Revised USGS Big Lost River100-yr flood } \\
\text { (Hortness and Rousseau, 2002) }\end{array}$ \\
\hline 110 & & $\mathrm{R}$ & & $\mathrm{R}$ & Revised Big Lost River 500-yr flood (this study) \\
\hline 130 & & $\mathrm{R}$ & & $\mathrm{R}$ & Data for stage-probability curves \\
\hline $150(\sim 5295)$ & $\mathrm{T}$ & $\mathrm{T}, \mathrm{R}$ & $\mathrm{T}$ & $\mathrm{T}, \mathrm{R}$ & $\begin{array}{c}\text { Preferred discharge for Big Lost River 10,000-yr } \\
\text { paleohydrologic bound (Ostenaa and others, 1999). } \\
\text { Preferred discharge for late Holocene Big Lost River } \\
\text { paleofloods (this study) }\end{array}$ \\
\hline $176(\sim 6215)$ & $\mathrm{T}$ & $\mathrm{T}, \mathrm{R}$ & $\mathrm{T}$ & $\mathrm{T}, \mathrm{R}$ & $\begin{array}{l}\text { USGS 100-yr flood downstream of INEEL } \\
\text { Diversion Dam (Kjelstrom and Berenbrock, 1998) }\end{array}$ \\
\hline $200(\sim 7060)$ & $\mathrm{T}$ & $\mathrm{T}, \mathrm{R}$ & $\mathrm{T}$ & $\mathrm{T}, \mathrm{R}$ & Data for stage-probability curves \\
\hline $250(\sim 8830)$ & $\mathrm{T}$ & $\mathrm{T}, \mathrm{R}$ & $\mathrm{T}$ & T,R & $\begin{array}{l}\text { Preferred discharge for Big Lost River 10,000-yr } \\
\text { paleohydrologic bound (this study) }\end{array}$ \\
\hline $300(\sim 10,595)$ & $\mathrm{T}$ & $\mathrm{T}, \mathrm{R}$ & $\mathrm{T}$ & $\mathrm{T}, \mathrm{R}$ & Data for stage-probability curves \\
\hline $400(\sim 14,125)$ & $\mathrm{T}$ & $\mathrm{T}, \mathrm{R}$ & $\mathrm{T}$ & $\mathrm{T}, \mathrm{R}$ & Data for stage-probability curves \\
\hline $700(\sim 24,720)$ & $\mathrm{T}$ & $\mathrm{T}, \mathrm{R}$ & $\mathrm{T}$ & T,R & $\begin{array}{l}\text { Adopted INEEL interim 100-yr flood; Estimated } \\
\text { dam break flow at INTEC for Mackay Dam 100-yr } \\
\text { flood failure (Koslow and Van Haaften, 1986) }\end{array}$ \\
\hline \multicolumn{6}{|c|}{$\begin{array}{l}\text { Notes: } \\
1 \text { Steady-state discharge input at upstream end of reach near INEEL Diversion Dam } \\
2 \text { Entries in table indicate flow model used for each scenario: T - TRIMR2D with 20-ft rectangular grid as } \\
\text { input topography; R - RICOM with 5-, 10-, and 20-ft variable grid as input topography. Limits of 5-ft } \\
\text { mesh were defined by extent of inundation from TRIMR2D model of } 100 \mathrm{~m}^{3} / \mathrm{s} \text { with no infiltration and } \\
\text { partial culverts; limits of } 10-\mathrm{ft} \text { mesh by extent of TRIMR2D } 200 \mathrm{~m}^{3} / \mathrm{s} \text { inundation for same scenario. }\end{array}$} \\
\hline
\end{tabular}


Table 5-2 Discharge-AEP Results from the FFA.

\begin{tabular}{|c|c|c|c|}
\hline Discharge & $5 \%$ & Mean & $95 \%$ \\
\hline$($ cms $)$ & AEP $(1 / \mathrm{yr}, \mathrm{T}=\mathrm{yr})$ & AEP $(1 / \mathrm{yr}, \mathrm{T}=\mathrm{yr})$ & AEP $(1 / \mathrm{yr}, \mathrm{T}=\mathrm{yr})$ \\
\hline \hline 25 & $1.16 \times 10^{-01}(9)$ & $1.84 \times 10^{-01}(5)$ & $3.19 \times 10^{-01}(3)$ \\
\hline 63 & $4.901 \times 10^{-02}(20)$ & $7.41 \times 10^{-02}(14)$ & $9.82 \times 10^{-02}(10)$ \\
\hline 106 & $1.02 \times 10^{-03}(977)$ & $4.15 \times 10^{-03}(241)$ & $9.14 \times 10^{-03}(109)$ \\
\hline 150 & $2.74 \times 10^{-04}(3651)$ & $8.61 \times 10^{-04}(1162)$ & $1.95 \times 10^{-03}(513)$ \\
\hline 176 & $1.32 \times 10^{-04}(7588)$ & $4.10 \times 10^{-04}(2436)$ & $8.42 \times 10^{-04}(1188)$ \\
\hline 200 & $8.46 \times 10^{-05}(11,823)$ & $2.51 \times 10^{-04}(3991)$ & $5.44 \times 10^{-04}(1838)$ \\
\hline 250 & $5.30 \times 10^{-05}(18,872)$ & $1.21 \times 10^{-04}(8269)$ & $2.15 \times 10^{-04}(4660)$ \\
\hline 300 & $4.02 \times 10^{-05}(24,855) *$ & $8.70 \times 10^{-05}(11,499)$ & $1.47 \times 10^{-04}(6784)$ \\
\hline 400 & $2.51 \times 10^{-05}(39,851) *$ & $5.71 \times 10^{-05}(17,513)$ & $1.03 \times 10^{-04}(9737)$ \\
\hline 700 & $2.92 \times 10^{-06}(342,392) *$ & $2.18 \times 10^{-05}(45,839) *$ & $3.90 \times 10^{-05}(25,653) *$ \\
\hline \hline * Values with little or diminished statistical significance (See Section 4.0).
\end{tabular}


Table 5-3 Stage - Probability Sites

\begin{tabular}{|c|c|c|c|c|}
\hline \multicolumn{2}{|r|}{ Site $^{1}$} & $\mathrm{x}$-coordinate & $\mathrm{y}$-coordinate & \multirow{2}{*}{ Notes } \\
\hline $\begin{array}{l}\text { Map } \\
\text { Ref \# }\end{array}$ & Description & 20-ft grid & 20-ft grid & \\
\hline \multicolumn{5}{|c|}{ TRA Sites } \\
\hline 1 & TRA - Monroe Ave & 2209 & 788 & upstream side in small channel \\
\hline 2 & TRA-715 (evap. pond) & 2277 & 819 & sm. channel upstream of old Monroe \\
\hline 3 & TRA southeast corner & 2222 & 827 & outside fence \\
\hline 4 & TRA northwest corner & 2212 & 979 & outside fence \\
\hline 5 & TRA-670 (ATR) & 2225 & 926 & southeast corner \\
\hline 6 & TRA-670 (ATR) & 2220 & 921 & south side on Cod Street \\
\hline 7 & TRA-632 & 2216 & 892 & \\
\hline 8 & TRA-621 & 2242 & 888 & \\
\hline 9 & TRA-715 (evap. pond) & 2288 & 828 & inside north pond \\
\hline \multicolumn{5}{|c|}{ INTEC Sites } \\
\hline 10 & INTEC Tank Farm & 2387 & 471 & NW corner \\
\hline 11 & NWCF (Bldg 659) & 2399 & 428 & SE corner \\
\hline 12 & CPP-749 & 2311 & 403 & West side \\
\hline 13 & INTEC - NE corner & 2470 & 464 & outside fence \\
\hline 14 & INTEC -nr west gate & 2345 & 474 & \\
\hline 15 & BLR - NW corner of INTEC & 2388 & 539 & in main channel \\
\hline Notes: & ali & . & 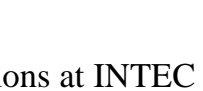 & TRA \\
\hline
\end{tabular}


Table 5-4 Probabilistic Stage Estimates for INTEC and TRA Sites (100 and 500 floods).

\begin{tabular}{|c|c|c|c|c|c|c|c|}
\hline \multicolumn{2}{|r|}{ Site } & \multirow{2}{*}{\multicolumn{3}{|c|}{$\begin{array}{c}\text { AEP }=10^{-2} \\
\text { Return period }=100 \mathrm{yr} \\
\text { Modeled Water Surface Elevation }(\mathrm{ft})^{*}\end{array}$}} & \multirow{2}{*}{\multicolumn{3}{|c|}{$\begin{array}{c}\text { AEP }=2 \times 10^{-3} \\
\text { Return period }=500 \mathrm{yr} \\
\text { Modeled Water Surface Elevation }(\mathrm{ft})^{*}\end{array}$}} \\
\hline Map & \multirow{2}{*}{ Description } & & & & & & \\
\hline Ref \# & & $5 \%$ & mean & $95 \%$ & $5 \%$ & mean & $95 \%$ \\
\hline \multicolumn{8}{|c|}{ TRA Sites } \\
\hline 1 & TRA - Monroe Ave & 4924.49-4924.56 & $4924.55-4924.60$ & 4924.61-4924.65 & $4924.58-4924.63$ & 4924.67-4924.70 & 4924.72-4924.75 \\
\hline 2 & $\begin{array}{l}\text { TRA-715 (evap. } \\
\text { pond) }\end{array}$ & 4918.36-4918.56 & $4918.50-4918.64$ & $4918.63-4918.71$ & $4918.57-4918.67$ & $4918.73-4918.81$ & 4918.81-4918.91 \\
\hline 3 & TRA southeast corner & dry & dry & dry & dry & dry & dry \\
\hline 4 & TRA northwest corner & dry & dry & dry & dry & dry & dry \\
\hline 5 & TRA-670 (ATR) & dry & dry & dry & dry & dry & dry \\
\hline 6 & TRA-670 (ATR) & dry & dry & dry & dry & dry & dry \\
\hline 7 & TRA-632 & dry & dry & dry & dry & dry & dry \\
\hline 8 & TRA-621 & dry & dry & dry & dry & dry & dry \\
\hline 9 & $\begin{array}{l}\text { TRA-715 (evap. } \\
\text { pond) }\end{array}$ & dry & dry & dry & dry & dry & dry \\
\hline \multicolumn{8}{|c|}{ INTEC Sites } \\
\hline 10 & INTEC Tank Farm & 4912.57-4913.12 & $4912.92-4913.29$ & 4913.26-4913.45 & $4913.09-4913.37$ & 4913.50-4913.65 & 4913.72-4913.85 \\
\hline 11 & NWCF (Bldg 659) & dry & dry & dry & dry & dry & dry \\
\hline 12 & СРP-749 & $4916.30-4916.40$ & $4916.42-4916.51$ & 4916.54-4916.60 & $4916.48-4916.55$ & 4916.63-4916.69 & 4916.71-4916.78 \\
\hline 13 & INTEC - NE corner & 4907.04-4907.17 & $4907.18-4907.27$ & 4907.31-4907.35 & 4907.25-4907.31 & $4907.42-4907.47$ & 4907.53-4907.59 \\
\hline 14 & INTEC -nr west gate & 4916.30-4916.40 & 4916.42-4916.51 & 4916.54-4916.60 & 4916.48-4916.55 & 4916.63-4916.69 & 4916.71-4916.78 \\
\hline 15 & $\begin{array}{c}\text { BLR - NW corner of } \\
\text { INTEC }\end{array}$ & 4913.03-4913.10 & 4913.13-4913.18 & 4913.22-4913.26 & 4913.18-4913.22 & 4913.34-4913.38 & 4913.46-4913.50 \\
\hline
\end{tabular}


Table 5-5 Probabilistic Stage Estimates for INTEC and TRA Sites (2000 and 10000 year floods).

\begin{tabular}{|c|c|c|c|c|c|c|c|}
\hline \multicolumn{2}{|r|}{ Site } & \multirow{2}{*}{\multicolumn{3}{|c|}{$\begin{array}{c}\text { AEP }=5 \times 10^{-4} \\
\text { Return period }=2000 \mathrm{yr} \\
\text { Modeled Water Surface Elevation }(\mathrm{ft})^{*}\end{array}$}} & \multirow{2}{*}{\multicolumn{3}{|c|}{$\begin{array}{c}\text { AEP }=1 \times 10^{-4} \\
\text { Return period }=10000 \mathrm{yr} \\
\text { Modeled Water Surface Elevation }(\mathrm{ft})^{*}\end{array}$}} \\
\hline \multirow{2}{*}{$\begin{array}{l}\text { Map } \\
\text { Ref \# }\end{array}$} & \multirow{2}{*}{ Description } & & & & & & \\
\hline & & $5 \%$ & mean & $95 \%$ & $5 \%$ & mean & $95 \%$ \\
\hline \multicolumn{8}{|c|}{ TRA Sites } \\
\hline 1 & TRA - Monroe Ave & $4924.68-4924.71$ & $4924.77-4924.80$ & $4924.86-4924.90$ & $4924.83-4924.86$ & 4925.04-4925.09 & $4925.36-4925.43$ \\
\hline 2 & $\begin{array}{l}\text { TRA-715 (evap. } \\
\text { pond) }\end{array}$ & $4918.74-4918.82$ & 4918.91-4918.99 & $4919.06-4919.13$ & 4919.01-4919.07 & 4919.36-4919.45 & 4919.89-4919.99 \\
\hline 3 & TRA southeast corner & dry & dry-4922.21 & $4922.36-4922.45$ & $4922.20-4922.37$ & $4922.81-4922.96$ & $4923.76-4924.02$ \\
\hline 4 & $\begin{array}{l}\text { TRA northwest } \\
\text { corner }\end{array}$ & dry & dry & dry & dry & 4923.38-4923.52 & $4924.14-4924.20$ \\
\hline 5 & TRA-670 (ATR) & dry & dry & dry & dry & dry & dry \\
\hline 6 & TRA-670 (ATR) & dry & dry & dry & dry & dry & 4923.29-4923.32 \\
\hline 7 & TRA-632 & dry & dry & dry & dry & dry & dry \\
\hline 8 & TRA-621 & dry & dry & dry & dry & dry & dry \\
\hline 9 & $\begin{array}{l}\text { TRA-715 (evap. } \\
\text { pond) }\end{array}$ & dry & dry & dry & dry & dry & dry \\
\hline & & & & TEC Sites & & & \\
\hline 10 & INTEC Tank Farm & 4913.54-4913.68 & 4913.87-4913.98 & $4914.08-4914.18$ & $4914.01-4914.11$ & 4914.49-4914.57 & 4914.86-4914.89 \\
\hline 11 & NWCF (Bldg 659) & dry & dry-4911.35 & $4911.77-4911.81$ & $4911.22-4911.77$ & 4911.93-4911.96 & 4912.03-4912.06 \\
\hline 12 & СРР-749 & $4916.64-4916.71$ & $4916.79-4916.85$ & $4916.93-4916.96$ & $4916.88-4916.92$ & $4917.15-4917.24$ & $4917.45-4917.48$ \\
\hline 13 & INTEC - NE corner & $4907.44-4907.49$ & $4907.58-4907.64$ & $4907.71-4907.77$ & $4907.66-4907.72$ & 4907.91-4907.95 & $4908.09-4908.13$ \\
\hline 14 & INTEC -nr west gate & 4916.64-4916.71 & $4916.79-4916.85$ & $4916.93-4916.96$ & 4916.88-4916.92 & $4917.15-4917.22$ & $4917.41-4917.45$ \\
\hline 15 & $\begin{array}{c}\text { BLR - NW corner of } \\
\text { INTEC }\end{array}$ & $4913.36-4913.40$ & $4913.52-4913.62$ & 4913.71-4913.75 & $4913.64-4913.71$ & $4913.90-4913.93$ & $4914.07-4914.13$ \\
\hline
\end{tabular}




\subsection{REFERENCES}

Andrews, E.D., 1984, Bed-material entrainment and hydraulic geometry of gravel-bed rivers in Colorado: Geological Society of America Bulletin, v. 95, p. 371-378.

Baker, V.R., and Costa, J.E., 1987, Flood power, in Mayer, L., and Nash, D., eds., Catastrophic Flooding: Boston, MA, Allen \& Unwin, p. 1-21.

Baker, V.R., Kochel, R.C., and Patton, P.C., eds., 1988, Flood geomorphology: New York, John Wiley and Sons, 503 p.

Berenbrock, C., and Doyle, J.D., 2004, Stage-discharge relations for selected culverts and bridges in the Big Lost River flood plain at the Idaho National Engineering and Environmental Laboratory, Idaho: U.S. Geological Survey Water Resources Investigations Report 044066, Idaho Falls, ID, 62 p.

Berenbrock, C., Rousseau, J.P., Orr, B.R., Twining, B.V., and Whnke, A., in prep., Flood flow and sediment characteristics of bedrock constrictions in the Big Lost River at the Idaho National Engineering and Environmental Laboratory, Idaho [DRAFT]: U.S. Geological Survey Water Resources Investigations Report 03-xxx, Idaho Falls, ID.

Birkeland, P.W., 1999, Soils and geomorphology: New York, Oxford University Press, 430 p.

Carson, M. A., and Griffiths, G.A., 1987, Bedload transport in gravel channels: Journal of Hydrology New Zealand, v. 26, no. 1, p. 1-151.

Cerling, T.E., Poreda, R.J., and Rathburn, S.L., 1994, Cosmogenic ${ }^{3} \mathrm{He}$ and ${ }^{21} \mathrm{Ne}$ age of the Big Lost River flood, Snake River Plain, Idaho: Geology, v. 22, p. 227-230.

Connor, M.A., 1998, Final report on the Jackson Lake archeologal project, Grand Teton National Park, Wyoming: Report prepared for Bureau of Reclamation, Pacific Northwest Office, Boise, ID, with contributions by K.L. Pierce, S. Lundstrom, and J.M. Good, Technical Report No. 46, Department of the Interior, National Park Service, Midwest Archeological Center, Lincoln, Nebraska, 278 p.

Cook, J.L., 1987, Quantifying peak discharges for historical floods: Journal of Hydrology, v. 96, p.29-40.

Costa, J.E., 1978, Holocene stratigraphy in flood frequency analysis: Water Resources Research, v. 14, p. 626-632.

Fiedler, F.R., 2002, Infiltration rates to support high-resolution hydraulic modeling at Idaho National Engineering and Environmental Laboratory, Department of Civil Engineering, University of Idaho, Moscow, ID, 13 p.

Forman, S.L., Smith, R.P., Hackett, W.R., Tullis, J.A., and McDaniel, P.A., 1993, Timing of late Quaternary glaciations in the western United States based on the age of loess on the eastern Snake River Plain, Idaho: Quaternary Research, v. 40, p. 30-37.

Geslin, J.K., Link, P.K., and Fanning, C.M., 2002, High-precision provenance determination using detrital-zircon ages and petrography of Quaternary sands on the eastern Snake River Plain, Idaho: Geology, v. 27, no. 4, p. 295-298.

Good, J.M., and Pierce, K.L., 1996, Interpreting the landscapes of Grand Teton and Yellowstone National Parks, recent and ongoing geology: Grand Teton Natural History Association, Grand Teton National Park, Moose, Wyoming, 58 p.

Harding, William M, 2002, Northwind Environmental, Inc. letter report to Dr. Kenneth Reid, State Historic Preservation Office, Boise, ID, dated September 6, 2002, 8 p. 
Hortness, J.E., and Rousseau, J.P., 2003, Estimating the magnitude of the 100-year peak flow in the Big Lost river at the Idaho National Engineering and Environmental Laboratory, Idaho: U.S. Geological Survey Water Resources Investigations Report 02-4299, Idaho Falls, ID, 36 p.

House, P.K., Pearthree, P.A., and Klawon, J.E., 2002, Historical flood and paleoflood chronology of the lower Verde River, Arizona, in: House, P.K., Webb, R.H., Baker, V.R., and Levish, D.R., eds., Ancient Floods, Modern Hazards:Principles and Applications of Paleoflood Hydrology: Water and Science Application 5, American Geophysical Union, Washington, D.C., p. 267-293.

Jarrett, R.D., and England, J.F., Jr., 2002, Reliability of paleostage indicators for paleoflood studies, in House, P.K., Webb, R.H., Baker, V.R., and Levish, D.R., eds, Ancient Floods, Modern Hazards: Principles and Applications of Paleoflood Hydrology: Water Science and Application Volume 5, American Geophysical Union, Washington, D.C., p. 91-109

Johnson, D.L., and Johnson, D.N., 2003, Mima and other animal mounds as point-centered biomantles: Geol. Soc. Amer., Abstracts with Programs v.35;n. 6, p. 258.

Kessler, M.A., and Werner, B.T., 2003, Self-organization of sorted patterned ground: Science, v. 299, p. 380-383.

Kjelstrom, L.C., 1991, Idaho, floods and droughts, in Paulson, R.W., Chase, E.B., Roberts, R.S., and Moody, D.W., National Water Summary 1988-89 - Hydrologic events and floods and droughts: U.S. Geological Survey Water-Supply Paper 2375, p. 255-262.

Kjelstrom, L.C., and Berenbock, C., 1996, Estimated 100-year peak flows and flow volumes in the Big Lost River and Birch Creek at the Idaho National Engineering and Environmental Laboratory, Idaho: U.S. Geological Survey Water-Resources Investigations Report 964163, 23 p.

Koslow, K.N., and Van Haaften, D.H., 1986, Flood routing analysis for a failure of Mackay Dam: EG\&G Idaho, Inc. report prepared for the U.S. Department of Energy, contract no. DEAC07-76IDO1570, 33 p.

Knudsen, K.L., Sowers, J.M., Ostenaa, D.A., and Levish, D.R., 2002, Evaluation of glacial outburst flood hypothesis for the Big Lost River, Idaho, in: House, P.K., Webb, R.H., Baker, V.R., and Levish, D.R., eds., Ancient Floods, Modern Hazards:Principles and Applications of Paleoflood Hydrology: Water and Science Application 5, American Geophysical Union, Washington, D.C., p. 217-235.

Kuntz, M.A., Skipp, B., Lamphere, M.A., Scott, W.E., Pierce, K.L., Dalrymple, G.B., Champion, D.E., Embree, G.F., Page, W.R., Morgan, L.A., Smith, R.P., Hackett, W.R., and Rodgers, D.W., 1994, Geologic map of the Idaho National Engineering Laboratory and adjoining area, eastern Idaho, U.S. Geological Survey Miscellaneous Investigation Map I-2330, scale 1:100,000.

Levish, D.R., 2002, Paleohydrologic bounds - non-exceedence information for flood hazard assessment, in: House, P.K., Webb, R.H., Baker, V.R., and Levish, D.R., eds., Ancient Floods, Modern Hazards:Principles and Applications of Paleoflood Hydrology: Water and Science Application 5, American Geophysical Union, Washington, D.C., p. 175-190.

Levish, D.R., Ostenaa, D.A., and O’Connell, D.R.H., 1994, A non-inundation approach to paleoflood hydrology for the event-based assessment of extreme flood hazards, in 1994 Annual Conference Proceedings, Association of State Dam Safety Officials: Lexington, KY, Association of State Dam Safety Officials, p. 69-82. 
Levish, D.R., Ostenaa, D.A., and O’Connell, D.R.H., 1996, Paleohydrologic bounds and the frequency of extreme floods: in Gruntfest, E. (ed.), Twenty years later what we have learned since the Big Thompson flood: Boulder, University of Colorado, Natural Hazards Research and Applications Information Center, Special Publication No. 33, p. 171-182.

Levish, D.R., Ostenaa, D.A., and O’Connell, D.R.H., 1997, Paleoflood hydrology and dam safety: Waterpower '97, Proceedings of the International Conference on Hydropower, Atlanta, GA, p. 2205-2214.

Licciardi, J.M., Clark, P.U., Brook, E.J., Pierce, K.L., Kurz, M.D., Elmore, D., and Sharma, P., 2001, Cosmogenic ${ }^{3} \mathrm{He}$ and ${ }^{10} \mathrm{Be}$ chronologies of the late Pinedale northern Yellowstone ice cap, Montana: Geology, v. 29, p. 1095-1098.

Licciardi, J.M., Clark, P.U., Brook, E.J., Elmore, D., and Sharma, P., 2004, Variable responses of western U.S. glaciers during the last deglaciation: Geology, v. 32, p. 81-84.

Magilligan, F.J., 1992, Thresholds and the spatial variability of flood power during extreme floods: Geomorphology, v. 5, p. 373-390.

McFadden, L.D., McDonald, E.V., Wells, S.G., Anderson, K., Quade, J., and Forman, S.L., 1998, The vesicular layer and carbonate collars of desert soils and pavements: formation, age and relation to climate change: Geomorphology, v. 24, p. 101-145.

Miall, A.D., 1996, The Geology of Fluvial Deposits: Sedimentary Facies, Basin Analysis, and Petroleum Geology: Springer-Verlag, Berlin, Heidelberg, 582 p.

Miller, A.J. and Cluer, B.L., 1998, Modeling considerations for simulation of flow in bedrock channels: in Tinkler, K.J. and Wohl, E.E., eds., Rivers over rock: Fluvial processes in bedrock channels: Washington, DC, American Geophysical Union, Geophysical Monograph 107, p. 61-104.

NRC (National Research Council), 1995, Natural climate variability on decade-to-century time scales: Washington, D.C., National Academy Press, Climate Research Committee, 630 p.

NRC (National Research Council), 1999, Improving American River flood frequency analyses: Washington, D.C., National Academy Press, Committee on American River Flood Frequencies, $120 \mathrm{p}$.

O’Connell, D.R.H., 1998, FLDFRQ3 Three-parameter maximum likelihood flood-frequency estimation with optional probability regions using parameter grid integration: User's Guide (Release 1.0), ftp:// ftp.seismo.usbr.gov/pub/outgoing/geomagic/scr/fldfrq3/, June 2000.

O’Connell, D.R.H., 2005, Nonparametric Bayesian flood frequency estimation: Journal of Hydrology, v. 313, p. 79-96.

O’Connell, D.R.H., Levish, D.R., and Ostenaa, D.A., 1996, Bayesian flood frequency analysis with paleohydrologic bounds for late Holocene paleofloods, Santa Ynez River, California: in Twenty years later what we have learned since the Big Thompson flood: Boulder, University of Colorado, Natural Hazards Research and Applications Information Center, Special Publication No. 33, p. 183-196.

O’Connell, D.R.H., Levish, D.R., and Ostenaa, D.A., 1998, Risk-based hydrology: Bayesian flood-frequency analyses using paleoflood information and data uncertainties: Proceedings of the First Federal Interagency Hydrologic Modeling Conference, April 19 23, 1998, Tropicana Hotel, Las Vegas, Nevada, vol. 1, p. 4-101 to 4-108.

O’Connell, D.R.H., Ostenaa, D.A., Levish, D.R., and Klinger, R.E., 2002. Bayesian flood frequency analysis with paleohydrologic bound data, Water Resour. Res. 38 (5), DOI 10.1029/2000WR000028. 
Ostenaa, D.A., and Levish, D.R., 1996, Event-based assessment of extreme flood hazards for dam safety: in Proceedings, Association of State Dam Safety Officials Western Regional Conference, Association of State Dam Safety Officials, Lexington, KY, p. 41-54.

Ostenaa, D.A., and Levish, D.R., 1997, Reconnaissance Paleoflood Study for Ochoco Dam, Crooked River Project, Oregon: Denver, CO, Bureau of Reclamation, Seismotectonic Report 96-2, 20 p., 1 folded plate, 2 appendices.

Ostenaa D.A., Levish, D.R., and O’Connell, D.R.H., 1996, Paleoflood study for Bradbury Dam, Cachuma Project, California: Denver, CO, Bureau of Reclamation, Seismotectonic Report 96-3, 86 p., 1 folded plate, 4 appendices.

Ostenaa D.A., Levish, D.R., O’Connell, D.R.H., and Cohen E.A., 1997, Paleoflood study for Causey and Pineview Dams, Weber Basin and Ogden River Projects, Utah: Denver, CO, Bureau of Reclamation, Seismotectonic Report 96-6, 69 p., 3 appendices.

Ostenaa D.A., Levish, D.R., Klinger, R.E., and O’Connell, D.R.H., 1999, Phase 2 Paleohydrologic and Geomorphic Studies for the Assessment of Flood Risk for the Idaho National Engineering and Environmental Laboratory, Idaho: Denver, CO, Bureau of Reclamation, Geophysics, Paleohydrology and Seismotectonics Group, Report 99-7, 112 p., 1 folded plate, 4 appendices.

Ostenaa, D.A., O’Connell, D.R.H., Walters, R.A., Creed, R.J., 2002, Holocene paleoflood hydrology of the Big Lost River, western Idaho National Engineering and Environmental Laboratory, Idaho in: Link, P.K., and Mink, L.L., eds., Geology, Hydrology, and Environmental Remediation: Idaho National Engineering and Environmental Laboratory, Eastern Snake River Plain, Idaho: Boulder, CO, Geological Society of America Special Paper 353, p. 91-110.

Parker, G., 1978, Self-formed straight rivers with equilibrium banks and mobile bed. Part 2. The gravel river: Journal of Fluid Mechanics, v. 89, part 1, p. 127-146.

Peterson, L. and Harding, W., 2002, Mitigation of site 10BT2189 (BLR-8) at the Idaho National Environmental and Engineering Laboratory, Butte County, Idaho: DRAFT, September, 2002, North Wind Environmental, Inc., NW Project 2072.202, Idaho Falls, ID, 51 p.

Pierce, K.L., 1979, History and dynamics of glaciation in the northern YellowstoneNational Park area: U.S. Geological Survey Professional Paper 729-F, 90 p.

Pierce, K.L., and Good, J.D., 1992, Field guide to the Quaternary geology of Jackson Hole, Wyoming: US Geol. Surv. Open-File Report 92-504, 54 p.

Pierce, K.L., and Morgan, L.A., 1992, The track of the Yellowstone hot spot: Volcanism, faulting, and uplift, in Link, Paul Karl, Kuntz, M.A., and Platt, Lucian B., eds., Regional Geology of Eastern Idaho and Western Wyoming: Geological Society of America Memoir 179, p. $1-53$.

Rathburn, S.L., 1991, Quaternary channel changes and paleoflooding along the Big Lost River, Idaho National Engineering Laboratory: TriHydro Corporation report prepared for EG\&G Idaho, Inc., subcontract no. C90-132903, 33 p.

Richmond, G.M., 1986, Stratigraphy and chronology of glaciations in Yellowstone National Park, in Sibrava, V., et al., eds., Quaternary glaciations in the Northern Hemisphere: Quaternary Science Reviews, v. 5, p. 83-98.

Scott, W.E., 1982, Surficial geologic map of the eastern Snake River Plain and adjacent areas, $111^{\circ}$ to $115^{\circ}$ W., Idaho and Wyoming: U.S. Geological Survey Miscellaneous Investigations Series Map I-1372, scale 1:250,000. 
SSHAC, 1995, Recommendations for probabilistic seismic hazard analysis: Guidance on uncertainty and use of experts: NUREG/CR-6372, 170 p.

Simpson, D.T., Kolbe, T.E., Ostenaa, D.A., Levish, D.R., and Klinger, R.E., 1999, Lower Big Lost River chronosequence - implications for glacial outburst flooding [abs.]: Geological Society of America, Abstracts with Programs, v. 31, no. 4, p. A-56.

Stearns, H.T., Crandall, L., and Steward, W.G., 1938, Geology and ground-water resources of the Snake River Plain in southeastern Idaho: U.S. Geological Survey Water-Supply Paper 774, $268 \mathrm{p}$.

Stedinger, J.R., and Cohn, T.A., 1986, Flood frequency analysis with historical and paleoflood information: Water Resources Research, v. 22, p. 785-793.

Sturchio, N.C., Pierce, K.L., Murrell, M.T., and Sorey, M.L., 1994, Uranium-series ages of travertines and timing of the last glaciation in the northern Yellowstone area, WyomingMontana: Quaternary Research, v. 41, p. 265-277.

Thackery, G..D., Lundeen, K.A., and Borgert, J.A., 2004, Latest Pleistocene alpine glacier advances in the Sawtooth Mountains, Idaho, USA: Reflections of midlatitude moisture trasport at the close of the last glaciation: Geology, v. 32, no. 3, p. 225-228.

Tullis, J.A., 1995, Characteristics and origin of earth-mounds on the eastern Snake River Plain, Idaho: Idaho Fall, Lockheed Martin Idaho Technologies, Idaho National Engineering Laboratory, INEL-95/0505, September 1995, 90 p.

Whitlock, C., 1993, Postglacial vegetation and climate of Grand Teton and southern Yellowstone National Parks: Ecological Monographs, v. 63, p. 173-198. 